Cochrane Database of Systematic Reviews

\title{
Case management approaches to home support for people with dementia (Review)
}

Reilly S, Miranda-Castillo C, Malouf R, Hoe J, Toot S, Challis D, Orrell M

Reilly S, Miranda-Castillo C, Malouf R, Hoe J, Toot S, Challis D, Orrell M.

Case management approaches to home support for people with dementia.

Cochrane Database of Systematic Reviews 2015, Issue 1. Art. No.: CD008345. DOI: 10.1002/14651858.CD008345.pub2.

www.cochranelibrary.com 
TABLE OF CONTENTS

HEADER

ABSTRACT

PLAIN LANGUAGE SUMMARY

SUMMARY OF FINDINGS

BACKGROUND

OBJECTIVES

METHODS

RESULTS

Figure 1.

Figure 2.

Figure 3.

Figure 4.

Figure 5.

Figure 6.

DISCUSSION

Figure 7.

AUTHORS' CONCLUSIONS

ACKNOWLEDGEMENTS

REFERENCES

CHARACTERISTICS OF STUDIES

DATA AND ANALYSES

Analysis 1.1. Comparison 1 Case management versus usual care (primary outcomes), Outcome 1 Institutionalised (number of participants admitted to residential or nursing homes) (as reported at each time point).

Analysis 1.2. Comparison 1 Case management versus usual care (primary outcomes), Outcome 2 Institutionalised (nursing home stays, mean number of days per month).

Analysis 1.3. Comparison 1 Case management versus usual care (primary outcomes), Outcome 3 Time to institutionalisation. .

Analysis 1.4. Comparison 1 Case management versus usual care (primary outcomes), Outcome 4 Hospital admission (mean number of nights/.

Analysis 1.5. Comparison 1 Case management versus usual care (primary outcomes), Outcome 5 Hospital admissions: (number of participants admitted to hospital).

Analysis 1.6. Comparison 1 Case management versus usual care (primary outcomes), Outcome 6 Mortality (number of deaths, participants) (as reported at each time point).

Analysis 1.7. Comparison 1 Case management versus usual care (primary outcomes), Outcome 7 Quality of life (participants). Analysis 1.8. Comparison 1 Case management versus usual care (primary outcomes), Outcome 8 Quality of life (carers). ....... Analysis 1.9. Comparison 1 Case management versus usual care (primary outcomes), Outcome 9 Caregiver burden.

Analysis 2.1. Comparison 2 Case management versus usual care (secondary outcomes), Outcome 1 Cognition measures (participants).

Analysis 2.2. Comparison 2 Case management versus usual care (secondary outcomes), Outcome 2 Behavioural measures (participants).

Analysis 2.3. Comparison 2 Case management versus usual care (secondary outcomes), Outcome 3 Depression/mood measures (participants).

Analysis 2.4. Comparison 2 Case management versus usual care (secondary outcomes), Outcome 4 Function measures (participants).

Analysis 2.5. Comparison 2 Case management versus usual care (secondary outcomes), Outcome 5 Carer distress (behavioural) measures (NPI-distress/reaction RMBPC).

Analysis 2.6. Comparison 2 Case management versus usual care (secondary outcomes), Outcome 6 Mood/depression measures (carers).

Analysis 2.7. Comparison 2 Case management versus usual care (secondary outcomes), Outcome 7 Carer well-being - GHQ (changes from baseline).

Analysis 2.8. Comparison 2 Case management versus usual care (secondary outcomes), Outcome 8 Social support measures. . Analysis 2.9. Comparison 2 Case management versus usual care (secondary outcomes), Outcome 9 Satisfaction with health plan (carers) changes from baseline. 
Analysis 2.10. Comparison 2 Case management versus usual care (secondary outcomes), Outcome 10 Satisfaction with care (carers).

Analysis 2.11. Comparison 2 Case management versus usual care (secondary outcomes), Outcome 11 Leaving the study early (patients) unwilling or unable to provide information (including died/ institutionalised).

Analysis 3.1. Comparison 3 Case management versus usual care (secondary outcomes: service use/cost ), Outcome 1 Use of community-based services (number of participants/ carers).

Analysis 3.2. Comparison 3 Case management versus usual care (secondary outcomes: service use/cost), Outcome 2 Health service use by participants (number of participants).

Analysis 3.3. Comparison 3 Case management versus usual care (secondary outcomes: service use/cost ), Outcome 3 Health service use by participants (continuous outcomes).

Analysis 3.4. Comparison 3 Case management versus usual care (secondary outcomes: service use/cost), Outcome 4 Cost of service (participants).

Analysis 3.5. Comparison 3 Case management versus usual care (secondary outcomes: service use/cost), Outcome 5 Healthcare and care-giving costs (USD or EUR)).

Analysis 3.6. Comparison 3 Case management versus usual care (secondary outcomes: service use/cost), Outcome 6 Health services costs (participants) (Medicare expenditures) (community services usage) in USD or EUR.

Analysis 3.7. Comparison 3 Case management versus usual care (secondary outcomes: service use/cost ), Outcome 7 Health service use by carers (dichotomous outcomes).

Analysis 3.8. Comparison 3 Case management versus usual care (secondary outcomes: service use/cost), Outcome 8 Health service use by carers (continuous outcomes).

Analysis 3.9. Comparison 3 Case management versus usual care (secondary outcomes: service use/cost), Outcome 9 Informal caregiver time (hours).

Analysis 3.10. Comparison 3 Case management versus usual care (secondary outcomes: service use/cost ), Outcome 10 Medicare expenditures; community services usage in Dollars.

Analysis 3.11. Comparison 3 Case management versus usual care (secondary outcomes: service use/cost), Outcome 11 Cost of services (carers).

ADDITIONAL TABLES

APPENDICES

WHAT'S NEW

CONTRIBUTIONS OF AUTHORS 
[Intervention Review]

\section{Case management approaches to home support for people with dementia}

Siobhan Reilly ${ }^{1}$, Claudia Miranda-Castillo 2 , Reem Malouf ${ }^{3}$, Juanita Hoe ${ }^{4}$, Sandeep Toot ${ }^{5}$, David Challis 6 , Martin Orrell ${ }^{4}$

1Division of Health Research, Faculty of Health and Medicine, Lancaster University, Lancaster, UK. 2Escuela de Psicología, Facultad de Medicina, Universidad de Valparaíso, Valparaíso, Chile. ${ }^{3}$ National Perinatal Epidemiology Unit (NPEU), University of Oxford, Oxford, UK. ${ }^{4}$ Mental Health Sciences Unit, University College London, London, UK. ${ }^{5}$ Research and Development Department, North East London NHS Foundation Trust, Goodmayes Hospital, London, UK. ${ }^{6}$ Personal Social Services Research Unit, University of Manchester, Manchester, UK

Contact address: Siobhan Reilly, Division of Health Research, Faculty of Health and Medicine, Lancaster University, C07 Furness Building, Lancaster, LA1 4YG, UK. s.reilly@lancaster.ac.uk.

Editorial group: Cochrane Dementia and Cognitive Improvement Group

Publication status and date: Edited (no change to conclusions), published in Issue 10, 2015.

Citation: Reilly S, Miranda-Castillo C, Malouf R, Hoe J, Toot S, Challis D, Orrell M. Case management approaches to home support for people with dementia. Cochrane Database of Systematic Reviews 2015, Issue 1. Art. No.: CD008345. DOI: 10.1002/14651858.CD008345.pub2.

Copyright @ 2015 The Cochrane Collaboration. Published by John Wiley \& Sons, Ltd.

\section{A B S T R A C T}

\section{Background}

Over 35 million people are estimated to be living with dementia in the world and the societal costs are very high. Case management is a widely used and strongly promoted complex intervention for organising and co-ordinating care at the level of the individual, with the aim of providing long-term care for people with dementia in the community as an alternative to early admission to a care home or hospital.

\section{Objectives}

To evaluate the effectiveness of case management approaches to home support for people with dementia, from the perspective of the different people involved (patients, carers, and staff) compared with other forms of treatment, including 'treatment as usual', standard community treatment and other non-case management interventions.

\section{Search methods}

We searched the following databases up to 31 December 2013: ALOIS, the Specialised Register of the Cochrane Dementia and Cognitive Improvement Group, The Cochrane Library, MEDLINE, EMBASE, PsycINFO, CINAHL, LILACS, Web of Science (including Science Citation Index Expanded (SCI-EXPANDED) and Social Science Citation Index), Campbell Collaboration/SORO database and the Specialised Register of the Cochrane Effective Practice and Organisation of Care Group. We updated this search in March 2014 but results have not yet been incorporated.

\section{Selection criteria}

We include randomised controlled trials (RCTs) of case management interventions for people with dementia living in the community and their carers. We screened interventions to ensure that they focused on planning and co-ordination of care.

\section{Data collection and analysis}

We used standard methodological procedures as required by The Cochrane Collaboration. Two review authors independently extracted data and made 'Risk of bias' assessments using Cochrane criteria. For continuous outcomes, we used the mean difference (MD) or standardised mean difference (SMD) between groups along with its confidence interval $(95 \% \mathrm{CI})$. We applied a fixed-or random-effects model as appropriate. For binary or dichotomous data, we generated the corresponding odds ratio (OR) with $95 \% \mathrm{Cl}$. We assessed heterogeneity by the $I^{2}$ statistic. 


\section{Main results}

We include 13 RCTs involving 9615 participants with dementia in the review. Case management interventions in studies varied. We found low to moderate overall risk of bias; $69 \%$ of studies were at high risk for performance bias.

The case management group were significantly less likely to be institutionalised (admissions to residential or nursing homes) at six months (OR $0.82,95 \% \mathrm{Cl} 0.69$ to $0.98, \mathrm{n}=5741,6 \mathrm{RCTs}, \mathrm{I}^{2}=0 \%, \mathrm{P}=0.02$ ) and at 18 months (OR $0.25,95 \% \mathrm{Cl} 0.10$ to $0.61, \mathrm{n}=363,4 \mathrm{RCTs}, \mathrm{I}^{2}=0 \%$, $\mathrm{P}=0.003)$. However, the effects at $10-12$ months (OR $0.95,95 \% \mathrm{Cl} 0.83$ to $\left.1.08, \mathrm{n}=5990,9 \mathrm{RCTs}, \mathrm{I}^{2}=48 \%, \mathrm{P}=0.39\right)$ and 24 months $(\mathrm{OR}$ $1.03,95 \% \mathrm{Cl} 0.52$ to $\left.2.03, \mathrm{n}=201,2 \mathrm{RCTs}, \mathrm{I}^{2}=0 \%, \mathrm{P}=0.94\right)$ were uncertain. There was evidence from one trial of a reduction in the number of days per month in a residential home or hospital unit in the case management group at six months $(\mathrm{MD}-5.80,95 \% \mathrm{Cl}-7.93$ to $-3.67, \mathrm{n}$ $=88,1 \mathrm{RCT}, \mathrm{P}<0.0001$ ) and at 12 months (MD $-7.70,95 \% \mathrm{Cl}-9.38$ to $-6.02, \mathrm{n}=88,1 \mathrm{RCT}, \mathrm{P}<0.0001)$. One trial reported the length of time until participants were institutionalised at 12 months and the effects were uncertain (hazard ratio (HR): $0.66,95 \% \mathrm{Cl} 0.38$ to $1.14, \mathrm{P}=0.14$ ). There was no difference in the number of people admitted to hospital at six (4 RCTs, 439 participants), 12 (5 RCTs, 585 participants) and 18 months (5 RCTs, 613 participants). For mortality at 4-6, 12, 18 - 24 and 36 months, and for participants' or carers' quality of life at 4, 6, 12 and 18 months, there were no significant effects. There was some evidence of benefits in carer burden at six months (SMD $-0.07,95 \% \mathrm{Cl}$ -0.12 to $-0.01, n=4601,4$ RCTs, $\left.\right|^{2}=26 \%, P=0.03$ ) but the effects at 12 or 18 months were uncertain. Additionally, some evidence indicated case management was more effective at reducing behaviour disturbance at 18 months (SMD $-0.35,95 \% \mathrm{Cl}-0.63$ to $-0.07, \mathrm{n}=206,2 \mathrm{RCTs} \mathrm{I}^{2}$ $=0 \%, \mathrm{P}=0.01$ ) but effects were uncertain at four (2 RCTs), six (4 RCTs) or 12 months (5 RCTs).

The case management group showed a small significant improvement in carer depression at 18 months (SMD $-0.08,95 \% \mathrm{Cl}-0.16$ to -0.01 , $\left.n=2888,3 R C T s, I^{2}=0 \%, P=0.03\right)$. Conversely, the case management group showed greater improvement in carer well-being in a single study at six months (MD $-2.20 \mathrm{Cl} \mathrm{Cl}-4.14$ to $-0.26, \mathrm{n}=65,1 \mathrm{RCT}, \mathrm{P}=0.03$ ) but the effects were uncertain at 12 or 18 months. There was some evidence that case management reduced the total cost of services at 12 months (SMD $-0.07,95 \% \mathrm{Cl}-0.12$ to $-0.02, n=5276,2 \mathrm{RCTs}, \mathrm{P}=0.01$ ) and incurred lower dollar expenditure for the total three years ( $M D=-705.00,95 \% \mathrm{Cl}-1170.31$ to $-239.69, n=5170,1 R C T, P=0.003)$. Data on a number of outcomes consistently indicated that the intervention group received significantly more community services.

\section{Authors' conclusions}

There is some evidence that case management is beneficial at improving some outcomes at certain time points, both in the person with dementia and in their carer. However, there was considerable heterogeneity between the interventions, outcomes measured and time points across the 13 included RCTs. There was some evidence from good-quality studies to suggest that admissions to care homes and overall healthcare costs are reduced in the medium term; however, the results at longer points of follow-up were uncertain. There was not enough evidence to clearly assess whether case management could delay institutionalisation in care homes. There were uncertain results in patient depression, functional abilities and cognition. Further work should be undertaken to investigate what components of case management are associated with improvement in outcomes. Increased consistency in measures of outcome would support future meta-analysis.

\section{PLAIN LANGUAGE SUMMARY}

\section{Case management approaches to home support for people with dementia}

Background: Many people are affected by dementia and the numbers are expected to rise as populations age. Most types of dementia are characterised by loss of memory and impairment in other cognitive functions, accompanied by functional impairment and difficulties in performing activities of daily living. The increasing number of people with dementia means more demand for both informal and formal sources of care. The extent of support provided depends on factors such as living situation, patient's and carer's characteristics, service provision, and availability of social networks. There are also wider financial costs of care, for example carers missing work for appointments or crises, becoming part-time workers, or leaving work altogether. Developing interventions such as case management, which enhances the co-ordination between different agencies involved in community care, might offer the support necessary to cover some of the needs of people with dementia and their carers. How case management is organised and implemented varies widely, and access to this type of care is influenced by long-term care funding policies and cultural variations in different countries. Case management has been tested in people with dementia and in carers in a number of countries and healthcare systems, but it is not clear whether current evidence supports its effectiveness.

Study characteristics: We found 13 randomised controlled trials (RCTs), including 9615 participants with dementia worldwide. Eleven RCTs also included carers. Studies were conducted in different countries, varied in size and healthcare systems and compared various types of case management interventions with usual care or augmented usual care.

Key findings: Some studies examined the benefit of case management in reducing admissions to residential or nursing homes (institutionalisation). We found benefits at six months and 18 months but not at 12 and 24 months. However, when only studies which were clearly focused upon delaying institutionalisation or prolonging the period of community care were included we found a reduction in institutionalisation at 12 months. Some studies examined the benefits of case management in terms of reduced hospital length of stay, and there was evidence to suggest that it might increase at six months. Some studies indicated that case management was more effective at reducing behaviour disturbance at 18 months, reducing carer burden and depression and improving carer well-being at six months and social support at 12 months. Case management increases the use of community services but there was some indication that overall healthcare 
costs may be reduced in the first year. Some studies reported that case management was no more effective than usual care in improving patient depression, functional abilities or cognition. There was not enough evidence to clearly assess whether case management could increase the length of time until people with dementia were admitted to care homes.

Quality of the evidence: There were some problems regarding the methods of the studies. Similarly, the different ways in which the case management interventions were provided and the differences in outcome measurements made it difficult to draw clear conclusions. 


\section{SUMMARY OF FINDINGS}

Summary of findings for the main comparison. Case management versus usual care for people with dementia

Case management versus usual care for people with dementia

Patient or population: people with dementia

Settings: community

Intervention: case management ${ }^{1}$

Comparison: treatment as usual, standard community treatment, other non-case management or waiting list controls

\begin{tabular}{|c|c|c|c|c|c|c|}
\hline \multirow[t]{3}{*}{ Outcomes } & \multicolumn{2}{|c|}{ Illustrative comparative risks* $(95 \% \mathrm{Cl})$} & \multirow{3}{*}{$\begin{array}{l}\text { Relative ef- } \\
\text { fect } \\
(95 \% \mathrm{CI})\end{array}$} & \multirow{3}{*}{$\begin{array}{l}\text { No of Partici- } \\
\text { pants } \\
\text { (studies) }\end{array}$} & \multirow{3}{*}{$\begin{array}{l}\text { Quality of the } \\
\text { evidence } \\
\text { (GRADE **) }\end{array}$} & \multirow[t]{3}{*}{ Comments } \\
\hline & Assumed risk & Corresponding risk & & & & \\
\hline & $\begin{array}{l}\text { treatment as } \\
\text { usual, stan- } \\
\text { dard commu- } \\
\text { nity treat- } \\
\text { ment, oth- } \\
\text { er non-case } \\
\text { management } \\
\text { or waiting } \\
\text { list controls }\end{array}$ & case management & & & & \\
\hline $\begin{array}{l}\text { Institutionalised } \\
\text { (number of partic- } \\
\text { ipants admitted to } \\
\text { residential or nurs- } \\
\text { ing homes) at } 10 \text { - } \\
12 \text { months }\end{array}$ & 189 per 1000 & $\begin{array}{l}198 \text { per } 1000 \\
\text { (169 to } 211)\end{array}$ & $\begin{array}{l}\text { OR } 0.95 \\
\text { (0.83 to } 1.08)\end{array}$ & $\begin{array}{l}5990 \\
\text { (9 studies) }\end{array}$ & $\begin{array}{l}\oplus \oplus \ominus \ominus \\
\operatorname{low}^{2,3}\end{array}$ & $\begin{array}{l}\text { No significant advantage in the case } \\
\text { management group. When a sensi- } \\
\text { tivity analysis was performed upon } \\
5 \text { studies (Chien- Hong Kong } 2008 \text {; } \\
\text { Chien - Hong Kong 2001; Chu - Cana- } \\
\text { da; Eloniemi-Sulkava 2001; Elonie- } \\
\text { mi-Sulkava 2009) where the goals of } \\
\text { the intervention were focused upon } \\
\text { delaying institutionalisation, those in } \\
\text { the case management group were sig- } \\
\text { nificantly less likely to be institution- } \\
\text { alised }(\mathrm{OR} 0.29,95 \% \mathrm{Cl} 0.15 \text { to } 0.55, \mathrm{n}= \\
464, \mathrm{I}^{2}=0 \%, \mathrm{P}=0.0002 \text { ). }\end{array}$ \\
\hline $\begin{array}{l}\text { Time to institu- } \\
\text { tionalisation at } 12 \\
\text { months }\end{array}$ & See comment & See comment & Not estimable & $\begin{array}{l}125 \\
\text { (1 study) }\end{array}$ & $\begin{array}{l}\oplus \oplus \ominus \ominus \\
\text { low }^{4,5}\end{array}$ & $\begin{array}{l}\text { Only one trial reported the length of } \\
\text { time until participants were institu- } \\
\text { tionalised (Eloniemi-Sulkava 2009) } \\
\text { and showed a non-significant differ- }\end{array}$ \\
\hline
\end{tabular}




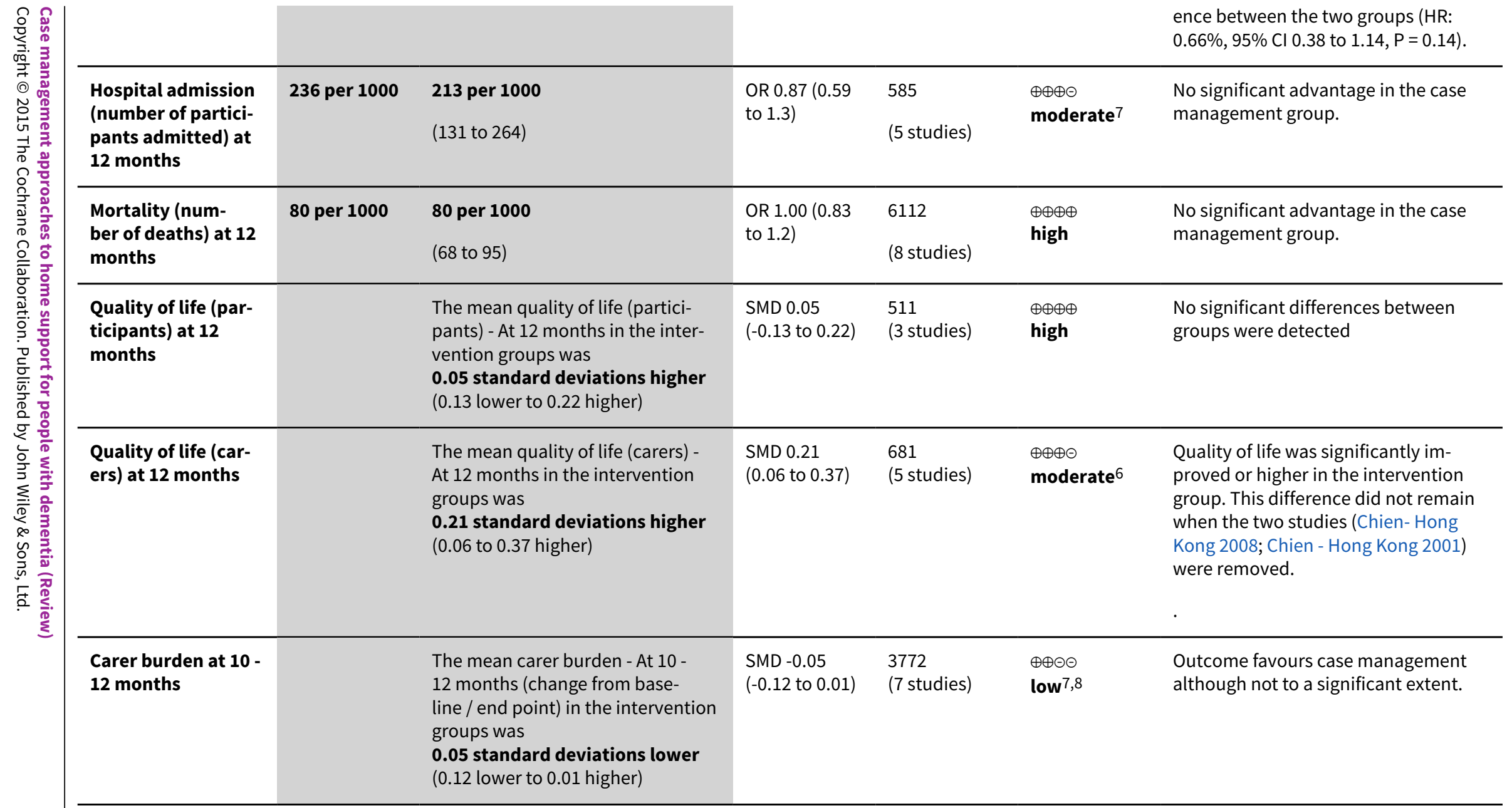

*The basis for the assumed risk (e.g. the median control group risk across studies) is provided in footnotes. The corresponding risk (and its $95 \%$ confidence interval) is based on the assumed risk in the comparison group and the relative effect of the intervention (and its $95 \% \mathrm{Cl}$ ).

Cl: Confidence interval; OR: Odds ratio; HR: Hazard ratio;

**GRADE Working Group grades of evidence

High quality: Further research is very unlikely to change our confidence in the estimate of effect.

Moderate quality: Further research is likely to have an important impact on our confidence in the estimate of effect and may change the estimate.

Low quality: Further research is very likely to have an important impact on our confidence in the estimate of effect and is likely to change the estimate.

Very low quality: We are very uncertain about the estimate. 
We included all randomised controlled trials of case management interventions for people with dementia of any type who lived in the community and their carers. We screened interventions to ensure that they predominantly focused on planning and co-ordination of care. There was wide variation in the components of case management and how it was delivered.

21 trial rated at high risk of bias and another trial analysis was not consistent with randomisation. Other trials had 1 or more risks of bias.

3 Heterogeneity: $I^{2}=51 \%, P=0.39$.

41 study with high rates of comorbidity (Charlson co-morbidity index (SD): Intervention 2.4 (1.5), Control 2.4 (1.8)).

1 study - intervention group: $n=63$; control group $n=62$

${ }^{6}$ Heterogeneity: $I^{2}=80 \% ; P=0.0006$.

71 trial rated at high risk of bias.

8Heterogeneity: $I^{2}=80 \% ; P=0.09$ 


\section{B A C K G R O U N D}

Globally, the number of people affected by dementia is anticipated to rise exponentially as populations age (Lobo 2000), representing one of the greatest challenges to health and social services. It is estimated that, worldwide, 35.6 million people have dementia and that this number is projected to almost double every 20 years, to 65.7 million in 2030 and 115.4 million in 2050 (Alzheimer's Disease International 2009; WHO 2012). In 2001, 5.4\% of the population aged 60 or over in Western Europe had dementia (Ferri 2005). Several metaanalyses show similar estimated dementia prevalence rates, rising exponentially with increasing age; $1 \%$ in people aged between 60 and 64 years to $34 \%$ in people aged between 90 and 94 . Incidence rates of dementia per 100 person-years range from 1 at 60 to 64 years to 65 to 70 at between 90 and 94 years (Fratiglioni 2001). Furthermore, most people with dementia live in developing countries ( $60 \%$ in 2001 , rising to $71 \%$ by 2040 ); numbers in developed countries are forecast to increase by 100\% between 2001 and 2040, but by more than $300 \%$ in India, China, and their south Asian and western Pacific neighbours (Ferri 2005).

The annual societal costs of dementia in the UK have been estimated at GBP 23 billion (Luengo-Fernandez 2010) and more recently at GBP 21 billion (Knapp 2014). This divides into 20\% healthcare costs and $45 \%$ social care costs (publicly and privately funded) and 35\% unpaid carer costs (Knapp 2014). Worldwide, most people with dementia live in the community. Most developing countries do not have a specific strategy to face the challenges of dementia, and community services for older people are very limited. In contrast, increasing numbers of developed countries have policies about dementia care. In general, these policies emphasise the importance of caring for highly dependent older people for as long as possible at home (Australian Health Ministers Conference 2006; Eagar 2007; Hofman 1991; Royal Commission 1999: Tsutsui 2007; Wimo 2007). Case management has become integral to dementia care strategies (Australian Health Ministers Conference 2006; Department of Health 2008; Diwan 2001b; Hofmarcher 2007; Ikegami 2002; Somme 2012; Tsutsui 2007). For example, case management has featured prominently as a strategy for co-ordinating dementia care in France, where the aim was to have 1000 co-ordinators whose role has been created on the basis of current case management evidence (French Ministry of Health 2008). How case management is organised and implemented varies widely, and access to this type of care is influenced by long-term care funding policies of different countries. A recent report funded by the Department of Health for England concluded that if case management is used to co-ordinate care overall costs would increase by around GBP 225 million, comprising a saving of around GBP 1.15 billion on health and social care costs but an increase of almost GBP 1.4 billion in the imputed costs of unpaid care (Knapp 2014).

\section{Description of the condition}

Dementia is defined as a progressive syndrome (group of symptoms) characterised by neuropsychological impairments, psychiatric and behavioural symptoms and reduced ability to perform activities of daily life (Burns 2003). These deficits cause significant impairment in social or occupational functioning, and represent a significant decline from a previous level of functioning (American Psychiatric Association 2000).

The increasing number of people with dementia makes for a growing demand for care, which may come from informal and formal sources. The extent and nature of support provided depends on several factors such as living situation, patient's and carer's characteristics, service provision, and availability of social networks. Carers have a key role in diagnosis, particularly with background and historical information. Some research also suggests that co-resident carers could be replacing support provided through social services. Furthermore, they may reduce the likelihood of the person with dementia to access formal social and health support, which may disadvantage both of them (Nelson 2002). Reasons why carers do not use formal services include: the stigma associated with the diagnosis of dementia, perceived lack of need, care recipient's refusal to accept help from services, service characteristics, and lack of knowledge about service availability (Brodaty 2005; Moriarty 1999). All of these findings show people with dementia to be a highly vulnerable group. Case management, which is intended to enhance the co-ordination between different agencies involved in community care, might improve the overall level of care and support for people with dementia and their carers.

\section{Description of the intervention}

In this review, case management is defined as any intervention delivered in the community (not in hospital or residential care settings) predominantly focused on the planning and co-ordination of care required to meet the identified needs of the person with dementia. The review was guided by this definition, as case management (also known as care management) is often used fairly loosely in the literature. Although definitions vary enormously, case management has been defined as "an intervention using a human service professional (typically a nurse or social worker) to arrange and monitor an optimum package of long term care services" (Applebaum 1990). A number of researchers define case management in a multifaceted way, including: functions (co-ordination and linkage); goals (maintaining vulnerable people at home or independently); core tasks (case finding, assessment, etc); target group; differentiating features (intensity of involvement, breadth of services overseen, duration of involvement); and multilevel response (clientlevel goals and system-level goals) (Challis 1995; Challis 2002). Although planned variations within these definitions constitute models of case management, there may be substantial geographical variation in how case management is implemented, along with variation in the health structures in which it operates. The terms case management and care management have often been employed interchangeably. Care management can be defined as a strategy for organising and co-ordinating care services at the level of the individual patient. It involves mobilising and influencing various agencies and services to achieve clearly-formulated goals, rather than each provider pursuing separate and perhaps diverse goals (Challis 1993).

\section{How the intervention might work}

Frail older people or those with dementia, requiring long-term care in their own homes, have a great variety of needs stemming from the degree and type of mental impairment suffered, the extent of their physical disability, the amount of family and neighbourly support available, and the time, duration and preferences for types of care. The range of services available to support people with dementia at home varies across different countries. The most common services include: home care (support with general domestic tasks and with self care), day centres (support with leisure activities), home-delivered meals, and respite care (a short break away from the carer). Health services might include: nursing, counselling, 
occupational therapy, aids to mobility and mental health care. The voluntary sector also offers different kinds of help including: information, telephone help lines, befriending and carers' support groups.

The wide variety of needs may not correspond to the relatively inflexible and limited range of services available. The help provided may often be only a partial solution to people's needs and may not necessarily respond to their preferences. Furthermore, these services are often organisationally highly fragmented, coming from a wide range of sources both formal and informal, including health and social care services, family, friends and neighbours. As a consequence, the picture of resource provision for the frail older person may be a series of piecemeal contributions from a range of different services, with no one service or professional having an unambiguous responsibility for taking a broader view of need beyond their own particular remit. Assessment and care plans tend, therefore, to be 'service-oriented' rather than 'client-centred', piecemeal and not holistic, defining needs in terms of available services rather than individual problems. Even where appropriate assessments and care plans are effected, they are rarely closely monitored and therefore fail to keep pace with changes in the health and dependency of the elderly person (Challis 2003; Reuben 2006).

The lack of any one person clearly responsible for cementing together these fragmented services into a coherent package is a significant factor in reducing the capability to prevent admission to institutional care. However, an integrated system of care for an individual elderly person has to be consciously created. It is likely neither to happen spontaneously nor to arise from simply improving the individual services that constitute the care package. In short, a more effective and efficient long-term care system may require both an enhancement of the content of services and also improved case management (Challis 1986). It is likely that the presence of behaviours such as wandering, resistance to accepting help in performing activities of daily living, disruptive behaviours that interfere with others' activities (especially those of the carer), and physical and verbal aggression, will require increased intervention from the case manager as maintaining an adequate care plan for that client may become problematic (Diwan 2001a; Diwan 2001b). The impact of case management may lead to a reduction in carer stress as well as improving care, and thereby have the effect of extending the stay in the community for the person with dementia.

\section{Why it is important to do this review}

Some research has indicated that early provision of in-home support and case management for people with dementia can decrease institutionalisation (Challis 2002; Chu 2000; Gaugler 2005); however, this effect may decrease over time (Eloniemi-Sulkava 2001). Indeed, institutionalisation is more likely to be avoided if carers feel supported (Schoenmakers 2008). No systematic reviews have specifically addressed whether this is actually the case. Although a number of reviews and meta-analyses of non-pharmacological interventions for people with dementia have been published, few specifically focus on case management interventions or on people with dementia maintaining community residence (Parker 2008; Spijker 2008; Thompson 2007; Van Citters 2004). Similarly, reviews which focus on case management do not specifically address people with dementia (Dieterich 2010; Hesse 2014; Hutt 2004; Marshall 1997). One review found no evidence for savings in healthcare expenditures or for reductions in hospital utilisation (Pimouguet 2010). Another review indicated that the factors that appear to be related to greater case management efficacy are the integration between the health and social service organisations and the intensity of case management (Somme 2012). Both of these reviews were descriptive and did not perform any meta-analyses.

\section{O B J E C T IVES}

\section{Primary objective}

To evaluate the effectiveness of case management approaches to home support for people with dementia from the perspective of the different people involved (patients, carers, and staff) compared with other forms of treatment, including 'treatment as usual', standard community treatment and other non-case management interventions.

\section{Secondary objective}

To study whether other potential mediating variables affect case management outcomes (e.g. key structural and organisational features of case management interventions and also the methodological characteristics of studies).

\section{METHODS}

\section{Criteria for considering studies for this review}

\section{Types of studies}

We considered all relevant randomised controlled trials (RCTs), and economic evaluations conducted alongside the RCTs. We judged that the RCTs located were sufficient in number and participants to perform meta-analysis and to justify the exclusion of quasi-randomised studies, such as controlled before-and-after studies (CBAs) and interrupted time series (ITSs) of case management interventions.

\section{Types of participants}

People of any age and gender with dementia of any type, including Alzheimer's disease, vascular dementia or mixed Alzheimer's and vascular dementia, who live in the community (excluding people in institutions receiving 24 -hour care) and their carers. We include studies that focus on patients only or both patient and carer dyads, whereas we exclude those that focused exclusively on carers.

\section{Types of interventions}

\section{Experimental intervention}

Any case management intervention delivered in the community (not in hospital or in residential care settings) that predominantly focused on the planning and co-ordination of care required to meet the identified needs of the person with dementia. This may or may not have been part of multi-component interventions.

\section{Control}

'Treatment as usual', standard community treatment, other noncase management or waiting-list controls. This may include any method of care such as primary health care (services that are offered in the community, e.g. general practitioners, and not in hospitals or specialist centres, and are usually the first point of contact for a patient). This may occur in isolation or along with referrals and management by mental health professionals, who may or may not be part of a community mental health team for elderly people. 


\section{Types of outcome measures}

Outcome measures related either to patients or to patient-carer dyads. We do not include studies which focus exclusively on carer outcomes. For the analysis, outcomes were grouped into 3/3 - 4; 4 $6 / 6 ; 10$ - 12/12; 18; 24; 36 months. In the Discussion section, we further define short-term outcomes as those measured at less than 12 months, medium-term as equal to or greater than 12 months but less than 18 months, and longer-term as greater than or equal to 18 months.

\section{Primary outcomes}

\section{People with dementia/care recipients}

1.1 Institutionalised (number of people admitted to residential or nursing homes)

1.2 Institutionalised (nursing home stays, mean number of days per month)

\subsection{Time to institutionalisation}

1.4 Hospital admission (mean number of nights)

1.5 Hospital admissions: (number of people admitted to hospital)

1.6 Mortality (number of deaths, participants) as reported at each time point in trials

1.7 Quality of life (participants)

\section{Carers}

1.8 Quality of life (carers)

1.9 Carer burden

\section{Secondary outcomes}

People with dementia/care recipients

2.1 Cognition measures

2.2 Behavioural measures

2.3 Depression/mood measures

2.4 Function/dependency measures

\section{Carers}

2.5 Carer distress (behaviour) measures

2.6 Carer depression/mood measures

2.7 Carer well-being

2.8 Social support measures

2.9 Carer satisfaction with health plan

2.10 Carer satisfaction with care

2.11 Leaving the study early

Service use/costs

3.1 - 3.3 Use of services (participants)

\section{7 - 3.9 Health service use by carers and informal care}

\section{$3.10-3.11$ Cost of services (carers)}

\section{Outcomes included in the 'Summary of findings' table}

We have constructed a Summary of findings for the main comparison for the following outcomes: number of dementia patients institutionalised at 10 to 12 months; time to institutionalisation at 12 months; hospital admission at 12 months; mortality at 12 months; participants' quality of life at 12 months; care-givers' quality of life at 12 months; and care-givers' burden.

\section{Search methods for identification of studies}

\section{Electronic searches}

See Cochrane Dementia and Cognitive Improvement Group for methods used in reviews.

We searched the ALOIS, Specialised Register of the Cochrane Dementia and Cognitive Improvement Group (CDCIG) on 31 December 2013. This register contains records from the following major healthcare databases:The Cochrane Library, MEDLINE, EMBASE, PsycINFO, CINAHL and LILACS, and many ongoing clinical trial databases and other grey literature sources.

The search terms used to identify relevant studies on dementia for the Group's Specialised Register can be found in the Group's module on The Cochrane Library. We used the following search terms for database searches: old ${ }^{*}$, elder ${ }^{\star}$, aged, patient care management, patient care team, case management, intensive case management, care management, managed care programs, community mental health team, specialist mental health service, community mental health, community mental health services, community mental health centres, community care, long term care, community-based long-term care, dementia care, intermediate care, crisis resolution, crisis intervention, home treatment, home care, home nursing, home care services, care coordination, care pathway, managed care, outreach, assertive outreach, disease management, carer support, family intervention, Admiral Nursing, assessment and service arrangement, health services for the aged, geriatric health service, family-based therapy.

We also searched The Cochrane Library, MEDLINE, EMBASE, PsycINFO, CINAHL, LILACS, ongoing clinical trial databases and other grey literature sources for the most recent records. The search terms used to identify relevant studies on dementia for the Group's Specialised Register were combined with the terms listed above (see Appendix 1 for the search strategies).

We also searched the following sources: Web of Science (including Science Citation Index Expanded (SCI-EXPANDED) and Social Science Citation Index), Campbell Collaboration/SORO database. We also searched the Specialised Register of the Cochrane Effective Practice and Organisation of Care Group using the search terms: dementia OR demented OR Alzheimer in any field.

We ran a pre-publication top-up search on 5 March 2014. We have put one publication identified as potentially relevant to this review (Samus 2014) into Studies awaiting classification and will fully assess and incorporate it as appropriate at update.

3.4 - 3.6 Cost of services (participants) 


\section{Searching other resources}

We contacted first authors of identified RCTs that were potentially suitable for inclusion in order to request additional information on related new, unpublished, or in-press studies that we had not identified in the main search. We also cross-checked the reference lists and citation reports of trials and relevant systematic reviews identified by the above methods.

\section{Data collection and analysis}

\section{Selection of studies}

Two pairs of review authors (SR and $\mathrm{JH}$ ) and ( $\mathrm{JH}$ and $\mathrm{CM}$ ) independently examined the titles and abstracts of citations obtained from the original search in accordance with the defined inclusion criteria, and discarded the irrelevant articles. Two review authors (SR and DC) examined citations from the updated searches (completed in February 2012, February 2013 and December 2013). We obtained the full text of the citation for further evaluation where it was not possible to accept or reject on the basis of the title or abstract by either review author. Two review authors again independently examined the full texts and undertook a repeated assessment for inclusion into the review. Where we disagreed on acceptance or rejection, we reached a consensus through discussion between the whole review team. We attempted to obtain additional information from the study authors. Details of all studies which initially appeared to meet the inclusion criteria but which we later excluded on retrieval of the full-text are given in the Characteristics of excluded studies tables. We kept a record of the reasons for exclusion.

\section{Data extraction and management}

The review authors SR, CM and ST extracted data, and either SR or RM undertook a double extraction. We used a standardised data extraction form and recorded the following characteristics:

- Country of conduct.

- Study design, randomisation method.

- The number of participants eligible for inclusion in each study, number randomised, and reasons for exclusion.

- The number of participants evaluated at follow-up(s) and the follow-up time points.

- Participant characteristics including age, gender, comorbidities, diagnosis and type of dementia, dementia severity, type of health care or community setting, reason for case management and method of identification for eligibility for case management.

- Case management interventions: categorised according to established domains such as goals, roles and range of tasks, breadth of services spanned, intensity of intervention, duration, skill mix, training required, delivery method (team/individual worker), case load size, and whether the intervention was provided in a standardised way.

- Comparison interventions: standard care, no intervention, or other type of case management.

- Outcomes: both primary and secondary outcomes relevant to this review; outcomes not usable for this review.

- Confounding variables; these may have been related to dementia treatment, dementia severity and other comorbidities.

We extracted the following summary statistics for continuous outcome measures at each time point: the mean change from baseline (if reported); the standard deviation (SD) of the mean change, and the number of participants for each treatment group at each assessment. We defined the baseline assessment as the latest available assessment prior to randomisation, but no longer than two months before randomisation. We used the Abrams 2005 technique to impute the standard deviation of the mean change (see Cochrane Handbook for Systematic Reviews of Interventions (Higgins 2011), section 16.1.3.2). Where changes from baseline were not reported, we extracted the mean, the standard deviation and the number of people in each treatment group at each time point. We considered combining end-point and change from baseline data unless different scales were used, as standardised mean differences (SMDs) are not statistically permissible. If different scales were used we opted for the type of data that was reported more frequently. For dichotomous outcome data (e.g. admitted to hospital/not admitted), we extracted the number in each outcome category at each time point. Where outcome measures arose from ordinal rating scales and the rating scales had a reasonably large number of categories (more than 10), we treated the data as continuous variables arising from a normal distribution. For each outcome measure, to allow an intention-to-treat analysis, we sought the data irrespective of compliance, whether or not the participant was subsequently deemed ineligible or was otherwise excluded from treatment or follow-up. If intention-to-treat data were not available in the publication, we sought 'on-treatment' data (i.e. the data of those who completed the trial). To facilitate comparison between trials we converted variables that could be reported in different metrics, such as days in hospital (mean days per year, per week or per month) to a common metric (e.g. mean days per month). We extracted data for all time points reported in each study.

We obtained additional data or information or both relating to the intervention and its implementation for eight trials: Bass - Ohio; Callahan - Indianapolis; Chu - Canada; Dias - Goa India; Eloniemi-Sulkava 2001; Eloniemi-Sulkava 2009; Jansen - Netherlands; Vickrey - California. We did not contact authors of studies identified in the top-up search for this information (Chien - Hong Kong 2001; Lam - Hong Kong).

\section{Assessment of risk of bias in included studies}

Five review authors worked independently to assess and score the studies' methodological quality in order to identify any potential sources of systematic bias. At least two review authors (from CM, ST, JH, SR and RM) assessed each included study for risk of bias using the tool described in the Cochrane Handbook for Systematic Reviews of Interventions (Higgins 2011). This tool covers sequence generation, allocation concealment, blinding and completeness of outcome data, selective reporting, and other biases. If the raters disagreed, we sought consensus with the involvement of another member of the review team. We contacted authors where inadequate details of trial methods were provided in the study reports, in order to obtain further information; otherwise we assigned a rating of 'unclear'. For cluster-randomised clinical trials, we followed Chapter 16.3 of the Cochrane Handbook for Systematic Reviews of Interventions to identify design-specific biases.

\section{Measures of treatment effect}

For continuous outcomes measured with a single scale, we calculated the mean difference (MD) between groups and its 95\% confidence interval. If different scales were used to measure the same construct, then we calculated the standardised mean difference 
(SMD). For dichotomous data, we calculated odds ratios (ORs) and their $95 \%$ confidence intervals $(\mathrm{Cl})$.

\section{Unit of analysis issues}

Where there were repeated observations on participants in longterm studies, we included outcomes at different time points in separate analyses. Where outcomes from different studies were measured at similar time points, we combined them. We used the following time points in the analyses: 3 months/3 - 4 months; 4 6 months/ 6 months; 10 - 12 months/12 months; 18 months; 24 months; 36 months.

\section{Cluster-randomised trials}

As case management may be implemented as an organisational intervention, cluster-randomised trials may be used as a way of avoiding bias associated with contamination. Randomisation may be by clinician or by practice. We identified studies using cluster randomisation and we adjusted the precision of the analysis based on these studies in the meta-analysis using the 'effective sample size' method outlined in the Cochrane Handbook for Systematic Reviews of Interventions (Higgins 2011). We calculated the effective sample size of groups in each cluster trial to be the original sample size divided by the 'design effect'. The design effect was calculated by ' $1+(M-1) I C C$ ', where $M$ represents the average cluster size and ICC is the intraclass correlation coefficient. For dichotomous data, we divided both the total number of participants and the number experiencing the event by the same design effect. For continuous data, only the sample size was reduced and means and standard deviations remained unchanged (see Cochrane Handbook for Systematic Reviews of Interventions (Higgins 2011) section 16.3.6). Where clustering had been appropriately incorporated into the analysis of primary studies, i.e. using a method which accounted for intraclass correlation, we presented these data as if from a non-cluster-randomised study, but adjusted for the clustering effect. If the ICC was not reported we assumed it to be 0.1 (Ukoumunne 1999).

\section{Studies with multiple treatment groups}

Where a study reported multiple case management or comparison interventions, we combined all relevant experimental intervention groups of the study into a single group, and all relevant control intervention groups into a single control group (Higgins 2011).

\section{Dealing with missing data}

We attempted to obtain missing data from trial authors. Where standard deviations for continuous outcomes were not reported, and were not available from the authors, we calculated them from the standard errors of the mean (SEM). If this was not possible, we used the SD from other studies in the review for the same outcome measures.

We describe the amount and kind of missing data related to participants' dropout that could be retrieved from the original authors in the Characteristics of included studies table, and we discuss their impact. The potential impact of the missing data on the results depends on the extent of missing data, the pooled estimate of the treatment effect and the variability of the outcomes. In some measures data have been inflated (e.g. we inflated monthly service use data for hospital admissions to the relevant time period such as six months, 12 months, etc) in order to allow us to combine such data with others in one meta-analysis.
To assess 'leaving the study early' in included studies, we calculated the proportion of randomised participants in each arm who left the study early (including those who died or were institutionalised) at each of the time points $3-4,6,12,18,24$ and 36 months.

\section{Assessment of heterogeneity}

We examined statistical heterogeneity between trials using the $\mathrm{Chi}^{2}$ statistic (a Chi ${ }^{2} \mathrm{P}$ value of less than 0.10 has been considered indicative of significant heterogeneity) and the $\mathrm{I}^{2}$ statistic (Higgins 2003). The $I^{2}$ statistic is an estimate of the percentage of total variation across studies that can be attributed to heterogeneity rather than to chance. This statistic is interpreted as follows: $0 \%$ to $40 \%$ might not be important, $30 \%$ to $60 \%$ might represent moderate levels of heterogeneity, $50 \%$ to $90 \%$ might represent substantial levels of heterogeneity, and $75 \%$ to $100 \%$ considerable heterogeneity (Deeks 2011).

\section{Assessment of reporting biases}

Reporting biases arise when the dissemination of research findings is influenced by the nature and direction of results (Egger 1997). We are aware that funnel plots may be useful in investigating smallstudy effects but are of limited power to detect such effects when there are few studies. We examined the funnel plot of one of our primary outcomes to test for asymmetry, which can indicate a number of issues including: selection bias (such as publication bias), poor methodological quality, and true heterogeneity. We also report any instances of selective outcome reporting in the Assessment of risk of bias in included studies.

\section{Data synthesis}

Where possible, the results tables report the absolute differences and relative per cent differences in outcomes between the intervention and control groups, as well as the absolute changes corrected for baseline differences between the control and intervention groups.

We combined data when we considered that outcomes in individual studies were similar. We used a fixed-effect model to provide a pooled estimated effect from continuous and binary data. When we detected significant heterogeneity (an I ${ }^{2}$ statistic of $50 \%$ or more) we used a random-effects model for analysis.

\section{Subgroup analysis and investigation of heterogeneity}

We explored heterogeneity in each meta-analysis.

If data were clearly heterogeneous, we checked to ensure that they had been correctly extracted and entered and that there were no unit-of-analysis errors. If the high levels of heterogeneity remained, we explored it using two prespecified characteristics of studies that may be associated with heterogeneity:

1. Variations in implementation or content of the case management interventions.

2. Quality of the study: we defined low-quality studies as being at high risk of bias for allocation concealment (Higgins 2011).

If these characteristics failed to account for the heterogeneity, we continued to investigate for other possible sources. If we identified other characteristics of the studies which accounted for heterogeneity, we discuss these post hoc reasons and the sensitivity of the estimate of effect size for the primary outcome to the inclusion 
and exclusion of the relevant studies. If heterogeneity remained considerable (i.e. above 75\%, Deeks 2011) we did not report the results in a meta-analysis.

\section{GRADE and 'Summary of findings' table:}

We used GRADE software to describe the quality of the overall body of evidence for each outcome in the Summary of findings for the main comparison. Quality is defined as the degree of confidence which can be placed in the estimates of treatment benefits and harms. There are four possible ratings: 'high', 'moderate', 'low' and 'very low'. Rating evidence as 'high quality' implies that we are confident in our estimate of the effect, and further research is very unlikely to change this. A rating of 'very low' quality implies that we are very uncertain about the obtained summary estimate of the effect.

The GRADE approach rates evidence from RCTs which do not have serious limitations as 'high quality'. However, several factors can lead to the downgrading of the evidence to 'moderate', 'low' or 'very low'. The degree of downgrading is determined by the seriousness of these factors: study limitations (risk of bias); inconsistency; indirectness of evidence; imprecision; and publication bias (Guyatt 2008; Higgins 2011)

\section{Sensitivity analysis}

We conducted sensitivity analyses to assess the effects of excluding studies considered to be at high risk of bias, based on concealment of allocation methods. We repeated the analysis of any relevant outcomes excluding any study rated as being at high risk of bias. We report any significant differences in the results in the relevant outcome section.

\section{RES U L T S}

\section{Description of studies}

See Characteristics of included studies; Characteristics of excluded studies; Characteristics of studies awaiting classification; Characteristics of ongoing studies.

\section{Results of the search}

The electronic searches (see Appendix 1) were performed in December 2008 and were updated in February 2012, February 2013 and 31 December 2013. We performed a prepublication top-up search on 5 March 2014, but have not incorporated the findings of that search into the results of the review.

SR, JH and CM screened the 10,440 references identified in the original search (December 2008). Updated searches identified a further 1211 (February 2012) and 820 (February 2013) references respectively. We examined 147 papers in full text, of which we excluded 99, as they were either not randomised controlled trials (RCTs) or included participants who did not have dementia. We excluded a further 34 studies (see flow diagram in Figure 1; Characteristics of excluded studies) leaving 13 studies judged to be eligible for inclusion in the review (Bass - Ohio; Callahan - Indianapolis; Chien- Hong Kong 2008; Chien - Hong Kong 2001; Chu - Canada; Dias - Goa India; Eloniemi-Sulkava 2001; Eloniemi-Sulkava 2009; Hinchliffe - UK; Jansen - Netherlands; Lam - Hong Kong); Newcomer - US; Vickrey - California. 
Figure 1. Study flow diagram.

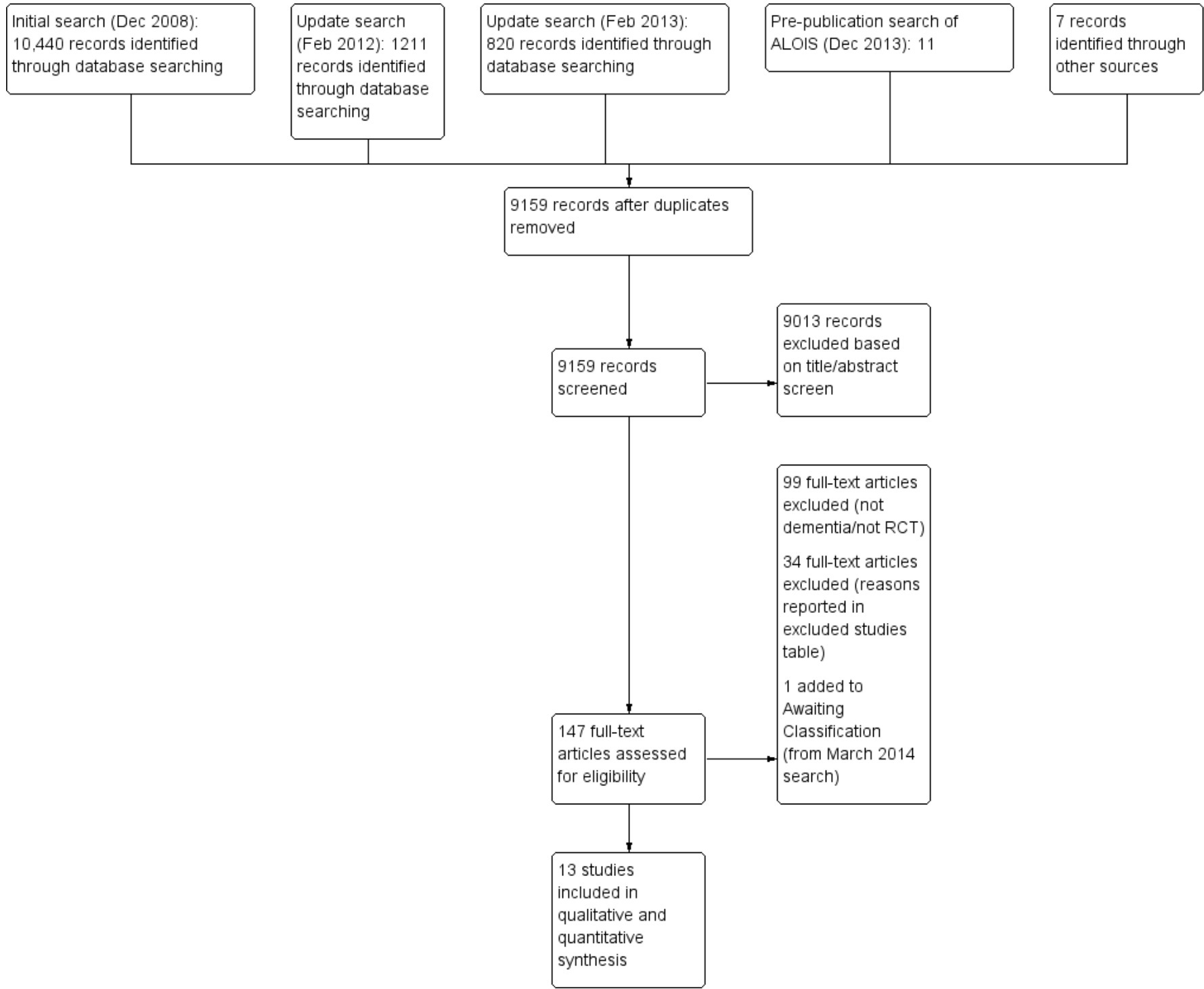

The 13 included studies randomised a total of 9615 participants (8095 from the Newcomer - US study). Four trials were based in the US (Bass - Ohio; Callahan - Indianapolis; Newcomer - US; Vickrey California); four in Europe (Eloniemi-Sulkava 2001; Eloniemi-Sulkava 2009; Hinchliffe - UK; Jansen - Netherlands), three in Hong Kong (Chien- Hong Kong 2008; Chien - Hong Kong 2001; Lam - Hong Kong), one in Canada (Chu - Canada) and another in India (Dias Goa India).

We identified one relevant ongoing study (Iliffe - UK). One report (Samus 2014) from an updated search on 6th March 2014 has been added to Studies awaiting classification.

All but one study (Lam - Hong Kong) required further outcome information, and we contacted the authors of these studies, obtaining additional data for 10 trials: Bass - Ohio; Callahan - Indianapolis; Chien- Hong Kong 2008; Chien - Hong Kong 2001; Chu - Canada; Dias - Goa India; Eloniemi-Sulkava 2001; Eloniemi-Sulkava 2009; Jansen - Netherlands; Vickrey - California.

\section{Included studies}

\section{Study length}

All but three trials (Chien- Hong Kong 2008; Dias - Goa India; Hinchliffe - UK) had a duration of 12 months or more. Nine of the remaining trials reported data at 12 months (Bass - Ohio; Callahan - Indianapolis; Chien - Hong Kong 2001; Eloniemi-Sulkava 2001; Eloniemi-Sulkava 2009; Jansen - Netherlands; Lam - Hong Kong; Newcomer - US; Vickrey - California) and another study reported data at 10 months (Chu - Canada). Where possible we report these together. Three trials had a duration of 18 months (Callahan - Indianapolis; Chu - Canada; Chien - Hong Kong 2001), two trials lasted two years (Eloniemi-Sulkava 2001; Eloniemi-Sulkava 2009) and the longest trial lasted three years (Newcomer - US).

\section{Design}

Most studies presented a parallel longitudinal design, although one trial was a multi-arm parallel study (Newcomer - US) including two different case management models. Two studies were cluster-randomised trials (Callahan - Indianapolis; Vickrey - Califor- 
nia). Seven studies were multicentre trials (Callahan - Indianapolis; Chien- Hong Kong 2008; Chien - Hong Kong 2001; Dias - Goa India; Jansen - Netherlands; Newcomer - US; Vickrey - California). Six studies were conducted at single centres (Bass - Ohio; Chu - Canada; Eloniemi-Sulkava 2001; Eloniemi-Sulkava 2009; Hinchliffe - UK; Lam - Hong Kong).

\section{Types of participants}

Thirteen trials included a total of 9615 participants with dementia. Four trials included participants only with Alzheimer's Disease based on DSM-IV criteria (Callahan - Indianapolis; Chien- Hong Kong 2008; Chien - Hong Kong 2001; Chu - Canada). The majority of participants (75\%) in another trial were diagnosed with Alzheimer's Disease (Vickrey - California). Most trials involved participants with various diagnoses of dementia (see Characteristics of included studies).

Most trials stated the severity of the dementia or gave cognitive test scores (the Mini Mental State Examination (MMSE) or the Blessed Dementia Scale). Six studies included both mild and moderate dementia severity (Bass - Ohio; Callahan - Indianapolis; Chien- Hong Kong 2008; Chien - Hong Kong 2001; Dias - Goa India; Lam - Hong Kong). Three studies included predominantly moderate dementia severity (Eloniemi-Sulkava 2001; Eloniemi-Sulkava 2009; Newcomer - US) and four studies included mostly mild dementia severity (Chu - Canada; Hinchliffe - UK; Jansen - Netherlands; Vickrey - California). We did not pursue subgroup analyses by dementia severity, as we considered that they were unlikely to generate meaningful results given the small number of studies and the diversity of case management interventions.

A number of studies reported on comorbidities in the included participants (Bass - Ohio; Callahan - Indianapolis; Eloniemi-Sulkava 2009; Jansen - Netherlands; Vickrey - California). Other studies excluded people with physical comorbidities. Eloniemi-Sulkava 2001 included only those participants not suffering from any other severe diseases (e.g. stroke, cancer). Dias - Goa India excluded people if they had severe comorbid physical health conditions. Lam Hong Kong also excluded people with significant concomitant diseases with more than one hospital admission in the previous twelve months.

Most studies included patient and carer dyads (Chien- Hong Kong 2008; Chien - Hong Kong 2001; Chu - Canada Dias - Goa India; Eloniemi-Sulkava 2001; Eloniemi-Sulkava 2009; Hinchliffe - UK; Jansen Netherlands; Lam - Hong Kong; Vickrey - California) or included carers in the study (Bass - Ohio; Callahan - Indianapolis; Newcomer US).

Participants were recruited from primary care (Callahan - Indianapolis; Jansen - Netherlands; Vickrey - California), from outpatient, day care resources and other secondary care services (Bass Ohio; Chien- Hong Kong 2008; Chien - Hong Kong 2001; Chu - Canada; Eloniemi-Sulkava 2001; Eloniemi-Sulkava 2009; Hinchliffe - UK; Lam - Hong Kong) or from public announcements in newspapers (Eloniemi-Sulkava 2009; Hinchliffe - UK).

Four studies reported the dementia medications used by the participants: Callahan - Indianapolis; Chien - Hong Kong 2001; ChienHong Kong 2008; Vickrey - California.

\section{Types of interventions}

We extracted information from trials according to the prespecified case management characteristics in our review protocol. Where possible we supplemented this by information provided by the study authors. These details have been summarised in the Characteristics of included studies tables and in four additional tables (see Table 1; Table 2; Table 3; Table 4). We have attempted to describe and categorise the trials with the aim of exploring whether potential mediating variables (e.g. key structural and organisational features of case management interventions) affect case management outcomes. This narrative assessment of the evidence was challenging, as the studies examine interventions which are both complex and variable and details were not always reported or were unavailable from the study authors.

We attempted to categorise the 13 studies into a typology of case management (Table 5). There were four studies where the case manager encouraged self management of care and tended to empower the carer to arrange their own care where possible (Bass - Ohio; Chien- Hong Kong 2008; Chien - Hong Kong 2001; Dias Goa India). There were two short-term (Hinchliffe - UK; Lam - Hong Kong) and seven longer-term interventions where the case manager was more involved with and ensured appropriate delivery of services (Callahan - Indianapolis; Chu - Canada; Eloniemi-Sulkava 2001; Eloniemi-Sulkava 2009; Jansen - Netherlands; Newcomer US; Vickrey - California).

\section{Goals}

Although not always easy to discern from the papers, the reported objectives of these case management interventions varied (see Table 1). Eleven studies reported that a goal of the intervention was to reduce carer depression,strain and burden, or to improve carer mental health and quality of life (Bass - Ohio; Chien- Hong Kong 2008; Chien - Hong Kong 2001; Chu - Canada; Dias - Goa India; Eloniemi-Sulkava 2009; Hinchliffe - UK; Jansen - Netherlands; Lam - Hong Kong; Newcomer - US; Vickrey - California). Five studies reported that a goal of the intervention was to delay institutionalisation or prolong the period of community care (Chien- Hong Kong 2008; Chien - Hong Kong 2001; Chu - Canada; Eloniemi-Sulkava 2001; Eloniemi-Sulkava 2009). It is also interesting to note that this was not a specific goal of the Dias - Goa India study, as Goa does not have residential facilities to look after people with dementia. Furthermore, because the Newcomer - US demonstration was designed to improve carer well-being, no a priori assumptions were made about the intervention's effect on rates of nursing home entry.

Four trials aimed to increase early use of home care and other community services (Chien - Hong Kong 2001; Chu - Canada; Newcomer - US; Vickrey - California) and four aimed to reduce the number of neuropsychiatric symptoms/behavioural problems (Callahan Indianapolis; Dias - Goa India; Eloniemi-Sulkava 2009; Hinchliffe UK).

Only one trial explicitly aimed to improve participants' quality of life (Jansen - Netherlands). Four trials aimed to improve the quality of care of the person with dementia (Callahan - Indianapolis; Eloniemi-Sulkava 2009; Jansen - Netherlands; Vickrey - California). Two trials aimed to initiate early long-term planning related to issues such as housing, finance, legal matters, care-giving support and respite services (Chu - Canada; Vickrey - California). One tri- 
al aimed to improve carer sense of competence (Eloniemi-Sulkava 2009).

\section{Staff mix}

Case managers were employed from various professional groups (Table 3). These were registered nurses (Chien- Hong Kong 2008; Chien - Hong Kong 2001; Eloniemi-Sulkava 2001; Eloniemi-Sulkava 2009), district nurses (x 3) (Jansen - Netherlands), advanced practice nurse (x 2) (Callahan - Indianapolis), social workers and occupational therapists (Chu - Canada), social workers (Bass - Ohio; Newcomer - US; Vickrey - California), a community-based occupational therapist (Lam - Hong Kong), and a psychiatrist (Hinchliffe UK). One study recruited health care advisors without a professional qualification (Dias - Goa India). There were also variations within studies, for example each site in the Newcomer - US study was implemented in different ways; the Illinois programme employed nurses as case managers (Shelton 2001), whereas other sites employed social workers, mental health professionals, and gerontology specialists. As expected, nurses and social workers were the most common occupational groups.

Many of the case managers worked within a multidisciplinary team: (Callahan - Indianapolis; Chu - Canada; Dias - Goa India; Eloniemi-Sulkava 2001; Eloniemi-Sulkava 2009; Hinchliffe - UK; Lam Hong Kong; Newcomer - US). In Callahan - Indianapolis the primary care physician and the care manager were supported through two additional mechanisms. First, the care manager had weekly meetings with a support team comprising a geriatrician, geriatric psychiatrist, and a psychologist who reviewed the care of new and active patients and monitored adherence to the standard protocols. Second, the care manager was supported by a web-based longitudinal tracking system that managed the schedule for patient contacts, tracked the patient's progress and current treatments, and provided an instrument for communicating the patient's and carer's current clinical status to the entire care team. In Hinchliffe UK a multidisciplinary team (consultant psychiatrist, psychologist, community psychiatric nurse, social worker and pharmacist) generated an individualised plan aimed at reducing the most distressing behaviours.

Case managers who did not work in a multidisciplinary team were reported to work with another professional or within a single discipline team. In Chien- Hong Kong 2008, each family was assigned one case manager who, together with another nurse in the centre, summarised the assessment data and in collaboration with the carers prioritised problem areas and formulated a multidisciplinary education programme for each family on effective dementia care; for example, cognitive stimulation. In Jansen - Netherlands, three district nurses who specialised in geriatric care acted as case managers of both participant and carer. In Bass - Ohio, two part-time care consultants and one part-time care consultant assistant/volunteer worked with 100 families. The case manager in Vickrey - California operated as an individual worker.

\section{Location}

All case managers were based in the community, as this was one of our inclusion criteria (Table 3). Three were based within a primary care setting (Callahan - Indianapolis; Jansen - Netherlands; Vickrey - California) and case managers in two studies were based in a dementia resource centres (Chien- Hong Kong 2008; Chien - Hong Kong 2001).

\section{Training of case managers}

Details relating to the training of case managers were reported in six trials. In one study (Eloniemi-Sulkava 2009) the family care coordinator (FCC) was a trained public health registered nurse with advanced practice education (31/2 years) and special education in dementia care (one year). She and the geriatrician were trained and tutored throughout the intervention by a dementia expert. In Eloniemi-Sulkava 2001 the co-ordinator was a registered nurse with a public health background who received extensive training, support and advice in dementia care from dementia specialists. The district nurse case managers in the Jansen - Netherlands trial specialised in geriatric care and were trained in working with the resident assessment instrument - home care (RAI-HC) (a computerised multidimensional instrument), and in organising family meetings. They also received two seminars on how to deal with people with dementia and their informal carers. They met on a monthly basis to discuss innovations and geriatric cases, and were supervised by a staff member of their home care organisation. In Dias - Goa India, the health care advisors (HCAs) underwent one week of intensive training through role play and interactive training methods. The HCAs were trained in key skills including listening and counselling, bereavement counselling, stress management and health advice for common health problems. Case managers in Chien- Hong Kong 2008 received 32 hours of formal training from the researchers, and those in Chien - Hong Kong 2001 received an unspecified amount of formal training by the research team. There was no specific training given within the Bass - Ohio trial. Another trial reported that the case managers, who were mostly social workers, received formal training and used an Internet-based care management software system for care planning and co-ordination (Vickrey - California).

\section{Mode of delivery of case management}

Almost all trials used face-to-face visits, and many specified that home visits were carried out (Chien- Hong Kong 2008; Chien - Hong Kong 2001 Dias - Goa India; Eloniemi-Sulkava 2001; Eloniemi-Sulkava 2009; Hinchliffe - UK; Jansen - Netherlands). One study operated solely on telephone-based case management which was delivered within a partnership between a managed care health system and an Alzheimer's Association (Bass - Ohio). In this study $20 \%$ of participants had a Kaiser case management visit during the oneyear period, and only $3 \%$ had more than one visit. A number of other studies used telephone case management to complete follow-up assessments (Vickrey - California) or to monitor participants when home visits were not considered necessary (Eloniemi-Sulkava 2009; Jansen - Netherlands; Lam - Hong Kong).

\section{Intensity - caseload size}

The intensity of case management input can be measured by examining the caseload size (Table 3). Caseload size was reported in eight of the trials and is described here in order of intensity. In Hinchliffe - UK the case manager, a psychiatrist, had a case load of approximately 13 to 20 participants. In Dias - Goa India there were 20 to 21 participants per home care advisor. In the Jansen - Netherlands trial three nurses visited 99 participants and their informal carers, which formed a small part of their overall activities. In one of the two case management models that were implemented in the Newcomer - US study, model B sites (higher intensity of case management) had a target case manager-to-client ratio of 1:30 and a slightly higher reimbursement limit of between USD 430 and USD 699 per month per client. In Lam - Hong Kong, the case manager, a 
community-based occupational therapist, saw 59 participants over a period of four months. In the Eloniemi-Sulkava 2009 trial there was one case manager to 60 participants, and in Vickrey - California it was approximately 50 participant/carer dyads per care manager. In Bass - Ohio there were two part-time care consultants and one part-time care consultant assistant/volunteer per 100 families. This trial was described as an 'intensive-care management intervention' (Chodash 2006). In the other case management model implemented in the Newcomer - US study, model A sites (lower intensity of case management) operated with a target case manager-toclient ratio of 1:100 in addition to a monthly community service reimbursement limit or cap of between USD 290 and USD 489 per month per client.

\section{Intensity - frequency of contact and duration}

Intensity of case management can also be measured by examining the frequency of contacts with case managers. We converted data for each study to monthly contacts from the data reported, and we present it in Table 3 for 11 of the studies. They ranged from around one contact per month (Callahan - Indianapolis; Chu - Canada; Eloniemi-Sulkava 2001; Eloniemi-Sulkava 2009; Hinchliffe - UK; Lam - Hong Kong; Vickrey - California) to two or more contacts per month (Bass - Ohio; Chien- Hong Kong 2008; Chien - Hong Kong 2001; Dias - Goa India).

The duration of the intervention ranged from four months to two years, and this matched the follow-up period for all but two studies (Chien - Hong Kong 2001; Lam - Hong Kong). There were five studies with interventions of six months or less (Chien- Hong Kong 2008; Chien - Hong Kong 2001; Dias - Goa India; Hinchliffe - UK; Lam - Hong Kong), three studies with interventions of 12 months (Bass Ohio; Callahan - Indianapolis; Jansen - Netherlands) and the rest were between 18 and 36 months (Chu - Canada; Eloniemi-Sulkava 2001; Eloniemi-Sulkava 2009; Newcomer - US; Vickrey - California). The intervention period was shorter than the follow-up period in the Chien - Hong Kong 2001 trial (intervention six months, final follow-up 12 months) and the Lam - Hong Kong trial (intervention four months, final follow-up 12 months). (See Appendix 2 for further details)

\section{Co-ordination of services}

The case manager was formally responsible for co-ordination of care and treatment between organisations and agencies (Table 3) in Chien- Hong Kong 2008; Chu - Canada; Eloniemi-Sulkava 2001; Eloniemi-Sulkava 2009; Jansen - Netherlands; Vickrey - California. In Callahan - Indianapolis the geriatric nurse practitioner co-ordinated participant and carer contact with other primary care clinic appointments and made home visits to accommodate participants' schedules and needs. However, in the Bass - Ohio trial, the care consultants contacted service agencies on behalf of participants and care-givers with the aim of facilitating them.

Regarding the breadth of services spanned (the extent to which case managers had a comprehensive role) in only four studies did it appear that case managers were taking responsibility for managing the wider care network (Chu - Canada; Eloniemi-Sulkava 2001; Newcomer - US; Vickrey - California). By contrast, although there was an element of co-ordination, other studies focused more on the work of their own service (Callahan - Indianapolis; Chien - Hong Kong 2001; Dias - Goa India; Eloniemi-Sulkava 2009; Hinchliffe - UK; Lam - Hong Kong), which represents a narrower focus of case management responsibility.

\section{Study protocols/treatment algorithms}

The interventions for many of the trials were reported to rely on the use of a protocol or manual to facilitate standardised implementation (Bass - Ohio; Callahan - Indianapolis; Chu - Canada; Eloniemi-Sulkava 2001; Eloniemi-Sulkava 2009; Jansen - Netherlands Vickrey - California; available on web site www.adc.ucla.e$\mathrm{du} /$ access/access.swf). Another trial was described as a flexible stepped care model without a manual (Dias - Goa India).

\section{Other interventions}

All interventions had multiple components of case management and some were part of a wider intervention such as collaborative care (Callahan - Indianapolis) or a disease management programme (Chien- Hong Kong 2008; Vickrey - California). Some had many components (Callahan - Indianapolis; Eloniemi-Sulkava 2001; Eloniemi-Sulkava 2009; Vickrey - California) and others had fewer (Dias - Goa India)

Some trials tested the effectiveness of interventions that incorporated case management in a more complex intervention. For example, treatment guidelines for Alzheimer's disease as delivered through a collaborative care model in a primary care setting (Callahan - Indianapolis). Intervention components were based on the chronic care model and emphasised linkages with community resources and multi-agency co-ordination. Key components included dementia care managers, formal procedures for communication within and between organisations and agencies, as well as including: adherence to 23 dementia guideline recommendations; Internet-based care management; collaborative care planning with carers; carer self-management support; ongoing follow-up; and provider education. Internet-based care management software was also used in the Vickrey - California trial.

\section{Case management tasks}

We separately assessed the tasks and components covered by the case management intervention (Reilly 2010) for all the studies, and summarise them in Table 4. Although the core tasks of assessment, care planning and implementation/management were common to all but one trial (Dias - Goa India), there was considerable variation in their delivery. All but one of the trials (Hinchliffe - UK) reported that the implementation of the care plan was monitored. In Dias Goa India there were twice-monthly meetings with a psychiatrist to review the participant's progress. There was greater variation when it came to the coverage of tasks associated with more complex care co-ordination, such as arranging and allocating services and managing the care network. To some extent all studies apart from four (Bass - Ohio; Chien- Hong Kong 2008; Chien - Hong Kong 2001; Dias - Goa India) stated that they arranged and allocated services. These trials were more focused on: co-ordinating family care; empowering the carers and people with dementia to make use of their social support network, along with establishing support from community groups or healthcare resources; and providing emotional support to carers.

Case managers in only two trials held or managed a budget for purchasing services (Eloniemi-Sulkava 2009; Newcomer - US). It was noted in the Eloniemi-Sulkava 2001 trial that the carers contacted the co-ordinator only 10 times outside working hours in the two years. This was because the co-ordinator had no extra money to buy services for the participants and those services within the financial means of the participants were used. 


\section{Case management components}

Interventions in all trials included carer education, and most included participant education components (Table 4); for example, Bass - Ohio provided education and training programmes, support groups, respite reimbursement, and a nationwide programme for 'wanderers'.

The role of the case manager in seven of the studies included a medications review/management component: Callahan - Indianapolis; Dias - Goa India; Eloniemi-Sulkava 2001; Eloniemi-Sulkava 2009; Hinchliffe - UK; Lam - Hong Kong; Vickrey - California. For example, in the Callahan - Indianapolis study the programme was integrated with primary care and the nurse practitioner worked with the primary care physicians to evaluate symptoms or change medications.

Case managers in all but two studies (Chien- Hong Kong 2008; Lam - Hong Kong) provided emotional/therapeutic support to participants or carers. Fewer were involved in advocating for the participant (Bass - Ohio; Chu - Canada; Eloniemi-Sulkava 2001; Eloniemi-Sulkava 2009; Lam - Hong Kong; Vickrey - California) or providing advice regarding benefits, financial and legal issues (Callahan - Indianapolis; Chu - Canada; Dias - Goa India; Eloniemi-Sulkava 2009; Vickrey - California).

As noted earlier in the 'Types of interventions' section we also attempted to categorise the 13 studies into a typology of case management (Table 5).

\section{Types of comparison group}

Two studies used a waiting-list control where participants received the intervention after six months (Dias - Goa India) and after 16 weeks (Hinchliffe - UK). The features of standard care were variable across trials run in different countries at different time periods ( $\mathrm{Ta}$ ble 2). Eight trials described a fairly straightforward standard care (Bass - Ohio; Chu - Canada; Eloniemi-Sulkava 2001; Hinchliffe - UK; Jansen - Netherlands; Lam - Hong Kong; Newcomer - US; Vickrey California) and are described in more detail in Table 2 and in the Characteristics of included studies tables. The comparison group in the remaining trials received augmented usual care (Callahan Indianapolis; Chien- Hong Kong 2008; Chien - Hong Kong 2001; Dias - Goa India; Eloniemi-Sulkava 2009).

\section{Use of case management in usual care group}

One study (Chu - Canada) provided appropriate data to allow us to examine the difference in case management usage between the groups. In this trial the control group also had access to case management. The intervention group received a mean 16.7 hours of case management per month (37/37 participants) compared to nine hours for the control group (35/38 participants). However, a significantly greater proportion of the intervention group had access to case management compared to the control group at three months (odds ratio (OR) 10.97, 95\% confidence interval (CI) 3.47 to $34.65, \mathrm{n}=75, \mathrm{P}<0.0001), 10$ months (OR $3.73,95 \% \mathrm{Cl} 1.18$ to 11.79 , $\mathrm{P}=0.02$ ) and 18 months (OR $4.14,95 \% \mathrm{Cl} 1.56$ to $10.97, \mathrm{P}=0.004$ ).

The Bass - Ohio trial also reported data that were relevant but which were in a format that we could not analyse.

We also noted in the Newcomer - US study that control group cases might have been exposed to comparable benefits, such as case management and community care benefits if they were participat- ing in state Medicaid programmes. For this reason, the demonstration programmes were encouraged not to seek or accept applications from those receiving Medicaid. They complied with this request, but researchers were unable to prevent the applicants from entering Medicaid programmes later. In total $7.5 \%$ of the treatment group and $7.7 \%$ of the controls were Medicaid programme recipients for some portion of the study observation period. Statistical controls were used to adjust for the potential effect of Medicaid participation. Most of the Medicaid participation occurred after the person with dementia entered a nursing home, which was a censoring outcome. The direction of bias for those entering Medicaid while still in the community would be to reduce case management and community service treatment differences relative to the controls.

\section{Types of outcome measures}

Many trials used different scales in assessing treatment effects for various outcomes. We show only details of scales that provided usable data in Table 6. Reasons for exclusion of data are given under 'Outcomes' in Characteristics of included studies. We considered outcomes in relation to the impact of the intervention on the person with dementia and on the family carer. Many trials had common outcomes, such as cognition, mood, behaviour and dependency of the person with dementia; mood, burden and well-being of the carer; and service use. Different scales were used in assessing treatment effects for various outcomes. We conducted statistical pooling using standardised mean differences where appropriate.

\section{Excluded studies}

Of the 9159 records screened, we excluded 9013 on title and abstract, and examined the full texts of 147 studies; we excluded 99 of these because they were not RCTs or they were not focused upon people with dementia. The Characteristics of excluded studies table lists trials which were potentially relevant $(n=34)$ but which did not meet all the inclusion criteria for the review, together with the reasons for which we excluded them. We excluded 25 because the experimental intervention did not meet our inclusion criteria for case management, three trials because the experimental intervention or comparison intervention was hospital-based and not delivered in the community (Baldwin - UK; Fabris - Italy; Lu - China), and another three because they were focused only upon carers of people with dementia (Weinberger - US; Kwak - Georgia; Schoenmakers-Belgium), another two because of study design (Aliberti Las Vegas; Mostardt - Germany) and a further study because both groups received case management (Callahan-Indianapolis).

\section{Ongoing studies}

We are aware of only one currently ongoing study (Iliffe - UK; see Characteristics of ongoing studies). We have contacted the lead author of this study and data were not available in time to include in this review.

\section{Studies awaiting classification}

One study (Samus 2014) is awaiting classification, as this was not possible within the timeframe of the review (Characteristics of studies awaiting classification).

\section{Risk of bias in included studies}

We obtained additional information relating to the risk of bias of studies included in the review from authors of eight trials: Bass 
- Ohio; Callahan - Indianapolis; Chu - Canada; Dias - Goa India; Eloniemi-Sulkava 2001; Eloniemi-Sulkava 2009; Jansen - Netherlands; Vickrey - California.

At least two review authors (from CM, JH, SR, RM, ST) independently evaluated the methodological quality of each study, using
The Cochrane Collaboration's 'Risk of bias' tool (Higgins 2011). We made judgements of risk of bias across nine domains (see Risk of bias in included studies). We compared judgements and resolved disagreements by discussion. The 'Risk of bias' summary is shown in Figure 2 and Figure 3.

\section{Figure 2. Risk of bias graph: review authors' judgements about each risk of bias item presented as percentages} across all included studies.

\begin{tabular}{|l} 
Random sequence generation (selection bias) \\
Allocation concealment (selection bias) \\
Blinding (performance bias and detection bias): Participants \\
Blinding (performance bias and detection bias): Personnel \\
Blinding (performance bias and detection bias): Outcome assessors \\
Blinding (performance bias and detection bias): Other \\
Incomplete outcome data (attrition bias) \\
Selective reporting (reporting bias) \\
\hline Low risk of bias
\end{tabular}


Figure 3. Risk of bias summary: review authors' judgements about each risk of bias item for each included study.

\begin{tabular}{|c|c|c|c|c|c|c|c|c|c|}
\hline & 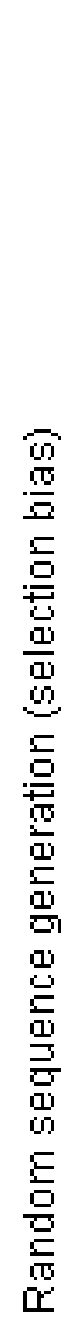 & 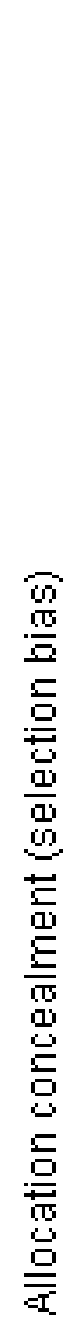 & 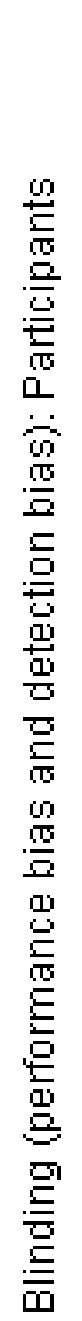 & 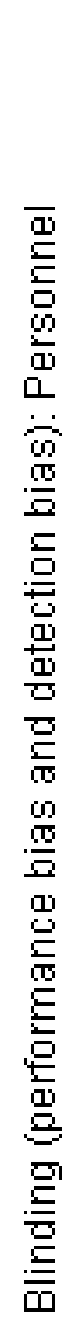 & 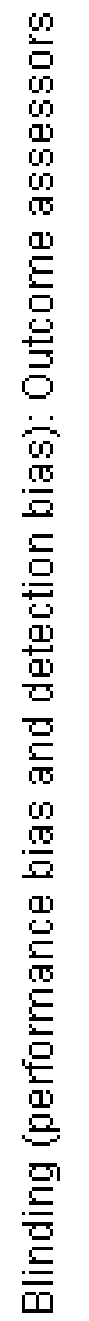 & 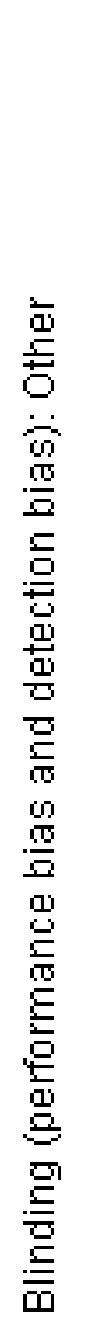 & 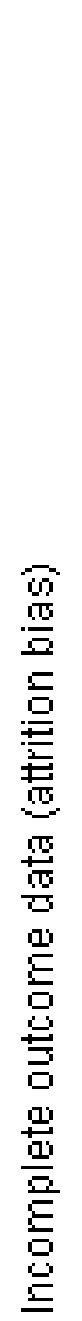 & 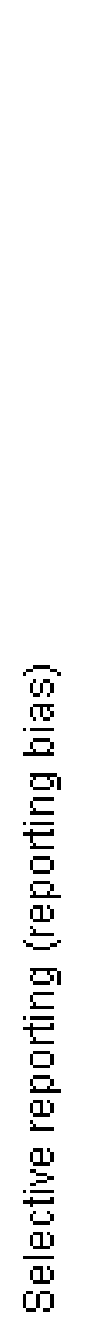 & 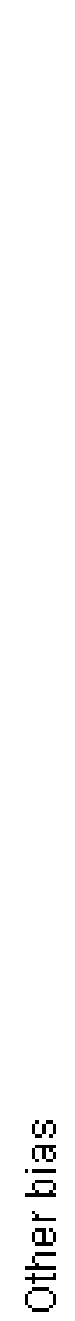 \\
\hline Bass - Ohio & & & & & & & & & $?$ \\
\hline Callahan - Indianapolis & & & $?$ & $?$ & & $?$ & + & & $?$ \\
\hline Chien - Hong Kong 2001 & $?$ & $?$ & $?$ & $?$ & & + & + & & $?$ \\
\hline Chien- Hong Kong 2008 & $?$ & $?$ & $?$ & $?$ & & & $?$ & & $?$ \\
\hline Chu-Canada & & & & & & $?$ & & & $?$ \\
\hline Dias - Goa India & & $?$ & & $?$ & & & & & \\
\hline Eloniemi-Sulkava 2001 & & & & & & & & & + \\
\hline Eloniemi-Sulkava 2009 & & & & & & 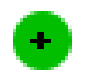 & & $?$ & + \\
\hline Hinchliffe - UK & & $?$ & & $?$ & + & & $?$ & & $?$ \\
\hline
\end{tabular}

Case management approaches to home support for people with dementia (Review) Copyright $\odot 2015$ The Cochrane Collaboration. Published by John Wiley \& Sons, Ltd.

\begin{tabular}{|c|c|c|c|c|c|c|c|c|c|}
\hline 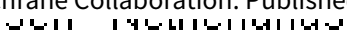 & (I) & 争 & to & $\boldsymbol{\sigma}$ & $\theta$ & $\bullet$ & $\cdot$ & $\bullet$ & - \\
\hline Lam - Hong Kong & + & + & 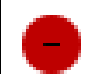 & $?$ & + & + & + & + & + \\
\hline ewcomer & + & + & & $?$ & $?$ & + & & & $?$ \\
\hline
\end{tabular}




\section{Allocation}

\section{Generation of random number sequence}

Eleven studies provided detailed information about the methods used for sequence generation. Most studies were classified at a low risk of selection bias. The most frequent method used was a random number table (Callahan - Indianapolis; Dias - Goa India; Jansen - Netherlands; Lam - Hong Kong) or a computerised random number generator (Newcomer - US; Vickrey - California). One study used block randomisation (Eloniemi-Sulkava 2009) and another used a random permuted block system (Hinchliffe - UK). Three studies were at risk of selection bias (Bass - Ohio; Chu - Canada; Eloniemi-Sulkava 2001) and two studies did not supply enough information for a determination (Chien- Hong Kong 2008; Chien - Hong Kong 2001).

\section{Allocation concealment}

Seven studies were rated at low risk of bias for allocation concealment, as they described the methods used. Most of them used central randomisation (Callahan - Indianapolis; Eloniemi-Sulkava 2009; Newcomer - US; Vickrey - California). One study used numbered sealed envelopes (Eloniemi-Sulkava 2001). The rest of the studies did not provide enough information, and we classified them as at unclear risk (Chien- Hong Kong 2008; Chien - Hong Kong 2001; Dias - Goa India; Hinchliffe - UK; Jansen - Netherlands) or at high risk (Bass - Ohio; Chu - Canada).

Overall, most studies were free of selection bias due to use of adequate methods for random sequence generation and allocation concealment.

\section{Blinding}

\section{Performance bias (blinding of participants)}

Since case management is a non-pharmacological intervention, we assumed that participants were not totally blind to treatment assignment. In this respect, most of the studies were classified as being at high risk (Bass - Ohio; Chu - Canada; Dias - Goa India; Eloniemi-Sulkava 2001; Eloniemi-Sulkava 2009; Hinchliffe - UK; Jansen Netherlands; Lam - Hong Kong; Newcomer - US) or at unclear risk (Callahan - Indianapolis; Chien- Hong Kong 2008; Chien - Hong Kong 2001). Only one study was rated as being at low risk: Vickrey - California was a cluster-randomised trial, so participants were unaware of clinic randomisation status until baseline assessment and were not reminded of randomisation status at follow-up.

\section{Performance bias (blinding of personnel)}

Case managers who carried out the intervention could not be blinded to intervention allocation, so in this section we considered whether personnel other than case managers and outcome assessors were blinded to treatment assignment. Six studies (Callahan - Indianapolis; Chien- Hong Kong 2008; Chien - Hong Kong 2001; Hinchliffe - UK; Lam - Hong Kong; Newcomer - US) were rated at unclear risk because they did not mention measures taken to blind personnel. Chu - Canada and Jansen - Netherlands, responding to email communication, pointed out that personnel such as physicians were not blind to participants' allocation. Participants in Bass - Ohio could have volunteered to their physicians or nurses whether they were assigned to the intervention or control group over the course of the study. Three studies (Eloniemi-Sulkava 2001; Elonie-
mi-Sulkava 2009; Vickrey - California) were classified as being at low risk, due to blinding of any or all staff, physicians and care providers.

\section{Detection bias (blinding of outcome assessment)}

Out of the 13 studies, nine (69\%) had blinded outcome assessors (Bass - Ohio; Callahan - Indianapolis; Chien- Hong Kong 2008; Chien - Hong Kong 2001; Eloniemi-Sulkava 2001; Eloniemi-Sulkava 2009; Hinchliffe - UK; Jansen - Netherlands; Lam - Hong Kong) and were classified as being at low risk. One study (Chu - Canada) did not take any measures to blind the assessors, while Dias - Goa India attempted to blind outcome assessors by keeping information about allocation status in a separate office from the outcome evaluation teams. In order to evaluate the masking process, researchers were asked to guess the intervention status. Two-thirds of the assessors guessed the allocation status correctly. We classified two studies as unclear (Newcomer - US; Vickrey - California). The authors in the Vickrey - California study pointed out that "medical record abstractors could have discerned aspects of the study intervention, and we did not assess the extent to which abstractors were blinded to intervention status" (email communication sent 20th November 2010). The Newcomer - US study did not report whether or not outcome assessors were blinded.

\section{Summary}

We can conclude that all of the studies were subject to performance bias inherent in any psychosocial intervention such as non-blinded participants and non-blinded case managers. However, most of the studies made an effort to blind outcome assessors, which led to an overall low risk of detection bias.

\section{Incomplete outcome data}

Only five studies were classified as being at low risk of attrition bias (Callahan - Indianapolis; Chien - Hong Kong 2001; Eloniemi-Sulkava 2001; Eloniemi-Sulkava 2009; Lam - Hong Kong) as although they had missing outcome data, this was balanced in numbers across intervention groups, with similar reasons for missing data across groups. We rated four studies at high risk. Bass - Ohio study had some missing follow-up data for psychosocial outcomes. Also, numbers allocated to the groups and numbers lost to follow-up were not clearly reported. We rated Chu - Canada study as high risk, since for some outcomes 'as treated' analyses were performed, with substantial differences between the intervention received and that assigned at randomisation. We rated Dias - Goa India and Newcomer - US at high risk, due to the high rates of missing data in both groups, even though this was balanced in numbers across groups. Finally, we rated four studies as being at unclear risk. Chien- Hong Kong 2008 did not state clearly either the number of participants randomised or the attrition rates for each group. Hinchliffe - UK and Vickrey - California had an imbalance in numbers and reasons for missing data across the groups. In Jansen - Netherlands there was attrition at follow-up and some imbalance in numbers of missing data across the groups at six months.

\section{Selective reporting}

We classified eight studies at low risk of selective reporting bias (Chien- Hong Kong 2008; Chien - Hong Kong 2001; Dias - Goa India; Eloniemi-Sulkava 2001; Eloniemi-Sulkava 2009; Jansen - Netherlands; Lam - Hong Kong; Vickrey - California). We rated the remaining five studies at high risk of reporting bias, as they did not report 
data on all the outcomes that were specified within the study. Even though Chu - Canada provided some of the information requested, there were still some data missing on primary outcomes such as total home care usage outcomes (standard deviations for mean number of hours), total numbers institutionalised (standard deviations), and length of time participants remained in the community. In addition, activities of daily living (measured by Alberta Assessment and Placement Instrument (AAPI)) were not reported. Secondary outcomes were not reported by Bass - Ohio, Hinchliffe - UK and Newcomer - US. There was also a reporting bias in Callahan Indianapolis, with analysis that was not consistent with randomisation, and the intraclass correlation coefficients not reported.

\section{Other potential sources of bias}

Of the 13 studies, we rated seven as being at unclear risk of other biases. Three had problems regarding baseline differences between the groups. Bass - Ohio did not report a test to assess baseline differences, and Hinchliffe - UK did not provide baseline data. In Callahan - Indianapolis there were some baseline differences between groups: a higher proportion of the augmented usual care group were black: $40 / 69$ (58\%) compared to the intervention group $(35 / 84 ; 42 \%)(P=0.05)$. A higher proportion of the augmented usual care group were women $(66 / 69 ; 96 \%)$ compared to the intervention group $(70 / 84 ; 83 \%)(P=0.02)$. However, these differences were adjusted for in subsequent analyses.
Some degree of contamination may have occurred in four studies. In two studies (Chien- Hong Kong 2008,Chien - Hong Kong 2001) even though the intervention was given to only the experimental group, the two centres provided both groups with routine dementia care. Also, in the Chu - Canada study, a significant proportion of the control group received case management. In Newcomer - US, some of the participants might have received case management and community care benefits (as part of the Medicaid programmes) while still in the community, consequently reducing case management and community service treatment differences relative to the controls.

\section{Effects of interventions}

See: Summary of findings for the main comparison Case management versus usual care for people with dementia

\section{Primary outcomes:}

Case management compared to usual care: effect on people with dementia (care recipients)

\subsection{Institutionalised (number of participants admitted to residential or nursing homes)}

(Figure 4, Analysis 1.1) 
Figure 4. Forest plot of comparison: 1.1 Institutionalised (number of patients admitted to residential or nursing homes) (as reported at each time point in trials)

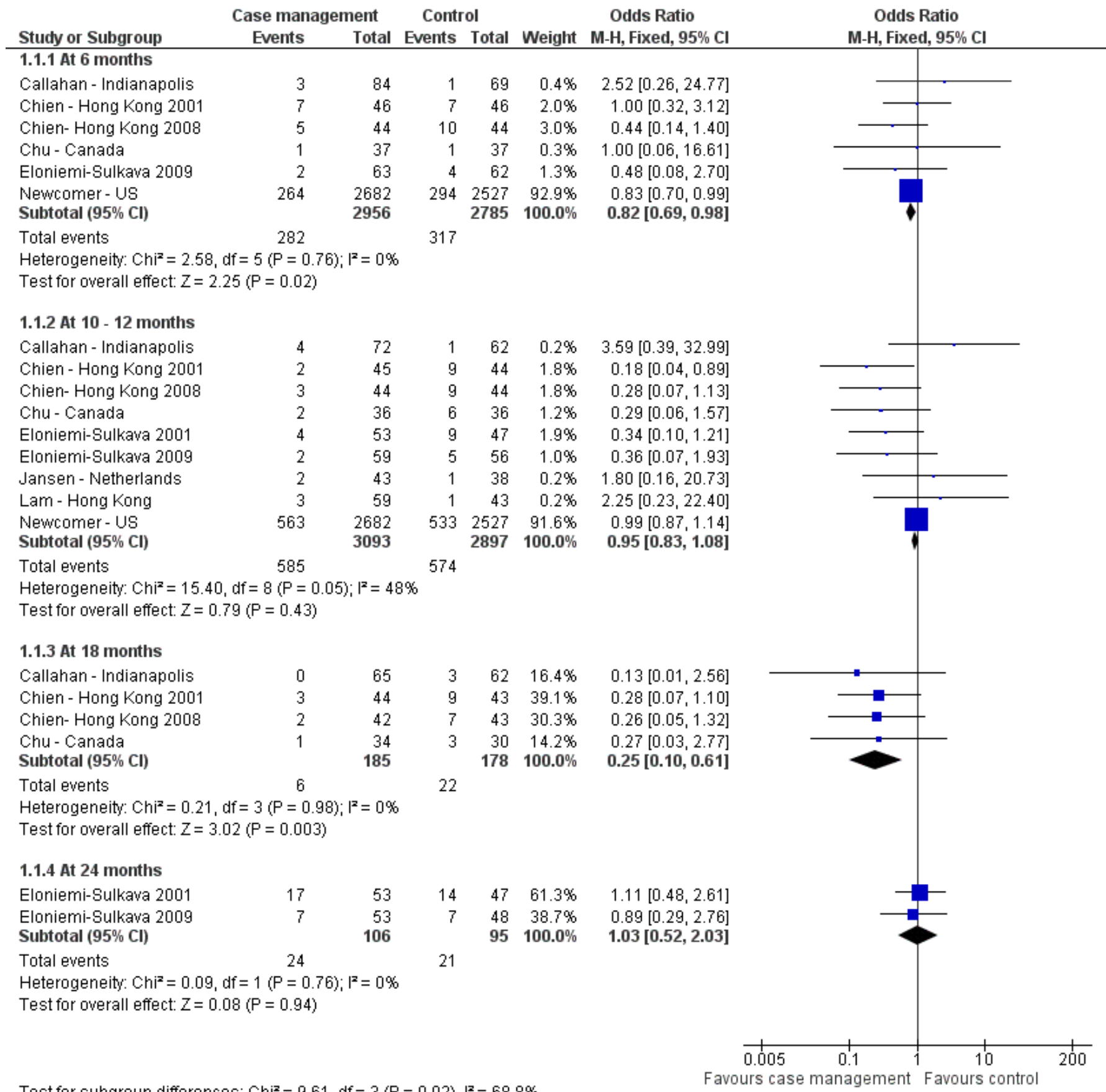

Test for subqroup differences: $\mathrm{Chi}^{2}=9.61, \mathrm{df}=3(\mathrm{P}=0.02), \mathrm{I}^{2}=68.8 \%$

ings we excluded Chu - Canada (rated as a low-quality study). Reanalysing the data did not alter the results.

Data were available for six studies (Callahan - Indianapolis; ChienHong Kong 2008; Chien - Hong Kong 2001; Chu - Canada; Eloniemi-Sulkava 2009; Newcomer - US) that reported the proportion of participants who had an admission to either residential or nursing homes at six months. Those in the case management group were significantly less likely to be institutionalised (odds ratio (OR) $0.82,95 \%$ confidence interval $(\mathrm{Cl}) 0.69$ to $0.98, \mathrm{n}=5741, \mathrm{I}^{2}=0 \%, \mathrm{P}$ $=0.02$ ). However, these results were dominated by a single large study (Newcomer - US). In order to test the robustness of our find-

\subsubsection{At 10 - 12 months}

The proportion of participants who had an admission to either residential or nursing homes at 10 to 12 months was reported in nine studies (Callahan - Indianapolis; Chien- Hong Kong 2008; Chien - Hong Kong 2001; Chu - Canada; Eloniemi-Sulkava 2001; Eloniemi-Sulkava 2009; Jansen - Netherlands; Lam - Hong Kong; Newcomer - US). At this time point we found no significant differences 
between groups (OR $0.95,95 \% \mathrm{Cl} 0.83$ to $1.08, \mathrm{n}=5990, \mathrm{I}^{2}=48 \%, \mathrm{P}$ $=0.43)$. However these data were moderately heterogeneous $\left(I^{2}=\right.$ $48 \%, P=0.43)$. When we used a random-effects model there were no significant differences between groups $(P=0.09)$. We conducted a sensitivity analysis on those studies which had reported that the goals of the intervention were focused upon delaying institutionalisation or prolonging the period of community care. Five studies (Chien- Hong Kong 2008; Chien - Hong Kong 2001; Chu - Canada; Eloniemi-Sulkava 2001; Eloniemi-Sulkava 2009) were included and the meta-analysis indicated that those in the case management group were significantly less likely to be institutionalised (OR 0.29 $\mathrm{Cl} 0.15$ to $0.55, \mathrm{n}=464, \mathrm{I}^{2}=0 \%, \mathrm{P}=0.0002$ ).

\subsubsection{At 18 months}

Four studies provided 18-month data (Callahan - Indianapolis; Chien- Hong Kong 2008; Chien - Hong Kong 2001; Chu - Canada). The case management group were significantly less likely to be institutionalised (OR $0.25,95 \% \mathrm{Cl} 0.10$ to $0.61, \mathrm{n}=363, \mathrm{I}^{2}=0 \%, \mathrm{P}=$ $0.003)$.

\subsubsection{At 24 months}

Twenty-four-month data were available for two studies (Eloniemi-Sulkava 2001; Eloniemi-Sulkava 2009). These showed no significant differences between treatment groups (OR 1.03, 95\% Cl 0.52 to $2.03, n=201, I^{2}=0 \%, P=0.94$ ).

\subsection{Institutionalised (nursing home stays, mean number of days per month)}

(Analysis 1.2)

We found data on this outcome from two studies.

\subsubsection{At six months}

One small study (Chien- Hong Kong 2008) revealed a significant reduction in the number of days per month in a residential home or hospital unit in the case management group at six months (mean difference (MD) $-5.80,95 \% \mathrm{Cl}-7.93$ to $-3.67, \mathrm{n}=88, \mathrm{P}<0.0001$ ).

\subsubsection{At 12 months}

This study also revealed a significant reduction in the number of days per month in a residential home or hospital unit in the case management group at 12 months (MD $-7.70,95 \% \mathrm{Cl}-9.38$ to -6.02 , $\mathrm{n}=88, \mathrm{P}<0.0001)$.

\subsubsection{At 18 months}

Another study (Vickrey - California) reported the number of days per month institutionalised and did not find any significant differences between groups at 18 months (MD $0.17,95 \% \mathrm{Cl}-0.92$ to $1.26, \mathrm{n}=$ $267, P=0.76$ ). Data were skewed for this study.

\subsection{Time to institutionalisation}

\section{(Analysis 1.3)}

\subsubsection{At 12 months}

Only one trial reported the length of time until participants were institutionalised (Eloniemi-Sulkava 2009), and showed no significant difference between the two groups (hazard ratio (HR) $0.66,95 \% \mathrm{Cl}$ 0.38 to $1.14, \mathrm{P}=0.14)$. The authors also note that the difference between groups at 18 months was significant, however we could not use these data in the review as the results were only presented as a figure. Although data were not reported, the authors of the Callahan - Indianapolis study also stated that the time to nursing home placement did not differ between groups.

\subsection{Hospital admission (mean number of nights)}

\section{(Analysis 1.4)}

Data were available from five studies for this outcome (Bass - Ohio; Callahan - Indianapolis; Eloniemi-Sulkava 2009; Jansen - Netherlands; Vickrey - California). Standard deviations were imputed for one study (Callahan - Indianapolis) using standard deviations from other studies (Jansen - Netherlands at six and 12 months and Eloniemi-Sulkava 2009 at 18 months). Data from the 24-month follow-up could not be entered as the standard deviations were not available and could not be imputed from other studies. Hospital admission utilisation data (number of nights per month) were inflated by 18 months for one study (Vickrey - California) so that we could combine it with other studies. However, heterogeneity remained high even when we excluded other studies, so we have only reported the six-month results here.

\subsubsection{Hospital admissions at six months}

Data were available from three studies at six months (Callahan - Indianapolis; Eloniemi-Sulkava 2009; Jansen - Netherlands). We detected between-group differences in the number of nights associated with hospital admissions with a small but significant difference in favour of the control group (MD 0.63, 95\% $\mathrm{Cl} 0.40$ to $0.86, \mathrm{n}=341$, $\mathrm{I}^{2}=40 \%, \mathrm{P}=0.00001$ ).

\subsubsection{Hospital admissions at 12 months}

As there was considerable heterogeneity at 12 months, we have not reported the meta-analysis as it would be misleading to quote an average value for the intervention effect.

\subsubsection{Hospital admissions at 18 months}

At 18 months there was considerable heterogeneity, so again we have not reported the meta-analysis.

\subsection{Hospital admissions: (number of participants admitted to hospital)}

(Analysis 1.5)

\subsubsection{Admitted to hospital at six months}

Data were available from four studies (Callahan - Indianapolis; Chien- Hong Kong 2008; Chien - Hong Kong 2001; Eloniemi-Sulkava 2009) showing no significant differences between treatment groups (OR 1.06, 95\% Cl 0.61 to $1.84, n=439, \mathrm{I}^{2}=0 \%, \mathrm{P}=0.84$ ).

\subsubsection{Admitted to hospital at 12 months}

Data were available from five studies (Bass - Ohio; Chien- Hong Kong 2008; Chien - Hong Kong 2001; Callahan - Indianapolis; Eloniemi-Sulkava 2009) showing no significant differences between treatment groups (OR $0.87,95 \% \mathrm{Cl} 0.59$ to $1.30, \mathrm{n}=585, \mathrm{I}^{2}=3 \%, \mathrm{P}=0.51$ ). When we excluded Bass - Ohio (a low-quality study), and reanalysed the data to test the robustness of our findings, the results were unchanged.

\subsubsection{Admitted to hospital at 18 months}

Data were available from five studies (Callahan - Indianapolis; Chien- Hong Kong 2008; Chien - Hong Kong 2001; Eloniemi-Sulka- 
va 2009; Vickrey - California), showing no significant differences between treatment groups (OR $0.76,95 \% \mathrm{Cl} 0.53$ to $1.10, \mathrm{n}=613, \mathrm{I}^{2}=$ $14 \%, P=0.14)$.

\subsection{Mortality (number of participant deaths, as reported at each time point in trials)}

(Analysis 1.6)

\subsubsection{At 4 - 6 months}

Data were available from eight studies (Callahan - Indianapolis; Chu - Canada; Dias - Goa India; Eloniemi-Sulkava 2009; Hinchliffe - UK; Jansen - Netherlands; Lam - Hong Kong; Newcomer - US). By four to six months, 87 deaths occurred in the 3030 people in the case management group compared with 94 in the 2834 people in the standard care group (OR $0.86,95 \% \mathrm{Cl} 0.64$ to $1.16, \mathrm{n}=5864, \mathrm{I}^{2}=1 \%, \mathrm{P}$ $=0.32$ ).

Mortality was high (18 participants, 22\%) for one trial (Dias - Goa India).

\subsubsection{At 12 months}

Data were available from eight studies (Callahan - Indianapolis; Chu - Canada; Eloniemi-Sulkava 2001; Eloniemi-Sulkava 2009; Jansen Netherlands; Lam - Hong Kong; Newcomer - US; Vickrey - California). By 12 months, 252 deaths occurred in the 3173 people in the case management group compared with 236 in the 2939 people in the standard care group (OR $1.00,95 \% \mathrm{Cl} 0.83$ to $1.20, \mathrm{n}=6112, \mathrm{I}^{2}$ $=0 \%, P=0.98$ ).

\subsubsection{At 18 - 24 months}

Data were available from five studies (Callahan - Indianapolis; Chien - Hong Kong 2001; Chu - Canada; Eloniemi-Sulkava 2001; Eloniemi-Sulkava 2009). By 18 to 24 months 20 deaths occurred in the 260 people in the case management group compared with 19 in the 253 people in the standard care group (OR 1.00, 95\% Cl 0.52 to $1.92, \mathrm{n}=513, \mathrm{I}^{2}=4 \%, \mathrm{P}=1.00$ ).

\subsubsection{At 36 months}

Data were available from one study (Newcomer - US). By 36 months, 941 deaths occurred in the 2682 people in the case management group compared with 872 in the 2527 people in the standard care group (OR 1.03, 95\% $\mathrm{Cl} 0.92$ to $1.15, \mathrm{n}=5209, \mathrm{P}=0.66$ ).

\subsection{Quality of life (participants)}

(Analysis 1.7)

We found three studies (Jansen - Netherlands; Lam - Hong Kong; Vickrey - California) assessing quality of life of participants with various scales at different time points (Table 6).

\subsubsection{At four months}

At four months we detected no significant differences between groups in the single study (Lam - Hong Kong) which used the Personal Well-Being Index-Intellectual Disability (PWI-ID) (MD -3.74, $95 \% \mathrm{Cl}-12.42$ to $4.94, \mathrm{n}=99, \mathrm{P}=0.40$ ).

\subsubsection{At six months}

At six months there was no significant difference between groups in the single study (Jansen - Netherlands) which used the Dementia
Quality of Life (DQOL) instrument (MD $0.26,95 \% \mathrm{Cl}-0.45$ to $0.97, \mathrm{n}$ $=58, \mathrm{P}=0.47$ ).

\subsubsection{At 12 months}

At 12 months quality of life was measured using three scales: PWI-ID (Lam - Hong Kong); DQOL (Jansen - Netherlands) and Health Utilities Index Mark 3 (HUI3) (Vickrey - California). As with the previous findings, results did not suggest significant differences between groups (standardised mean difference (SMD) $0.05,95 \% \mathrm{Cl}-0.13$ to $\left.0.22, n=511,\left.\right|^{2}=0 \%, P=0.60\right)$.

\subsubsection{At 18 months}

The longer-term data at 18 months using the HUI3 did not show any difference between the two groups in the Vickrey - California study ( $M D 0.06,95 \% \mathrm{Cl}-0.05$ to $0.17, \mathrm{n}=225, \mathrm{P}=0.30$ ).

\section{Case management compared to usual care: effect on carers}

\subsection{Quality of life (carers)}

(Analysis 1.8)

Five studies assessed carer quality of life with four different measures: World Health Organization Quality of Life (WHOQoL-BREF) (Chien- Hong Kong 2008; Chien - Hong Kong 2001), Short Form 36item health survey (SF-36) (Jansen - Netherlands), EuroQol 5-Dimensions (EQ-5D) (Vickrey - California) and the Personal Well-being index for adults (PWI-A) (Lam - Hong Kong) (Table 6).

\subsubsection{At four months}

At four months we found no significant differences between groups in the single study (Lam - Hong Kong) which used the Personal WellBeing Index for adults (PWI-A) (MD $-0.25,95 \% \mathrm{Cl}-0.66$ to $0.15, \mathrm{n}=$ $99, \mathrm{P}=0.21$ ).

\subsubsection{At six months}

At six months there was no significant difference between groups in a single study (Chien- Hong Kong 2008), (MD 0.33, 95\% Cl -0.09 to $0.75, \mathrm{n}=88, \mathrm{P}=0.13$ ).

\subsubsection{At 12 months}

At 12 months carer quality of life was available from all five studies using the four scales (WHOQoL-BREF, SF-36, EQ-5D and PWI-A). Initially using a fixed-effect model we found that carers in the case management group had a significantly better quality of life (SMD $0.21 \mathrm{Cl} 0.06$ to $0.37, \mathrm{n}=681$ ). However these data were highly heterogeneous $\left(I^{2}=80 \%, P=0.0006\right)$. When we used a random-effects model there were no significant differences between groups $(P=$ 0.11 ). A sensitivity analysis indicated that two studies (Chien- Hong Kong 2008; Chien - Hong Kong 2001) contributed most to the variation among the studies. While the other three studies demonstrated a statistical homogeneity (heterogeneity: $\mathrm{Chi}^{2}=0.94, \mathrm{df}=2(\mathrm{P}=$ $\left.0.63) ; I^{2}=0 \%\right)\left(\right.$ SMD $0.02 \mathrm{Cl}-0.16$ to $\left.-0.20, n=501, \mathrm{I}^{2}=0 \%, \mathrm{P}=0.84\right)$ we found no significant difference in quality of life between the groups. One way of explaining why these two studies may be out of line with the others may be helped by our categorisation of the studies ( $\mathrm{Ta}-$ ble 5). We describe these studies as ones in which the case manager encouraged self management of care and tended to empower the carer to arrange their own care where possible. These studies also used the WHOQoL-BREF. 


\subsubsection{At 18 months}

Similarly at 18 months for two studies, we found that carers in the case management group had a significantly better quality of life (SMD $0.25,95 \% \mathrm{Cl} 0.04$ to $0.46, \mathrm{n}=373$ ), which was measured using two scales (WHOQoL-BREF, EQ-5D) (Chien - Hong Kong 2001; Vickrey - California). Again these data was highly heterogeneous $\left(I^{2}=\right.$ $94 \%, P=0.0001)$. When we applied a random-effects model there were no significant differences between groups (SMD 0.50, 95\% Cl
-0.47 to $1.48, n=373, I^{2}=94 \%, P=0.31$ ). Re-analysing the results, excluding Chien - Hong Kong 2001 which was categorised differently on our case management typology (Table 5) (see 1.8.3 above) left a single study, Vickrey - California, showing no difference between the groups ( $M D 0.01,95 \% \mathrm{Cl}-0.09$ to $0.11, \mathrm{n}=281, \mathrm{P}=0.85$ ).

\subsection{Carer burden}

(Analysis 1.9; Figure 5)

Figure 5. Forest plot of comparison: 1.9 Caregiver burden.

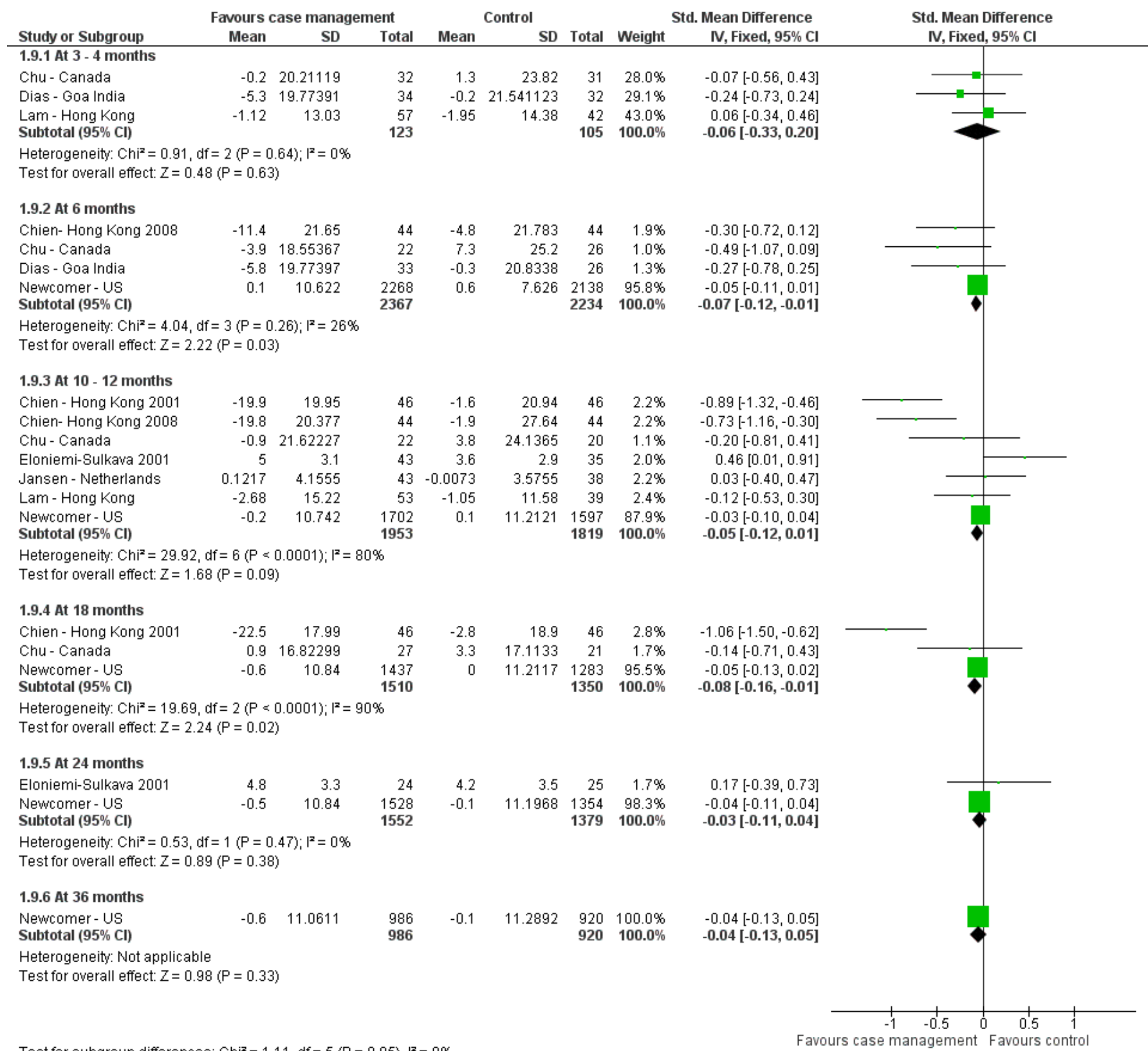

ences between groups (SMD $-0.06,95 \% \mathrm{Cl}-0.33$ to $0.20, \mathrm{n}=228, \mathrm{I}^{2}$ $=0 \%, P=0.63$ ).

\subsubsection{At 3 - 4 months}

Three studies measured the change from baseline at three or four months, using the Zarit burden Interview scale (ZBI) (Chu - Canada; Dias - Goa India; Lam - Hong Kong). We found no significant differ- 


\subsubsection{At six months}

We include four studies which measured the change from baseline to six months. These studies used the ZBI (Chu - Canada; Dias Goa India; Newcomer - US) and Family Caregiving Burden Inventory (FCBI) (Chien- Hong Kong 2008). The findings significantly favoured the case management intervention group (SMD $-0.07 \mathrm{Cl}-0.12$ to $\left.-0.01, n=4601, I^{2}=26 \%, P=0.03\right)$. When we excluded Chu - Cana$\mathrm{da}$ (a low-quality study), and reanalysed the data to test the robustness of our findings, the results were unchanged (SMD $-0.06,95 \%$ $\mathrm{Cl}-0.12$ to $\left.0.00, \mathrm{n}=4553, \mathrm{I}^{2}=0 \%, \mathrm{P}=0.04\right)$.

\subsubsection{At 10 - 12 months}

We include seven studies which measured the change from baseline to 10 to 12 months. These studies used the ZBI (Chu - Canada; Lam - Hong Kong; Newcomer - US), Family Caregiving Burden Inventory (FCBI) (Chien- Hong Kong 2008; Chien - Hong Kong 2001) and the Self-Perceived Pressure by Informal Care (SPPIC) questionnaire (Jansen - Netherlands). It was not clear what measure was used in Eloniemi-Sulkava 2001; although further data were sent by the authors they did not specify the measure used. We detected no significant differences between groups (SMD $-0.05,95 \% \mathrm{Cl}-0.12$ to $\left.0.01, n=3772, I^{2}=80 \%, P=0.09\right)$. However, if we remove two studies (Chien- Hong Kong 2008; Chien - Hong Kong 2001) that were categorised differently on our case management typology (Table 5), the heterogeneity is significantly reduced $\left(\mathrm{I}^{2}=6 \%\right)$ and there are still no significant differences between the groups (SMD $-0.02,95 \% \mathrm{Cl}$ -0.09 to $\left.0.05, n=3592, I^{2}=20 \%, P=0.55\right)$. When we excluded a lowquality study (Chu - Canada), and reanalysed the data to test the robustness of our findings, the results were unchanged.

\subsubsection{At 18 months}

We include three studies measuring the change from baseline to 18 months. These studies used the ZBI (Chu - Canada; Newcomer US) and the FCBI measure (Chien - Hong Kong 2001). The findings favoured the case management intervention group (SMD $-0.08 \mathrm{Cl}$ -0.16 to $\left.-0.01, n=2860, I^{2}=90 \%, P=0.02\right)$. Sensitivity analysis indicated that one study (Chien - Hong Kong 2001) which was classified differently on our case management typology (Table 5) contributes all the variation among the studies. When Chien - Hong Kong 2001 is removed the heterogeneity disappears $\left(I^{2}=0 \%\right)$ and any significant differences between groups are removed (SMD $-0.06,95 \% \mathrm{Cl}$ -0.13 to $\left.0.02, n=2768, I^{2}=0 \%, P=0.14\right)$. When we excluded $\mathrm{Chu}-$ Canada (a low-quality study), and reanalysed the data to test the robustness of our findings, the results were unchanged, but heterogeneity increased to an $\mathrm{I}^{2}$ of $95 \%$.

\subsubsection{At 24 months}

We include two studies measuring the change from baseline to 24 months. One study used the ZBI (Newcomer - US) and we await clarification regarding which measure was used in Eloniemi-Sulkava 2001. The findings favoured the case management intervention group (SMD -0.03, 95\% Cl -0.11 to $0.04, \mathrm{n}=2931, \mathrm{I}^{2}=0 \%, \mathrm{P}=0.38$ ).

\subsubsection{At 36 months}

One study measured the change from baseline to 36 months. This study used the ZBI (Newcomer - US). The findings favoured the case management intervention group (SMD $-0.04,95 \% \mathrm{Cl}-0.13$ to 0.05 , $\mathrm{I}^{2}=0 \%, \mathrm{n}=1906, \mathrm{P}=0.33$ ). It should be noted that there was a high attrition rate from this study (64\% in each group).

\section{Secondary outcomes:}

\section{Case management compared to usual care: effect on people with dementia/(care recipients)}

\subsection{Cognition measures}

(Analysis 2.1)

\subsubsection{At 3 - 4 months}

At three to four months we found no significant differences between groups in the two studies which used the Mini Mental State Examination (MMSE) (Chu - Canada) and the Cantonese MMSE (Lam - Hong Kong) (SMD -0.21, 95\% Cl -0.53 to 0.11, $\mathrm{n}=154, \mathrm{I}^{2}=0 \%, \mathrm{P}=$ $0.2)$.

\subsubsection{At six months}

At six months there were no significant differences between groups in the three studies which used the English (Chu - Canada) and Cantonese versions of the MMSE (Chien- Hong Kong 2008) and the Telephone Interview for Cognitive Status (TICS) (Callahan - Indianapolis) (SMD $0.03,95 \% \mathrm{Cl}-0.21$ to $0.27, \mathrm{n}=267, \mathrm{I}^{2}=0 \%, \mathrm{P}=0.82$ ).

\subsubsection{At 10 - 12 months}

Similarly at 10 to 12 months, we detected no significant differences between groups in the six studies which used the English (Chu - Canada; Eloniemi-Sulkava 2001) and Cantonese versions of the MMSE (Chien- Hong Kong 2008; Chien - Hong Kong 2001; Lam - Hong Kong) and the TICS (Callahan - Indianapolis) (SMD 0.00, 95\% CI-0.17 to $\left.0.18, \mathrm{n}=518, \mathrm{I}^{2}=0 \%, \mathrm{P}=0.96\right)$.

\subsubsection{At 18 months}

At 18 months we found no significant differences between groups in the three studies which used the English (Chu - Canada) and Cantonese versions of the MMSE (Chien - Hong Kong 2001) and the TICS (Callahan - Indianapolis) (SMD -0.02, 95\% Cl -0.27 to $0.22, \mathrm{n}=256$, $\left.\mathrm{I}^{2}=0 \%, \mathrm{P}=0.85\right)$.

\subsubsection{At 24 months}

This was also the case for the one study that measured cognition at 24 months (Eloniemi-Sulkava 2001) (SMD $0.07,95 \% \mathrm{Cl}-0.49$ to 0.63 , $\left.n=49, I^{2}=0 \%, P=0.79\right)$.

\subsection{Behavioural measures}

(Analysis 2.2; Figure 6) 
Figure 6. Forest plot of comparison: 2.2 Behavioural measures (participants).

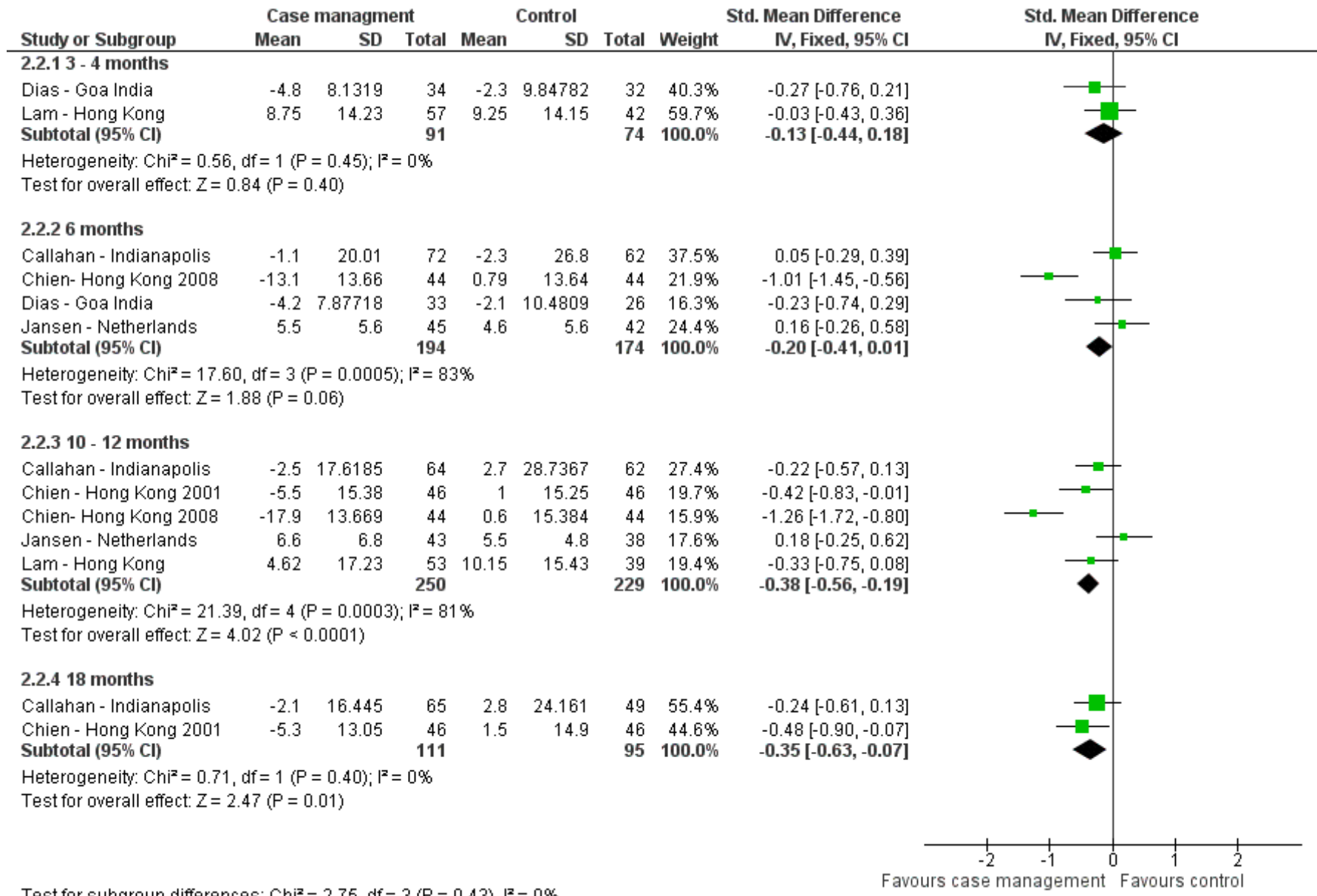

\subsubsection{At 3 - 4 months}

At three to four months there were no significant differences between groups in the two studies which used the English (Dias - Goa India) and the Chinese version of the Neuropsychiatric Inventory (NPI) (Lam - Hong Kong) (SMD -0.13, 95\% Cl -0.44 to 0.18, $\mathrm{n}=165$, $\left.\mathrm{I}^{2}=0 \%, \mathrm{P}=0.40\right)$.

\subsubsection{At six months}

We included four studies, measuring the change from baseline to six months, which found a significant difference in favour of the case management group in the four studies which used the English NPI (Callahan - Indianapolis; Chien- Hong Kong 2008; Dias - Goa India; Jansen - Netherlands) (SMD $-0.20,95 \% \mathrm{Cl}-0.41$ to $0.01, \mathrm{n}=368$, $\mathrm{I}^{2}=83 \%, \mathrm{P}=0.06$ ). If we remove two of the studies (Chien- Hong Kong 2008; Dias - Goa India) that were classified differently on our case management typology; the heterogeneity is eliminated entirely and the difference is no longer significant (SMD 0.09, 95\% Cl-0.17 to $0.36, \mathrm{n}=221, \mathrm{I}^{2}=0 \%, \mathrm{P}=0.49$ ).

\subsubsection{At 10 - 12 months}

We include five studies, measuring the change from baseline to 10 to 12 months. There were no significant differences between groups in these five studies which used the English (Callahan - Indianapolis; Chien- Hong Kong 2008; Chien - Hong Kong 2001; Jansen

(SMD - $0.38,95 \% \mathrm{Cl}-0.56$ to $-0.19, \mathrm{n}=479, \mathrm{I}^{2}=81 \%, \mathrm{P}=0.0001$ ). Again if we remove two of the studies (Chien- Hong Kong 2008; Chien - Hong Kong 2001) that were categorised differently on our case management typology (Table 5), the heterogeneity is significantly reduced $\left(I^{2}=36 \%\right)$ and the difference is no longer significant (SMD $-0.14,95 \% \mathrm{Cl}-0.37$ to $0.09, \mathrm{n}=299, \mathrm{I}^{2}=36 \%, \mathrm{P}=0.22$ ).

\subsubsection{At 18 months}

We include two studies which measured the change from baseline to 18 months or reported scores at 18 months. We found no differences between groups in the two studies which used the NPI (Callahan - Indianapolis; Chien - Hong Kong 2001) (SMD -0.35, 95\% Cl-0.63 to $-0.07, \mathrm{n}=206, \mathrm{I}^{2}=0 \%, \mathrm{P}=0.01$ ).

\subsection{Depression/mood measures}

(Analysis 2.3)

\subsubsection{At 3 - 4 months}

At three to four months we found no significant differences between groups in the two studies which used the Cornell Scale for Depression in Dementia (CSDD) (Lam - Hong Kong) and Geriatric Depression Scale (GDS) (Chu - Canada) (SMD $0.12 \mathrm{Cl}-0.19$ to $0.43, \mathrm{n}$ $\left.=164, \mathrm{I}^{2}=59 \%, \mathrm{P}=0.45\right)$. 


\subsubsection{At six months}

At six months there were no significant differences between groups in the two studies which used the CSDD (Callahan - Indianapolis) and GDS (Chu - Canada) (SMD 0.08, 95\% Cl -0.21 to $0.37, \mathrm{n}=185, \mathrm{I}^{2}$ $=0 \%, P=0.59)$.

\subsubsection{At 10 - 12 months}

At 10 to 12 months we found no significant differences between groups in the three studies which used the CSDD (Callahan - Indianapolis; Lam - Hong Kong) and GDS (Chu - Canada) (SMD -0.07, $95 \% \mathrm{Cl}-0.32$ to $0.17, \mathrm{n}=259, \mathrm{I}^{2}=0 \%, \mathrm{P}=0.59$ ).

\subsubsection{At 18 months}

At 18 months there were no significant differences between groups in the two studies which used the CSDD (Callahan - Indianapolis) and GDS (Chu - Canada) (SMD -0.02, 95\% Cl -0.33 to 0.29, $\mathrm{n}=159$, $\left.I^{2}=0 \%, P=0.90\right)$.

\subsection{Function/dependency measures}

(Analysis 2.4)

\subsubsection{At three months}

At three months we found no significant difference between groups in the one study which used the Everyday Abilities Scale for India (EASI) (Dias - Goa India) (SMD -0.20, 95\% Cl -0.68 to $0.29, \mathrm{n}=66, \mathrm{P}$ $=0.43$ ).

\subsubsection{At six months}

At six months there were no significant differences between groups in the three studies which used the EASI (Dias - Goa India), the Alzheimer's Disease Co-operative Study/Activities of Daily Living Inventory (ADCS-ADL) (Callahan - Indianapolis) and the Activities of Daily Living (Barthel) (Eloniemi-Sulkava 2009) measures (SMD $-0.03,95 \% \mathrm{Cl}-0.25$ to $0.19, \mathrm{n}=318, \mathrm{I}^{2}=0 \%, \mathrm{P}=0.81$ ).

\subsubsection{At 12 months}

At 12 months we detected no significant differences between groups in the two studies which used the EASI (Dias - Goa India) and the ADCS-ADL (Callahan - Indianapolis) (SMD 0.04, 95\% Cl -0.21 to $\left.0.29, n=251, I^{2}=32 \%, P=0.76\right)$.

\subsubsection{At 18 months}

At 18 months there was no significant difference between groups in the one study which used the ADCS-ADL (Callahan - Indianapolis) (SMD - $0.09,95 \% \mathrm{Cl}-0.46$ to $0.28, \mathrm{n}=114, \mathrm{P}=0.62$ ).

\section{Case management compared to usual care: effect on carers}

\subsection{Carer distress (behaviour measure)}

(Analysis 2.5)

\subsubsection{At three months}

At three months we found no significant difference between groups in the one study which used the Neuropsychiatric Inventory Caregiver Distress Scale NPI-D (Dias - Goa India (MD -2.50, 95\% Cl -6.87 to $1.87, \mathrm{n}=66, \mathrm{P}=0.26$ ).

\subsubsection{At six months}

At six months there were no significant differences between groups in the two studies which used the NPI-D (Callahan - Indianapolis;
Dias - Goa India) (MD -0.20, 95\% Cl -3.23 to $2.82, \mathrm{n}=193, \mathrm{I}^{2}=0 \%, \mathrm{P}$ $=0.89$ ).

\subsubsection{At 10 - 12 months}

At 10 to 12 months we found no significant difference between groups in the one study which used the NPI-D (Callahan - Indianapolis) (MD $-1.90,95 \% \mathrm{Cl}-6.00$ to $2.20, \mathrm{n}=126, \mathrm{P}=0.36$ ).

\subsubsection{At 18 months}

At 18 months there was no significant difference between groups in the one study which used the NPI-D (Callahan - Indianapolis) (MD $-0.50,95 \% \mathrm{Cl}-3.24$ to $2.24, \mathrm{n}=114, \mathrm{P}=0.72$ ).

\subsection{Carer depression/mood measures}

(Analysis 2.6)

\subsubsection{At six months}

At six months there were no significant differences between groups in the four studies which used the Patient Health Questionnaire-9 (PHQ-9) (Callahan - Indianapolis), the Centre for Epidemiological studies Depression scale (CES-D) (Chu - Canada; Jansen - Netherlands) and the Geriatric Depression Scale (GDS) (Newcomer - US) (SMD - $0.04,95 \% \mathrm{Cl}-0.10$ to $0.02, \mathrm{n}=4675, \mathrm{I}^{2}=0 \%, \mathrm{P}=0.15$ ).

\subsubsection{At 10 - 12 months}

At 10 to 12 months we found no significant differences between groups in the five studies which used the PHQ-9 (Callahan - Indianapolis), the CES-D (Chu - Canada; Jansen - Netherlands), the CESD modified (Bass - Ohio) and the GDS (Newcomer - US) (SMD -0.04, $95 \% \mathrm{Cl}-0.11$ to $\left.-0.02, \mathrm{I}^{2}=0 \%, \mathrm{n}=3705, \mathrm{P}=0.19\right)$.

When we excluded Bass - Ohio (a low-quality study) and reanalysed the data the results were unchanged.

\subsubsection{At 18 months}

At 18 months the case management group showed greater improvement in the depression/mood measures (CES-D) (Callahan Indianapolis), CES-D modified (Bass - Ohio) and the GDS (Newcomer - US) (SMD $-0.08,95 \% \mathrm{Cl}-0.16$ to $\left.-0.01, \mathrm{n}=2888, \mathrm{I}^{2}=0 \%, \mathrm{P}=0.03\right)$.

\subsubsection{At 24 months}

One study (Newcomer - US) indicated that there was a non-significant trend towards greater improvement in the case management group at 24 months (SMD $-0.06,95 \% \mathrm{Cl}-0.14$ to $0.01, \mathrm{n}=2887, \mathrm{P}=$ 0.08).

\subsubsection{At 36 months}

This study (Newcomer - US) indicated that there was no significant difference between groups at 36 months (SMD $-0.07,95 \% \mathrm{Cl}-0.16$ to $0.02, \mathrm{n}=1910, \mathrm{P}=0.15$ ).

\subsection{Carer well-being}

(Analysis 2.7)

\subsubsection{At 3 - 4 months}

At three to four months we found no significant differences between groups in the three studies which used the General Health Questionnaire (GHQ) (Dias - Goa India; Hinchliffe - UK; Lam - Hong Kong) (MD -2.53, 95\% Cl -5.20 to $0.13, n=203, I^{2}=73 \%, P=0.06$ ). Excluding Hinchliffe - UK, and reanalysing the data eliminated the het- 
erogeneity across studies and still showed no differences between groups (MD -1.18, 95\% Cl-2.69 to $0.33, \mathrm{n}=170, \mathrm{I}^{2}=0 \%, \mathrm{P}=0.13$ ).

\subsubsection{At six months}

At six months there was significantly greater improvement in the case management group in the one study which used the GHQ (Dias - Goa India) (MD -2.20, 95\% Cl-4.14 to $-0.26, \mathrm{n}=65, \mathrm{P}=0.03$ ).

\subsubsection{At 12 months}

At 12 months we noted a non-significant trend towards greater improvement in the case management group in the one study which used the GHQ (Lam - Hong Kong) (MD -1.90, 95\% Cl -4.11 to 0.31, n $=92, P=0.09$ ).

\subsection{Social support measures}

(Analysis 2.8)

\subsubsection{At six months}

At six months there was no significant difference between groups in the one study which used the six-item Social Support Questionnaire (SSQ6) (Chien- Hong Kong 2008) (SMD 0.18, 95\% Cl -0.24 to 0.60, $\mathrm{n}$ $=88, \mathrm{P}=0.14$ ).

\subsubsection{At 12 months}

At 12 months we found no significant differences between groups in the three studies which used the SSQ6 (Chien- Hong Kong 2008; Chien - Hong Kong 2001) and Medical Outcomes Study (MOS) Social Support Survey (Vickrey - California) (SMD 0.17, 95\% Cl -0.00 to 0.34, $\left.\mathrm{n}=541, \mathrm{I}^{2}=81 \%, \mathrm{P}=0.06\right)$. When Vickrey - California was excluded from the analysis (categorised differently on our case management typology Table 5), leaving two studies which used the SSQ6 (ChienHong Kong 2008; Chien - Hong Kong 2001), heterogeneity was eliminated and resulted in a significant difference between the groups in favour of the case management group (SMD $0.58,95 \% \mathrm{Cl} 0.28$ to $0.88, n=180, I^{2}=0 \%, P=0.0002$ ).

\subsubsection{At 18 months}

At 18 months there were no significant differences between groups in the two studies which used the SSQ6 (Chien - Hong Kong 2001) and MOS Social Support Survey (Vickrey - California) (SMD 0.13, $95 \% \mathrm{Cl}-0.07$ to $0.33, \mathrm{n}=382, \mathrm{I}^{2}=70 \%, \mathrm{P}=0.21$ ).

\subsection{Carer satisfaction with health plan}

(Analysis 2.9)

Two studies reported results that could be examined for satisfaction of carers. It is worth noting that one of these studies (Bass Ohio) did not report participant satisfaction data adequately for the results to be used for this review.

The Bass - Ohio study, which was rated at high risk of bias, evaluated carer satisfaction with Kaiser managed care services: satisfaction was measured regarding types of services, quality of services, and information. We could not use data on satisfaction with information, as it was not reported fully for the control group. There were no differences in changes from the baseline at 12 months, either for satisfaction with types of services (MD 0.02, 95\% Cl -0.26 to $0.30, n=157, P=0.89$ ) or for satisfaction with quality of services (MD $0.04,95 \% \mathrm{Cl}-0.17$ to $0.25, \mathrm{n}=157, \mathrm{P}=0.70$ ).

\subsection{Carer satisfaction with care}

(Analysis 2.10)

One study (Callahan - Indianapolis) assessed carer satisfaction with the participant's care with the question: "Over the last 3 months, how would you rate the quality of care [the patient] has received overall from the primary care clinic?". Individuals in the intervention group were significantly more satisfied than those in the control group at 12 months (OR $3.85,95 \% \mathrm{Cl} 1.82$ to $8.11, \mathrm{n}=153, \mathrm{P}=$ 0.0004 ) but there was no significant difference between groups at 18 months (OR $1.43,95 \% \mathrm{Cl} 0.73$ to $2.80, \mathrm{n}=153, \mathrm{P}=0.30$ ).

\subsection{Leaving the study early}

(Analysis 2.11)

If data for this outcome were not clearly presented in the tables, we took relevant data from the text of each report. We included those who were unwilling or unable to provide information (including those who died, were institutionalised, and those who switched treatment groups). Some studies reported completers only at each time point and others were intention-to-treat (ITT), i.e. all originally randomised. The implications of the data are that more weight is given to the ITT findings.

\subsubsection{At 3 - 4 months}

There were no significant differences between treatment groups at three to four months in three studies (Dias - Goa India; Hinchliffe UK; Lam - Hong Kong) (OR 0.66, 95\% $\mathrm{Cl} 0.28$ to $1.56, \mathrm{n}=223, \mathrm{I}^{2}=0 \%$, $P=0.34)$,

\subsubsection{At six months}

There were no significant differences between treatment groups at six months in five studies (Callahan - Indianapolis; Dias - Goa India; Eloniemi-Sulkava 2009; Jansen - Netherlands; Newcomer - US) (OR $0.99,95 \% \mathrm{Cl} 0.86$ to $1.14, \mathrm{n}=5728, \mathrm{I}^{2}=40 \%, \mathrm{P}=0.87$ ).

\subsubsection{At 12 months}

There were no significant differences between treatment groups at 12 months in seven studies (Callahan - Indianapolis; Eloniemi-Sulkava 2001; Eloniemi-Sulkava 2009; Jansen - Netherlands; Lam - Hong Kong; Newcomer - US; Vickrey - California) (OR 0.98, $95 \% \mathrm{Cl} 0.88$ to $1.09, \mathrm{n}=6232, \mathrm{I}^{2}=26 \%, \mathrm{P}=0.68$ ).

\subsubsection{At 18 months}

We found small but significant differences favouring the case management group (i.e. lower) for data at 18 months in six studies (Callahan - Indianapolis; Chien - Hong Kong 2001; Chien- Hong Kong 2008; Chu - Canada; Newcomer - US; Vickrey - California) (OR 0.88, $95 \% \mathrm{Cl} 0.79$ to $0.98, \mathrm{n}=6034, \mathrm{I}^{2}=0 \%, \mathrm{P}=0.02$ ). When we excluded Chu - Canada (a low-quality study) and reanalysed the data to test the robustness of our findings the results were unchanged.

\subsubsection{At 24 months}

There were small but significant differences favouring the case management group (i.e. lower) for data at 24 months (Eloniemi-Sulkava 2001; Eloniemi-Sulkava 2009; Newcomer - US) (OR 0.87, $95 \% \mathrm{Cl} 0.78$ to $\left.0.97, \mathrm{n}=5505, \mathrm{I}^{2}=0 \%, \mathrm{P}=0.01\right)$. 


\subsubsection{At 36 months}

By 36 months there was no significant difference between groups in the one study with data (Newcomer - US) (OR 0.98, 95\% Cl 0.88 to $1.10, \mathrm{n}=5304, \mathrm{P}=0.33$ ).

\section{Case management compared to usual care: (service use and cost secondary outcomes)}

The section below provides a summary of these results. We report full information in Appendix 3.

\section{1 - 3.3 Use of services (participants)}

\section{(Analysis 3.1; Analysis 3.2; Analysis 3.3)}

Data from service use and costs of care varied greatly between studies, both in terms of the range of services but also the time points evaluated. The range of services included assisted living, day care, home care, information provision, respite care, physician or nurse visits and accident and emergency visits. We also assessed healthcare costs and societal costs. The pattern suggested that, compared to the control group, people in the intervention group tended to use more social care services, but a similar amount of healthcare services. However, there was no consistent pattern in relation to overall costs of care, although in some comparisons the intervention group incurred fewer costs.

Four RCTs reported on different aspects of community-based services usage (Chu - Canada; Lam - Hong Kong; Newcomer - US; Vickrey - California). All significant differences favoured greater use of services in the case management group apart from one service - assisted living housing use at 12 months (Newcomer - US). The intervention group was significantly more likely to receive: home care use at 12 and 18 months, day care use at 4 and 12 months, respite care at 12 months, domestic paid helper use at 4 and 12 months, personal care use at 12 months, professional home health aide use at 18 months, services or information from local Alzheimer's Association at 18 months, services or information from care-givers' resource centre at 18 months and participation in a carer support group at 18 months.

Five RCTs reported on different aspects of participant health services usage (Bass - Ohio; Callahan - Indianapolis; Chu - Canada; Jansen - Netherlands; Vickrey - California). There were no differences between groups in most outcomes, apart from a significantly higher number of physician or nurse visits in the intervention group at 18 months (MD 5.40, 95\% Cl 0.51 to $10.29, \mathrm{n}=113, \mathrm{P}=$ 0.03 ). There were no differences in the emergency visits at 12 or 18 months, physician visits at 6 and 12 months or direct care (occupational therapy, physical therapy, social work, nursing and respiratory therapy) at 18 months.

We found no significant difference between groups in the one study (Jansen - Netherlands) that reported the number of outpatients geriatric/psychiatric team/diagnostic service consultations, medical specialist consultations, physiotherapist consultations or social work consultations at 12 months.

\section{4 - 3.6 Cost of services (participants)}

(Analysis 3.4; Analysis 3.5; Analysis 3.6)

Three studies (Eloniemi-Sulkava 2009; Newcomer - US; Vickrey California) reported data on healthcare costs. Eloniemi-Sulkava
2009 compared total health and social costs between the groups at 12 months. Costs were lower in the intervention group but this difference was borderline significant (MD $-7.99,95 \% \mathrm{Cl}-16.86$ to 0.89 , $\mathrm{n}=125, \mathrm{P}=0.08)$. The Vickrey - California trial showed no significant difference in healthcare costs from the payer perspective (including and excluding nursing home cost at 18 months) or from the society perspective between case management and control group.

Newcomer - US reported the effects of case management application on Medicare community services expenditures in year one, year two and year three, and for the total three-year period. Eloniemi-Sulkava 2009 reported total healthcare costs between the groups at 12 months. We have used the SMD to accommodate the two currencies (dollars and euros) for year one. When data were pooled from these two studies (Eloniemi-Sulkava 2009; Newcomer - US) at 12 months, a significant reduction in the total cost of services was apparent between the groups (SMD $-0.07,95 \% \mathrm{Cl}-0.12$ to $-0.02, n=5276, P=0.01$. There were no differences at years two or three, although the lower expenditure in the pooled case management groups was significantly lower than the control group for the total three years in the Newcomer - US study (MD -705.00, 95\% Cl -1170.31 to $-239.69, \mathrm{n}=5170, \mathrm{P}=0.003$ ).

\section{7 - 3.9 Health service use by carers and informal care}

(Analysis 3.7; Analysis 3.8; Analysis 3.9).

One study (Newcomer - US) estimated the impact of a case management intervention on health services usage for carers. Carers' utilisation of services was reported for one of the sites (Illinois) in the Newcomer - US study (Shelton 2001). Data on hospitalisation rates and emergency visits were collected over a three-year period. The risk of hospitalisation for the carers in the intervention group was significantly lower than in the control group (OR 0.51, 95\% Cl 0.33 to $0.81, \mathrm{n}=412, \mathrm{P}=0.005)$. The emergency department visits were significantly lower in the intervention group (OR $0.58,95 \% \mathrm{Cl} 0.38$ to $0.89, n=412, P=0.01$ ). Carer health service utilisation and Medicare expenditure data were presented for one of the sites (Illinois) for the Newcomer - US study (Shelton 2001) (Analysis 3.8). One other study also reported the use of services by carers (Jansen - Netherlands). There were no significant differences for any of the continuous outcomes reported, including annual hospital length of stay, number of admissions or primary care physician or outpatient geriatric/psychiatric team, medical specialist, physiotherapist consultations or informal carer time. We found no significant difference in the time for paid or unpaid skilled carers between the groups (Informal carer time spent care-giving (hours)) (MD -5.10, 95\% Cl -789.73 to $779.53, n=412, P=0.99$ ) (Vickrey - California) (Analysis 3.9).

\subsection{0 - 3.11 Cost of services (carers)}

\section{(Analysis 3.10; Analysis 3.11)}

In the Newcomer - US study, Medicare Part A expenditure (inpatient hospital, emergency department visits and skilled nursing home inpatient care) was based on the allowed amounts from Medicare claims for the period the person with Alzheimer's Disease was enrolled in the demonstration. For most claims, this included the amount paid by Medicare, plus additional amounts paid by individuals. The Medicare Part A expenditure at the one-year follow-up was lower for the case management group (combining A and $B$ models) but did not differ significantly from standard care (MD USD $-229.00,95 \% \mathrm{Cl}-489.48$ to $31.48, \mathrm{P}=0.08)$. By the two-year follow-up there were no differences (MD USD 17.00, 95\% Cl -943.97 to 977.97, 
$P=0.97$ ), nor were there any differences by three years (MD USD $-325.00,95 \% \mathrm{Cl}-770.89$ to $120.89, \mathrm{P}=0.15)$. We observed similar results for the case management group (combining $A$ and $B$ models) for the entire three-year follow-up, combining all demonstration sites in comparison to control (MD USD $-167.00,95 \% \mathrm{Cl}-946.28$ to $612.28, P=0.67)$. In one of the eight sites, Illinois, in which the delivery of case management was facilitated via nurse care managers rather than by social workers, the total cost was not much lower than other sites. A total reduction of USD $-436(95 \% \mathrm{Cl}-2321$ to 1049) was achieved compared to control over three years.

Although the average annualised Medicare reimbursement (annual health service cost) during the Newcomer - US study for carers in the intervention group (combining $A$ and $B$ models) was lower, the difference was not significant (MD USD $-681.00,95 \% \mathrm{Cl}-1382.40$ to $20.40, P=0.06$ ). The lower expenditure did not reach statistical significance for any of the separate years or for the total three-year follow-up period.

\section{DISCUSSION}

We have comprehensively collated evidence from 13 randomised controlled trials (RCTs) with a total of 9615 participants, which compare the effects of case management approaches for people with dementia and their carers with usual care. All but three of the RCTs had a duration of 12 months or more but only six trials lasted for 18 months or more. The studies included in this review came from a variety of countries and contexts, from the US, Canada, Finland, Netherlands, Hong Kong, India and the UK; from primary care practices, dementia resource centres, memory clinics, outpatient clinics, and day centres; and were administered by case managers from a range of professional groups.

We have summarised the results for short-, medium- and longerterm to help with the interpretation of the results and to help to guide future practice and research in this area. As this review identified a relatively small number of eligible studies, not all of which reported the same outcomes at the same time points, we still have only a limited understanding of the effects of case management and how desired outcomes are achieved. A few main factors restrict our understanding: the heterogeneity of case management interventions, limited process and cost evaluations, and the methodological limitations of the studies. These issues relate to the phenomenon of complex interventions and the need for multiple and rigorous studies to examine both their implementation and effectiveness.

\section{Summary of main results}

\section{Shorter-term outcomes (less than 12 months)}

The shorter-term outcomes in this review indicate a reduction in the proportion of people institutionalised at six months in the intervention group, although these results were dominated by a single large study (Newcomer - US). One study showed a reduction in the number of days per month in a residential home/hospital unit in the case management group in the short term (six months). At six months the results suggested that case management may increase hospital length of stay (by 0.86 days a month), the use of day care and domestic paid care when compared with standard care.

Four studies indicated a small but significant improvement in carer burden at six months but no effect at three to four months. No significant effects were present in favour of case management in the following outcomes in the short term: time to institutionalisation; number of people admitted to hospital; mortality; participant quality of life; cognition; depression; behaviour; function; carer quality of life; carer distress; mood; and social support.

\section{Medium-term outcomes (equal to or greater than 12 months, but less than 18 months)}

Case management for people with dementia was not more effective in terms of reducing the proportion institutionalised at 12 months. However, in a sensitivity analysis to explore high heterogeneity, we found that case management for people with dementia was more effective in reducing the proportion institutionalised at 12 months when we included only studies which evaluated interventions which were clearly focused upon delaying institutionalisation. One study showed a reduction in the number of days per month in a residential home/hospital unit in the case management group at one year.

Case management was more effective for quality of life outcomes in carers at 12 months, but these analyses were also heterogeneous; there was no effect when the results were reanalysed excluding two studies which were categorised as less intensive in our typology of case management. Case management was more effective in improving social support for carers, and carers were more satisfied with the quality of care received.

There was greater use of services in the case management group in home care use, day care use, respite care, domestic paid helper use and personal care use. One study also indicated a reduction in assisted living housing use at 12 months (Newcomer - US). Data from two studies at 12 months indicated a significant reduction in the total cost of services for the case management group. Similarly, pooled data from two studies indicated a significant reduction in the total cost of services at 12 months in the case management group.

There were no significant effects in favour of case management in the following outcomes in the medium term: time to institutionalisation (there were no longer-term data available); number of people admitted to hospital; mortality; participant quality of life; cognition; depression; behaviour; function; carer burden; carer quality of life; and carer mood.

Although not a prespecified outcome, we noted that the use of prescribed medications (for participants) was recorded for both groups in two of the studies. The use of cholinesterase inhibitors was significantly greater in the intervention group in the Callahan Indianapolis study (OR $3.22,95 \% \mathrm{Cl} 1.58$ to $6.56, \mathrm{n}=153, \mathrm{P}=0.001$ ) but there was no significant difference between groups in the Vickrey - California study (OR 1.12, 95\% Cl 0.63 to $1.98, \mathrm{n}=219, \mathrm{P}=0.70$ ). Vickrey - California also notes that although medication costs could not be included in their cost analyses, there was an increase of approximately 10 percentage points in the use of cholinesterase inhibitors among participants in the intervention group at follow-up versus no change among participants in the usual care group. Individuals in the intervention group in the Callahan - Indianapolis study were also significantly more likely to use antidepressants at 12 months (OR $2.17,95 \% \mathrm{Cl} 1.10$ to $4.29, \mathrm{n}=153, \mathrm{P}=0.03$ ). The intervention and control groups did not differ in the use of antipsychotics, sedative-hypnotics and memantine, and the rates of use were low. 


\section{Longer-term outcomes (greater than or equal to18 months)}

Case management was more effective than usual care in reducing the proportion institutionalised at 18 months, but not at 24 months, or in reducing the mean number of nights institutionalised at 18 months. No longer-term data were available.

This review did not find evidence of any impact on mortality rate. The longer-term data are quite informative where the study length might balance the rarity of the event in detecting any differences between the intervention effects. The longest and largest trial suggested that $35 \%$ versus $34 \%$ of participants had died at the threeyear follow-up (Newcomer - US).

Case management was more effective than usual care at reducing neuropsychiatric symptoms in people with dementia at the 18month follow-up period. There were no longer-term data available for neuropsychiatric symptoms in participants. Although there were no significant overall effects in favour of case management for quality of life or carer burden outcomes, one study did show positive results for both of these outcomes in the longer term. No significant effects were found at 24 or 36 months for carer burden. No longer-term results were available for carer quality of life.

We found no significant effects in favour of case management for the following outcomes in the longer term: participant quality of life; cognition; depression; function and carer mood; number of nights associated with hospital admissions; other health services usage for participants apart from a greater number of physician and nurse visits in the intervention group at 18 months in one study. Single studies also showed that at 18 months case management was more effective than usual care at providing access to support in the form of home care use, information services, and carer support groups.

Case management was significantly more effective at reducing hospitalisations and emergency department visits for carers during one three-year study. There was greater use of services in the case management group in home care use, professional home health aide use, services or information from local Alzheimer's Association, services or information from care-givers' resource centre and participation in a carer support group. No longer-term data were available.

Although there were very little data available on health service costs, the expenditure in the pooled case management groups was significantly lower than in the control group for the total three years in the Newcomer - US. These costs are for cases surviving six months or more in the community after enrolment. We sought mean monthly costs for all participants (including those who died or were institutionalised in the first six months) from the study authors, but these data were not available. There was also some indication that case management reduced the healthcare cost including nursing home cost at 18 months, but this did not reach statistical significance $(P=0.08)$ (Eloniemi-Sulkava 2009).

It is useful to explore some possible explanations for the results. Firstly, although it could be expected that case management would delay nursing home admission for people with dementia if care needs are better assessed, monitored and followed up within an integrated system of care, there were few intervention effects for this outcome. Providing case management in this context may reduce carer stress and burden and through this may have the effect of ex- tending the stay in the community by the person with dementia. As noted in the Background to this review, a more effective and efficient long-term care system may require both an enhancement of the content of services and also improved case management (Challis 1986). In some of the trials reviewed, the former was sometimes difficult to discern and the information provided on the interventions may suggest that enhancement of the content of services had not eventuated for participants in many of the studies. Although use of many of the community-based services was significantly higher in the intervention group, it was not always clear whether the case manager reviewed the care package and whether service packages changed in a timely manner to reflect the changing needs of the person with dementia. Furthermore, these data were available for nine studies, but only five of them specified that reducing institutionalisation was a goal of the intervention. Indeed, the Newcomer - US study was designed to improve care-giver well-being, and no a priori assumptions had been made about the demonstration's effect on nursing home entry rates. There were also a number of methodological difficulties with the reporting and recording of this outcome in some of the studies. The timing of participant admission to residential or nursing homes was not reported in all studies, and a number of studies report cumulative data at the endpoint of the trial. More trials should address this outcome at each follow-up point, which would be fairly easy to collect and report in a CONSORT diagram. Some of the studies (e.g. Callahan - Indianapolis; Eloniemi-Sulkava 2009; Jansen - Netherlands) included a high proportion of participants with a number of comorbidities, and indicated that this might lead to admission to a nursing or care home in a shorter period of time, whilst other studies were more likely to exclude these patients (e.g. Eloniemi-Sulkava 2001; Lam - Hong Kong). The Eloniemi-Sulkava 2009 study was described as "pragmatic in nature with more liberal inclusion criteria than in many previous trials. The characteristics of the patients with dementia illustrate that they were older, they experienced more severe dementia, and more behavioural and psychological symptoms of dementia (BPSDs) than in many dementia drug trials or carer trials. Our participants may, thus, represent "real life" situations better than many prior studies."

The review indicates that case management improves neuropsychiatric symptoms in participants with dementia at the 18-month follow-up period. Two of the studies using the neuropsychiatric inventory (NPI) at 18 months indicated an approximate six-point reduction in the case management group (MD -6.14, 95\% Cl -10.77 to $\left.-1.51, \mathrm{n}=153, \mathrm{I}^{2}=0 \%, \mathrm{P}=0.009\right)$. Estimates have indicated that a one-point deterioration on the NPI is associated with an additional USD 250 - 400 per year in direct healthcare costs (Murman 2005). Neuropsychiatric symptoms are among the most common predictors of institutionalisation (Yaffe 2002). Case management approaches in a number of studies (Callahan - Indianapolis; Dias - Goa India; Eloniemi-Sulkava 2009; Hinchliffe - UK) were characterised by behavioural management techniques centred on individual participants' behaviour and psycho-education strategies intended to change carers' behaviour, both of which have been shown to be generally successful for reducing neuropsychiatric symptoms, and the effects of these interventions last for months (Livingston 2005). Although there is little compelling longer-term evidence that case management is cost-effective, it is possible that given the positive effects on some outcomes, the intervention may represent a worthwhile approach to improving the quality of dementia care and health outcomes for people with dementia, and to reducing carer burden. 


\section{Overall completeness and applicability of evidence}

This review includes 13 RCTs, and many of the outcomes do not involve large numbers of people. Considering the number of people who might be in receipt of or benefit from this intervention, case management for people with dementia is not well evaluated, particularly for those in developing countries.

We requested further information from authors of all the studies that required additional details on outcomes reported. Although extra information on the implementation of the case management interventions was provided for seven of the trials, in most cases it would be difficult to replicate the interventions in another setting. Few studies were provided by pre-existing teams or professionals, and many studies may therefore have been contaminated by the experimental setting. A significant proportion of the trials compared the case management interventions with augmented usual care and it may be that this augmented care is closer to usual care in Europe and more applicable to everyday care.

The majority of studies presented data at one year (three RCTs) or longer (seven RCTs). This is a reasonable length of time to assess differences in intervention effects; however, longer-term data are needed to fully measure the impact on care home admissions. Three studies presented data of six months or less.

\section{Type of study design}

Most studies were individually randomised trials, but two were cluster-randomised; these had wider system-level collaborative care interventions where the intervention is also applied to the providers of care rather than solely to the individual participant. Cluster-RCTs are recommended in these situations, as RCTs based on individual participants may be vulnerable to contamination (Ukoumunne 1999). Future versions of the review, with additional studies, will need to explore in a sensitivity analysis whether the outcomes are sensitive to the inclusion of such trials.

Access to forms of case management or other services were a feature of some of the control groups for studies included in this review. The use of case management was measured among the control groups for this review, and we found a significant difference in the numbers receiving case management in the intervention and control arms, but there may be some degree of contamination in the results. The Chu - Canada study reported that the control group also had access to the standard home-care programme. It was noted in the Newcomer - US study that control group cases may have been exposed to comparable benefits, such as case management and community care benefits if they were participating in the Medicaid programmes. For this reason, the demonstration programmes were encouraged not to seek or accept applications from those receiving Medicaid. However, there were still around $7 \%$ of participants each in the treatment and control groups who were Medicaid recipients. Statistical controls were put in place to adjust for the potential effect of Medicaid participation. Our results did not illuminate any particular effects of these differences in control conditions on the outcomes.

\section{Type of participants}

There was a mix of trials from Europe, USA, Hong Kong, Canada and India. Studies included a wide variability of participants and carers, although only one study reported that a high proportion of participants were socio-economically disadvantaged (Calla- han - Indianapolis). This variability reflected the severity of dementia; six studies included both mild and moderate severity (Bass Ohio; Callahan - Indianapolis; Chien- Hong Kong 2008; Chien - Hong Kong 2001; Dias - Goa India; Lam - Hong Kong). Three studies included predominantly moderate (Eloniemi-Sulkava 2001; Eloniemi-Sulkava 2009; Newcomer - US) and four studies included mostly mild dementia (Chu - Canada; Hinchliffe - UK; Jansen - Netherlands; Vickrey - California). A number of trials reported participants with significant comorbidities (Bass - Ohio; Callahan - Indianapolis; Eloniemi-Sulkava 2009; Jansen - Netherlands; Vickrey - California), whilst others excluded those with physical comorbidities (Eloniemi-Sulkava 2001; Dias - Goa India; Lam - Hong Kong). As we did not pursue subanalyses involving dementia severity, further work may be necessary to ascertain whether the severity of dementia or other subgroups are more or less likely to benefit from case management.

\section{Type of intervention}

Case management is a complex intervention with multiple components which facilitates access to treatment, services and support both for people with dementia and for their carers. The goals of the studies included in the review were varied; they focused on reducing carer depression and burden, improving carer quality of life, delaying institutionalisation, reducing the number of neuropsychiatric symptoms/behavioural problems, increasing early use of home care and other community services, facilitating long-term planning, and improving carer competence in caring. In many studies the case management interventions were specifically targeted at predetermined outcomes (e.g. carer burden or institutionalisation), and it is possible that other beneficial effects of the interventions were not measured.

Case managers delivering the intervention were from a range of professional backgrounds (nurses, social workers, occupation therapists, and psychiatrists) and were based in a variety of settings, including primary care and dementia resource centres. The training which the case managers received to deliver case management also varied considerably between the trials, both in the mode of provision of training and the content. Only three trials reported on provision of dementia training for their case managers, and several of the studies did not report any details on training for the case managers. The case manager was responsible for co-ordination of care and treatment between organisations and agencies. It would appear that in only three of the studies were the case managers taking responsibility for managing the wider care network. In many other studies they appeared to be more focused on co-ordinating the work of their own service alone, which represents a narrower focus of case management responsibility. Such differences in case manager involvement and their range and breadth of responsibilities are likely to be critical determinants of variations in outcome.

In this review, case management focused on the planning and coordination of care required to meet the identified needs of the person with dementia, although the forms of case management differed. The core tasks of assessment, care planning and implementation/management were common to all but one trial, but there was considerable variation in their delivery. Most studies used faceto-face contact to deliver case management, but one used solely telephone contact. The intensity of the case management varied; the frequency of contact between the case managers and the participants/carers varied from one to two or more contacts per month, and caseload size ranged between 13 and 100 participants. Length of intervention varied between four months and 
two years. However, given the limited data available for the longterm effects of case management, it is difficult to conclude whether these observed effects are due to the duration or frequency of the intervention, or to other mediating variables.

In our second objective we aimed to study whether other potential mediating variables affect case management outcomes (e.g. key structural and organisational features of case management interventions, and also the methodological characteristics of studies). We categorised the trial interventions according to many components (Table 1; Table 3; Table 4; Table 5). Although this enabled us to provide a synthesis of the context and characteristics of the case management interventions, the design of the trials did not permit us to identify components of the interventions that might represent the most important active ingredients. The fairly small numbers of studies that could be included in many of the meta-analyses at each particular time point also limited subgrouping on case management characteristics,making it difficult to meet our second objective. Since the case management interventions varied considerably (e.g. content of case management interventions; target populations; degree of control and influence over allocation of care resources; and intensity and duration) it was difficult to interpret the results and to link outcomes to the specific components of the interventions. Differences in health care delivery in various countries, the impact of culture on care, the attitude and acceptance of care and institutional care should also be considered in future updates of this review.

\section{Quality of the evidence}

The quality of the included studies is variable, but most were free of selection bias due to the use of adequate methods for random sequence generation and allocation concealment. However, all of the studies included in the review were subject to some level of performance bias, where either the participants or the case managers or both were unblinded (Summary of findings for the main comparison). Nine out of the 13 studies had blinded outcome assessors and the others were either at high or unclear risk, but overall there was a low risk of detection bias. There were large variations in the sample sizes within studies. The Newcomer - US study had 8095 participants, while Hinchliffe - UK had only 40 . Most studies had between 100 and 200 participants. There was some attrition bias in some of the studies.

We found clinical and methodological heterogeneity in terms of participants, interventions, comparisons and outcome measures. Applying 'Risk of bias' criteria to the studies has identified some methodological limitations, although some of these (e.g. blinding of participants and clinicians) reflect the reality of conducting complex intervention trials in practice. Some studies rated at high risk of bias for blinding of participants used self-reported outcomes and service use data which may not be as vulnerable to bias as an unblinded external observer. There was no evidence that removing the two studies rated at high risk of bias (assessed in terms of allocation concealment) had a large effect on the estimate of treatment effect in the main analyses. As illustrated in Figure 2, there is the impression of a low to moderate overall risk of bias in these trials. This would mean, therefore, a low to moderate risk of overestimating a positive effect. Making judgements about quality has been helped by a discernible improvement in the reporting of trial methodology; the studies that were rated at high risk of bias were conducted over a decade ago.

Some of the analyses, e.g. the number of hospital admissions at 6,12 and 18 months, quality of life of carers at 12 and 18 months, carer burden at 12 and 18 months, had a high value $I^{2}$ statistic, indicating either 'moderate' or 'substantial' heterogeneity according to the recommended interpretation (Deeks 2011).

Since there are several limitations to this review, our conclusions should be treated with caution. Although the number of included participants is high, the number of included studies is relatively low. We may therefore have missed true differences between groups. There is heterogeneity between the participants' demographics, types of dementia, intervention components, delivery methods, outcome measures and follow-up periods.

\section{Potential biases in the review process}

The search terms for the Specialised Register of the Cochrane Dementia and Cognitive Improvement Group (updated December 2013) should have been robust enough to detect relevant studies. It is possible that we have failed to identify small studies, but we think it unlikely that we would have missed large trials. We attempted comprehensive literature searching, but the fact that one citation has not yet been incorporated may be a source of potential bias. Studies published in languages other than English, and those with equivocal results, are often difficult to find (Egger 1997). Our search was biased by use of English phrases. However, given that the Specialised Register of the Cochrane Dementia and Cognitive Improvement Group covers many languages but is indexed in English, we feel that we are unlikely to have missed many studies within the register. It is also worth noting that the review did not include studies that were solely focused upon carers. This may be something we will reconsider for future updates.

Some of the meta-analyses have been dominated by the largest trial (Newcomer - US), and a funnel plot of the institutionalisation outcome appears slightly asymmetrical (Figure 7), suggesting that possible publication bias may be a factor for this outcome at least. However, tests for funnel plot asymmetry are not recommended when there are fewer than 10 studies in the meta-analysis, because test power is usually too low to distinguish chance from real asymmetry (Sterne 2011). Consideration should be given to the possibility of publication bias in this review. Trials which do not produce positive findings appear less likely to be published, which can lead to a biased set of studies being included in systematic reviews. However, there is likely to be a low risk of publication bias for this review, since our comprehensive search strategy did not restrict searches to peer-reviewed journals only; for example, the Jansen - Netherlands study, included in this review, was a PhD thesis conducted in the Netherlands. We cannot rule out the possibility that we have missed unpublished trials with negative results. In future, publishing of trials based on their results should be less of a problem, since many trials are now required to be included in a recognised clinical controlled trials register and many trial protocols are now being published. 
Figure 7. Funnel plot of comparison: 1.1 Institutionalised (number of patients admitted to residential or nursing homes)

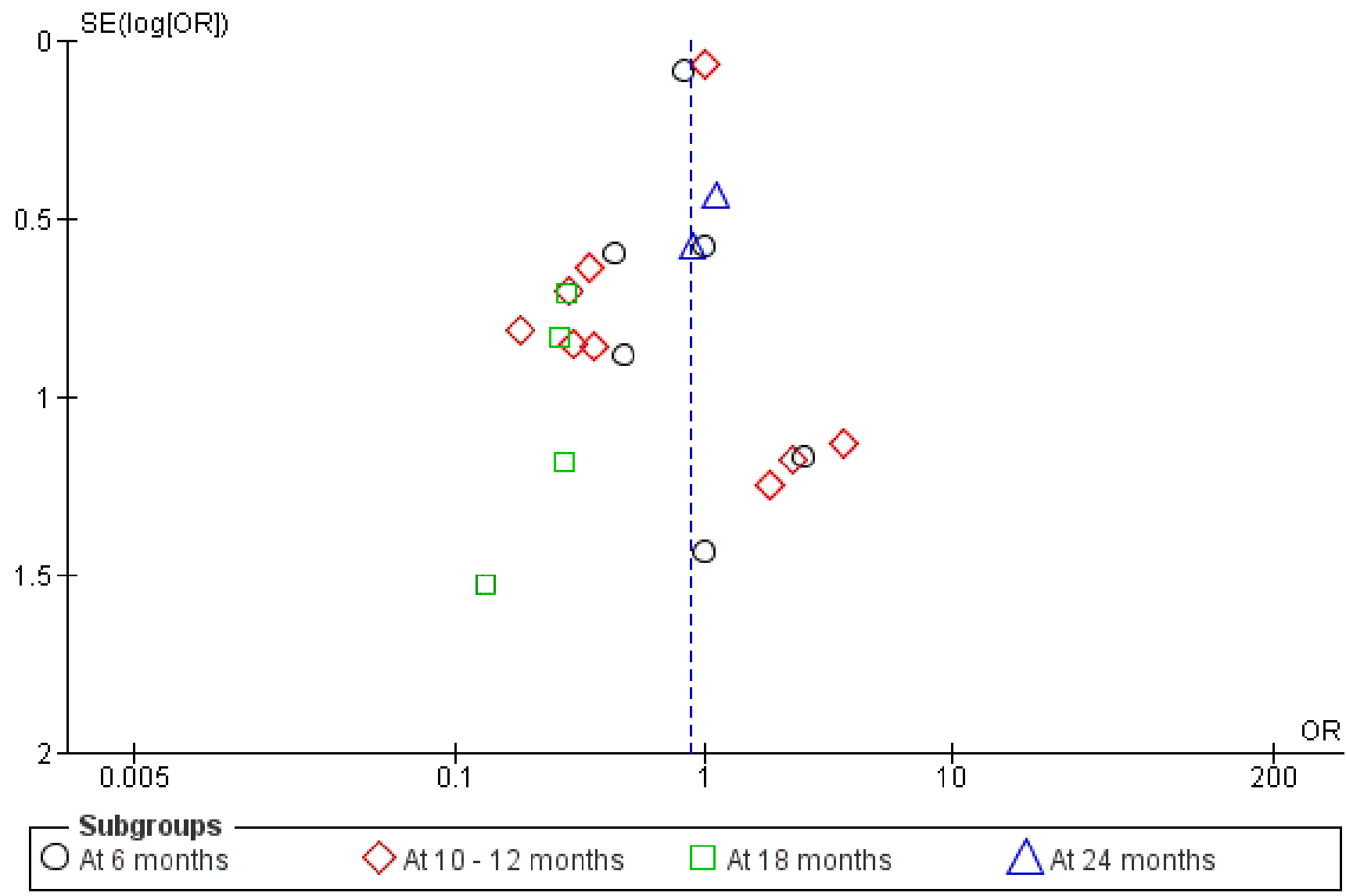

The quality of reporting was variable. We contacted authors of all studies where we identified missing outcome data. Given the complexity of the outcomes and intervention, this led to multiple requests for data. Some important data within the included studies were not reported clearly or in a format that could be used in the review, which is a shortcoming of the research community. Should we acquire more data from existing studies, we would probably know more about the effects of this widely-implemented approach of care.

Since publishing the protocol, we have made several changes as a result of editorial discussions on the best way to report and synthesise the data. In some cases protocol rules were not clear enough, so that the need for subsequent clarification arose and post hoc decisions had to be taken (Differences between protocol and review). In particular we prespecified what characteristics of studies could be associated with heterogeneity. The variability of interventions, outcomes and participant groups meant that often only a very small number of trials could be included in many of the metaanalyses. For example, owing to the small number of studies in the subgroups and the diversity of case management interventions, the subgroup analyses involving dementia severity were not pursued on the basis that they were unlikely to generate meaningful or relevant results. In addition, we have further specified how outcomes would be measured.

\section{Agreements and disagreements with other studies or reviews}

An important strength of this review is the use of a stringent definition of case management. A number of reviews have been completed in this area, but they are less specific when defining what case management is. The first review (Pimouguet 2010) covered 12 trials, seven of which we also reviewed here (Bass - Ohio; Callahan - Indianapolis; Chien- Hong Kong 2008; Chu - Canada; Eloniemi-Sulkava 2001; Newcomer - US; Vickrey - California). Like our review, Pimouguet 2010 noted the effects of delaying institutionalisation for people with dementia, but concluded that there was not sufficient evidence to draw conclusions about the effects of case management on costs and resource utilisation.

The most recent review (Somme 2012) included six studies, five of which we include in our review (Bass - Ohio; Callahan - Indianapolis; Eloniemi-Sulkava 2001; Newcomer - US; Vickrey - California). We excluded their sixth study (Weinberger - US), as the intervention was focused on carers only. Somme 2012 concluded that more effective case management related both to better integration between the health and social service organisations, and to the intensity of the case management.

The findings of the authors of a review of community care demonstrations in the US 25 years ago are still relevant today. They concluded that "expanding public financing of community services be- 
yond what already exists is likely to increase costs. Small nursing home cost reductions are more than offset by the increased costs of providing services to those who would remain at home even without the expanded services. However, expanded community services appear to make people better off and not to cause substantial reductions in family care-giving. Policymakers should move beyond asking whether expanding community care will reduce costs to addressing how much community care society is willing to pay for, who should receive it, and how it can be delivered efficiently" (Kemper 1987).

\section{AUTHORS' CONCLUSIONS}

\section{Implications for practice}

\section{For patients and carers}

There were some data to indicate that case management was effective in ameliorating some outcomes at certain time points relevant to people with dementia. However, the results were uncertain at other time points. Case management may represent a more patient-centred system of care. The data available suggest that admissions to care homes and overall healthcare costs are reduced. In addition, length of time to admission to long-term care was reduced, but more evidence is needed. The data did not indicate that case management improved cognition, functional status or depression, and there were no data available on the satisfaction of participants.

There were some data to suggest that case management may contribute to reduced carer burden, but much of these data were difficult to interpret, given the variation in interventions, outcome measures and reporting. One of the determinants of individual carer burden will be the level of formal and informal support available. However, the appropriate information to address these issues of substitution and complementary information was not always available in the studies. There was some indication that carers were less depressed and less likely to be hospitalised and to visit the emergency department in the longer term, and that service costs were reduced at one and three years. There were minimal data available on satisfaction with care, but the available data indicated that those receiving case management were more satisfied. There does not seem to be compelling evidence that case management substantially affects a carer's quality of life, carer well-being or reduces carer distress.

\section{For clinicians}

The heterogeneity in the interventions, outcomes and participants may explain these largely equivocal findings. The effects of case management in a 'comprehensive' form apply to only half of the studies included in the review (Table 5). A number of studies have evaluated a case management intervention on top of other health system changes (such as promoting adherence to recommended treatment protocols). Some conclusions, therefore, apply to differing variants of case management packages. One of the trials which was part of a wider quality improvement programme demonstrated that there were few differences in provider knowledge or attitudes favourable to dementia care, suggesting that this care model's effects on quality were primarily mediated through other components of the case management programme (Vickrey - California).

More attention needs to be given in future studies to demonstrating the extent to which the case management intervention is de- livered as planned. Well-developed training and protocol manuals will help with assuring the fidelity and replicability of the intervention. In one trial case managers were found not to be working to protocol (Jansen - Netherlands). The authors noted that improved "adherence to key care processes may lead to better quality of care and participant outcomes".

There are indications of benefits to increased involvement and linkage with primary care in case management interventions for people with dementia. Three out of the 13 studies were based within primary care (Callahan - Indianapolis; Jansen - Netherlands; Vickrey - California).

It is important that these interventions are targeted at the right populations. Some interventions were more assertive in co-ordination of care by case managers, which were targeted at people who were more likely to benefit from the intervention. However, at least two trials indicated that the intervention was not targeted appropriately (Jansen - Netherlands; Newcomer - US). It was noted in the latter study that the levels of burden and depression among carers were generally below those that would indicate clinical problems. It was suggested that to be more effective, the demonstration may have needed to target carers with clinically identified levels of burden and depression or other risk factors (e.g. low income, health crises, duration of care-giving, living separately from the care recipient) who could have benefited more from the demonstration interventions.

\section{For funders and policy makers}

Health care policy in the UK recommends the development of a comprehensive system of case management similar to that for people with long-term conditions using the Quality and Outcomes Framework register data from primary care (NICE 2006). Primary care and specialist services need to integrate care more effectively (Joint commissioning panel for mental health 2012) and case managers are likely to be able to facilitate this. The newly-evolving GP commissioning consortia will want to commission cost-effective models of care for people with dementia (Joint commissioning panel for mental health 2012). Indeed, care co-ordination features heavily in the recent guidance where commissioners are advised to work with their local dementia partnership to agree and implement a robust service model for care co-ordination (NICE 2013). A recent report has indicated that case management would substantially reduce health and social care costs but increase the costs of unpaid care (Knapp 2014). Case management features as a clear strategy for co-ordinating dementia care in France; the role of the co-ordinators has been created on the basis of current case management evidence (French Ministry of Health 2008).

This review shows that there is not yet a robust evidence base for the effectiveness of case management in meeting healthcare needs or cost effectiveness for patients or carers. Funders should support research which investigates the effectiveness of specific models of case management for people with dementia. The one citation in Studies awaiting classification may alter the conclusions of the review once assessed.

\section{Implications for research}

A future update of this review, including results from ongoing trials and those 'awaiting classification', may increase the precision of the estimates of effect sizes. Future systematic reviews and metaanalyses could be performed to investigate the effect of particular 
models of case management compared with standard care. This review would be strengthened by additional large-scale high-quality studies where specific features and modalities (e.g. telephone and face-to-face) of case management are investigated.

Further robust research is needed to determine whether case management care is an effective system for people with dementia and their carers, in terms of clinical outcomes and cost. Future trials need to be rigorous in design and delivery, with subsequent reporting to include high-quality descriptions of all aspects of methodology to enable appraisal and interpretation of results. Detailed process evaluations are also required, to identify components of this complex intervention and to facilitate the interpretation of trial outcomes.

Case management is a complex intervention (Campbell 2000); we recommend that a full description of care in the intervention and control groups is provided. In future it will be important to classify more closely the content of case management interventions and their fidelity to the expected intervention (McGrew 1994). Future studies will need to continue and increase this precision in discriminating between community-based staff doing some care co-ordination activities and a specific role of case manager, and also to delineate more carefully the content of the intervention itself and its core components. Process evaluations would help to identify the components of case management, understand how it is delivered and how issues of sustainability and replicability are addressed. Process evaluations are particularly important for interpreting outcomes, and for understanding how an intervention is implemented across multiple sites. Although seven of the 13 studies reported using standardised protocols, the use of well-developed manuals and protocols should be more widespread, since they can help to ensure the transparency, replicability and integrity of this complex intervention. This highlights the need for greater consistency in process level and quality of care indicators (which systematically describe how the interventions are implemented). These could include: the number of people with a care plan and how often it is monitored, reviewed and updated; the number of times visited, followed up or telephoned by the case manager; the number of phone calls or contacts that the case manager makes on behalf of the person with dementia or the carer. Future studies should consider including measures such as these to help ascertain the active ingredients of case management by relating these to their outcomes.

Only two of the studies reported data on the use of prescribed medications, and there were not enough data to draw reliable conclusions about whether or not certain prescribed medications have an influence on the effectiveness of case management interventions. This could be considered in future studies. Following CONSORT recommendations (CONSORT 2010a; CONSORT 2010b) in the reporting of future studies would greatly assist synthesis of data in reviews. The timing of participant admission to residential or nursing homes was not reported in all studies; a number of studies report cumulative data at the endpoint of the trial. More trials should address this outcome at each follow-up point, which would be fairly easy to collect and report in a CONSORT diagram.
We note that scale measurements (which may be both easier to collect and less ambiguous) were more likely than binary data to be reported in the papers for assessing clinical outcomes. More trials should address admissions to nursing homes at each follow-up point, admission to hospital and associated length of stay, along with the length of time until institutionalisation (which was only reported in one of the trials). Matters are complicated by the use of many scales for the same outcomes, which makes meta-analysis more difficult. Heterogeneous measurements were used to describe the same outcome, constituting a lost opportunity for researchers. Any relevant studies in this area should aim to provide data that are compatible with this review. There are few cost-effectiveness studies identified so far, and this gap should be addressed, particularly in relation to clinically meaningful benefits and the potential for cost savings with this intervention. More attention should also be paid to patient and carer perspectives in terms of measuring satisfaction, quality of life, well-being, social support and carer burden.

\section{ACKNOWLE D GEMENTS}

This review was supported through the Support at Home - Interventions to Enhance Life in Dementia (SHIELD) project (Application No RP-PG-0606-1083) which is funded by the National Institute of Health Research Programme Grants for Applied research funding scheme and Siobhan Reilly's fellowship award from National Institute of Health Research School for Primary Care Research at the University of Manchester.

We used another review on intensive case management for severe mental illness (Dieterich 2010) to help us to draft the review.

The authors wish to thank Jenny McCleery and the other editors of the Cochrane Dementia and Cognitive Improvement Group for their editorial support; Vittoria Lutje for developing the search strategy; Anna Noel-Storr, Trials Search Co-ordinator, who updated our searches and performed the initial screening of these records; $U$ Hla Htay for acting as consumer reviewer for this review. We also thank the peer reviewers including the consumer peer reviewer Catherine Hofstetter for their thoughtful comments and suggestions for improving the review, and Barry Wilson and Fiona Horton for proofreading the document.

The reviewers would also like to thank the study authors who responded to queries and requests for further information relating to the following studies: Bass - Ohio; Callahan - Indianapolis; Chu Canada; Dias - Goa India; Eloniemi-Sulkava 2001; Eloniemi-Sulkava 2009; Jansen - Netherlands; Vickrey - California.

The views and opinions expressed in this review are those of the authors and do not necessarily reflect those of the National Institute of Health Research, the NHS or the Department of Health. 


\section{R E F E R E N C E S}

\section{References to studies included in this review}

Bass - Ohio \{published and unpublished data\}

* Bass DM, Clark PA, Looman WJ, McCarthy CA, Eckert S. The Cleveland Alzheimer's Managed Care Demonstration: Outcomes after 12 months of Implementation. The Gerontologist 2003;43(1):73-85.

Clark PA, Bass DM, Looman WJ, McCarthy CA, Eckert S. Outcomes for patients with dementia from the Cleveland Alzheimer's Managed Care Demonstration. Aging and Mental Health 2004;8(1):40-51.

Judge KS, Bass DM, Snow AL, Wilson NL, Morgan R, Looman WJ, et al. Partners in Dementia Care: a care coordination intervention for lidividuals with dementia and their family caregivers. The Gerontologist 2011;51(2):261-72. [DOI: 10.1093/ geront/gnq097]

McCarthy K. Further information on study [personal communication]. Email to Juanita Hoe May 20th 2011.

Callahan - Indianapolis \{published and unpublished data\} Callahan C. Further information and data on the study [personal communication]. Email to Claudia Miranda 17the November 2010.

Callahan C. Further information and data on the study [personal communication]. Email to Martin Orrell 18th July 2011.

* Callahan CM, Boustani MA, Unverzagt FW, Austrom MG, Damush TM, Perkins AJ, et al. Effectiveness of collaborative care for older adults with Alzheimer disease in primary care: a randomized controlled trial. JAMA 2006;295(18):2148-57.

Guerriero Austrom M, Damush TM, Hartwell CW, Perkins T, Unverzagt $F$, Boustani $M$, et al. Development and implementation of nonpharmacologic protocols for the management of patients with Alzheimer's disease and their families in a multiracial primary care setting. The Gerontologist 2004;44(4):548-53.

\section{Chien - Hong Kong 2001 \{published data only\}}

* Chien WT, Lee IYM. Randomized controlled trial of a dementia care programme for families of home-resided older people with dementia. Journal of Advanced Nursing 2011;67(4):774-87.

Chien, WT. Further information on study [personal communication]. Email to Siobhan Reilly 3rd June 2014.

Chien- Hong Kong 2008 \{published data only\}

${ }^{*}$ Chien WT, Lee YM. A disease management program for families of persons in Hong Kong with dementia. Psychiatric Services 2008;59(4):433-6.

Chien, WT. Further information on study [personal communication]. Email to Siobhan Reilly 3rd June 2014.

\section{Chu - Canada \{published and unpublished data\}}

Chu P. Further information on study [personal communication]. Email to Siobhan Reilly 22nd June 2011.
* Chu P, Edwards J, Levin R, Thomson J. The use of clinical case management for early stage Alzheimer's patients and their families. American Journal of Alzheimer's Disease and Other Dementias 2000;15:284-90.

Joy E. Further information on study [personal communication]. Email to Siobhan Reilly 7th June 2011.

Dias - Goa India \{published and unpublished data\}

Dias A. Further information on study [personal communication]. Email to Juanita Hoe 17th May 2011.

* Dias A, Dewey ME, D'Souza J, Dhume R, Motghare DD, Shaji KS, et al. The effectiveness of a home care program for supporting caregivers of persons with dementia in developing countries: A randomised controlled trial from Goa, India. PLOS ONE 2008;3(6):e2333. [NCT00479271]

\section{Eloniemi-Sulkava 2001 \{published and unpublished data\}} Eloniemi-Sulkava U. Further information and data on the study [personal communication]. email sent to Martin Orrell 8th August 2011.

* Eloniemi-Sulkava U, Notkola IL, Hentinen M, Kivela SL, Sivenius J, Sulkava R. Effects of supporting community-living demented patients and their caregivers: a randomized trial. Journal of the American Geriatrics Society 2001;49(10):1282-7.

Eloniemi-Sulkava 2009 \{published and unpublished data\}

* Eloniemi-Sulkava U, Saarenheimo M, Laakkonen ML, Pietilä M, Savikko N, Kautiainen $\mathrm{H}$, et al. Family care as collaboration: effectiveness of a multicomponent support program for elderly couples with dementia: randomised controlled intervention study. Journal of the American Geriatrics Society 2009;57(12):2200-8.

Pitkälä K. Further information on study [personal communication]. Email to Claudia Miranda 20th May 2011.

Hinchliffe - UK \{published data only\}

Hinchliffe AC. Management of the Behavioural Symptoms of Dementia and the Effect on Carers. MD Thesis. University of London 2002.

* Hinchliffe AC, Hyman IL, Blizard B, Livingston G. Behavioural Complications of Dementia: Can they be treated?. International Journal of Geriatric Psychiatry 1995;10(10):839-47.

\section{Jansen - Netherlands \{published and unpublished data\}}

Jansen A. Further information on study and data [personal communication]. Emails to Claudia Miranda 16th November 2010; 27th May 2011; August 2011.

Jansen APD. Effectiveness of Case Management among Older Adults with Dementia Symptoms and their Informal Caregivers [PhDThesis]. Amsterdam: VU University, 2007.

* Jansen APD, Van Hout HPJ, Nijpels G, Rijmen F, Dröes RM, Pot AM, et al. Effectiveness of case management among older adults with early symptoms of dementia and their primary informal caregivers: A randomized clinical trial. International 
Journal of Nursing Studies 2011;48(8):933-43. [DOI: 10.1016/ j.ijnurstu.2011.02.004]

\section{Lam - Hong Kong \{published data only\}}

* Lam LC, Lee JS, Chung JC, Lau A, Woo J, Kwok TC. A randomized controlled trial to examine the effectiveness of case management model for community dwelling older persons with mild dementia in Hong Kong. International Journal of Geriatric Psychiatry 2011;25(4):395-402.

\section{Newcomer - US \{published data only (unpublished sought but not used)\}}

Arnsberger P, Fox P, Zhang X. Case manager-defined roles in Medicare Alzheimer's Disease Demonstration: relationship to client and caregiver outcomes. Care Management Journals 1999;1(1):29-37.

Fox P, Newcomer R, Yordi C, Arnsberger P. Lessons learned from the Medicare Alzheimer Disease Demonstration. Alzheimers Disease and Associated Disorders 2000;14(2):87-93.

Gaugler J, Kane R, Kane R, Newcomer R. Early communitybased service utilization and its effects on institutionalization in dementia caregiving. The Gerontologist 2005;45(2):177-85.

Miller R, Newcomer R, Fox P. Effects of the Medicare Alzheimer's Disease Demonstration on nursing home entry. Health Services Research 1999;34(3):691-714.

Newcomer R, Miller R, Clay T, Fox P. Effects of the Medicare Alzheimer's disease demonstration on Medicare expenditures. Health Care Financing Review 1999;20(4):45-65.

* Newcomer R, Spitalny M, Fox P, Yordi C. Effects of the Medicare Alzheimer's Disease Demonstration on the use of communitybased services. Health Services Research 1999;34(3):645-67.

* Newcomer R, Yordi C, DuNah R, Fox P, Wilkinson A. Effects of the Medicare Alzheimer's Disease Demonstration on caregiver burden and depression. Health Services Research 1999;34(3):669-89.

Shelton P, Schraeder C, Dworak D, Fraser C, Sager M. Caregivers' utilization of health services: results from the Medicare Alzheimer's Disease Demonstration, Illinois site. Journal of the American Geriatrics Society 2001;49(12):1600-5.

Yaffe K, Fox P, Newcomer R, Sands L, Lindquist K, Dane K, et al. Patient and caregiver characteristics and nursing home placement in patients with dementia. JAMA 2002;287(16):2090-7.

Yordi C, DuNah R, Bostram A, Fox P, Wilkinson A, Newcomer R. Caregiver supports: outcomes from the Medicare Alzheimer's disease demonstration. Health Care Financing Review 1997;19(2):97-117.

\section{Vickrey - California \{published and unpublished data}

Chodash J, Berry E, Lee M, Connor K, DeMonte R, Ganiats T, et al. Effect of a dementia care management intervention on primary care provider knowledge, attitudes, and perceptions of quality of care. Journal of the American Geriatrics Society 2006;54(2):311-7.
Connor KI, McNeese-Smith DK, Vickrey BG, Van Servellen GM Chang BL. Lee ML, et al. Determining care management activities associated with mastery and relationship strain for dementia caregivers. Journal of the American Geriatrics Society 2008;56(5):891-7. [DOI: 10.1111/j.1532-5415.2008.01643.x]

Duru OK, Ettner SL, Vassar SD, Chodosh J, Vickrey BG. Cost evaluation of a coordinated care management intervention for dementia.. The American Journal of Managed Care 2009;15(8):521-8.

Vickrey B. Further information on study [personal communication]. Email to Juanita Hoe 12th June 2011.

*Vickrey BG, Mittman BS, Connor KI, Pearson ML, Della Penna RD, Ganiats TG, et al. The effect of a disease management intervention on quality and outcomes of dementia care: a randomized controlled trial. Annals of Internal Medicine 2006;145(10):713-26.

\section{References to studies excluded from this review}

\section{Aliberti - Las Vegas \{published data only\}}

Aliberti E, Basso C, Schramm E. A collaborative approach for the care management of geropsychiatric services. Professional Case Management 2011;16(2):62-8.

\section{Baldwin - UK \{published data only\}}

Baldwin R, Pratt H, Goring H, Marriott A, Roberts C. Does a nurse-led mental health liaison service for older people reduce psychiatry morbidity in acute general medical wards? A randomised controlled trial. Age and Ageing 2004;33(5):472-8.

\section{Bellantonio - Connecticut \{published data only\}}

Bellantonio S, Kenny A, Fortinsky H, Kleppinger A, Robison J, Gruman C, et al. Efficacy of a geriatrics team intervention for residents in dementia-specific assisted lLiving facilities: effect on unanticipated transitions. Journal of the American Geriatrics Society 2008;56(3):523-8.

\section{Callahan-Indianapolis \{published data only\}}

Callahan CM, Boustani MA, Schmid AA, Austrom MG, Miller DK, Gao SJ, et al. Alzheimer's Disease Multiple Intervention Trial (Admit): study protocol for a randomized controlled clinical trial. Trials 2012;13(92):1.

Engedal - Oslo \{published data only\}

Engeldal K. Day care for demented patients in general nursing homes. Effects on admissions to institutions and mental capacity. Scandinavian Journal of Primary Health Care 1989;7(3):161-6.

\section{Fabris - Italy \{published data only\}}

* Fabris F, Molaschi M, Aimonino N, Ponzetto M, Maero B, Tibaldi V, et al. Home care for demented subjects: new models of care and home-care allowance. Archives of Gerontology and Geriatrics 2004;Supplement 9(9):155-62.

Tibaldi V, Aimonino N, Ponzetto M, Stasi MF, Amati D, Raspo S, et al. A randomized controlled trial of a home hospital intervention for frail elderly demented patients: behavioral 
disturbances and caregiver's stress. Archives of Gerontology and Geriatrics 2004;Supplement(9):431-6.

\section{Farran - US \{published data only\}}

Farran CJ, Gilley DW, McCann JJ, Bienias JL, Lindeman DA, Evans DA. Efficacy of behavioral interventions for dementia caregivers. Western Journal of Nursing Research 2007;29(8):944-960.

\section{Gerdner - US \{published data only\}}

Gerdner LA, Buckwalter KC, Reed D. Impact of a psychoeducational intervention on caregiver response to behavioral problems. Nursing Research 2002;51(6):363-74.

\section{Gitlin - US1 \{published data only\}}

Gitlin LN, Hauck WW, Dennis MP, Winter L. Maintenance of effects of the home environmental skill-building program for family caregivers and individuals with Alzheimer's Disease and related disorders. Journal of Gerontology: Series A, Biological sciences and medical sciences 2005;60(3):368-74.

\section{Gitlin - US2 \{published data only\}}

Gitlin LN, Winter L, Corcoran M, Dennis MP, Schinfeld S, Hauck WW. Effects of home environmental skill-building program on the caregiver-care recipient dyad: 6-month outcomes from the Philadelphia REACH initiative. The Gerontologist 2003;43(4):532-546.

\section{Gonyea - US \{published data only\}}

Gonyea J, O'Connor M, Boyle P. Project CARE: A randomised controlled trial of a behavioural intervention group for Alzheimer's Disease Caregivers. The Gerontologist 2006;46(6):827-832.

\section{Goodman - US \{published data only\}}

Goodman C, Pynoos J. A model telephone intervention and support program for caregivers of Alzheimer's patients. The Gerontologist 1990;30(3):399-404.

\section{Gormley - UK \{published data only\}}

Gormley N, Lyons D, Howard R. Behavioural management of aggression in dementia: a randomized controlled trial. Age and Ageing 2001;30(2):141-5.

\section{Graff - The Netherlands \{published data only\}}

Graff M, Adang E, Vernooij Dassen M, Dekker J, Jönsson L, Thijssen M, et al. Community occupational therapy for older patients with dementia and their caregivers: cost effectiveness study. BMJ 2008;336(7636):134-8. [DOI: 10.1136/ bmj.39408.481898.BE]

* Graff M, Vernooij Dassen M, Thijssen M, Dekker J, Hoefnagels W, Rikkert MG. Community based occupational therapy for patients with dementia and their caregivers: randomised controlled trial. BMJ 2006;333(7580):1196.

\section{Gutterman - US \{published data only\}}

Gutterman E, Markowitz J, Lewis B, Fillit H. Cost of Alzheimer's disease and related dementia in managed-medicare. Journal of the American Geriatrics Society 1999;47(9):1065-71.
Hébert - Canada \{published data only\}

Hébert R, Leclerc G, Bravo G, Girouard D, Lefrançois R. Efficacy of a support group programme for caregivers of demented patients in the community: a randomized controlled trial. Archives of Gerontology and Geriatrics 1994;18(1):1-14.

Hepburn - US \{published and unpublished data\}

Hepburn KW, Tornatore J, Center B, Ostwald SW. Dementia family caregiver training: affecting beliefs about caregiving and caregiver outcomes. Journal of the American Geriatrics Society 2001;49(4):450-7.

\section{Kwak - Georgia \{published data only\}}

Kwak J, Montgomery RJ, Kosloski K, Lang J. The impact of TCARE on service recommendation, use, and caregiver wellbeing. The Gerontologist 2011;51(5):704-13.

Lu - China \{published data only\}

Lu SP, Zhang YH, Xu YN, Huang Q, Fu X, Xie YJ. Hospitalcommunity -family whole-course nursing modes for patients with Alzheimer disease. Chinese Journal of Clinical Rehabilitation 2005;9(28):70-3.

Lukas - UIm \{published data only\}

Lukas A, Kilian R, Hay B, Muche R, Von Arnim CAF, Otto M, et al. Maintenance of health and relief for caregivers of elderly with dementia by using "initial case management". experiences from the Lighthouse Project on Dementia, Ulm, ULTDEM-study. Zeitschrift für Gerontologie und Geriatrie 2012;45(4):298-309.

\section{Mittelman - New York \{published data only\}}

Mittelman M, Haley W, Clay O, Roth D. Improving caregiver well-being delays nursing home placement of patients with Alzheimer disease. Neurology 2006;67(9):1592-9.

* Mittelman M, Roth D, Clay O, Haley W. Preserving health of Alzheimer caregivers: impact of a spouse caregiver intervention. American Journal of Geriatric Psychiatry 2007;15(9):780-9.

Mittelman M, Roth D, Haley W, Zarit H. Effects of a caregiver intervention on negative caregiver appraisals of behavior problems in patients with Alzheimer's disease: results of a randomized trial. The Journals of Gerontology. Series B, psychological sciences and social sciences 2004;59B(1):P27-34.

\section{Montgomery - US \{published data only\} \\ Montgomery RJV, Borgatta EF. The effects of alternative support strategies on family caregiving. The Gerontologist 1989;29(4):457-64.}

\section{Mostardt - Germany \{published data only\}}

Mostardt S, Matusiewicz D, Schröer W, Wasem J, Neumann A. Efficacy and cost effectiveness of case management in patients with dementia. Zeitschrift für Gerontologie und Geriatrie 2012;45(7):642-6.

\section{O'Connor - Cambridge UK \{published data only\}}

O'Connor DW, Pollitt PA, Brook CP, Reiss BB, Roth M. Does early intervention reduce the number of elderly people with dementia admitted to institutions for long term care?. BMJ 1991;302(6781):871-5. 
Onor - Italy \{published data only\}

Onor ML, Trevisiol M, Negro C, Signorini A, Saina M, Aguglia E. Impact of multimodal rehabilitative intervention on demented patients and their caregivers. Americal Journal of Alzheimer's Disease and Other Dementias 2007;22(4):261-72.

\section{Schoenmakers-Belgium \{published data only\}}

Schoenmakers B, Buntinx F, Delepeleire J. Supporting family carers of community-dwelling elder with cognitive decline: a randomized controlled trial. International Journal of Family Medicine 2010;2010(Article ID 184152):1. [DOI: 10.1155/2010/184152]

\section{Stenvall - Sweden \{published data only\}}

Stenvall M, Berggren M, Lundström M, Gustafson Y, Olofsson B. A multidisciplinary intervention program improved the outcome after hip fracture for people with dementia--subgroup analyses of a randomized controlled trial. Archives of Gerontology \& Geriatrics 2012;54(3):e284-9.

\section{Valimaki - Finland \{published data only\}}

Valimaki T, Vehvilainen-Julkunen K, Pietila AM, Pirttila T. Coping abilities at home: Rehabilitation in mild Alzheimer's Disease. 14th Alzheimer European Conference, Prague, Czech Republic. 2004; Vol. May 20-23:13-18.

\section{Van denDungen-Netherlands \{published data only\}}

Van den Dungen P, Moll van Charante EP, Van Marwijk HW, Van der Horst HE, Van de Ven PM, Van Hout HP. Case-finding of dementia in general practice and effects of subsequent collaborative care; design of a cluster RCT. BMC Public Health 2012;12:609. [DOI: 10.1186/1471-2458-12-609]

\section{Vernooij-DassenNetherland \{published data only\}}

Vernooij Dassen M, Felling A, Persoon J. Predictors of change and continuity in home care for dementia patients. International Journal of Geriatric Psychiatry 1997;12(6):671-7.

\section{Weinberger - US \{published data only\}}

Weinberger M, Gold DT, Divine GW, Cowper PA, Hodgson LG, Schreiner PJ, et al. Social service interventions for caregivers of patients with dementia: impact on health care utilization and expenditures. Journal of the American Geriatriatrics Society 1993;41(2):153-6.

\section{Wilcock - UK \{published data only\}}

Wilcock G. Development and evaluation of guidelines for detection and management of cases of dementia in the community. National Research Register 1999:1-2.

\section{Wisniewski - US \{published data only\}}

Wisniewski SR, Belle SH, Coon DW, Marcus SM, Ory MG, Burgio LD, et al. The Resources for Enhancing Alzheimer's Caregiver Health (REACH): Project design and baseline characteristics. Psychology and Aging 2003;18(3):375-84.

\section{Wolfs - The Netherlands \{published data only\}}

Wolfs C, Kessels A, Dirksen C, Severens J, Verhey F. Integrated multidisciplinary diagnostic approach for dementia care: randomised controlled trial. The British Journal of Psychiatry 2008;192(4):300-5.

\section{References to studies awaiting assessment}

Samus 2014 \{published data only\}

Samus QM, Johnston D, Black BS, Hess E, Lyman C, Vavilikolanu A, et al. A multi-dimensional home-based care coordination intervention for elders with memory disorders: the maximizing independence at home (MIND) pilot randomized trial. American Association for Geriatric Psychiatry 2014;22(4):398-414.

\section{References to ongoing studies}

Iliffe - UK \{published data only\}

Iliffe S, Robinson L, Bond J, Chew-Graham C, Katona C, Knapp M. A pragmatic randomised controlled trial to evaluate the effectiveness and cost effectiveness of Collaborative Care for people with Dementia in primary care (CARE-DEM trial). ref 08/53/99. http://www.nets.nihr.ac.uk/projects/hta/085399 2011.

\section{Additional references}

\section{Abrams 2005}

Abrams KR, Gillies CL, Lambert PC. Meta-analysis of heterogeneously reported trials assessing change from baseline. Statistics in Medicine 2005 2005;24(24):3823-44.

\section{Alexopoulos 1988}

Alexopoulos GS, Abrams RC, Young RC, Shamoian CA. Cornell Scale for Depression in Dementia. Biological Psychiatry 1988;23(3):271-84

\section{Alzheimer's Disease International 2009}

Alzheimer's Disease International. World Alzheimer's Report 2009. London: Alzheimer's Disease International, 2009.

\section{American Psychiatric Association 2000}

American Psychiatric Association. DSM-IV-TR Classification from Diagnostic and Statistical Manual of Mental Disorders. Washington, DC/London: American Psychiatric Publishing, 2000.

\section{Applebaum 1990}

Applebaum R, Austin C. Long Term Care Case Management: Design and Evaluation. New York: Springer, 1990.

\section{Australian Health Ministers Conference 2006}

Australian Health Ministers Conference. National framework for action on dementia: 2006 - 2010. 152.91.25.226/internet/main/publishing.nsf/Content/ D64BD892C6FDD167CA2572180007E717/\$File/nfad.pdf. Sydney: NSW Department of Health, (accessed 16 December 2014).

\section{Bass 2003}

Bass DM, Clark PA, Looman WJ, McCarthy CA, Eckert S. The Cleveland Alzheimer's Managed Care Demonstration: Outcomes after 12 months of Implementation. The Gerontologist 2003;43(1):73-85. 


\section{Brandt 1988}

Brandt J, Spencer M, Folstein M. The telephone interview for cognitive status. Neuropsychiatry, Neuropsychology and Behavioral Neurolology 1988;1:111-7.

\section{Brod 1999}

Brod J, Stewart AL, Sands L, Walton P. Conceptualization and measurement of quality of life in dementia: The dementia quality of life instrument (DQOL). The Gerontologist 1999;39(1):25-35.

\section{Brodaty 2005}

Brodaty $\mathrm{H}$, Thomson $\mathrm{C}$, Thompson C, Fine $\mathrm{M}$. Why caregivers of people with dementia and memory loss don't use services. International Journal of Geriatric Psychiatry 2005;20(6):537-46.

\section{Burns 2003}

Burns A, Downs M, Kampers W. Current Dementia. London: Science Press, 2003.

\section{Campbell 2000}

Campbell M, Fitzpatrick R, Haines A, Kinmonth AL, Sandercock P, Spiegelhalter D, Tyrer P. Framework for design and evaluation of complex interventions to improve health. $B M J$ 2000;321(7262):694-6.

\section{Challis 1986}

Challis DJ, Davies BP. Case Management in Community Care. Aldershot: Gower Press, 1986.

\section{Challis 1993}

Challis D. Alternatives to institutional care. In: Levy R, Howard $\mathrm{R}$, Burns A editor(s). Treatment and Care in Old Age Psychiatry. Petersfield: Wrightson Biomedical Publishing Ltd, 1993.

\section{Challis 1995}

Challis D, Darton R, Johnson L, Stone M, Traske K. Care Management and Health Care of Older People: The Darlington Community Care Project. Ashgate, 1995.

\section{Challis 2002}

Challis D, Von Abendorff R, Brown P, Chesterman J, Hughes J. Care management, dementia care and specialist mental health services: An evaluation. International Journal of Geriatric Psychiatry 2002;17(4):315-25.

\section{Challis 2003}

Challis D. Achieving coordinated and integrated care among long term care services: the role of care management. In: Brodsky J, Habib J, Hirschfeld M editor(s). Key Policy Issues in Long Term Care. Geneva: World Health Organization, 2003.

\section{Chang 1999}

Chang AM. Psychosocial Nursing Intervention to Promote SelfEsteem and Functional Independence Following Stroke [PhD thesis]. Hong Kong SAR: Department of Nursing, The Chinese University of Hong Kong, 1999.

\section{Chien 2005}

Chien WT. Family care for people with dementia. Signpost - To Older People and Mental Health Matters 2005;10(1):27-32.

\section{Chiu 1994}

Chiu HFK, Lee HC, Chung WS, Kwong PK. Reliability and validity of the Cantonese version of Mini-Mental State Examination - a preliminary study. Journal of Hong Kong College of Psychiatry 1994;4(Suppl 2):25-8.

\section{Chiu 1998}

Chiu HFK, Lam LCW, Chi I, Leung T, Li SW, Law WT, et al. Prevalence of dementia in Chinese elderly in Hong Kong. Neurology 1998;50(4):1002-9.

\section{Chodash 2006}

Chodash J, Berry E, Lee M, Connor K, DeMonte R, Ganiats T, et al. Effect of a dementia care management intervention on primary care provider knowledge, attitudes, and perceptions of quality of care. Journal of the American Geriatrics Society 2006;54(2):311-7.

\section{Chou 2002}

Chou KR, Jiann-Chyun L, Chu H. The reliability and validity of the Chinese version of the Caregiver Burden Inventory. Nursing Research 2002;51(5):324-31.

\section{Chu 2000}

Chu P, Edwards J, Levin R, Thomson J. The use of clinical case management for early stage Alzheimer' patients and their families. American Journal of Alzheimer's Disease and Other Dementias 2000;15(5):284-90.

\section{CONSORT 2010a}

Schulz KF, Altman DG, Moher D (CONSORT Group). CONSORT 2010 statement for reporting parallel group randomised trials. BMJ 2010;340:c332.

\section{CONSORT 2010b}

Moher D, Hopewell S, Schulz KF, Montori V, Gøtzsche PC, Devereaux PJ, et al (CONSORT Group). CONSORT 2010: Explanation and Elaboration: updated guidelines for reporting parallel group randomised trial. BMJ 2010;340:c869.

\section{Cummings 1994}

Cummings L, Mega M, Gray K, Rosenberg-Thompson S, Carsusi DA, Gornbein J. The Neuropsychiatric Inventory: comprehensive assessment of psychopathology in dementia. Neurology 1994;44(12):2308-14.

\section{Cummings 1998}

Cummings JL. Neuropsychiatric Inventory update. Los Angeles: Reed Neurological Research Center, 1998.

\section{Cummins 2005}

Cummins RA, Lau ALD. Personal Wellbeing Index - Intellecual Disability (Chinese). Manual, 3rd edn, 2005. School of Psychology, Deakin University and Hong Kong: Department of Rehabilitation Sciences, The Hong Kong Polytechnic University: Melbourne,. www.deakin.edu.au/research/acqol/instruments/ wellbeing-index/pwi-sc-chinese-cantonese.pdf (accessed 16th December 2014). 


\section{Deeks 2011}

Deeks JJ, Higgins JPT, Altman DG (editors). Chapter 9: Analysing data and undertaking meta-analyses. In: Higgins JPT, Green $S$ (editors). Cochrane Handbook for SystematicReviews of Interventions Version 5.1.0 [updated March 2011]. The Cochrane Collaboration, 2011. Available from www.cochranehandbook.org. The Cochrane Collaboration.

\section{Department of Health 2008}

Department of Health. Transforming the Quality of Dementia Care: Consultation on a National Dementia Strategy. London: The Stationery Office, 2008.

\section{Dieterich 2010}

Dieterich M, Irving CB, Park B, Marshall M. Intensive case management for severe mental illness. Cochrane Database of Systematic Reviews 2010, Issue 10. [DOI: 10.1002/14651858.CD007906.pub2]

\section{Diwan 2001a}

Diwan S, Ivy C, Merino D, Brower T. Assessing need for intensive case management in long-term care. The Gerontologist 2001;41(5):680-6.

\section{Diwan 2001b}

Diwan S, Phillips V. Agitation and dementia-related problem behaviours and case management in long-term care. International Psychogeriatrics 2001;13(1):5-21.

\section{Eagar 2007}

Eagar K, Owen A, Williams K, Westera A, Marosszeky N, England R, et al. Effective Caring: A Synthesis of the International Evidence on Carer Needs and Interventions. Sydney: Centre for Health Service Development, University of Wollongong, 2007.

\section{Egger 1997}

Egger M, Davey-Smith G, Schneider M, Minder CSO. Bias in meta-analysis detected by a simple, graphical test. $B M J$ 1997;13(7109):629.

\section{EuroQol 1990}

Williams, A (The EuroQuol Group). EuroQol - a new facility for the measurement of health-related quality of life. Health Policy 1990;16(3):199-208. [PUBMED: 10109801]

\section{Ferri 2005}

Ferri C, Prince M, Brayne C, Brodaty H, Fratiglioni L, Ganguli M, et al (Alzheimer's Disease International). Global prevalence of dementia: a Delphi consensus study. Lancet 2005;366(9503):2112-7.

\section{Fillenbaum 1999}

Fillenbaum G, Chandra V, Ganguli M. Development of an activities of daily living scale to screen for dementia in an illiterate rural older population in India. Age and Ageing 1999;28(2):161-8.

\section{Folstein 1975}

Folstein MF, Folstein SE, McHughPR. "Mini Mental State". A practical method for grading the cognitive state of patients for the clinician. Journal of Psychiatric Research 1975;12(3):189-98.

\section{Fratiglioni 2001}

Fratiglioni L, Rocca W. Epidemiology of dementia. In: Boller F, Grafman J editor(s). Handbook of Neuropsychology. Amsterdam: Elsevier Science, 2001.

\section{French Ministry of Health 2008}

Ministry of Health. French National Plan for "Alzheimer and related diseases" 2008 - 2012. www.plan-alzheimer.gouv.fr/ IMG/pdf/Plan_Alzheimer_2008-2012_uk.pdf (accessed 16th December 2014).

\section{Galasko 1997}

Galasko C, Bennett D, Sano M, Ernesto C, Thomas R, Grundman M, et al. An inventory to assess activities of daily living for clinical trials in Alzheimer's disease. The Alzheimer Disease Cooperative Study. Alzheimer Disease and Associated Disorders 1997;11(suppl 2):S33-9.

\section{Gaugler 2005}

Gaugler JE, Kane RL, Kane RA, Newcomer R. Early communitybased service utilization and its effects on institutionalization in dementia caregiving. The Gerontologist 2005;45(2):177-85.

\section{Goldberg 1979}

Goldberg DP, Hillier VF. A scaled version of the General Health Questionnaire. Psychological Medicine 1979;9(1):139-45.

\section{Goldberg 1997}

Goldberg DP, Gater R, Sartorius N, Ustun TB, Piccinelli M, Gureje O, Rutter C. The validity of two versions of the GHQ in the WHO study of mental illness in general health care. Psychol Med 1997;27(2):191-7.

\section{Guyatt 2008}

Guyatt GH, Oxman AD, Vist GE, Kunz R, Falck-Ytter Y, AlonsoCoello $P$, et al. GRADE: an emerging consensus on rating quality of evidence and strength of recommendations. BMJ (Clinical research ed) 2008;336(7650):924-6.

\section{Hesse 2014}

Hesse M, Vanderplasschen W, Rapp RC, Broekaert E, Fridell M. Case management for persons with substance use disorders. Cochrane Database of Systematic Reviews 2014, Issue 4. [DOI: 10.1002/14651858.CD006265.pub2]

\section{Higgins 2003}

Higgins JPT, Thompson SG, Deeks JJ, Altman DG. Measuring inconsistency in meta-analyses. BMJ 2003;327(7414):557-60.

\section{Higgins 2011}

Higgins JPT, Green S (editors). Cochrane Handbook for Systematic Reviews of Intervention Version 5.1.0 (updated March 2011). The Cochrane Collaboration, 2011. Available from www.cochrane-handbook.org. 


\section{Hofman 1991}

Hofman A, Rocca WA, Brayne C, Breteler MM, Clarke M, Cooper B, et al. The prevalence of dementia in Europe: a collaborative study of 1980-1990 findings. International Journal of Epidemiology 1991;20(3):736-48.

\section{Hofmarcher 2007}

Hofmarcher M, Oxley H, Rusticelli E. Improved Health System Performance Through Better Care Coordination. www.oecd.org/ els/health-systems/39791610.pdf (2007) (accessed 16th December 2014). [DOI: 10.1787/246446201766]

\section{Hughes 1982}

Hughes CP, Berg L, Danziger WL, Coben LA, Martin RL. A new clinical scale for the staging of dementia. British Journal of Psychiatry 1982;140:556-5572.

\section{Hutt 2004}

Hutt R, Rosen R, McCauley J. Case managing Long-term Conditions. What Impact Does it Have in the Treatment of Older People?. London: King's Fund, 2004.

\section{Ikegami 2002}

Ikegami N, Campbell JC. Choices, policy logics and problems in the design of long-term care systems. Social Policy Administration 2002;36(7):719-34.

\section{Joint commissioning panel for mental health 2012}

Joint commissioning panel for mental health. Guidance for Commissioners of Dementia Services: volume 2, Practical Mental Health Commissioning. www.jcpmh.info/wp-content/ uploads/jcpmh-dementia-guide.pdf (accessed 16th December 2014).

\section{Judge 2011}

Judge KS, Bass DM, Snow AL, Wilson NL, Morgan R, Looman WJ, et al. Partners in Dementia Care: a care coordination intervention for lidividuals with dementia and their family caregivers. The Gerontologist 2011;51(2):261-72. [DOI: 10.1093/ geront/gnq097]

\section{Kaufer 1998}

Kaufer DI, Cummings JL, Christine D, Bray T, Castellon S, Masterman D, et al. Assessing the impact of neuropsychiatric symptoms in Alzheimer's disease: the Neuropsychiatric Inventory Caregive Distress Scale. Journal of the American Geriatrics Society 1998;46(2):210-5.

\section{Kaufer 2000}

Kaufer DI, Cummings JL, Ketchl P, Smith V, MacMillan A, Shelley T, et.al. Validation of the NPI-Q, a brief clinical form of the Neuropsychiatric Inventory. Journal of Neuropsychiatry \& Clinical NEurosciences, 2000;12:233-239.

\section{Kemper 1987}

Kemper P, Applebaum R, Harrigan M. Community care demonstrations: what have we learned?. Health Care Financing Review 1987;8(4):87-100.

\section{Kind 1996}

Kind P. The EuroQol instrument: an index of health related quality of life.. In: Spiker B editor(s). Quality of Life and Pharmacoeconomics in Clinical Trials.. Philadelphia: LippincottRaven, 1996:191-201.

\section{Knapp 2014}

Knapp M, Comas-Herrera A, Wittenberg R, Hu B, King D, Rehill A, et al. Scenarios of dementia care: What are the impacts on cost and quality of life?. London: Personal Social Services Research Unit, London School of Economics and Political Science, 2014.

\section{Kohout 1993}

Kohout FJ, Berkman LF, Evans DA, Cornoni-Huntley J. Two shorter versions of the CES-D depression symptoms index. Journal of Aging and Health, 1993;5(2):179-93.

\section{Kroenke 2001}

Kroenke K, Spitzer RL, Williams JB. The PHQ-9: validity of a brief depression severity measure. Journal of General Internal Medicine 2001;16(9):606-13.

\section{Lau 2005}

Lau ALD, Cummins RA, McPherson W. An investigation into the cross cultural equivalence of the Personal Wellbeing Index. Social Indicators Research 2005;72(3):403-30.

\section{Lau 2006}

Lau ALD, Cummins RA, Lam PKW, et. al. A modified version of the Personal Wellbeing Index for measuring subjective wellbeing of people with cognitive impairment. 7th Conference of the International Society for Quality of Life Studies, Grahamstown, South Africa, July 2006.

\section{Leung 1997}

Leung KF, Tay M, Cheng SSW, Lin F. The Hong Kong Chinese Version World Health Organization Quality of Life Measure Abbreviated Version, QHO1OL-BREF (HK). Hong Kong: Hong Kong Hospital Authority, 1997.

\section{Leung 2001}

Leung KF, Lam LC, Chiu HF, Cummings JL, Chen QL. Validation study of the Chinese version of the neuropsychiatric inventory (CNPI). International Journal of Geriatric Psychiatry 2001;16(8):789-93.

\section{Lin 2003}

Lin YC, Dai YT, Hwang SL. The effect of reminiscence on the elderly population: a systematic review. Public Health Nursing 2003;4:297-306

\section{Livingston 2005}

Livingston G, Johnston K, Katona C, Paton J, Lyketsos CG, Old Age Task Force of the World Federation of Biological Psychiatry. Systematic review of psychological approaches to the management of neuropsychiatric symptoms of dementia. American Journal of Psychiatry 2005;162(11):1996-2021.

\section{Lobo 2000}

Lobo A, Launer LJ, Fratiglioni L, Andersen K, Di Carlo A, Breteler MM, et al. Prevalence of dementia and major subtypes 
in Europe: A collaborative study of population-based cohorts. Neurology 2000;54(11 Suppl 5):S4-9.

\section{Luengo-Fernandez 2010}

Luengo-Fernandez R, Leal J, Gray A. Dementia 2010. The Prevalence, Economic Cost and Research Funding of Dementia Compared With Other Major Diseases. Cambridge, Alzheimer's Research Trust: Health Economics Research Centre, University of Oxford for the Alzheimer's Research Trust., 2010.

\section{Mahoney 1965}

Mahoney FI, Barthel DW. Functional evaluation: the Barthel Index. Maryland State Medical Journal, 1965;14:61-5.

\section{Marshall 1997}

Marshall M, Gray A, Lockwood A, Green R. Case management for people with severe mental disorders. Cochrane Database of Systematic Reviews 2011, Issue 4. [DOI: 10.1002/14651858.CD000050.pub2]

\section{McGrew 1994}

McGrew JH, Bond GR, Dietzen L, Salyers M. Measuring the fidelity of implementation of a mental health program model. Journal of Consulting and Clinical Psychology 1994;62(4):670-8.

\section{McHorney 1993}

McHorney CA, Ware JE Jr, Raczek AE. The MOS 36-item ShortForm Health Survey (SF-36):II Psychometric and clinical tests of validity in measuring physical and mental health constructs. Medical Care 1993;31(3):247-63.

\section{Moriarty 1999}

Moriarty JM. Use of community and long-term care by people with dementia in the UK: a review of some issues in service provision and carer and user preferences. Aging and Mental Health 1999;3(4):311-19.

\section{Murman 2005}

Murman DL, Colenda CC. The economic impact of neuropsychiatric symptoms in Alzheimer's disease: can drugs ease the burden?. Pharmacoeconomics 2005;23(3):227-42.

\section{Nelson 2002}

Nelson T, Livingston G, Knapp M, Manela M, Kitchen G, Katona C. Slicing the health service cake: the Islington study. Age and Ageing 2002;31(6):445-40.

\section{Neumann 2000}

Neumann PJ, Sandberg EA, Araki SS, Kuntz KM, Feeny D, Weinstein MC. A comparison of HU12 and HU13 utility scores in Alzheimer's disease. Medical Decision Making 2000;20(4):413-22. [PUBMED: 11059474]

\section{NICE 2006}

National Institute for Health and Clinical Excellence and Social Care Institute for Excellence. Dementia: Supporting People with Dementia and Their Carers in Health and Social Care. www.nice.org.uk/guidance/cg42 (accessed 16th December 2014).

\section{NICE 2013}

National Institute for Health and Care Excellence. Support for Commissioning Dementia Care. www.nice.org.uk/guidance/ cmg48 (accessed April 2013).

\section{Parker 2008}

Parker D, Mills S, Abbey J. Effectiveness of interventions that assist caregivers to support people with dementia living in the community: a systematic review. International Journal of Evidence-Based Healthcare 2008;6(2):137-72.

\section{Pimouguet 2010}

Pimouguet C, Lavaud T, Dartigues JF, Helmer C. Dementia case management effectiveness on health care costs and resource utilization: a systematic review of randomized controlled trials. Journal of Nutrition, Health and Aging 2010;14(8):669-76.

\section{Pot 1995}

Pot AM, Van Dyck R, Deeg DJ. Perceived stress caused by informal caregiving. Construction of a scale. Tijdschrift voor Gerontologie en Geriatrie 1995;26(5):214-9.

\section{Radloff 1977}

Radloff LS. The CES-D scale: a self-report depression scale for research in the general population. Applied Psychological Measurement 1977;1:385-401.

\section{Radloff 1986}

Radloff L, Teri L. Use of the Center for Epidemiological StudiesDepression Scale with older adults. In: Brink TL editor(s). Clinical Gerontology: A Guide to Assessment and Intervention, Binghamton, NY: Haworth Press, 1986.

\section{Reilly 2010}

Reilly S, Hughes J, Challis D. Nurse case management for long term conditions: a review of implementation. Ageing and Society 2010;30(1):125-55.

\section{Rentz 1995}

Rentz CA. Reminiscence: a supportive intervention for the person with Alzheimer's Disease. Journal of Psychosocial Nursing 1995;33:15-20.

\section{Reuben 2006}

Reuben D. Meeting the needs of disabled older persons: can the fragments be pieced together?. Journals of Gerontology. Series A: Biological cciences and medical sciences 2006;61(4):365-6.

\section{Royal Commission 1999}

Royal Commission on the Funding of Long Term Care. With Respect to Old Age: Long Term Care? Rights and responsibilities. London: The Stationery Office, 1999.

\section{Sarason 1987}

Sarason IG, Sarason BR, Shearin EN, Pierce GR. A brief measure of social support: practical and theoretical implications. Journal of Social and Personal Relationships, 1987;4:497-510.

\section{Schoenmakers 2008}

Schoenmakers B, Buntinx F, Devroey D, Van Casteren V, DeLepeleire J. The process of definitive institutionalization 
of community dwelling demented vs non demented elderly: data obtained from a network of sentinel general practitioners. International Journal of Geriatric Psychiatry 2009;24(5):523-31. [DOI: 10.1002/gps.2147]

\section{Shelton 2001}

Shelton P, Schraeder C, Dworak D, Fraser C, Sager M. Caregivers' utilization of health services: results from the Medicare Alzheimer's Disease Demonstration, Illinois site. Journal of the American Geriatrics Society 2001;49(12):1600-5.

\section{Sherbourne 1991}

Sherbourne CD, Stewart AL. The MOS social support survey. Social Science and Medicine, 1991;32(6):705-14. [PUBMED: 2035047]

\section{Somme 2012}

Somme D, Trouve H, Dramé M, Gagnon D, Couturier Y, Saint-Jean O. Analysis of case management programs for patients with dementia: a systematic review. Alzheimers \& Dementia 2012;8(5):426-36. [DOI: http://dx.doi.org/10.1016/ j.jalz.2011.06.004]

\section{Spijker 2008}

Spijker A, Vernooij-Dassen M, Vasse E, Adang E, Wollersheim H, Grol R, et al. Effectiveness of non-pharmacological interventions in delaying the institutionalization of patients with dementia: a meta-analysis. Journal of the American Geriatrics Society 2008;56(6):1116-28.

\section{Sterne 2011}

Sterne JA, Sutton AJ, loannidis JP, Terrin N, Jones DR, Lau J, et al. Recommendations for examining and interpreting funnel plot asymmetry in meta-analyses of randomised controlled trials. BMJ 2011;343:d4002. [DOI: 10.1136/bmj.d4002.]

\section{Stewart 1988}

Stewart AL, Hays RD, Ware JE Jr. The MOS short-form general health survey. Reliability and validity in a patient population. Medical Care 1988;26(7):724-35.

\section{Teri 1992}

Teri L, Truax P, Logsdon R, Uomoto J, Zarit S, Vitaliano PP. Assessment of behavioral problems in dementia: the revised memory and behavior problems checklist (RMBPC). Psychology and Aging 1992;7(4):622-31.

\section{Thompson 2007}

Thompson CA, Spilsbury K, Hall J, Birks Y, Barnes C, Adamson, J. Systematic review of information and support interventions for caregivers of people with dementia. BMC Geriatrics 2007;7:18.

\section{Torrance 1996}

Torrance GW, Feeny DH, Furlong WJ, Barr RD, Zhang Y, Wang Q. Multiattribute utility function for a comprehensive health status classification system. Health Utilities Index Mark 2. Medical Care 1996;34(7):702-22.

\section{Tsutsui 2007}

Tsutsui T, Muramatsu N. Japan's universal long-term care system reform of 2005: containing costs and realising a vision. Journal of the American Geriatrics Society 2007;55(9):1458-63.

\section{Ukoumunne 1999}

Ukoumunne OC, Gulliford MC, Chinn S, Sterne JAC, Burney PGJ. Methods for evaluating area-wide and organisation-based interventions in health and health care: a systematic review. Health Technology Assessment 1999;3(5):3-92.

\section{Van Citters 2004}

Van Citters AD, Bartels S. A systematic review of the effectiveness of community-based mental health outreach services for older adults. Psychiatric Services 2004;55(11):1237-49.

\section{WHO 2012}

World Health Organization. Dementia: A public health priority. whqlibdoc.who.int/publications/2012/9789241564458_eng.pdf 2012 (accessed 16th December 2014).

\section{Wimo 2007}

Wimo A, Norlund A. Commentary on "Health economics and the value of therapy in Alzheimer's disease". Cost-effectiveness studies. Alzheimers \& Dementia 2007;3(3):157-61.

\section{Yaffe 2002}

Yaffe K, Fox P, Newcomer R, Sands L, Lindquist K, Dane K, et al. Patient and caregiver characteristics and nursing home placement in patients with dementia. JAMA 2002;287(16):2090-7.

\section{Yesavage 1983a}

Yesavage J, Brink T. Development and validation of a geriatric depression screening scale: A preliminary report. Journal of Psychiatric Research 1983;17(1):34-49.

\section{Yesavage 1983b}

Yesavage JT, Brink T, Rose TL, Aday MB. The Geriatric Depression Rating Scale: comparison with other self-report and psychiatric rating scales. In: Crook T, Ferris S, Bartus R editor(s). Assessment in Geriatric Psychopharmacology. New Canaan, CT: Mark Powley and Associates, 1983:153-167.

\section{Zarit 1980}

Zarit SH, Reever KE, Bach-Peterson J. Relatives of the impaired elderly: correlates of feelings of burden. The Gerontologist 1980;20(6):649-55.

\section{Zarit 1983a}

Zarit S, Orr N, Zarit J. Working with Families of Dementia Victims: A Treatment Manual. Washington DC: US Department of Health and Human Services, Officer of Human Developmental Services, 1983.

\section{Zarit 1983b}

Zarit SH, Zarit JM. Cognitive impairment. In: Lewinsohn PM, Teri L editor(s). Clinical Geropsychology. Elmsford, NY: Pergamon Press, 1983:38-81. 


\section{Zarit 1986}

Zarit S, Todd P, Zarit J. Subjective burden of husbands and wives as caregivers: a longitudinal study. The Gerontologist, 1986;26(3):260-6.

\section{Zarit 1987}

Zarit SH, Anthony CR, Boutselis M. Interventions with care givers of dementia patients: comparison of two approaches. Psychology and Aging, 1987;2(3):225-32.

\section{CHARACTERISTICS OF STUDIES}

Characteristics of included studies [ordered by study ID]

Bass - Ohio

Methods RCT

Follow-up: 12 months

Analysis: intention-to-treat.

Participants

\section{References to other published versions of this review}

\section{Reilly 2010}

Reilly S, Miranda-Castillo C, Sandhu S, Hoe J, Challis D, Orrell M. Case/care management approaches to home support for people with dementia. Cochrane Database of Systematic Reviews 2010, Issue Art. No.: CD008345. [DOI: 10.1002/14651858.CD008345]

* Indicates the major publication for the study

Setting: Health care co-ordinated with the Alzheimer's Association, Cleveland, Ohio, US.

Inclusion criteria: Selected dementia ICD-9 codes in the medical record followed by confirmation from by primary care physician; aged > 55 years; living in the community; living in the Cleveland Area Alzheimer's Association service area

1. Family level (consists of participants, carers, or dyads [both carers and participants]) $n=210: 127$ intervention; 83 control.

2. Interviewed carer subsample $n=183: 112$ intervention; 71 control.

3. Interviewed participant (PWD) sub-sample $n=121: 69$ intervention; 52 control.

4. In 94 families both the carer and PWD (dyad) were interviewed.

Age: PWD mean $=76.4($ SD 8.58) carer mean $=63.9($ SD 13.92)

Gender: PWD 41\% men; carer 28\% men

Diagnostic criteria: Selected dementia ICD-9 codes in the medical record followed by confirmation by primary care physician.

Diagnosis (medical records: Age-related cognitive decline 49.0\%; Dementia/amnesiac disorder 22.4\%; Alzheimer's Disease 13.3\%; Dementia 9.5\%; Dementia of the Alzheimer's Type 3.8\%; Vascular dementia, uncomplicated $1.4 \%)$.

Blessed score - 9.77 (SD 9.34); Intervention - 10.98 (SD 9.58); Control - 8.18 (SD 8.89)

Number of co-morbidities 2.7(SD 1.96);

\section{Intervention group:}

$\mathrm{n}=94$

Telephone-based care consultation delivered within a partnership between a managed care health system and an Alzheimer's Association.

Duration: 12 months

Intensity: follow-up biweekly, then reduced to monthly, then 3-monthly unless more visits needed.

2 part-time care consultants and 1 part-time care consultant assistant/volunteer per 100 families. 
Skill mix: Care consultation was delivered by 1 of the 3 Association staff members, 2 of whom are master's-prepared licensed social workers.

Case management tasks: assessment, care planning, implementation and monitoring of care plan.

Components: participant information and education, participant advocacy, provision of emotional support, carer education. A standardised protocol was followed by care consultants.

Breadth of services spanned: Case manager co-ordinates/liaises with other outside services.

\section{Control group:}

$\mathrm{n}=63$

Usual managed care services. Use of Association services other than care consultation by both the intervention and control groups is incorporated into the analysis.

(seeTable 2 for further details)

\begin{tabular}{|c|c|}
\hline \multirow[t]{17}{*}{ Outcomes } & Carer strain and depression \\
\hline & Carer satisfaction with types of services, quality of services. \\
\hline & Use of services: \\
\hline & Hospital admissions (number of nights) \\
\hline & Physician visits \\
\hline & Emergency department visits \\
\hline & Unable to use: \\
\hline & $\begin{array}{l}\text { Participant's Depression (Centre for Epidemiological studies Depression, CES-D modified); means and } \\
\text { SDs not reported at T2 }\end{array}$ \\
\hline & Cognition (Blessed test score) numbers in groups not reported clearly \\
\hline & Participant satisfaction with Kaiser services; means and SDs not reported at T2 \\
\hline & Carergiver satisfaction with information not reported fully for control group \\
\hline & Use of services: \\
\hline & $\begin{array}{l}\text { Case management visit (mean, SD of the proportion of participants who had case management visits } \\
\text { (yes }=1 \text { ) were presented) }\end{array}$ \\
\hline & rather than the mean number of visits). \\
\hline & $\begin{array}{l}\text { Direct care community services (includes personal care services, home health service, nursing home } \\
\text { care and respite service) (composite score } 0 \text { - } 4 \text {; we did not extract composite scores, preferring number } \\
\text { in receipt of services) }\end{array}$ \\
\hline & $\begin{array}{l}\text { Non-association information and support services (includes finding and arranging for services, legal as- } \\
\text { sistance, health information and emotional support or counselling) (composite score } 0 \text { - 4; we did not } \\
\text { extract composite scores, preferring number in receipt of services) }\end{array}$ \\
\hline & Attrition (data were not reported by group) \\
\hline
\end{tabular}

Notes Lost to follow-up: 14\% (25/182) - follow-up rates in intervention and control groups not reported separately.

\section{Risk of bias}


Bass - Ohio (Continued)

Random sequence genera- High risk tion (selection bias)

Participants and family carers were assigned to the intervention or control group after completion of baseline telephone interviews (i.e. initial data collection) by members of the research team. The research team was totally separate from the persons providing the intervention, as well as health care providers who identified eligible patients. Group assignment was ongoing over a 2-year period of recruitment as participants consented to enrol in the study. As names of consenting participants were received by the research team, the consent process was completed, followed by baseline telephone interviews by the research team. After baseline interviews, 2 participants were assigned to the intervention group followed by one participant to the control group. Each participant consisted of a patient and his/her family carer (dyad), except for a small number of patients who did not have a family carer.

Allocation concealment High risk
(selection bias)

Although the health care organisation referring participants did not know the sequence of assignment and were not notified of which group individuals were assigned to, it is possible that they may have worked this out since it was so regular.This information was only known to the research team, with assignment based solely on the pre-established sequence ( 2 intervention-group participants to one control-group participant).

\begin{tabular}{|c|c|c|}
\hline $\begin{array}{l}\text { Blinding (performance } \\
\text { bias and detection bias) } \\
\text { Participants }\end{array}$ & High risk & $\begin{array}{l}\text { Participants could have volunteered to their physicians or nurses whether } \\
\text { they were assigned to the intervention or control group over the course of the } \\
\text { study. }\end{array}$ \\
\hline
\end{tabular}

\begin{tabular}{|c|c|c|}
\hline $\begin{array}{l}\text { Blinding (performance } \\
\text { bias and detection bias) } \\
\text { Personnel }\end{array}$ & High risk & $\begin{array}{l}\text { Participants could have volunteered to their physicians or nurses whether } \\
\text { they were assigned to the intervention or control group over the course of the } \\
\text { study. If participants or family carers informed physicians/nurses of their par- } \\
\text { ticipation, it was not known by the research team or individuals delivering the } \\
\text { telephone intervention. }\end{array}$ \\
\hline
\end{tabular}

\begin{tabular}{|c|c|c|}
\hline $\begin{array}{l}\text { Blinding (performance } \\
\text { bias and detection bias) } \\
\text { Outcome assessors }\end{array}$ & Low risk & $\begin{array}{l}\text { Data collectors were blinded to whether participants were assigned to the in- } \\
\text { tervention or control group. }\end{array}$ \\
\hline
\end{tabular}

Blinding (performance $\quad$ Low risk None
bias and detection bias)
Other

\begin{tabular}{lll}
\hline $\begin{array}{l}\text { Incomplete outcome data } \\
\text { (attrition bias) } \\
\text { All outcomes }\end{array}$ & High risk & $\begin{array}{l}\text { Some missing follow-up data for psychosocial outcomes, numbers allocated } \\
\text { to the groups and numbers lost to follow-up not clearly reported }\end{array}$ \\
\hline $\begin{array}{l}\text { Selective reporting (re- } \\
\text { porting bias) }\end{array}$ & High risk & Selective outcome reporting may be present \\
\hline Other bias & Unclear risk & Baseline assessment: no test to assess differences between groups is reported \\
\hline
\end{tabular}

\begin{tabular}{ll} 
Callahan - Indianapolis & \\
\hline Methods & Cluster-RCT \\
& Follow-up: 6,12 and 18 months \\
& Analysis: Completers analysis was given at each time point \\
\hline Participants & $\begin{array}{l}\text { Setting: Two large primary care practices within } 2 \text { US university-affiliated healthcare systems from Jan- } \\
\text { uary 2002 through August 2004. }\end{array}$ \\
\hline
\end{tabular}


Callahan - Indianapolis (Continued)

Diagnosis: Dementia (Alzheimer's Disease)

Inclusion criteria: Alzheimer's Disease according to DSM-IV

$n=153$

Age: Mean: 77.5

Gender: 87 men, 66 women

$80 \%$ of the intervention group received cholinesterase inhibitors. $55 \%$ of the augmented usual care group also received cholinesterase inhibitors $(P=0.002)$.

MMSE mean (SD): Intervention group 18.6 (5.9); control group 17.5 (5.2)

Chronic disease score, mean (SD) Intervention 8.0 (3.9) Control 7.6 (4.0)

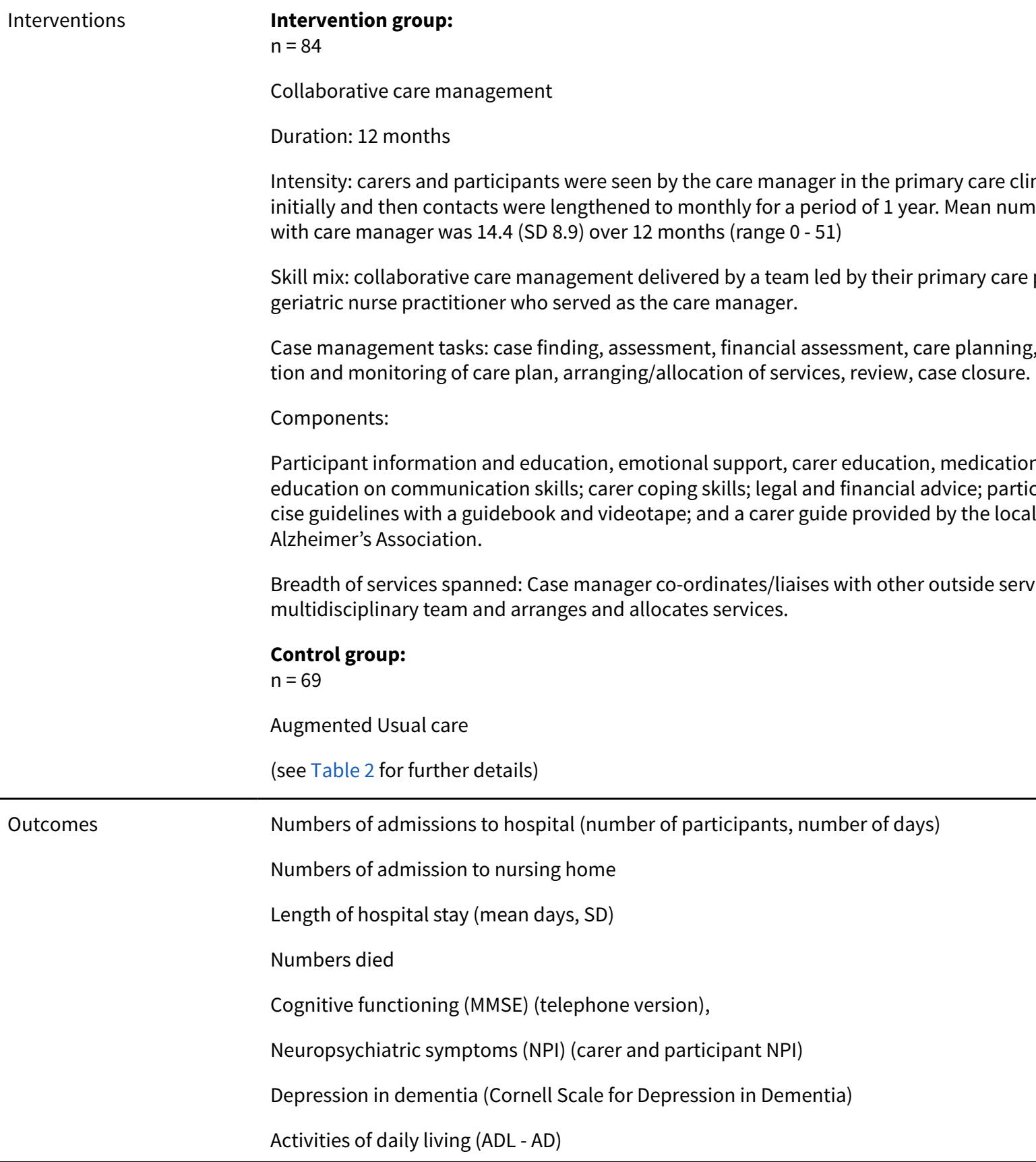
geriatric nurse practitioner who served as the care manager. tion and monitoring of care plan, arranging/allocation of services, review, case closure.

Components: Alzheimer's Association. multidisciplinary team and arranges and allocates services.

\section{Control group:}

$\mathrm{n}=69$

Augmented Usual care

(see Table 2 for further details)

Outcomes

\author{
Numbers of admissions to hospital (number of participants, number of days) \\ Numbers of admission to nursing home \\ Length of hospital stay (mean days, SD) \\ Numbers died \\ Cognitive functioning (MMSE) (telephone version), \\ Neuropsychiatric symptoms (NPI) (carer and participant NPI) \\ Depression in dementia (Cornell Scale for Depression in Dementia) \\ Activities of daily living (ADL - AD)
}

Skill mix: collaborative care management delivered by a team led by their primary care physician and a

Case management tasks: case finding, assessment, financial assessment, care planning, implementa-

Participant information and education, emotional support, carer education, medication management, education on communication skills; carer coping skills; legal and financial advice; participant exercise guidelines with a guidebook and videotape; and a carer guide provided by the local chapter of the

Breadth of services spanned: Case manager co-ordinates/liaises with other outside services, within 
Callahan - Indianapolis (Continued)

\author{
Carer mood (Patient Health Questionnaire-9) \\ Carer satisfaction : Primary care rated as very good or excellent (12/18 months) \\ Attrition \\ Cholinesterase inhibitor use \\ Health care use: cumulative physician or nurse visits (mean, SD) \\ Unable to use: \\ None
}

Notes Lost to follow-up: 25\% (39/153)

Almost 3 years of recruitment. Did not reach expected sample size $n=240$ - limits the power to detect smaller differences in cognition, activities of daily living, or nursing home placement.

Supported by grant R01 HS10884 from the Agency for Healthcare Research and Quality.

\title{
Risk of bias
}

\begin{tabular}{lll}
\hline Bias & Authors' judgement & Support for judgement \\
\hline $\begin{array}{ll}\text { Random sequence genera- } \\
\text { tion (selection bias) }\end{array}$ & Low risk & $\begin{array}{l}\text { Physicians were randomised in blocks of } 2 \text { stratified by teaching status (faculty } \\
\text { or resident) and the clinic site. A randomisation number table was used to as- } \\
\text { sign the first physician; an odd number meant physician was allocated to usual } \\
\text { care and even to intervention group. The second physician was then assigned } \\
\text { the opposite status. The process was repeated until all physicians were ran- } \\
\text { domised. }\end{array}$ \\
\end{tabular}

\begin{tabular}{lll}
\hline $\begin{array}{l}\text { Allocation concealment } \\
\text { (selection bias) }\end{array}$ & Low risk & $\begin{array}{l}\text { Allocation was adequately concealed up until participant completed baseline } \\
\text { assessment. Physicians were not informed about their randomisation status } \\
\text { and control physicians did not have access to the intervention. }\end{array}$ \\
\hline
\end{tabular}

\begin{tabular}{|c|c|c|}
\hline $\begin{array}{l}\text { Blinding (performance } \\
\text { bias and detection bias) } \\
\text { Participants }\end{array}$ & Unclear risk & $\begin{array}{l}\text { Participants and carers were blinded to the randomisation status of the physi- } \\
\text { cian up until counselling session, informed consent and baseline assessment } \\
\text { were completed. Then they were aware of receiving the intervention. }\end{array}$ \\
\hline
\end{tabular}

\begin{tabular}{|c|c|c|}
\hline $\begin{array}{l}\text { Blinding (performance } \\
\text { bias and detection bias) } \\
\text { Personnel }\end{array}$ & Unclear risk & $\begin{array}{l}\text { Diagnostic team and geriatric nurse practitioner were blinded to the randomi- } \\
\text { sation status of the physician up until counselling session, informed consent } \\
\text { and baseline assessment were completed. Then they were aware of perform- } \\
\text { ing the intervention. }\end{array}$ \\
\hline
\end{tabular}

\begin{tabular}{ll}
\hline $\begin{array}{l}\text { Blinding (performance } \\
\text { bias and detection bias) }\end{array} \quad$ Low risk & $\begin{array}{l}\text { Telephone interviewers were blinded to participants' randomisation status, } \\
\text { and they were not allowed to query respondents about their interventions. }\end{array}$
\end{tabular}

Outcome assessors

\begin{tabular}{|c|c|c|}
\hline $\begin{array}{l}\text { Blinding (performance } \\
\text { bias and detection bias) }\end{array}$ & Unclear risk & $\begin{array}{l}\text { Physician was blinded to the randomisation status, however, could have been } \\
\text { informed by the above participants }\end{array}$ \\
\hline
\end{tabular}

Other

\begin{tabular}{lll}
\hline $\begin{array}{l}\text { Incomplete outcome data } \\
\text { (attrition bias) } \\
\text { All outcomes }\end{array}$ & Low risk & $\begin{array}{l}\text { Missing outcome data balanced in numbers across intervention and control } \\
\text { groups with similar reasons for missing data across groups. }\end{array}$ \\
\hline $\begin{array}{l}\text { Selective reporting (re- } \\
\text { porting bias) }\end{array}$ & High risk & $\begin{array}{l}\text { Data were not fully reported in the paper, although the authors did send us } \\
\text { data: standard deviations for F3 (18 mo) cumulative physician/nurse visits, F2 } \\
(12 \mathrm{mo}) \text { and F3 (18 mo) cumulative hospitalisation rates, F2 (12 mo) and F3 (18 } \\
\text { mo) hospital days. }\end{array}$ \\
\hline
\end{tabular}


Callahan - Indianapolis (Continued)

Analysis not consistent with randomisation. No ICC was reported. Some selective reporting may be present.

Other bias Unclear risk

Some baseline differences between groups: Black: 40/69 (58\%) Augmented usual care group ; $35 / 84(42 \%)$ Intervention $(P=0.05)$. Women 66/69 $(96 \%)$ Augmented usual care group ; $70 / 84(83 \%)$ Intervention ( $P=0.02)$. However, these differences were adjusted for in subsequent analyses.

Chien - Hong Kong 2001

\begin{tabular}{ll}
\hline Methods & RCT \\
& Follow-up: 1 week, 12 and 18 months \\
& Analysis: intention-to-treat
\end{tabular}

\section{Participants}

Setting: 2 largest dementia resource centres in Hong Kong

Diagnosis: Alzheimer's Disease

Inclusion criteria: family members caring for a relative with dementia at home. Eligibity criteria:

i) aged at least 18 years and could speak and read Chinese; ii) lived with a relative who was diagnosed as having the Alzheimer's type of dementia (mild or moderate illness stage) according to the criteria of the DSM-IV, and they provided care for at least 4 hours per day; and iii) their relative suffered no comorbidity of other mental illness during the recruitment period

$\mathrm{n}=92$ dyads (participant and carer)

Carers' age: mean 45.1 (8.9) years

Participants' age: mean 67.8 (6.8) years

Gender: 52 men, 40 women

MMSE mean (SD) intervention: 17.5 (4.7); control 17.3 (3.9)

Duration of illness at recruitment: 2.1 years

$60 \%$ of participants' duration of illness less than 2 years.

$52 \%$ received cholinesterase inhibitors or $\mathrm{N}$-methyl-D-aspartate antagonists (e.g. donepezil and memantine)

\section{Intervention group:}

Each of the family participants was assigned one case manager, who conducted weekly home visits, family health and educational needs assessment using the Educational Needs Questionnaire (Chien 2005), and education about dementia care. In collaboration with the carers, the case managers prioritised the problems and formulated an individualised education and support programme for effective dementia care for each family. This preparatory phase lasted about 1 month. All family care sessions consisted of education, sharing and discussion, psychological support and problem-solving, in accordance with the common elements found effective in previous studies for carers. A protocol was specifically designed for this study, based on evidence from other family intervention studies in dementia.

Duration: 6 months (After 1 month's needs assessment and preparation, the DFCP was conducted for individual families, lasting about 5 months)

Intensity: 10 sessions held every other week for 2 hours. The family and the case manager met bi-weekly, for a total of 10 2-hour sessions 
Chien - Hong Kong 2001 (Continued)

Skill mix: Each family was assigned 1 nurse case manager who worked with another nurse in the centre.

"The committee designed an information and psychological support system linking case managers and dementia care services, health professionals and referrals."

Care management Tasks: Assessment, care planning, implementation and monitoring of care plan

Components: Participant information and education; carer education; provision of emotional/therapeutic support

Breadth of services spanned: Case manager co-ordinates/liaises with other outside services, within multidisciplinary team

Control group: Routine care

The routine care group participants received the usual family services provided by the dementia resources centres.

(seeTable 2 for further details)

Outcomes

Length of institutionalisation to a residential home or hospital unit - average number of days per month over the previous 6 months.

World Health Organization Quality of Life Measure (Brief HK version) (carers);

Social Support Questionnaire (SSQ6, 6 item);

MMSE

NPI Questionnaire (NPI, 12-item) (participants' symptoms, carers distress not reported);

Family Caregiving Burden Inventory (FCBI)

Attrition

Unable to use:

Utilisation of services - Family Support Services Index (FSSI)

Rate of institutionalisation:

Average number of residential placements or hospitalisations over the previous 6 months - we did not extract, as we preferred to enter numbers admitted, or mean number of nights/days)

Notes

Lost to follow-up: $98 \%$ of families completed the study. One family in the control group (loss of contact) and 1 family in the intervention group (mortality) at 18 months assessment

\section{Risk of bias}

\begin{tabular}{lll}
\hline Bias & Authors' judgement & Support for judgement \\
\hline $\begin{array}{l}\text { Random sequence genera- } \\
\text { tion (selection bias) }\end{array}$ & Unclear risk & $\begin{array}{l}\text { Method of randomisation was not mentioned, although it was stated that fam- } \\
\text { ilies were randomly selected from client list using computer-generated ran- } \\
\text { dom number list. }\end{array}$ \\
\hline $\begin{array}{l}\text { Allocation concealment } \\
\text { (selection bias) }\end{array}$ & Unclear risk & Precise method of concealment not described. \\
\hline $\begin{array}{l}\text { Blinding (performance } \\
\text { bias and detection bias) } \\
\text { Participants }\end{array}$ & Unclear risk & Not mentioned in the paper. \\
\hline
\end{tabular}

Blinding (performance
bias and detection bias) $\quad$ Unclear risk Not mentioned in the paper.


Chien - Hong Kong 2001 (Continued)

Personnel

\section{Blinding (performance Low risk} bias and detection bias)

Outcome assessors
A research assistant, who was blind to the participant assignment, administered the pretest before randomisation (Time 1), and asked the participants again to complete the outcome measures, including carers' burden, quality of life, social support, use of family services and client symptom severity scales, for 3 post-tests at 1 week (Time 2), 12 months (Time 3) and 18 months (Time 4) following the intervention.

Blinding (performance $\quad$ Low risk
bias and detection bias)
Other

\begin{tabular}{lll}
\hline $\begin{array}{l}\text { Incomplete outcome data } \\
\text { (attrition bias) } \\
\text { All outcomes }\end{array}$ & Low risk & $\begin{array}{l}\text { Low attrition. Missing outcome data balanced in numbers across intervention } \\
\text { groups. }\end{array}$ \\
\hline $\begin{array}{l}\text { Selective reporting (re- } \\
\text { porting bias) }\end{array}$ & Low risk & No apparent signs of selective outcome reporting. \\
\hline Other bias & Unclear risk & $\begin{array}{l}\text { Even though the intervention was given to only the experimental group, the } \\
2 \text { centres provided both groups with routine dementia care. Contamination } \\
\text { within each centre may have occurred. }\end{array}$ \\
\hline
\end{tabular}

\section{Chien- Hong Kong 2008}

\begin{tabular}{ll} 
Methods & RCT. \\
& Follow-up: 6 months. \\
& Analysis: intention-to-treat. \\
\hline
\end{tabular}

\begin{tabular}{ll}
\hline Participants & Setting: 2 dementia resource centres in Hong Kong \\
& Diagnosis: Alzheimer's Disease \\
Inclusion criteria: family carers being 18 years or older and living with and caring for a relative with & Alzheimer's disease (AD). AD diagnosis based on the DSM-IV criteria \\
$\mathrm{n}=88$ dyads (participant and carer) \\
Carers' age: mean 43.6 (9.2) years \\
Participants' age: mean 67.8 (6.8) years \\
Gender: 50 men, 38 women \\
Duration of illness: mean 2.8 (1.5) years \\
$80 \%$ of participants were at an early stage of dementia \\
$55 \%$ received cholinesterase inhibitors (e.g. donepezil) or N-methyl-D-aspartate antagonists (e.g. me- \\
mantine) \\
$\begin{array}{l}63 \% \text { received a low dosage of antipsychotic medication } \\
\text { MMSE mean (SD) Intervention } 17.5 \text { (4.7); control 17.3 (3.9) }\end{array}$ \\
$\begin{array}{l}\text { Intervention group: } \\
\mathrm{n}=44\end{array}$ \\
\hline Interventions
\end{tabular}


Chien- Hong Kong 2008 (Continued)

Dementia care management programme - an educational and supportive group for carers. It consisted of 5 phases-orientation to dementia care ( 1 session), educational workshop about dementia care (3 sessions), family role and strength rebuilding (6 sessions), community support resources (1 session), and review of programme and evaluation (1 session)

Duration: 6 months.

Intensity: 12 sessions that were held every other week and lasted 2 hours each

Skill mix: Each family was assigned 1 case manager who worked with another nurse in the centre. Case managers received 32 hours of formal training by the researchers and co-ordinated all levels of family care according to the results of a structured needs assessment

Care management Tasks: Assessment, care planning, implementation and monitoring of care plan

Components: carer education

Breadth of services spanned: Case manager co-ordinates/liaises with other outside services, within multidisciplinary team

\section{Control group:}

$\mathrm{n}=44$

Standard care with 6 month educational sessions in order to blind the participants of the treatment group allocation

(seeTable 2 for further details)

Outcomes

Length of institutionalisation over past 6 months (residential placements or hospitalisations, duration days per month) at 6 and 12 months

Length of institutionalisation in a residential home or hospital unit (length of hospital stay)

Carer quality of life (World Health Organization Quality of Life Scale)

Cognitive functioning (MMSE)

Neuropsychiatric symptoms (NPI) (participants' symptoms)

Carer burden (the Chinese version of the Family Caregiving Burden Inventory)

Carer social support (6-item social support questionnaire SSQ6)

Attrition

Unable to use:

Use of services (Family support services index); we did not extract composite scores, preferring number in receipt of services

Institutionalisation over past 6 months (residential placements or hospitalisations) (numbers of times we did not extract, preferring numbers admitted) group lost to follow-up at 12 months assessment

\section{Risk of bias}

\section{Bias}

Authors' judgement Support for judgement

Random sequence genera- Unclear risk Method of randomisation was not mentioned. tion (selection bias) 
Chien- Hong Kong 2008 (Continued)

Allocation concealment Unclear risk Not mentioned in the paper.
(selection bias)

\begin{tabular}{|c|c|c|}
\hline $\begin{array}{l}\text { Blinding (performance } \\
\text { bias and detection bias) } \\
\text { Participants }\end{array}$ & Unclear risk & $\begin{array}{l}\text { Carers were given } 6 \text { monthly education sessions on dementia care in the stan- } \\
\text { dard care group (control) to conceal the intervention of interest for family car- } \\
\text { ers. SInce the intervention also included assessment, care planning, imple- } \\
\text { menting and monitoring care plans, participants may not have been blind to } \\
\text { allocation. }\end{array}$ \\
\hline
\end{tabular}

Blinding (performance Unclear risk Not mentioned in the paper.
bias and detection bias)

Personnel

\begin{tabular}{|c|c|c|}
\hline $\begin{array}{l}\text { Blinding (performance } \\
\text { bias and detection bias) } \\
\text { Outcome assessors }\end{array}$ & Low risk & $\begin{array}{l}\text { One researcher was blind to the group assignment who administered tests be- } \\
\text { fore randomisation and at } 6 \text { and } 12 \text { months. }\end{array}$ \\
\hline
\end{tabular}

\begin{tabular}{lll}
\hline $\begin{array}{l}\text { Blinding (performance } \\
\text { bias and detection bias) } \\
\text { Other }\end{array}$ & Low risk & None. \\
\hline $\begin{array}{l}\text { Incomplete outcome data } \\
\text { (attrition bias) } \\
\text { All outcomes }\end{array}$ & Unclear risk & $\begin{array}{l}\text { Number randomised not stated clearly. Attrition not reported clearly for each } \\
\text { group. }\end{array}$ \\
\hline $\begin{array}{l}\text { Selective reporting (re- } \\
\text { porting bias) }\end{array}$ & Low risk & No apparent signs of selective outcome reporting; there were no missing data. \\
\hline $\begin{array}{l}\text { Other bias } \\
\text { Unclear risk }\end{array}$ & $\begin{array}{l}\text { Even though the intervention was given to only the experimental group, the } \\
2 \text { centres provided both groups with routine dementia care. Contamination } \\
\text { within each centre may have occurred. }\end{array}$
\end{tabular}

\section{Chu - Canada}

Methods RCT

Follow-up: 3 months, 6 months, 10 months, 14 months, 18 months

Analysis: Completers analysis was given at each time point

Participants Setting: Community home care. Participants were recruited from outpatient clinics as well as referred by physicians at North Alberta, Canada

Diagnosis: Alzheimer's Disease (AD) based on the Nathional Institute of Neurological and Communitive Disorders and Stroke

Inclusion criteria for the persons with dementia: Diagnosis of early stage Alzheimer's type dementia; not at imminent risk of placement in long-term facility; living in the community, having a carer living with them or in the same city without a serious illness

Inclusion criteria for carers: principal informal carers, no serious illness and living with the person with dementia or in the city

$\mathrm{n}=75$ dyads (participant and carer)

Baseline MMSE mean (SD) intervention 22.7 (3.8) (range reported: 28 - 11); control group 22.8 ( 4.2) (range reported: 29 - 13) 
Gender: numbers not reported, although "there were equal numbers of males and females"

$65 \%$ treatment group and $81 \%$ control group lived with their primary carer

Interventions

\section{Intervention group:}

$\mathrm{n}=37$

The Early Home Care Program provided case management, occupational therapy, physical therapy, social work, nursing, respiratory therapy, in-home respite, and out-of-home respite, homemaking, personal care assistance, volunteer service and psychiatric consultation.

Duration: 18 months

Intensity: The case manager made monthly contact by phone or home visit. The frequency of contacts increased as needed.

Skill mix: Case managers ( 1 for part of the study, 2 for 1 year of study - a social worker and an occupational therapist) and professionals such as occupational therapist, nurse and social worker were involved as appropriate

Care management tasks: Care planning, implementation/management of care plan, arranging/allocating services, monitoring the implementation of the care plan

Components: participant information and education, Participant advocacy, Legal/insurance/benefits/financial assistance, Provision of emotional/therapeutic support, Counselling/therapy

Breadth of services spanned: Case manager co-ordinates/liaises with other outside services, within multidisciplinary team, arranges and allocates services and manages care network

\section{Control group:}

$\mathrm{n}=38$

Participants were given an information package on community resources. As control group members became eligible for the conventional home care programme, they were informed accordingly. Control group participants who were admitted to the conventional home care programme maintained their group status.

(seeTable 2 for further details)

\section{Outcomes}

Participant well-being (using the Depression Scale-Short Form GDS Scale) (means and SDs at 3, 6, 10, 18 months)

Cognition (MMSE) (means and SDs at 3, 6, 10, 18 months);

Carer well-being (Burden Interview and CES-D Depression Scale) (means and SDs at 6, 10, 18 months)

Number using services (case management and in home support services such as respite personal care, homemaking)

Number using services (direct care such as occupational therapy, physical therapy, social work, nursing and respiratory therapy)

Attrition

Unable to use

Length of time participants remained in the community (not reported fully - just figure 1)

Activities of daily living (Alberta Assessment and Placement Instrument AAPI) (not reported) 
Chu - Canada (Continued)

Neuropsychiatric Syptoms (Memory and Behaviour Checklist) - problem behaviours and carer reaction

(means and SDs at 3, 6, 10, 18 months) (change scores not reported)

Notes Lost to follow-up 27/75 (36\%)

\section{Risk of bias}

\begin{tabular}{lll}
\hline Bias & Authors' judgement & Support for judgement \\
\hline $\begin{array}{ll}\text { Random sequence genera- } \\
\text { tion (selection bias) }\end{array}$ & High risk & $\begin{array}{l}\text { Participants were first stratified based on the carer's gender and then kinship } \\
\text { to the participants. Then, under each kinship category, the first participant } \\
\text { is assigned to } 1 \text { group and the second participant assigned to the alternate } \\
\text { group and so on. }\end{array}$
\end{tabular}

\begin{tabular}{lll}
\hline $\begin{array}{l}\text { Allocation concealment } \\
\text { (selection bias) }\end{array}$ & High risk & No method was used to conceal the allocation sequence. \\
\hline $\begin{array}{l}\text { Blinding (performance } \\
\text { bias and detection bias) } \\
\text { Participants }\end{array}$ & High risk & No measure was used to blind study participants. \\
\hline
\end{tabular}

Blinding (performance

High risk

No measure was used to blind study personnel.

bias and detection bias)

Personnel

Blinding (performance High risk No measure was used to blind outcome assessors
bias and detection bias)
Outcome assessors

\begin{tabular}{ll}
\hline $\begin{array}{l}\text { Blinding (performance } \\
\text { bias and detection bias) }\end{array}$ & Unclear risk \\
$\begin{array}{ll}\text { Other } & \text { A possible performance bias. At the start of the study the pilot project co-ordi- } \\
& \text { nator was also the only case manager involved. Then, further research funding } \\
& \text { was made available to hire a } 2 \text { nd case manager for a 12-month period. At the } \\
\text { end of the } 12 \text { months, it was back to } 1 \text { case manager, who was the project co- } \\
\text { ordinator. }\end{array}$
\end{tabular}

\begin{tabular}{lll}
\hline $\begin{array}{l}\text { Incomplete outcome data } \\
\text { (attrition bias) } \\
\text { All outcomes }\end{array}$ & High risk & $\begin{array}{l}\text { 'As treated' analysis done (for some outcomes) with substantial departure of } \\
\text { the intervention received from that assigned at randomisation. }\end{array}$ \\
\hline $\begin{array}{l}\text { Selective reporting (re- } \\
\text { porting bias) }\end{array}$ & High risk & $\begin{array}{l}\text { Data were not fully reported in the paper, although the authors did send us } \\
\text { further data analysis. There are some data missing for total home care usage } \\
\text { outcomes (SDs for mean number of hours) and total numbers institutionalised } \\
\text { (SDs). Length of time participants remained in the community. Activities of } \\
\text { daily living (Alberta Assessment and Placement Instrument AAPI) (not report- } \\
\text { ed). AAPI was devised locally and assesses people with dementia for long-term } \\
\text { care needs - systematic assessment, not a validated tool. }\end{array}$
\end{tabular}

\begin{tabular}{ll}
\hline Other bias & Unclear risk \\
& $\begin{array}{l}\text { A significant proportion of the control group received case management. As } \\
\text { control group members became eligible for the conventional home care pro- } \\
\text { gramme, they were informed accordingly. Control group participants who } \\
\text { were admitted to the conventional home care programme maintained their } \\
\text { group status. }\end{array}$
\end{tabular}

Dias - Goa India

Methods

Single-blind RCT (waiting list control - received intervention after 6 months) 
Dias - Goa India (Continued)

Follow-up: 3 and 6 months

Analysis: Completers analysis given at each time point

Participants

Setting: Participants were recruited by contacting a self-help line or by key informants in Goa, on the west coast of India

Diagnosis: dementia by DSM-IV criteria (specific type not mentioned)

Inclusion criteria: Mild and moderate dementia according to the Clinical Dementia Rating scale (CDR). Excluded if severe co-morbid physical health conditions

$\mathrm{n}=81$

Age: mean 78.3 (8) years.

Gender: Men $(P W D)=53$, Men (carers) $=10$

Interventions

Intervention group:

$\mathrm{n}=41$

The intervention was a flexible, stepped-care model primarily aimed at improving the awareness and knowledge of carers regarding dementia, to provide emotional support to carers, to maximise their care-giving resources and to improve care-giving skills.

Duration: minimum of 6 months

Intensity: The minimum frequency of visits was at least once a fortnight for 6 months. The maximum was based on the needs as assessed by the HCA. Thus, the visits could be more frequent depending on the need of that particular family

Skill mix: Intervention delivered by a community team composed of 2 full-time HCAs, 2 psychiatrists and a lay counsellor. The minimum requirements for being a HCA were knowledge of the local language, being literate, preferably passed higher secondary school, and motivated to be involved in the community care of older people. They received intensive training for a week through role play and interactive training methods. The HCA were trained in key skills, including listening and counselling skills, bereavement counselling, stress management and health advice for common health problems. The HCAs were supported and supervised by the 2 part-time specialists: 2 psychiatrists (1 supporting each team) and 1 counsellor (supporting both teams)

Care management tasks: case finding; implementation and monitoring of care plan. The HCAs referred people back to the psychiatrist, or advised the families about services

Components: medication management, counselling, carer education, legal advice

Breadth of services spanned: case manager works within multidisciplinary team; co-ordinates outside services.

\section{Control group:}

$\mathrm{n}=40$

The control-arm dyads received only education and information regarding dementia, and were then placed on a waiting list to receive the intervention after 6 months. They were free to utilise the existing health services during this time.

(seeTable 2 for further details) 
Dias - Goa India (Continued)

Participant's functional ability using Everyday Ability Scale for India (EASI)

Outcomes not used:

None

\begin{tabular}{ll}
\hline Notes & Lost to follow-up 27\% (22/81) \\
Mortality was high; $22 \%(18)$ died during the study
\end{tabular}

\section{Risk of bias}

\begin{tabular}{|c|c|c|}
\hline Bias & Authors' judgement & Support for judgement \\
\hline $\begin{array}{l}\text { Random sequence genera- } \\
\text { tion (selection bias) }\end{array}$ & Low risk & $\begin{array}{l}\text { Randomisation of dyads (participants with dementia and carers) was carried } \\
\text { out by an 'independent person', based on a simple random number tables. }\end{array}$ \\
\hline $\begin{array}{l}\text { Allocation concealment } \\
\text { (selection bias) }\end{array}$ & Unclear risk & Methods of allocation to intervention or control sequence was not clarified. \\
\hline $\begin{array}{l}\text { Blinding (performance } \\
\text { bias and detection bias) } \\
\text { Participants }\end{array}$ & High risk & Participants were aware of the allocation status. \\
\hline $\begin{array}{l}\text { Blinding (performance } \\
\text { bias and detection bias) } \\
\text { Personnel }\end{array}$ & Unclear risk & $\begin{array}{l}\text { The Home Care Advisors (HCA) team who delivered the intervention were } \\
\text { aware of intervention/control allocated status. No mention of other personnel } \\
\text { blinding. }\end{array}$ \\
\hline $\begin{array}{l}\text { Blinding (performance } \\
\text { bias and detection bias) } \\
\text { Outcome assessors }\end{array}$ & High risk & $\begin{array}{l}\text { Blinding of outcome assessors was attempted by keeping allocation status in } \\
\text { a separate office from the outcome evaluation teams. Families were also in- } \\
\text { structed not to divulge information on the visits by the Home Care Advisor. In } \\
\text { order to evaluate the masking process, researchers were asked to guess the in- } \\
\text { tervention status. } 2 / 3 \text { of the assessors correctly guessed the allocation status. }\end{array}$ \\
\hline $\begin{array}{l}\text { Blinding (performance } \\
\text { bias and detection bias) } \\
\text { Other }\end{array}$ & Low risk & None. \\
\hline
\end{tabular}

\begin{tabular}{lll}
$\begin{array}{l}\text { Incomplete outcome data } \\
\text { (attrition bias) } \\
\text { All outcomes }\end{array}$ & High risk & $\begin{array}{l}\text { Missing outcome data balanced in numbers across intervention groups with } \\
\text { similar reasons for missing data across groups. }\end{array}$ \\
\hline $\begin{array}{l}\text { Selective reporting (re- } \\
\text { porting bias) }\end{array}$ & Low risk & All outcomes are reported equally for both groups. \\
\hline Other bias & Low risk & $\begin{array}{l}\text { Baseline assessment: At baseline groups were equivalent, except for the fact } \\
\text { that carers in the intervention group had higher GHQ scores. However, this dif- } \\
\text { ference was adjusted for in subsequent analyses. }\end{array}$
\end{tabular}

Eloniemi-Sulkava 2001

\begin{tabular}{ll}
\hline Methods & RCT \\
& Follow-up: 1 year and 2 years \\
& Analysis: Competers analysis was reported at each time point $(6,12,18$ and 24 months) \\
\hline Participants & Setting: Participants were recruited from 5 municipalities in Finland \\
\hline
\end{tabular}


Eloniemi-Sulkava 2001 (Continued)

$$
\text { Inclusion criteria: }
$$

Aged $>65$, living at home, entitled to payment for community care, receiving primary support from an informal carer; must not be suffering from any other severe diseases (e.g. stroke, cancer) that might lead to institutionalisation in the near future

Exclusion criteria:

Patients were excluded if they and their carers were not able to participate in annual training courses

$\mathrm{n}=100$

Age: 79.5 mean

Gender: 47 men, 53 women

Diagnosis: Alzheimer's disease $(A D)$ intervention $n(\%)=30(57)$; control $n(\%)=24(51)$

Vascular dementia, intervention $\mathrm{n}(\%)=16(30)$, control $\mathrm{n}(\%)=19(40)$

Other dementia $\mathrm{n}(\%)=$ intervention $7(13)$; cont $\mathrm{n}(\%)=4(9)$

MMSE score, mean (SD), intervention 14.4 (6.2), control 15.3 (5.5)

Severity of cognitive impairment (MMSE): (intervention) Mild 40\%; Moderate 24\%; Severe 36\%; (control) Mild 38\%; Moderate 38\%; Severe 24\%.

2-year intervention programme of systematic, comprehensive support by a dementia family care coordinator who had access to the physician and co-ordinated the care, services, and support of the families. She provided advocacy for participants and carers, comprehensive support for participants and carers, continuous and systematic counselling, annual training courses for participants and carers, follow-up calls, in-home visits, assistance with arrangements for social and healthcare services and 24hour-per-day availability by mobile telephone

Duration: 2 years

Intensity: The frequency of contacts varied from once a month to 5 times a day, depending on the situation of the participants and their carers

Skill mix: Intervention delivered by a care co-ordinator who had access to the physician. The co-ordinator was a registered nurse with a public health background who received extensive training, support and advice in dementia care from dementia specialists

Care management tasks: assessment, care planning, Implementation/management of care plan, arranging/allocating services

Components: provide participant information and education, participant advocacy, provision of emotional/therapeutic support, counselling/therapy, carer education

Breadth of services spanned: case manager co-ordinates/liaises with other outside services, within multidisciplinary team, arranges and allocates services and manages care network

\section{Control group:}

$\mathrm{n}=47$

The control group received the usual services provided for geriatric patients in community care by the municipal social and healthcare system or the private sector 
Eloniemi-Sulkava 2001 (Continued)

Carer burden at 12, 24 months (not clear which scale? Zarit burden scale? authors were contacted for clarification);

Cognition at 12, 24 months (MMSE)

Outcomes not used:

Time to institutionalisation/maintenance of community residence (the period in community care) (hazard ratios, $\mathrm{P}$ values, $\mathrm{Cl}$ )

(probability of remaining in the community Kaplan Meier method was used to estimate probabilities of survival without institutionalisation)

\begin{tabular}{l} 
Lost to follow-up: \\
At 12 months: intervention 10/53; control 12/47 \\
At 24 month:intervention $n=26 / 53$, control $n=22 / 47$ \\
\hline
\end{tabular}

\section{Risk of bias}

\begin{tabular}{|c|c|c|}
\hline Bias & Authors' judgement & Support for judgement \\
\hline $\begin{array}{l}\text { Random sequence genera- } \\
\text { tion (selection bias) }\end{array}$ & High risk & $\begin{array}{l}\text { Randomisation to intervention or control using numbered sealed envelopes. } \\
\text { The final } 14 \text { participants were allocated to intervention groups at a rate of 2:1 } \\
\text { as opposed to 1:1 like the earlier participants, therefore some degree of bias } \\
\text { present. }\end{array}$ \\
\hline $\begin{array}{l}\text { Allocation concealment } \\
\text { (selection bias) }\end{array}$ & Low risk & $\begin{array}{l}\text { Staff allocating participants to treatment groups were blinded to allocations. } \\
100 \text { sealed non-transparent envelopes which contained } 53 \text { allocations to inter- } \\
\text { vention group and } 47 \text { allocations to control group. }\end{array}$ \\
\hline $\begin{array}{l}\text { Blinding (performance } \\
\text { bias and detection bias) } \\
\text { Participants }\end{array}$ & High risk & Participants knew which intervention they were receiving. \\
\hline $\begin{array}{l}\text { Blinding (performance } \\
\text { bias and detection bias) } \\
\text { Personnel }\end{array}$ & Low risk & $\begin{array}{l}\text { Staff who could refer participants for institutionalisation (primary outcomes) } \\
\text { were blinded to their treatment group. }\end{array}$ \\
\hline $\begin{array}{l}\text { Blinding (performance } \\
\text { bias and detection bias) } \\
\text { Outcome assessors }\end{array}$ & Low risk & $\begin{array}{l}\text { The main outcome (placement in long-term institutional care) was assessed } \\
\text { blindly via a group of experts (usually a chief physician, head nurse, and social } \\
\text { worker) who were unaware of the allocation situation and generally unaware } \\
\text { that a patient was participating in the study. }\end{array}$ \\
\hline $\begin{array}{l}\text { Blinding (performance } \\
\text { bias and detection bias) } \\
\text { Other }\end{array}$ & Low risk & None. \\
\hline $\begin{array}{l}\text { Incomplete outcome data } \\
\text { (attrition bias) } \\
\text { All outcomes }\end{array}$ & Low risk & $\begin{array}{l}\text { Missing outcome data balanced in numbers across intervention groups with } \\
\text { similar reasons for missing data across groups. }\end{array}$ \\
\hline $\begin{array}{l}\text { Selective reporting (re- } \\
\text { porting bias) }\end{array}$ & Low risk & No apparent selective reporting. \\
\hline Other bias & Low risk & None. \\
\hline
\end{tabular}


Eloniemi-Sulkava 2009

$\begin{array}{ll}\text { Methods } & \text { RCT } \\ & \text { Follow-up: } 6 \text { months, } 12 \text { months, } 24 \text { months }\end{array}$

Participants

Setting: couples were recruited from February 2004 and May 2004, by newspaper announcements and from the Alzheimer's drug users register of the Social Insurance Institution of Finland

Inclusion criteria: A spouse was caring for his/her partner with dementia at home, living in Helsinki, minimum score of 1 on the CDR, maximum score of 23 on the MMSE

$\mathrm{n}=125$

Age: 77.5 mean

Gender: 78 men, 47 women

Diagnosis: Participants had to have an aetiological diagnosis of dementia based on a specialist's examinations, including a brain CT or MRI scans. (Alzheimer's Disease 85\%; Vascular Dementia 9\%; Other 6\%)

Severity of cognitive impairment: Mild 26\%; Moderate 55\%; Severe 19\%

MMSE score, mean (SD) Intervention 13.4 (6.2); Control 14.2 (6.6)

Charlson comorbidity index: Control 2.4 (SD 1.8); Intervention 2.4 (SD 1.5)

\section{Intervention group:}

$\mathrm{n}=63$

Setting: primary care

The core elements of the intervention consisted of a family care co-ordinator's (FCC) actions, a geriatrician's medical investigations and treatments, goal-oriented support group meetings for spouse carers, and individual tailored services. The intervention was initiated by a home visit from the FCC.

Duration: maximum of 24 months but it varied because of the phased recruitment and the attrition of the participants

Intensity: Tailored and individualised

Skill mix: Intervention delivered by the FCC who was a trained public health registered nurse with advanced practice education (altogether 3.5 years) and special education in dementia care (1 year).

Care management tasks: case finding/screening, assessment, care planning, implementation/management of care plan, arranging/allocating services

Components: provide participant information and education, participant advocacy, pharmacy/medications review/management/prescribing, provision of emotional/therapeutic support

Breadth of services spanned: case manager co-ordinates/liaises with other outside services and co-ordinates/liaises with geriatrician, arranges and allocates services, does not manage care network

\section{Control group:}

$\mathrm{n}=62$

The control group received the usual services from the municipal social and healthcare system and/or the private sector, depending on their own initiative.

(seeTable 2 for further details)

Outcomes

Numbers and $\%$ of deaths of people with dementia;

Number and \% of people institutionalised 
Eloniemi-Sulkava 2009 (Continued)

$$
\text { Functional Ability (Barthel Index) (1 year) }
$$

BPSDs (NPI) (1 year)

Costs of municipal healthcare and social care services (excluding services used from intervention budget)(total Euros per year)

Time to institutionalisation (hazard ratios, $\mathrm{Cl}$, P values)

Use and costs of services from intervention budget (total number used);

Unable to use (Service use data not used as we extracted number of participants who used service, which was not reported):

Cumulative institutionalisation (Kaplan Meier curves log rank tests);

Use of municipal healthcare and social care services (number of used services) - not reported separately;

Use of healthcare services (primary care physicians' visits, specialist polyclinic visits, primary nurses' visits, dentists' visits, days in primary care hospitals, days in specialised care hospitals, respite care days in institutions, days in long-term institutional care; number of used services, costs; number of used services, costs - P values and SDs not reported);

Use of community care services (district nurses' home visits, visits in ambulatory physiotherapy, participation in group, physiotherapy, days in II World War veterans' rehabilitation institutions, domestic help home visits (common help for couples), meals on wheels (common help for couples), day care (visits), bathing services; number of used services, costs - P values and SDs not reported);

Used intervention services [FCC (home visits, office visits, telephone calls to/from families, telephone calls for arranging proper service), Geriatrician (home visits, office visits, telephone calls), Home physiotherapy, (visits), rehabilitation in institutional care (days), home respite care, peer support group meetings, (participations), group meetings for challenging care-giving situations, participations (18 carers participated in groups of 6 people for 5 group meetings), dementia information sessions ( 3 sessions) (participations)]. Reported for intervention group only

Care-giver burden (Zarit burden scale) - change scores not reported

Not used (outcomes not prespecified in our review protocol)

Numbers of deaths of carers

Participants were not evaluated after they had been institutionalised Intervention group:

0 - 6 months: 2 died, 2 institutionalised; 6 - 12 months: 4 died, 2 institutionalised; 12 - 24 months: 5 died,7 institutionalised (total 11 died, 11 institutionalised)

Control Group:

0 - 6 months: 2 died; 4 institutionalised; 6 - 12 months: 3 died, 5 institutionalised; 12 - 24 months: 6 died, 7 institutionalised (total 11 died, 16 institutionalised)

The intervention costs included the salaries of the FCC and geriatrician (EUR 117,000), home-based physiotherapy for spouses with dementia (EUR 72,593), and rehabilitation periods in dementia care units (EUR 67,106), costs of peer support groups (EUR 47,531), group meetings for challenging care-giving situations (EUR 3,000), tutoring of the FCC and the geriatrician (EUR 10,000), home respite care (EUR 7383), office rents (EUR 5000), miscellaneous (e.g. transportation of the FCC and the geriatrician, hip protectors, nutrition supplements: EUR 1391), and dementia information sessions (EUR 750). These expenses account for EUR 2923/intervention family per year. Intervention costs (EUR 331,754) 
Eloniemi-Sulkava 2009 (Continued)

This study was conducted in the Central Union for the Welfare of the Aged and as a part of the Geriatric

Rehabilitation project Research grants were received from the Finnish Slot Machine Association

The authors were independent of the funding organisations

\section{Risk of bias}

\begin{tabular}{lll} 
Bias & Authors' judgement & Support for judgement \\
\hline $\begin{array}{l}\text { Random sequence genera- } \\
\text { tion (selection bias) }\end{array}$ & Low risk & $\begin{array}{l}\text { The couples were randomly assigned by block randomisation (block size 10) } \\
\text { into intervention and control groups. }\end{array}$ \\
\hline $\begin{array}{l}\text { Allocation concealment } \\
\text { (selection bias) }\end{array}$ & Low risk & $\begin{array}{l}\text { Once } 10 \text { couples fulfilled randomisation criteria, the study nurse phoned the } \\
\text { randomisation centre staff who had not met the couples or seen the clinical } \\
\text { records. }\end{array}$
\end{tabular}

Blinding (performance High risk Participants were not blinded to the allocated intervention.

bias and detection bias)

Participants

$\begin{array}{ll}\begin{array}{l}\text { Blinding (performance } \\ \text { bias and detection bias) }\end{array} & \text { Low risk } \\ \begin{array}{l}\text { Personnel } \\ \text { The use of health and social services were retrieved from central registers and } \\ \text { therefore, they were blinded to participants. However, the study nurses (case } \\ \text { managers) were not blinded to RCT-allocation - it was impossible to keep up } \\ \text { since the participants talked so openly about their experiences of the study. }\end{array}\end{array}$

\begin{tabular}{lll}
\hline $\begin{array}{l}\text { Blinding (performance } \\
\text { bias and detection bias) } \\
\text { Outcome assessors }\end{array}$ & Low risk & $\begin{array}{l}\text { The intervening nurse was different from the assessors nurses and did not par- } \\
\text { ticipate in the assessments. }\end{array}$ \\
\hline $\begin{array}{l}\text { Blinding (performance } \\
\text { bias and detection bias) } \\
\text { Other }\end{array}$ & Low risk & None \\
\hline
\end{tabular}

\begin{tabular}{|c|c|c|}
\hline $\begin{array}{l}\text { Incomplete outcome data } \\
\text { (attrition bias) } \\
\text { All outcomes }\end{array}$ & Low risk & $\begin{array}{l}\text { Missing outcome data balanced in numbers across intervention groups with } \\
\text { similar reasons for missing data across groups. }\end{array}$ \\
\hline
\end{tabular}

\begin{tabular}{|c|c|c|}
\hline $\begin{array}{l}\text { Selective reporting (re- } \\
\text { porting bias) }\end{array}$ & Unclear risk & $\begin{array}{l}\text { The length of time until participants were institutionalised at } 12 \text { months was } \\
\text { reported. However this was only presented as a figure so could not be used. } \\
\text { The authors note that the difference between groups at } 18 \text { months was signifi- } \\
\text { cant. }\end{array}$ \\
\hline Other bias & Low risk & None \\
\hline
\end{tabular}

Hinchliffe - UK

\begin{tabular}{ll}
\hline Methods & RCT (Waiting list controls received a delayed intervention package at 16 weeks) \\
Follow-up: 4 and 8 months \\
Analysis: Completers analysis was used \\
\hline
\end{tabular}

Participants Setting: Participants were recruited from inner city area of North London from local day centres, GPs, hospital discharges, and some of them self-referred following reports in local newspapers

Diagnosis: dementia based on DSM-III criteria (specific type not mentioned). MMSE not reported 
Hinchliffe - UK (Continued)

Inclusion criteria: Participants had to be aged $>65$, had to have fulfilled DSM-III-R criteria for dementia, living with a carer, not in current contact with psychiatric services, behavioural problems present in PWD

$\mathrm{n}=40$ dyads (participants and carers)

Age: 81 mean

Gender: 24 men, 16 women

Interventions

\section{Intervention group:}

$\mathrm{n}=22$

The intervention group received an individualised care package for the carer and the person with dementia, which considered medication (for managing verbal and/or physical aggression, night disturbance, restlessness and sexual disinhibition); psychological techniques (charts recording precipitants of aggression, involving of participants in pleasant activities, distraction techniques, etc) and social measures (referral to day centre, respite for carers, application for benefits)

Duration: 4 months

Intensity: During the intervention period, each participant and carer received a mean of 12 visits (6 - 19) lasting an average of 58 minutes $(31-87)$

Skill mix: Interventions were planned by a multidisciplinary team (consultant psychiatrist of old age, clinical psychologist, and where possible a community psychiatric nurse, psychiatric soclal worker and occupational therapist) and were implemented in the participant's home by a psychiatrist

Care management tasks: assessment, care planning, implementation/management of care plan, arranging/allocating services, case closure (discharged back to their GP)

Components: provide participant information and education, pharmacy/medications review/management/prescribing, provision of emotional/therapeutic support, carer education

Breadth of services spanned: case manager co-ordinates/liaises with other outside services, within multidisciplinary team; arranges and allocates services

\section{Control group:}

$\mathrm{n}=18$

Waiting list controls received a delayed intervention package at 16 weeks

Outcomes General Health Questionnaire (carers)

Attrition

Outcomes not used:

Behavioural symptoms of person with dementia assessed (Present Behavioural Examination; PBE); change in carer mental health (GHQ/GMS (ICD-10) (mean change or mean end points, SDs not reported - number that significantly improved was reported but this was not defined)

Notes Lost to follow-up: $18 \%(7 / 40)$

\section{Risk of bias}

\begin{tabular}{lll} 
Bias & Authors' judgement & Support for judgement \\
\hline $\begin{array}{l}\text { Random sequence genera- } \\
\text { tion (selection bias) }\end{array}$ & Low risk & Random permuted block system. \\
\hline
\end{tabular}


Hinchliffe - UK (Continued)

\begin{tabular}{l}
$\begin{array}{l}\text { Allocation concealment } \\
\text { (selection bias) }\end{array}$ \\
\hline
\end{tabular}

Blinding (performance $\quad$ High risk Participants were not blinded to the allocated intervention
bias and detection bias)
Participants

Blinding (performance Unclear risk Not mentioned in the paper.
bias and detection bias)
Personnel

\begin{tabular}{|c|c|c|}
\hline $\begin{array}{l}\text { Blinding (performance } \\
\text { bias and detection bias) } \\
\text { Outcome assessors }\end{array}$ & Low risk & Outcome assessors were blinded. \\
\hline $\begin{array}{l}\text { Blinding (performance } \\
\text { bias and detection bias) } \\
\text { Other }\end{array}$ & Low risk & None. \\
\hline $\begin{array}{l}\text { Incomplete outcome data } \\
\text { (attrition bias) } \\
\text { All outcomes }\end{array}$ & Unclear risk & $\begin{array}{l}\text { There was an imbalance in number and reasons for missing data across the } \\
\text { groups: } 7 \text { people were lost to the study, } 2 \text { from group } 1 \text { ( } 1 \text { moved away and an- } \\
\text { other withdrew consent) and } 5 \text { from group } 2 \text { ( } 4 \text { died and } 1 \text { entered residential } \\
\text { care). }\end{array}$ \\
\hline $\begin{array}{l}\text { Selective reporting (re- } \\
\text { porting bias) }\end{array}$ & High risk & $\begin{array}{l}\text { Phase } 2 \text { data missing for GHQ. Phase } 1 \text { and Phase } 2 \text { data missing means and } \\
\text { SDs for PBE. Some outcomes were not adequately reported and so selective } \\
\text { outcome reporting could be present. }\end{array}$ \\
\hline Other bias & Unclear risk & No baseline data reported. \\
\hline
\end{tabular}

\section{Jansen - Netherlands}

\begin{tabular}{ll}
\hline Methods & RCT \\
Follow-up:6 and 12 months \\
Analysis: Intention-to-treat \\
\hline
\end{tabular}

Participants Setting: Participants were recruited from 6303 older general practice patients in West-Freisland, the Netherlands. Primary care physicians screened dementia symptoms and performed a cognitive assessment

Diagnosis: dementia (specific type not mentioned).

Inclusion criteria: persons with MMSE < 24 or a risk of dementia of at least 50\% (7 Minutes Screen test); aged 65 years or older, with a carer available

$\mathrm{n}=99$ dyads (participants and carers)

Age: 81.5 mean, $73 \%$ of participants were 75 years+

Gender: 35 men, 64 women

MMSE mean (SD): intervention group 22.0 (4.2); control group 22.7 (3.8)

Chronic diseases $(\% \geq 1)$ : intervention group $72 \%$; control group $60 \%$

Randomisation took place at participant level among 55 GPs and a diabetes care centre. 
Jansen - Netherlands (Continued)

Interventions

\section{Intervention group:}

$n=54$

Case management delivered by district nurses who had a co-ordinating function consisting of assessment, giving advice and information, planning, co-ordination, organising collaboration and monitoring of care. The case managers provided practical, informational and socio-emotional support

Standard Activities: The case managers started the intervention with a home visit in which they administered an assessment of general functioning of the participant and potential protocols for problem areas.

Used the Resident Assessment Instrument Home Care (RAI-HC) which assesses the general functioning of the participant and provides protocols for the management of 30 potential and actual problem areas.

Tailor-made activities: referral of participants and carers to other healthcare professionals, organisation of family meetings.

Duration: 12 months

Intensity: the 3 case managers spent a mean time of 10.8 hours a year per participant-carer dyad on the case management intervention.

Skill mix: Intervention was delivered by a case manager (district nurse) who was trained in working with a computerised protocol and in organising family meetings. They also received 2 seminars on how to deal with participants with dementia and their informal carers. They met monthly to discuss innovations and geriatric cases while supervised by a staff member of their home care organisation.

Care management tasks: assessment, care planning, implementation/management of care plan, arranging/allocating services, monitoring the implementation of the care plan

Components: provide participant information and education, carer education, provision of emotional/therapeutic support

Breadth of services spanned: case manager co-ordinates/liaises with other outside services, arranges and allocates services.

\section{Control group:}

$\mathrm{n}=45$

In the usual care group the participants could receive care depending on their own initiative.

(seeTable 2 for further details)

Participant's quality of life - Dementia Quality of Life (DQOL) (overall score entered)

Carergiver's quality of life using SF-36 (mental health component entered)

Carer's psychological well-being (CES-D)

Carer's burden (SSPIC)

Number institutionalised (1 year)

Number died (6 months, 1 year)

Mean number of days in hospital per month (6,12 months - from authors)

Attrition (6 months, 1 year)

Outcomes not used (Service use data not used, as we extracted number of participants who used service): 
Jansen - Netherlands (Continued)

Carer's sense of competence (SCQ) (Primary outcome measure) (not prespecified in review protocol)

Use of primary care (mean number of consults, median)

Home care (hours a week, median)

Outpatient geriatric/psychiatric team/diagnostic service (number of consults, median)

Day care (mean number of days, median)

Medical specialist (mean number of consults, median)

Physiotherapist (mean number of consults, median)

Psychologist (mean number of consults, median)

Social Worker (mean number of consults, median)

Notes

Lost to follow-up: $12 \%(12 / 99)$ at 6 months

Total lost to follow-up $18 \%(18 / 99)$ at 12 months

The study was supported by grants from The Netherlands Organisation for Health Research and Development (ZonMw), The Hague, the Netherlands (grant No. 2200.0114)

\section{Risk of bias}

\begin{tabular}{lll}
\hline Bias & Authors' judgement & Support for judgement \\
\hline $\begin{array}{l}\text { Random sequence genera- } \\
\text { tion (selection bias) }\end{array}$ & Low risk & $\begin{array}{l}\text { Randomisation was carried out by an independent person using random num- } \\
\text { ber tables. }\end{array}$ \\
\hline
\end{tabular}

\begin{tabular}{lll}
\hline $\begin{array}{l}\text { Allocation concealment } \\
\text { (selection bias) }\end{array}$ & Unclear risk & Not mentioned in the paper. \\
\hline $\begin{array}{l}\text { Blinding (performance } \\
\text { bias and detection bias) }\end{array}$ & High risk & $\begin{array}{l}\text { Participants were aware of their intervention/control status. Participants knew } \\
\text { that 2 different interventions were studied and they were informed about } \\
\text { group assignment. }\end{array}$ \\
\hline
\end{tabular}

Blinding (performance High risk bias and detection bias) Personnel
GPs might have known about participants in the intervention group because nurses might have contacted them about those patients. This might have encouraged GPs to give more attention to people with dementia and carers in the usual care group.

\begin{tabular}{ll}
\hline Blinding (performance & Low risk
\end{tabular}

bias and detection bias)

Outcome assessors

\begin{tabular}{|c|c|c|}
\hline $\begin{array}{l}\text { Blinding (performance } \\
\text { bias and detection bias) } \\
\text { Other }\end{array}$ & Low risk & $\begin{array}{l}\text { Researchers were blinded until they finished analysing data. Primary care } \\
\text { practitioners and interviewers were blinded to group assignment unless par- } \\
\text { ticipants revealed their allocation. }\end{array}$ \\
\hline
\end{tabular}

Incomplete outcome data Unclear risk (attrition bias)

All outcomes

There was attrition at follow-up and some imbalance in number of missing data across the groups at 6 months.

\begin{tabular}{lll}
\hline $\begin{array}{l}\text { Selective reporting (re- } \\
\text { porting bias) }\end{array}$ & Low risk & No apparent selective reporting. \\
\hline Other bias & Low risk & $\begin{array}{l}\text { Some differences between the groups at baseline: Carers in the intervention } \\
\text { group had less social support. Participants in the intervention group had been }\end{array}$
\end{tabular}




$\begin{array}{ll}\text { Methods } & \text { RCT } \\ & \text { Follow-up:4 and } 12 \text { months } \\ \text { Analysis: Intention-to-treat }\end{array}$

Participants

Setting: recruited from psychogeriatric outpatient and memory clinics of Prince of Wales Hospital, a teaching hospital in Hong Kong.

Diagnosis: dementia (specific type not mentioned)

Inclusion criteria: Community-dwelling people aged 65 years old or above, diagnosed to have mild dementia, with Chinese MMSE (Chiu 1998) scored 15+, and/or a Clinical Dementia Rating of 1 (Hughes 1982).

Exclusion criteria included: (1) no family carer (defined as a family member who visited the person at least once a month); (2) refused home visits by case manager, (3) participants with significant concomitant diseases with more than 1 hospital admission in the previous 12 months. The last criterion was introduced in order to obtain a more homogeneous sample of people with dementia with relatively stable physical condition.

$\mathrm{n}=102$ dyads (participants and carers);

Age mean (SD): Intervention: 78.6 (6.4), Control: 78.2 (5.4)

Women: Intervention 35 (59\%), Control: 24 (56\%)

Dementia-related drug; Intervention: 18 (31\%), Control: 14 (33\%)

Antipsychotics: Intervention: 9 (15\%), Control: 3 (7\%)

Antidepressants: Intervention 14 (24\%), Control 12 (28\%)

MMSE mean (SD): Intervention: 17.6 (5.2), Control: 18.0 (5.1)

CSDD mean (IQR): Intervention: $3.0(1.0,6.0)$, Control: $4.0(1.0,7.0)$

NPI mean (IQR): Intervention $14.0(5.0,29.5)$, Control: $17.0(6.0,35.0)$

PWI-ID mean (SD): Intervention 69.6 (20.0), Control 72.2 (18.6)

Carers: Intervention $\mathrm{n}=59$ Control $\mathrm{n}=43$

Women: Intervention: 45 (76\%), Control: 30 (70\%)

Spouse: Intervention: 15 (25\%), Control: 15 (35\%)

ZBI mean (SD): Intervention: 33.2 (17.8), Control: 32.3 (15.8)

PWI-A mean (SD): Intervention: 63.6 (15.1), Control: 61.2 (18.5)

GHQ mean (SD): Intevention: 13.1 (5.4), 14.2 (6.6)

Interventions

\section{Intervention group}

$\mathrm{n}=59$

A case management model for people with mild dementia, whereby resources within the family and in the community were mobilised and optimally used. Community-dwelling psychiatric and geriatrics outpatients with mild dementia were randomised to receive case management by a trained occupational therapist for 4 months.

The participants were assigned to a case manager (CM) who was a trained occupational therapist. The intervention period lasted for 4 months. During the intervention period, regular home visits were carried out. The $\mathrm{CM}$ offered interventions in the following areas:

1. Assessment and advice

2. Home-based programme on cognitive stimulation 
Lam - Hong Kong (Continued)

\section{Case management}

Duration: 4 months

Intensity: low minimum requirements for carer visits (1 visit per month)/CM accessible by a telephone hotline during working hours Monday to Saturday

Skill mix: Intervention was delivered by a case manager (a community-based occupational therapist) who liaised closely with psychogeriatricians or geriatricians in the memory/outpatient clinics. The $\mathrm{CM}$ liaised closely with the psychogeriatricians or geriatricians in the clinics. An early review could be arranged if necessary

Case management tasks: assessment, care planning, implementation and monitoring of care plan, arranging/allocation of services, monitoring the implementation of the care plan, review, case closure

Components: participant and carer education/advice (see above), medication reviews (followed up at 3 monthly intervals in the psychogeriatric or memory clinics)

Breadth of services spanned: Case manager co-ordinates/liaises with other outside services, within multidisciplinary team and arranges and allocates care/services but does not manages care network

\section{Control group}

$n=43$

One home visit for home safety was performed by the same occupational therapist with the control participants at the beginning of the trial, but the participants did not have access to case management. Both groups were followed up at 3-monthly intervals in the psychogeriatric or memory clinics.

(seeTable 2 for further details)

\begin{tabular}{|c|c|c|}
\hline Outcomes & Zarit Carer burden int & view (ZBI) (Zarit 1986) (primary) \\
\hline & General Health Questi & nnaire (GHQ) (Goldberg 1997) (carer depression) (primary) \\
\hline & Personal Well-Being Ir & lex for adults (carer quality of life) (primary) \\
\hline & Chinese Mini Mental S & te Examination (CMMSE) (Chiu 1998) \\
\hline & Cornell Scale for Depr & ssion in Dementia (CSDD) (Alexopoulos 1988) \\
\hline & Neuropsychiatric Inve & tory (NPI) \\
\hline & Personal Well-Being Ir & lex-Intellectual Disability (PWI-ID) (Cummins 2005a; Cummins 2005) (primary) \\
\hline & Admission to nursing & mes at 12 months \\
\hline & Use of social care sup & rt (paid helpers, day care, home help and respite care) \\
\hline & Attrition & \\
\hline & Outcomes not used: & \\
\hline & none & \\
\hline Notes & Loss to follow-up: $3 \%$ & 4 months; $10 \%$ at 12 months \\
\hline Risk of bias & & \\
\hline Bias & Authors' judgement & Support for judgement \\
\hline $\begin{array}{l}\text { Random sequence genera- } \\
\text { tion (selection bias) }\end{array}$ & Low risk & $\begin{array}{l}\text { Randomisation was carried out by an independent research assistant using } \\
\text { random number tables. }\end{array}$ \\
\hline
\end{tabular}


Lam - Hong Kong (Continued)

Allocation concealment Low risk Another research assistant who administered the assessments both to persons (selection bias) with dementia and to their carers in both $\mathrm{CM}$ and control groups was blinded to the randomised allocation.

Blinding (performance $\quad$ High risk Participants were not blinded to the allocated intervention.
bias and detection bias)

bias and detection bias)

Participants

Blinding (performance $\quad$ Unclear risk $\quad$ Not mentioned in the paper.
bias and detection bias)

bias and detection bias)

Personnel

\begin{tabular}{lll}
\hline $\begin{array}{l}\text { Blinding (performance } \\
\text { bias and detection bias) } \\
\text { Outcome assessors }\end{array}$ & Low risk & $\begin{array}{l}\text { Another research assistant who administered the assessments both to persons } \\
\text { with dementia and their carers in both CM and control groups was blinded to } \\
\text { the randomised allocation. }\end{array}$ \\
\hline $\begin{array}{l}\text { Blinding (performance } \\
\text { bias and detection bias) } \\
\text { Other }\end{array}$ & Low risk & None. \\
\hline
\end{tabular}

\begin{tabular}{|c|c|c|}
\hline $\begin{array}{l}\text { Incomplete outcome data } \\
\text { (attrition bias) } \\
\text { All outcomes }\end{array}$ & Low risk & $\begin{array}{l}\text { Low attrition. Missing outcome data balanced in numbers across intervention } \\
\text { groups. } 102 \text { participants entered the trial, } 10 \text { participants dropped out ( } 7 \text { died, } \\
2 \text { CVA, } 1 \text { unaccounted for). }\end{array}$ \\
\hline
\end{tabular}

Selective reporting (re- Low risk None.

porting bias)

Other bias Low risk None.

Newcomer - US

\begin{tabular}{ll}
\hline Methods & RCT \\
& Follow-up: 6, 12, 18, 24, 36 months \\
& Analysis: Intention-to-treat \\
\hline
\end{tabular}

Participants Setting: Participants were enrolled voluntarily from Illinois, Tennessee, Oregon, New York, Ohio, Florida, Minessota, and West Virginia in the USA (1988 - 1994)

Diagnosis: dementia (specific type not mentioned)

MMSE mean (SD): Intervention 14.2 (8.7); Control 14.6 (8.6)

Inclusion criteria: Physician-certified diagnosis of dementia, be enrolled in (or eligible for) both parts A and $\mathrm{B}$ of Medicare, and resident in the study sites areas.

$n=8095$

Age mean (SD): Intervention: 78.5 (7.8), Control: 78.7 (8.0)

Gender: \% women: Intervention: 39.4, Control: 42.5

Interventions

\section{Intervention group:}

$\mathrm{n}=4151$

Two case management models were implemented. Model A (low reimbursement - high caseload) sites operated with a target case manager-to-client ratio of 1:100 and had a monthly community service re- 
Newcomer - US (Continued)

imbursement limit or cap from USD 290 through USD 489 per month per participant. Model B (high reimbursement - low caseload) sites had a target case manager-to-client ratio of 1:30 and a slightly higher reimbursement limit of from USD 430 through USD 699 per month per participant

Duration: not clear - demonstration operational December 1989 - November 1994

Intensity: Model A sites had a 1:100 case manager to participant ratio, whereas Model B sites had a 1:30 ratio

Skill mix: Each site agency implemented the demonstration in somewhat different ways. For example, the Illinois programme employed nurses as case managers, whereas other sites employed social workers, mental health professionals, and gerontology specialists.

Care management tasks: assessment, care planning, implementation/management of care plan, arranging/allocating services, case budget management/budget holding; monitoring the implementation of the care plan. Case management was largely oriented to assessment, client monitoring, care planning, and situational problem-solving

Components: provide patient/carer information and education; provision of emotional/therapeutic support, counselling, carer education

Breadth of services spanned: case manager co-ordinates/liaises with other outside services, within multidisciplinary team, arranges and allocates care/services and manages care network. One element ignored by this demonstration was the co-ordination of case manager and primary care physician activities. This was not an explicit focus in any site, nor was it an expectation of the demonstration

\section{Control group:}

$n=3944$

Participants in the control group continued to receive their usual care (not described further).

(seeTable 2 for further details)

Carer's burden (Zarit Burden Scale),

Carer's depression (Geriatric Depression Scale),

Home entry rates (number entering nursing homes in first six months),

Mortality (died during first 6 months and died during second 6 months of period)

Use of home care services: chore care use, companion care use, personal care use, any home care use during year; hours during year. Home care variable is created by combining chore, companion, and personal care into a single measure (\% used; mean and SD hours during year).

Day care use (\% used; mean and SD day care days during the year)

Assisted living housing use (\% used; mean and SD day care days during the year)

Annual mean (SD) number of hospital admissions for care-givers (Illinois site - Shelton 2001)

Annual mean length of hospital stay for care-givers (Illinois site - Shelton 2001)

Annual mean (SD) number of emergency department visits (Illinois site - Shelton 2001)

Medicare expenditures (in US dollars)

Outcomes not used

Home entry rates (number entering nursing homes not presented for each group for each time period; number of home placement in second 6 months - not entered because cumulative figures for 12 months not reported) 
Newcomer - US (Continued)

$$
\mathrm{n}=5304 \text { for Carer's outcomes }
$$

Carers lost to follow-up (carer burden and depression measures): 6 months (17\%), 12 months (38\%), 18 months (49\%), 24 months (46\%), 36 months (64\%)

\section{Risk of bias}

\begin{tabular}{lll} 
Bias & Authors' judgement & Support for judgement \\
\hline $\begin{array}{l}\text { Random sequence genera- } \\
\text { tion (selection bias) }\end{array}$ & Low risk & $\begin{array}{l}\text { Random number-generating algorithm was used to assign cases into the treat- } \\
\text { ment and control groups. }\end{array}$ \\
\hline $\begin{array}{l}\text { Allocation concealment } \\
\text { (selection bias) }\end{array}$ & Low risk & $\begin{array}{l}\text { The demonstration sites were responsible for recruiting applicants to the } \\
\text { demonstration. After screening and qualifying the applicants, their names } \\
\text { were given to the programme evaluators, for random assignment into the } \\
\text { treatment or control groups. The sites were notified of those selected into the } \\
\text { treatment group. }\end{array}$
\end{tabular}

Blinding (performance $\quad$ High risk Participants were not blinded to the allocated intervention.
bias and detection bias)
Participants

Blinding (performance $\quad$ Unclear risk $\quad$ Not mentioned in the paper.
bias and detection bias)
Personnel

Blinding (performance
$\begin{aligned} & \text { bias and detection bias) } \\ & \text { Outcome assessors }\end{aligned}$

Blinding (performance $\quad$ Low risk $\quad$ None.
bias and detection bias)
Other

\begin{tabular}{|c|c|c|}
\hline $\begin{array}{l}\text { Incomplete outcome data } \\
\text { (attrition bias) } \\
\text { All outcomes }\end{array}$ & High risk & $\begin{array}{l}\text { Missing data high in both groups, although balanced in numbers across } \\
\text { groups. }\end{array}$ \\
\hline
\end{tabular}

\begin{tabular}{|c|c|c|}
\hline $\begin{array}{l}\text { Selective reporting (re- } \\
\text { porting bias) }\end{array}$ & High risk & $\begin{array}{l}\text { The } 3 \text { papers have different sample sizes, therefore selective reporting is a pos- } \\
\text { sibility. }\end{array}$ \\
\hline Other bias & Unclear risk & $\begin{array}{l}\text { Control group cases might be exposed to comparable benefits, such as case } \\
\text { management and community care benefits if they were participating in state } \\
\text { Medicaid programmes. For this reason, the demonstration programmes were } \\
\text { encouraged not to seek or accept applications from those receiving Medic- } \\
\text { aid. They complied with this request, but researchers had no ability to prevent } \\
\text { the applicants from entering Medicaid programmes later. In total } 7.5 \% \text { of the } \\
\text { treatment group and } 7.7 \% \text { of the controls were Medicaid programme recipi- } \\
\text { ents for some portion of the study observation period. Statistical controls were } \\
\text { used to adjust for the potential effect of Medicaid participation. Most of the } \\
\text { Medicaid participation occurred after the case entered a nursing home, which } \\
\text { was a censoring outcome. The direction of bias for those entering Medicaid } \\
\text { while still in the community would be to reduce case management and com- } \\
\text { munity service treatment differences relative to the controls. }\end{array}$ \\
\hline
\end{tabular}


Vickrey - California

$\begin{array}{ll}\text { Methods } & \text { Cluster-RCT } \\ & \text { Follow-up: 12, 18 months } \\ & \text { Analysis: intention-to-treat }\end{array}$

Participants

Setting: Participants were recruited from 18 primary care clinics within 3 healthcare organisations and 3 community agencies providing services for persons with dementia and their carers in the San Diego, California metropolitan area. Private group practice, academic group practice, and health maintenance organisation practice types were represented by the 3 health care organisations. Participants were identified by querying health care organisation administrative databases for occurrence during the previous year of a dementia diagnosis code

Inclusion criteria: People with dementia, aged 65+, with an informal carer

$\mathrm{n}=408$ dyads (participant and carer)

Age: 80.1 mean

Gender: 184 men 224 women

Diagnosis: Intervention group: AD 176 (76.9\%), VAD 16 (6.9\%), other 37 (16.2\%); Control group: AD 128 (75.7\%), VAD $15(8.9 \%)$, other $26(15.4 \%)$

Severity of cognitive impairment: Blessed score (SD): Intervention: 5.7 (3.4), Control: 6.3 (4.2)

Charlson co-morbidity index (SD): Intervention 2.7 (1.8), Control 2.7 (1.8)

Baseline cholinesterase inhibitor use: Intervention 128 (54\%), Control 93 (55\%)

Interventions

Case management approaches to home support for people with dementia (Review)

Copyright $\odot 2015$ The Cochrane Collaboration. Published by John Wiley \& Sons, Ltd.

$\mathrm{n}=238$ in-home reassessments every 6 months ment of care plan carried out usually by telephone

\section{Intervention group:}

Intervention components were based on the chronic care model and emphasised linkages with community resources and multi-agency co-ordination. Key components included dementia care managers, formal procedures for communication within and between organisations and agencies, included adherence to 23 dementia guideline recommendations, Internet-based care management, collaborative care planning with carers, carer self-management support, ongoing follow-up, and provider education.

Participant carer dyads in the intervention arm were assigned a care manager, who was trained in the use of Internet-based care management software. The care managers performed a structured home assessment, identified problems, initiated care plan actions, and sent a summary to the primary care physician and other designated providers. Care managers provided ongoing follow-up as needed, with

Duration: 18 months or until case closed or no longer enrolled in programme

Intensity: $77 \%$ of the dyads received an initial visit from a care manager and $55 \%$ had a formal reassessment. The median number of assessment and reassessment visits was 2 . There were an average of 15 follow-up telephone calls from a care manager per dyad.

Skill mix: Care managers were mainly social workers who received formal training and used an Internet-based care management software system for care planning and co-ordination

Care management tasks: case finding/screening, assessment, care planning, implementation/manage-

Components: carer education and co-ordination between organisations and agencies

The care managers were responsible for co-ordinating care and making referrals. The care managers (primarily social workers) used an Internet-based care management software system for care planning and co-ordination. Referrals were made using the software package and follow-up assessments were 
Vickrey - California (Continued)

Breadth of services spanned: case manager co-ordinates/liaises with other outside services and within team, arranges and allocates services and manages care network

\section{Control group:}

$\mathrm{n}=170$

Participants, carers and providers in the usual care group were not offered study interventions. Control group received care as usual, continuing to receive care from their usual providers. They were not offered any of the specialised dementia care management developed as the study intervention

Outcomes

The ICC $>0.03$ of the outcomes reduced the sample size by a factor of 1.57

Participant's quality of life (Health Unilities Index Mark 3)

Carer's quality of life (EuroQol-5D)

Carer's social support

Cholinesterase inhibitor use (at 12 or 18 months)

Service use at 18 months: number received: in home, volunteer, or paid respite care services; services from a professional home health aide; services from a paid professional carer; adult day care, services or information from local Alzheimer's Association, services or information from Caregiver Resource Centre, services or information from meals on wheels

Number participated in carer support group

Institutionalised/nursing home stays: mean number of days per month (we inflated monthly means by 18 months)

Hospital admissions/inpatient utilisation: number of nights per month (we inflated monthly means by 18 months).

Hospital admissions: (number with any stays in 18 months)

Emergency department visits: mean number of days per month (we inflated monthly means by 18 months)

Emergency department: (number with visits in 18 months)

Informal care-giving: hours per month: (aid unskilled, unpaid unskilled)

Healthcare in the home per month: (home nurse visits, home health aide visits)

Use of one or more community services, respite care, home health aid, professional carer services, adult day care, carer's support group

Unable to use (not reported in useable format):

Cognitive status (MMSE or other formal test) $\mathrm{n} / \%$ reported (mean/SD not reported)

Participant's behaviour (CDBS) (mean/SD not reported)

Not used (not prespecified in our review protocol)

Participant's health care

Carer's confidence in care-giving

Carer's mastery

Carer receiving the needed help with behavioural problem (satisfaction)

Adherence to 23 dementia guideline recommendations at follow-up (primary outcome) 
Vickrey - California (Continued)

Carer's knowledge about dementia

Primary care provider knowledge, attitudes and perceptions of quality of care

Notes Lost to follow-up: 12 months 11\% (45/408); 18 months 29\% (118/408) (cumulative)

12-month follow-up $n=47$ (Intervention: 33; Control: 14)

Intervention = 15 withdrew, 3 people with dementia died, 5 switched, 10 non-response

Control $=4$ withdrew, 1 person with dementia died, 1 switched, 8 non-response

18-month follow-up $\mathrm{n}=118$ (Intervention: 72; Control: 46)

Intervention = 19 withdrew, 34 people with dementia died, 5 switched, 14 non-response

Control $=6$ withdrew, 20 people with dementia died, 6 switched, 14 non-response

\section{Risk of bias}

\begin{tabular}{lll}
\hline Bias & Authors' judgement & Support for judgement \\
\hline $\begin{array}{l}\text { Random sequence genera- } \\
\text { tion (selection bias) }\end{array}$ & Low risk & Randomisation of clinics using a computerised random-number generator. \\
\hline $\begin{array}{l}\text { Allocation concealment } \\
\text { (selection bias) }\end{array}$ & Low risk & $\begin{array}{l}\text { This was a cluster-randomised trial, with the clinic as the unit of randomisa- } \\
\text { tion. There were a fixed number of clinics involved in the study and these were } \\
\text { paired by volume. The study statistician conducted the randomisation of each } \\
\text { pair of clinics into intervention and usual care arms, using a method described } \\
\text { in the publication of the main study findings. No clinics or study participants } \\
\text { were specifically notified that they were in an intervention or usual care arm. } \\
\text { Adjusted multiple regression analysis was used to overcome the complex clus- } \\
\text { ter design. }\end{array}$ \\
\hline
\end{tabular}

$\begin{array}{ll}\begin{array}{l}\text { Blinding (performance } \\ \text { bias and detection bias) }\end{array} & \text { Low risk } \\ \begin{array}{ll}\text { Participants } & \text { Participants were unaware of clinic randomisation status until baseline as- } \\ & \text { sessment and were not reminded of randomisation status at follow-up, al- } \\ & \text { though study participants in the intervention arm were contacted by the care } \\ \text { manager and offered the programme being tested, and intervention clinic } \\ \text { physicians were offered physician education programmes. }\end{array}\end{array}$

$\begin{array}{ll}\begin{array}{l}\text { Blinding (performance } \\ \text { bias and detection bias) }\end{array} & \text { Low risk } \\ \begin{array}{ll}\text { Personnel } & \text { Nontrally at UCLA) were specifically notified about intervention/usual care sta- } \\ & \text { tus of any study participants, except for care managers at the sites and an un- } \\ & \text { blinded research assistant at UCLA who informed care managers about new } \\ \text { participants. }\end{array}\end{array}$

\begin{tabular}{|c|c|c|}
\hline $\begin{array}{l}\text { Blinding (performance } \\
\text { bias and detection bias) } \\
\text { Outcome assessors }\end{array}$ & Unclear risk & $\begin{array}{l}\text { Eight nurse abstractors completed a 3-day training and were not informed of } \\
\text { participant randomisation status or study hypotheses and received no inter- } \\
\text { vention description (perhaps unclear risk: "medical record abstractors could } \\
\text { have discerned aspects of the study intervention, and we did not assess the ex- } \\
\text { tent to which abstractors were blinded to intervention status") }\end{array}$ \\
\hline
\end{tabular}

Blinding (performance $\quad$ Low risk
bias and detection bias)

Other

\begin{tabular}{|c|c|c|}
\hline $\begin{array}{l}\text { Incomplete outcome data } \\
\text { (attrition bias) }\end{array}$ & Unclear risk & $\begin{array}{l}\text { There was an imbalance in number and reasons for missing data across the } \\
\text { groups. }\end{array}$ \\
\hline
\end{tabular}

All outcomes 
Vickrey - California (Continued)

Selective reporting (re- Low risk No apparent selective reporting.
porting bias)

Other bias Low risk None.

AD: Alzheimer's Disease

ADL-AD: Activities of Daily Living - Alzheimer's Disease

BPSD: behavioural and psychological symptoms of dementia

CDBS: California Dementia Behaviour Scale

CDR: Clinical Dementia Rating

CSDD: Cornell Scale for Depression in Dementia

$\mathrm{CT}$ : computed tomography

DFCP: Dementia Family Care Programme

DSM-III-R: Diagnostic and Statistical Manual of Mental Disorders Edition III, revised

DSM-IV: Diagnostic and Statistical Manual of Mental Disorders Edition IV

GHQ: General Health Questionnaire

ICC: intraclass correlation coefficient

ICD9: International Classification of Diseases 9th edition

IQR: Inter quartile range

MMSE: Mini Mental State Examination

MRI: magnetic resonance imaging

NPI: Neuropsychiatric Inventory

PBE: Present Behavioural Examination

PWD: person with dementia

$\mathrm{RCT}$ : randomised controlled trial

SD: standard deviation

VAD: vascular Alzheimer's Disease

ZBI: Zarit carer Burden Interview

Characteristics of excluded studies [ordered by study ID]

\begin{tabular}{ll}
\hline Study & Reason for exclusion \\
\hline Aliberti - Las Vegas & Not an RCT. \\
\hline Baldwin - UK & The intervention was not delivered in the community. \\
\hline Bellantonio - Connecticut & Did not meet criteria for case management intervention. \\
\hline Callahan-Indianapolis & $\begin{array}{l}\text { Both groups receiving case management (collaborative care) - intervention receiving home-based } \\
\text { occupational therapy. }\end{array}$ \\
\hline Engedal - Oslo & Did not meet criteria for case management intervention. \\
\hline Fabris - Italy & Hospital-based control group. \\
\hline Farran - US & Did not meet criteria for case management intervention. \\
\hline Gerdner - US & Psychoeducational Intervention which did not meet criteria for case management. \\
\hline Gitlin - US1 & Did not meet criteria for case management intervention. \\
\hline Gitlin - US2 & Did not meet criteria for case management intervention. \\
\hline Gonyea - US & Did not meet criteria for case management intervention. \\
\hline
\end{tabular}




\begin{tabular}{|c|c|}
\hline Study & Reason for exclusion \\
\hline Goodman - US & Did not meet criteria for case management intervention. \\
\hline Gormley - UK & Did not meet criteria for case management intervention. \\
\hline Graff - The Netherlands & Did not meet criteria for case management intervention. \\
\hline Gutterman - US & Did not meet criteria for case management intervention. \\
\hline Hepburn - US & Did not meet criteria for case management intervention. \\
\hline Hébert - Canada & Psycho-educational Intervention which did not meet criteria for case management. \\
\hline Kwak - Georgia & The study focused only upon carers of people with dementia. \\
\hline Lu - China & The intervention is delivered in the hospital and in the community. \\
\hline Lukas - Ulm & Did not meet criteria for case management intervention. \\
\hline Mittelman - New York & Did not meet criteria for case management intervention. \\
\hline Montgomery - US & Did not meet criteria for case management intervention. \\
\hline Mostardt - Germany & Not an RCT: quasi experiment/observational study with two matched groups \\
\hline O'Connor - Cambridge UK & Did not meet criteria for case management intervention. \\
\hline Onor - Italy & Did not meet criteria for case management intervention. \\
\hline Schoenmakers-Belgium & The study focused only upon carers of people with dementia. \\
\hline Stenvall - Sweden & $\begin{array}{l}\text { Did not meet criteria for case management intervention - individual care planning not case man- } \\
\text { agement at home. Subgroup analysis. }\end{array}$ \\
\hline Valimaki - Finland & Did not meet criteria for case management intervention. \\
\hline Van denDungen-Netherlands & Did not meet criteria for case management intervention. \\
\hline Vernooij-DassenNetherland & Did not meet criteria for case management intervention. \\
\hline Weinberger - US & Study focused only upon carers of people with dementia. \\
\hline Wilcock - UK & $\begin{array}{l}\text { RCT proposal for psycho-educational intervention. Did not meet criteria for case management in- } \\
\text { tervention. }\end{array}$ \\
\hline Wisniewski - US & Did not meet criteria for case management intervention. \\
\hline Wolfs - The Netherlands & Did not meet criteria for case management intervention. \\
\hline
\end{tabular}

\section{Characteristics of studies awaiting assessment [ordered by study ID]}

Samus 2014

Methods 18-month RCT


Samus 2014 (Continued)

Objectives: To assess whether a dementia care coordination intervention delays time to transition from home and reduces unmet needs in elders with memory disorders.

Participants

303 community-living elders from 28 postal code areas of Baltimore, MD.

Participants: Age 70+ years, with a cognitive disorder, community-living, English-speaking, and having a study partner available.
Setting: Intervention: 18-month care co-ordination intervention to systematically identify and address dementia-related care needs through individualised care planning; referral and linkage to services; provision of dementia education and skill-building strategies; and care monitoring by an interdisciplinary team.

\section{Outcomes}

Notes
Primary outcomes were time to transfer from home and total percent of unmet care needs at 18 months.

Results: Intervention participants had a significant delay in time to all-cause transition from home and the adjusted hazard of leaving the home was decreased by $37 \%$ (Hazard ratio: 0.63, 95\% Confidence Interval: $0.42 \mathrm{e} 0.94$ ) compared with control participants. Although there was no significant group difference in reduction of total percent of unmet needs from baseline to 18 months, the intervention group had significant reductions in the proportion of unmet needs in safety and legal/advance care domains relative to controls. Intervention participants had a significant improvement in self-reported quality of life (QOL) relative to control participants. No group differences were found in proxy-rated QOL, neuropsychiatric symptoms, or depression. Conclusions: A home-based dementia care co-ordination intervention delivered by non-clinical community workers trained and overseen by geriatric clinicians led to delays in transition from home, reduced unmet needs, and improved self-reported QOL.

\section{Characteristics of ongoing studies [ordered by study ID]}

Iliffe - UK

Trial name or title

Methods

\section{CARE-DEM trial}

This study will develop and evaluate the feasibility of collaborative care for people with dementia in primary care. It will create a training programme for primary care staff to enable them to undertake case management with patients with dementia and their families (Work package 1 ). The feasibility of implementing the training programme will be tested in a pilot rehearsal trial (Work package 2), which will also allow effect sizes to be estimated for a definitive main trial. Qualitative methods will be used to study the development process and implementation in the field, as well as to inform refinement of the training programme and introduction of the case management methods into routine practice.

If the intervention appears to be effective, the researchers will seek further funding for Work package 3 , a definitive main trial which will address the key research question:

Primary objective: To evaluate the clinical and cost effectiveness of usual care augmented by collaborative care, compared to usual care, at reducing behavioural and psychological disorders in people with dementia in primary care.

Secondary objectives of this study:

1) To develop and pilot the feasibility of a UK model of collaborative care for dementia, led by a primary-care based case manager using evidence based care pathways (Work packages $1 \& 2$ ). 2) To provide a detailed description and analysis of the case management intervention, including a description of how it works in practice, and a toolkit for its replication should the intervention prove effective (Work package 2 \& Qualitative study).

3) To explore the acceptability and value of a collaborative care model in dementia, delivered by a case manager, to people with dementia, their family carers and other dementia care professionals and services (Qualitative study). 
Iliffe - UK (Continued)

Secondary objectives of the follow-on study (Work package 3)

4) To conduct a cost-utility analysis of usual care augmented by collaborative care management, compared to usual care, on NHS resource utilisation by people with dementia and their family carers. The outcome in this analysis would be change in quality-adjusted life years (QALYs) derived from the DEMQOL (using an algorithm currently being developed in a study by Banerjee, Brazier, Knapp and others, funded by the HTA) (Work package 3, definitive trial).

\begin{tabular}{ll}
\hline Participants & Not known \\
\hline Interventions & Not known \\
\hline Outcomes & Not known \\
\hline Starting date & March 2011 \\
\hline Contact information & $\begin{array}{l}\text { Professor Stephen Iliffe, Professor of Primary Care for Older People, Centre for Ageing Population } \\
\text { Studies, University College London } \\
\text { Steve lliffe/Louise Robinson (co Pls), Bond J, Chew-Graham C, Katona C, Knapp M. }\end{array}$ \\
\hline Notes & Publication expected September 2014 \\
\hline
\end{tabular}

\section{DATA AND ANALYSES}

\section{Comparison 1. Case management versus usual care (primary outcomes)}

\begin{tabular}{|c|c|c|c|c|}
\hline Outcome or subgroup title & $\begin{array}{l}\text { No. of } \\
\text { studies }\end{array}$ & $\begin{array}{l}\text { No. of } \\
\text { partici- } \\
\text { pants }\end{array}$ & Statistical method & Effect size \\
\hline $\begin{array}{l}1 \text { Institutionalised (number of partici- } \\
\text { pants admitted to residential or nursing } \\
\text { homes) (as reported at each time point) }\end{array}$ & 9 & & Odds Ratio (M-H, Fixed, 95\% Cl) & Subtotals only \\
\hline 1.1 At 6 months & 6 & 5741 & Odds Ratio (M-H, Fixed, 95\% Cl) & $0.82[0.69,0.98]$ \\
\hline 1.2 At $10-12$ months & 9 & 5990 & Odds Ratio (M-H, Fixed, 95\% Cl) & $0.95[0.83,1.08]$ \\
\hline 1.3 At 18 months & 4 & 363 & Odds Ratio (M-H, Fixed, 95\% Cl) & $0.25[0.10,0.61]$ \\
\hline 1.4 At 24 months & 2 & 201 & Odds Ratio (M-H, Fixed, 95\% Cl) & $1.03[0.52,2.03]$ \\
\hline $\begin{array}{l}2 \text { Institutionalised (nursing home stays, } \\
\text { mean number of days per month) }\end{array}$ & 2 & & $\begin{array}{l}\text { Mean Difference (IV, Fixed, 95\% } \\
\mathrm{CI})\end{array}$ & Subtotals only \\
\hline 2.1 At 6 months & 1 & 88 & $\begin{array}{l}\text { Mean Difference (IV, Fixed, 95\% } \\
\mathrm{CI} \text { ) }\end{array}$ & $-5.80[-7.93,-3.67]$ \\
\hline 2.2 At 12 months & 1 & 88 & $\begin{array}{l}\text { Mean Difference (IV, Fixed, 95\% } \\
\mathrm{Cl} \text { ) }\end{array}$ & $-7.70[-9.38,-6.02]$ \\
\hline 2.3 At 18 months & 1 & 267 & $\begin{array}{l}\text { Mean Difference (IV, Fixed, 95\% } \\
\mathrm{Cl} \text { ) }\end{array}$ & $0.17[-0.92,1.26]$ \\
\hline
\end{tabular}




\begin{tabular}{|c|c|c|c|c|}
\hline Outcome or subgroup title & $\begin{array}{l}\text { No. of } \\
\text { studies }\end{array}$ & $\begin{array}{l}\text { No. of } \\
\text { partici- } \\
\text { pants }\end{array}$ & Statistical method & Effect size \\
\hline 3 Time to institutionalisation & 1 & & Hazard Ratio (Fixed, 95\% Cl) & Subtotals only \\
\hline 3.1 At 12 months & 1 & & Hazard Ratio (Fixed, 95\% Cl) & $0.66[0.38,1.14]$ \\
\hline $\begin{array}{l}4 \text { Hospital admission (mean number of } \\
\text { nights/ }\end{array}$ & 3 & & $\begin{array}{l}\text { Mean Difference (IV, Random, } \\
95 \% \mathrm{CI})\end{array}$ & Subtotals only \\
\hline 4.1 at 6 months & 3 & 341 & $\begin{array}{l}\text { Mean Difference (IV, Random, } \\
95 \% \mathrm{CI})\end{array}$ & $0.63[0.40,0.86]$ \\
\hline $\begin{array}{l}5 \text { Hospital admissions: (number of par- } \\
\text { ticipants admitted to hospital) }\end{array}$ & 6 & 1637 & Odds Ratio (M-H, Fixed, 95\% Cl) & $0.85[0.67,1.09]$ \\
\hline 5.1 Admitted to hospital at 6 months & 4 & 439 & Odds Ratio (M-H, Fixed, 95\% Cl) & $1.06[0.61,1.84]$ \\
\hline 5.2 Admitted to hospital at 12 months & 5 & 585 & Odds Ratio (M-H, Fixed, 95\% Cl) & $0.87[0.59,1.30]$ \\
\hline 5.3 Admitted to hospital at 18 months & 5 & 613 & Odds Ratio (M-H, Fixed, 95\% Cl) & $0.76[0.53,1.10]$ \\
\hline $\begin{array}{l}6 \text { Mortality (number of deaths, partici- } \\
\text { pants) (as reported at each time point) }\end{array}$ & 11 & & Odds Ratio (M-H, Fixed, 95\% Cl) & Subtotals only \\
\hline 6.1 At $4-6$ months & 8 & 5864 & Odds Ratio (M-H, Fixed, 95\% Cl) & $0.86[0.64,1.16]$ \\
\hline 6.2 At 12 months & 8 & 6112 & Odds Ratio (M-H, Fixed, 95\% Cl) & $1.00[0.83,1.20]$ \\
\hline 6.3 At $18-24$ months & 5 & 513 & Odds Ratio (M-H, Fixed, 95\% Cl) & $1.00[0.52,1.92]$ \\
\hline 6.4 At 36 months & 1 & 5209 & Odds Ratio (M-H, Fixed, 95\% Cl) & $1.03[0.92,1.15]$ \\
\hline 7 Quality of life (participants) & 3 & & $\begin{array}{l}\text { Mean Difference (IV, Fixed, 95\% } \\
\mathrm{CI})\end{array}$ & Subtotals only \\
\hline 7.1 At 4 months & 1 & 99 & $\begin{array}{l}\text { Mean Difference (IV, Fixed, 95\% } \\
\mathrm{CI})\end{array}$ & $-3.74[-12.42,4.94]$ \\
\hline 7.2 At 6 months & 1 & 58 & $\begin{array}{l}\text { Mean Difference (IV, Fixed, 95\% } \\
\mathrm{CI})\end{array}$ & $0.26[-0.45,0.97]$ \\
\hline 7.3 At 12 months & 3 & 511 & $\begin{array}{l}\text { Mean Difference (IV, Fixed, 95\% } \\
\mathrm{CI})\end{array}$ & $0.03[-0.06,0.12]$ \\
\hline 7.4 At 18 months & 1 & 225 & $\begin{array}{l}\text { Mean Difference (IV, Fixed, 95\% } \\
\mathrm{CI})\end{array}$ & $0.06[-0.05,0.17]$ \\
\hline 8 Quality of life (carers) & 5 & & $\begin{array}{l}\text { Std. Mean Difference (IV, Fixed, } \\
95 \% \mathrm{CI})\end{array}$ & Subtotals only \\
\hline 8.1 at 4 months & 1 & 99 & $\begin{array}{l}\text { Std. Mean Difference (IV, Fixed, } \\
95 \% \mathrm{Cl})\end{array}$ & $-0.25[-0.66,0.15]$ \\
\hline 8.2 At 6 months & 1 & 88 & $\begin{array}{l}\text { Std. Mean Difference (IV, Fixed, } \\
95 \% \mathrm{CI} \text { ) }\end{array}$ & $0.33[-0.09,0.75]$ \\
\hline
\end{tabular}




\begin{tabular}{|c|c|c|c|c|}
\hline Outcome or subgroup title & $\begin{array}{l}\text { No. of } \\
\text { studies }\end{array}$ & $\begin{array}{l}\text { No. of } \\
\text { partici- } \\
\text { pants }\end{array}$ & Statistical method & Effect size \\
\hline 8.3 At 12 months & 5 & 681 & $\begin{array}{l}\text { Std. Mean Difference (IV, Fixed, } \\
95 \% \mathrm{Cl} \text { ) }\end{array}$ & $0.21[0.06,0.37]$ \\
\hline 8.4 At 18 months & 2 & 373 & $\begin{array}{l}\text { Std. Mean Difference (IV, Fixed, } \\
95 \% \mathrm{Cl} \text { ) }\end{array}$ & $0.25[0.04,0.46]$ \\
\hline 9 Caregiver burden & 8 & & $\begin{array}{l}\text { Std. Mean Difference (IV, Fixed, } \\
95 \% \mathrm{CI} \text { ) }\end{array}$ & Subtotals only \\
\hline 9.1 At 3 - 4 months & 3 & 228 & $\begin{array}{l}\text { Std. Mean Difference (IV, Fixed, } \\
95 \% \mathrm{CI})\end{array}$ & $-0.06[-0.33,0.20]$ \\
\hline 9.2 At 6 months & 4 & 4601 & $\begin{array}{l}\text { Std. Mean Difference (IV, Fixed, } \\
95 \% \mathrm{CI} \text { ) }\end{array}$ & $-0.07[-0.12,-0.01]$ \\
\hline 9.3 At $10-12$ months & 7 & 3772 & $\begin{array}{l}\text { Std. Mean Difference (IV, Fixed, } \\
95 \% \mathrm{CI} \text { ) }\end{array}$ & $-0.05[-0.12,0.01]$ \\
\hline 9.4 At 18 months & 3 & 2860 & $\begin{array}{l}\text { Std. Mean Difference (IV, Fixed, } \\
95 \% \mathrm{CI} \text { ) }\end{array}$ & $-0.08[-0.16,-0.01]$ \\
\hline 9.5 At 24 months & 2 & 2931 & $\begin{array}{l}\text { Std. Mean Difference (IV, Fixed, } \\
95 \% \mathrm{CI} \text { ) }\end{array}$ & $-0.03[-0.11,0.04]$ \\
\hline 9.6 At 36 months & 1 & 1906 & $\begin{array}{l}\text { Std. Mean Difference (IV, Fixed, } \\
95 \% \mathrm{CI} \text { ) }\end{array}$ & $-0.04[-0.13,0.05]$ \\
\hline
\end{tabular}

\section{Analysis 1.1. Comparison 1 Case management versus usual care (primary outcomes), Outcome 1 Institutionalised} (number of participants admitted to residential or nursing homes) (as reported at each time point).

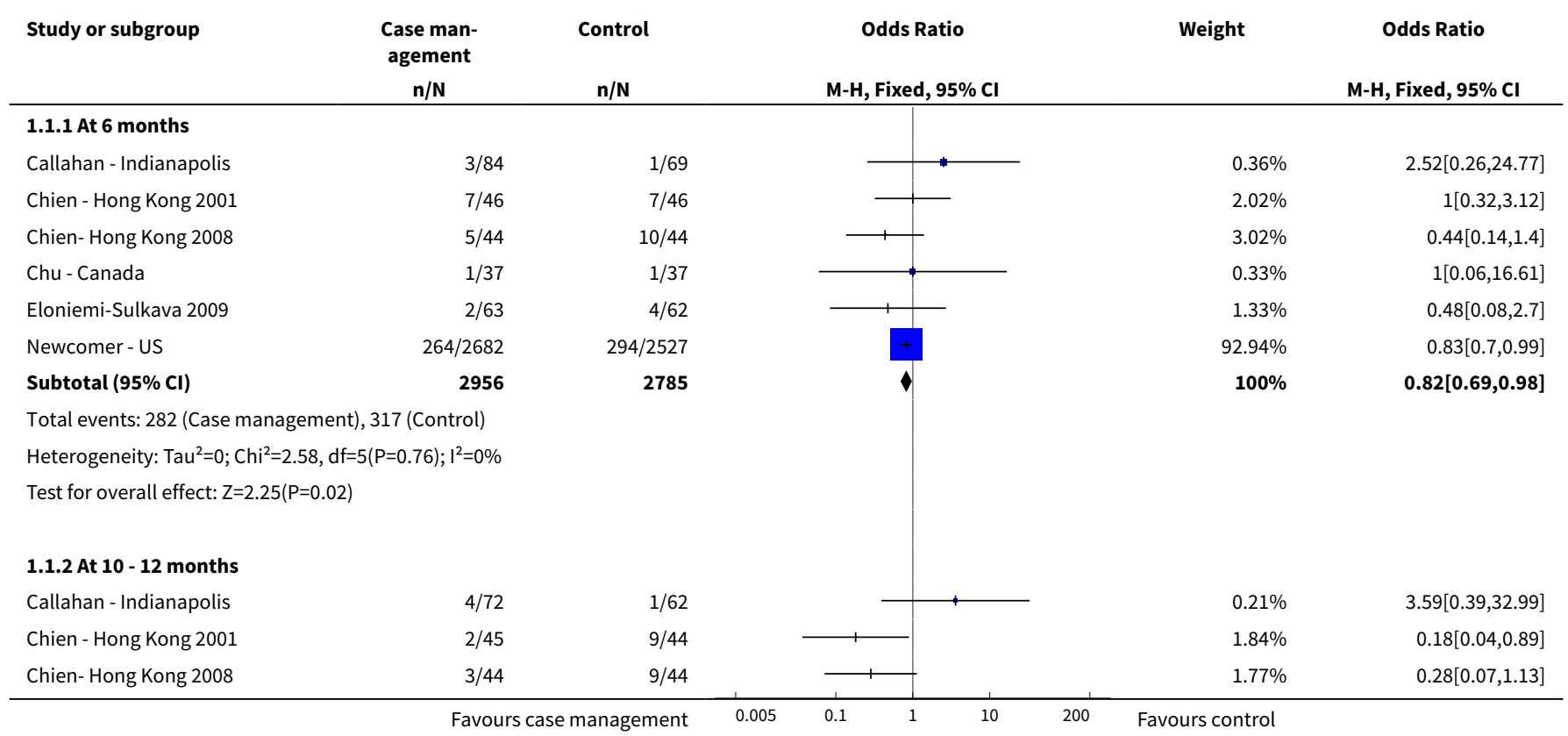




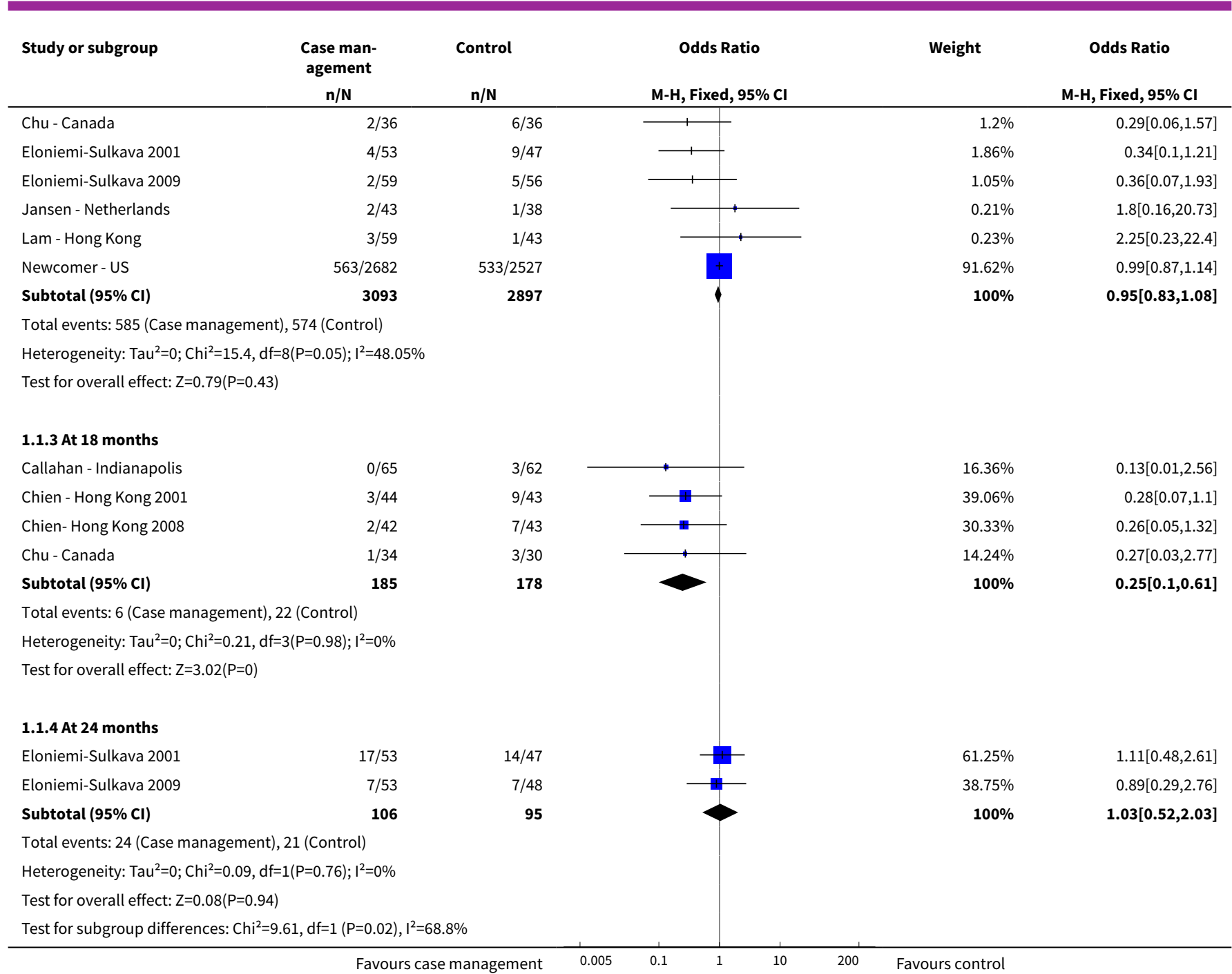

Analysis 1.2. Comparison 1 Case management versus usual care (primary outcomes), Outcome 2 Institutionalised (nursing home stays, mean number of days per month).

\begin{tabular}{|c|c|c|c|c|c|c|c|}
\hline \multirow[t]{2}{*}{ Study or subgroup } & \multicolumn{2}{|c|}{ Case management } & \multicolumn{2}{|c|}{ Control } & \multirow{2}{*}{$\begin{array}{c}\text { Mean Difference } \\
\text { Fixed, } 95 \% \mathrm{Cl}\end{array}$} & \multirow[t]{2}{*}{ Weight } & \multirow{2}{*}{$\begin{array}{c}\text { Mean Difference } \\
\text { Fixed, } 95 \% \mathrm{Cl}\end{array}$} \\
\hline & $\mathbf{N}$ & $\operatorname{Mean}(\mathrm{SD})$ & $\mathbf{N}$ & Mean(SD) & & & \\
\hline \multicolumn{8}{|l|}{ 1.2.1 At 6 months } \\
\hline Chien- Hong Kong 2008 & 44 & $11.1(5.1)$ & 44 & $16.9(5.1)$ & & $100 \%$ & $-5.8[-7.93,-3.67]$ \\
\hline 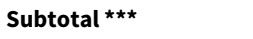 & 44 & & 44 & & & $100 \%$ & $-5.8[-7.93,-3.67]$ \\
\hline \multicolumn{8}{|c|}{ Heterogeneity: Not applicable } \\
\hline \multicolumn{8}{|c|}{ Test for overall effect: $Z=5.33(P<0.0001)$} \\
\hline \multicolumn{8}{|l|}{ 1.2.2 At 12 months } \\
\hline Chien- Hong Kong 2008 & 44 & $9.4(2.3)$ & 44 & $17.1(5.2)$ & & $100 \%$ & $-7.7[-9.38,-6.02]$ \\
\hline 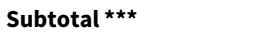 & 44 & & 44 & & & $100 \%$ & $-7.7[-9.38,-6.02]$ \\
\hline \multicolumn{8}{|c|}{ Heterogeneity: $\mathrm{Tau}^{2}=0 ; \mathrm{Chi}^{2}=0, \mathrm{df}=0(\mathrm{P}<0.0001) ; \mathrm{I}^{2}=100 \%$} \\
\hline \multicolumn{8}{|c|}{ Test for overall effect: $Z=8.98(P<0.0001)$} \\
\hline
\end{tabular}




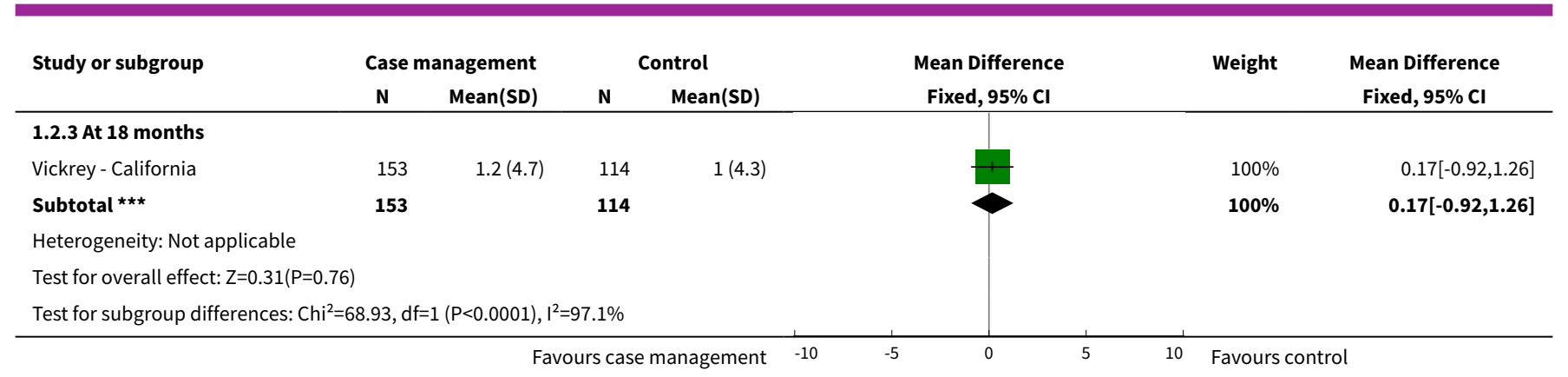

Analysis 1.3. Comparison 1 Case management versus usual care (primary outcomes), Outcome 3 Time to institutionalisation.

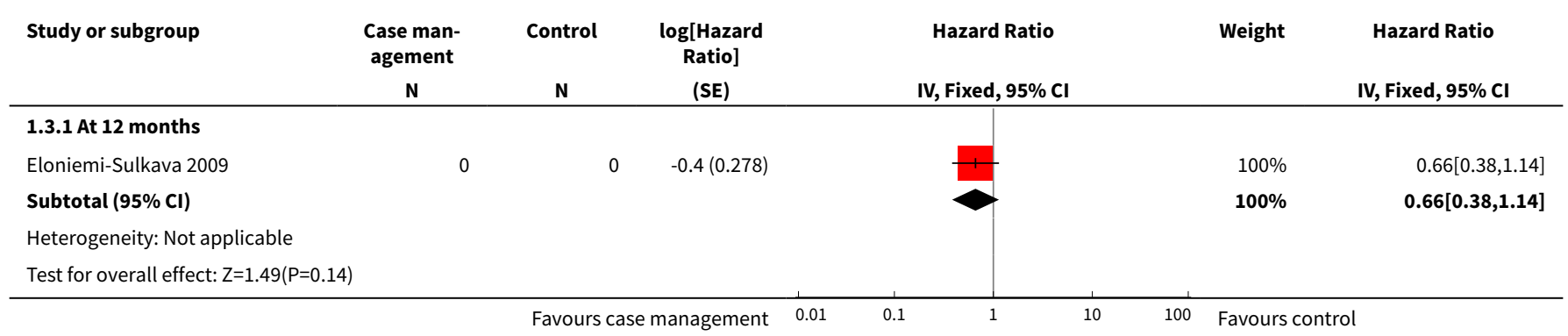

Analysis 1.4. Comparison 1 Case management versus usual care (primary outcomes), Outcome 4 Hospital admission (mean number of nights/.

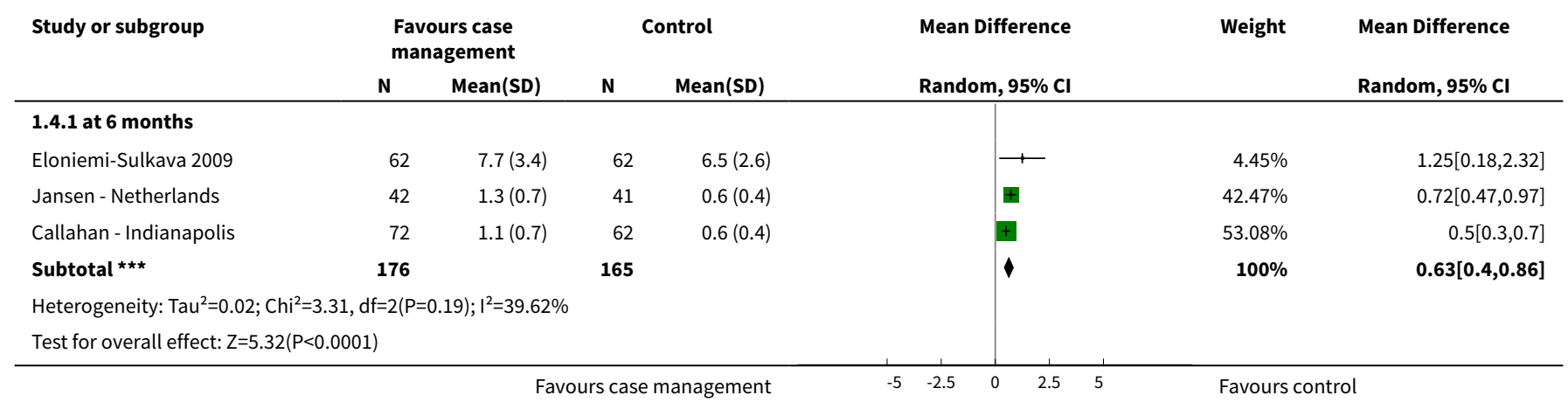

Analysis 1.5. Comparison 1 Case management versus usual care (primary outcomes), Outcome 5 Hospital admissions: (number of participants admitted to hospital).

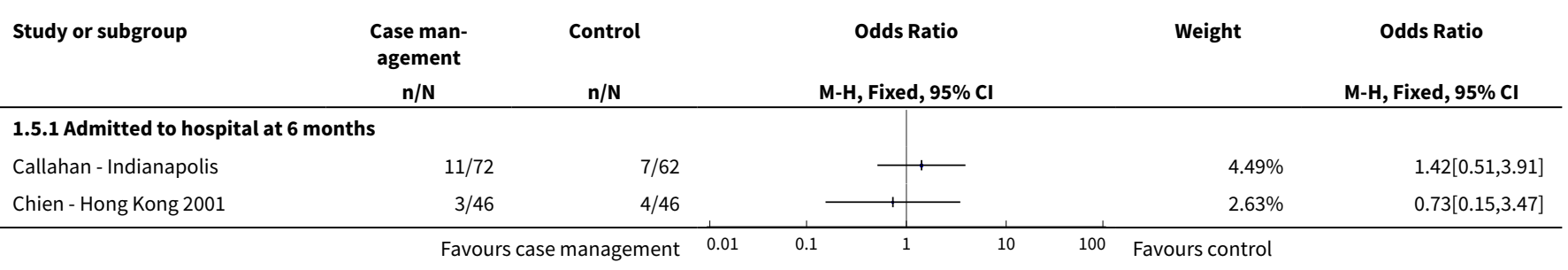




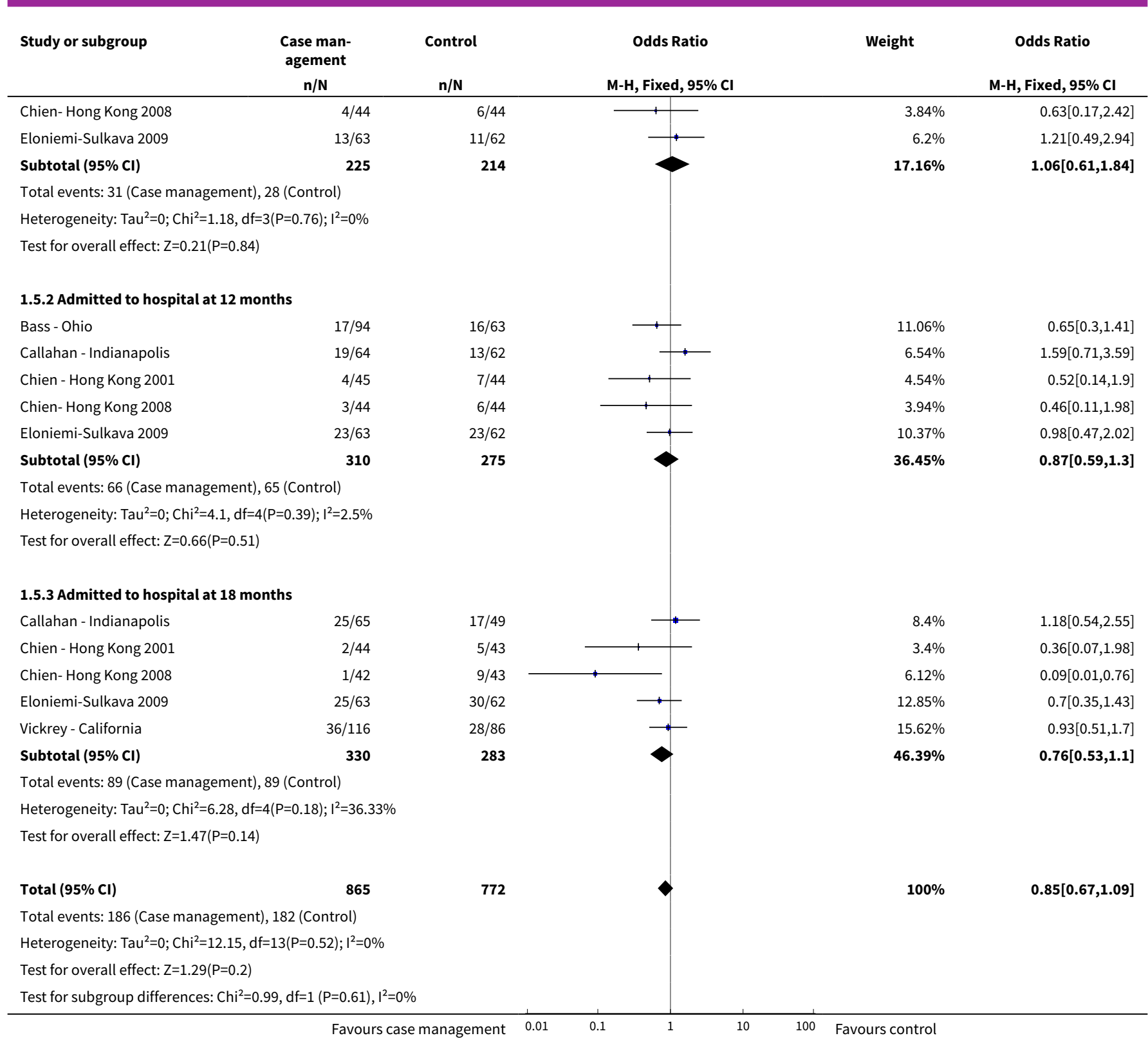

$\begin{array}{lllllll}\text { Favours case management } & 0.01 & 0.1 & 1 & 10 & 100 & \text { Favours control }\end{array}$

Analysis 1.6. Comparison 1 Case management versus usual care (primary outcomes), Outcome 6 Mortality (number of deaths, participants) (as reported at each time point).

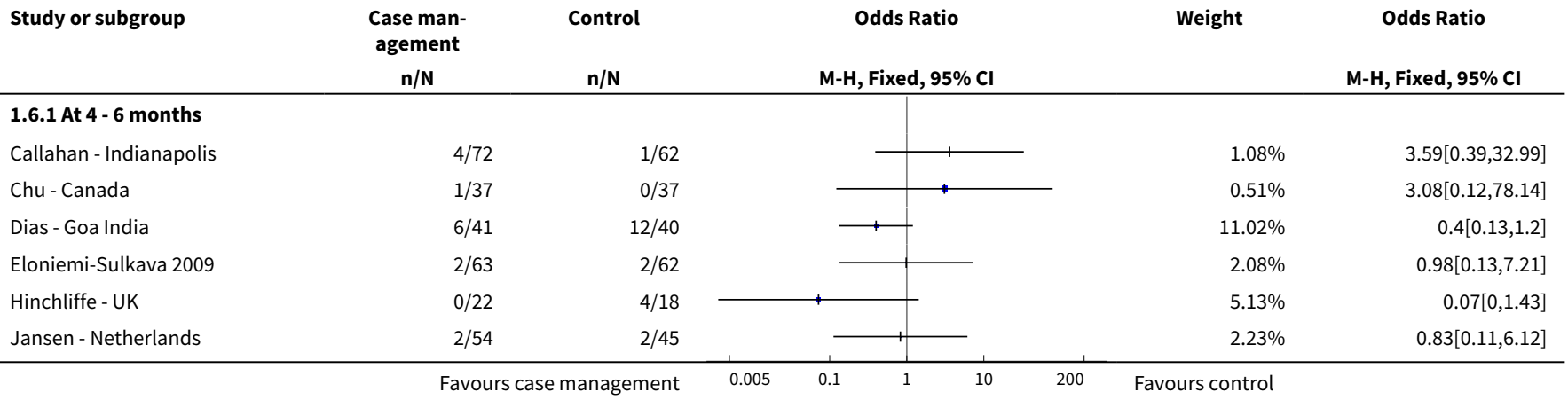




\begin{tabular}{|c|c|c|c|c|c|}
\hline Study or subgroup & $\begin{array}{c}\text { Case man- } \\
\text { agement } \\
n / N\end{array}$ & $\begin{array}{c}\text { Control } \\
\text { n/N }\end{array}$ & $\begin{array}{c}\text { Odds Ratio } \\
\text { M-H, Fixed, 95\% CI }\end{array}$ & Weight & $\begin{array}{c}\text { Odds Ratio } \\
\text { M-H, Fixed, } 95 \% \mathrm{Cl}\end{array}$ \\
\hline Lam - Hong Kong & $2 / 59$ & $1 / 43$ & 1 & $1.19 \%$ & $1.47[0.13,16.8]$ \\
\hline Newcomer - US & $70 / 2682$ & $72 / 2527$ & & $76.76 \%$ & $0.91[0.65,1.28]$ \\
\hline Subtotal $(95 \% \mathrm{Cl})$ & 3030 & 2834 & & $100 \%$ & $0.86[0.64,1.16]$ \\
\hline \multicolumn{6}{|c|}{ Heterogeneity: Tau $^{2}=0 ; \mathrm{Chi}^{2}=7.04, \mathrm{df}=7(\mathrm{P}=0.43) ; \mathrm{I}^{2}=0.51 \%$} \\
\hline \multicolumn{6}{|c|}{ Test for overall effect: $Z=1(P=0.32)$} \\
\hline \multicolumn{6}{|l|}{ 1.6.2 At 12 months } \\
\hline Callahan - Indianapolis & $3 / 64$ & $2 / 62$ & 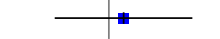 & $0.86 \%$ & $1.48[0.24,9.15]$ \\
\hline Chu - Canada & $2 / 37$ & $0 / 37$ & $\rightarrow$ & $0.21 \%$ & $5.28[0.24,113.87]$ \\
\hline Eloniemi-Sulkava 2009 & $4 / 63$ & $3 / 62$ & & $1.26 \%$ & $1.33[0.29,6.22]$ \\
\hline Jansen - Netherlands & $4 / 54$ & $3 / 45$ & & $1.35 \%$ & $1.12[0.24,5.29]$ \\
\hline Lam - Hong Kong & $6 / 59$ & $4 / 43$ & & $1.86 \%$ & $1.1[0.29,4.18]$ \\
\hline Newcomer - US & $225 / 2682$ & $220 / 2527$ & & $92.68 \%$ & $0.96[0.79,1.17]$ \\
\hline Vickrey - California & $2 / 161$ & $1 / 116$ & & $0.51 \%$ & $1.45[0.13,16.14]$ \\
\hline Subtotal $(95 \% \mathrm{Cl})$ & 3173 & 2939 & $Y$ & $100 \%$ & $1[0.83,1.2]$ \\
\hline \multicolumn{6}{|c|}{ Total events: 252 (Case management), 236 (Control) } \\
\hline \multicolumn{6}{|c|}{ Heterogeneity: $\operatorname{Tau}^{2}=0 ; \mathrm{Chi}^{2}=2.46, \mathrm{df}=7(\mathrm{P}=0.93) ; \mathrm{I}^{2}=0 \%$} \\
\hline \multicolumn{6}{|c|}{ Test for overall effect: $Z=0.03(P=0.98)$} \\
\hline \multicolumn{6}{|l|}{ 1.6.3 At $18-24$ months } \\
\hline Callahan - Indianapolis & $1 / 65$ & $4 / 62$ & - & $22.44 \%$ & $0.23[0.02,2.09]$ \\
\hline Chien - Hong Kong 2001 & $1 / 46$ & $0 / 46$ & & $2.69 \%$ & $3.07[0.12,77.24]$ \\
\hline Eloniemi-Sulkava 2009 & $5 / 63$ & $6 / 62$ & & $31 \%$ & $0.8[0.23,2.79]$ \\
\hline Subtotal $(95 \% \mathrm{Cl})$ & 260 & 253 & & $100 \%$ & $1[0.52,1.92]$ \\
\hline \multicolumn{6}{|c|}{ Total events: 20 (Case management), 19 (Control) } \\
\hline \multicolumn{6}{|c|}{ Heterogeneity: $\mathrm{Tau}^{2}=0 ; \mathrm{Chi}^{2}=4.19, \mathrm{df}=4(\mathrm{P}=0.38) ; \mathrm{I}^{2}=4.46 \%$} \\
\hline \multicolumn{6}{|c|}{ Test for overall effect: $Z=0(P=1)$} \\
\hline \multicolumn{6}{|l|}{ 1.6.4 At 36 months } \\
\hline Newcomer - US & $941 / 2682$ & $872 / 2527$ & & $100 \%$ & $1.03[0.92,1.15]$ \\
\hline Subtotal $(95 \% \mathrm{CI})$ & 2682 & 2527 & 1 & $100 \%$ & $1.03[0.92,1.15]$ \\
\hline \multicolumn{6}{|c|}{ Total events: 941 (Case management), 872 (Control) } \\
\hline \multicolumn{6}{|c|}{ Heterogeneity: Not applicable } \\
\hline \multicolumn{6}{|c|}{ Test for overall effect: $Z=0.44(P=0.66)$} \\
\hline Test for subgroup differe & , $d f=1(P=0.76)$ & & & & \\
\hline
\end{tabular}

Analysis 1.7. Comparison 1 Case management versus usual care (primary outcomes), Outcome 7 Quality of life (participants).

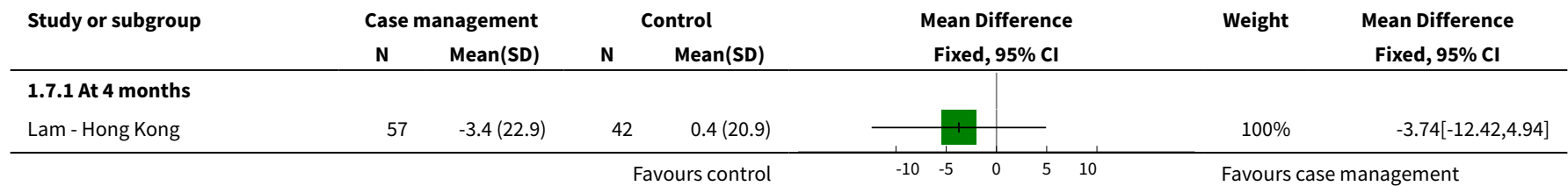




\begin{tabular}{|c|c|c|c|c|c|c|c|}
\hline \multirow[t]{2}{*}{ Study or subgroup } & \multicolumn{2}{|c|}{ Case management } & \multicolumn{2}{|c|}{ Control } & \multirow{2}{*}{$\begin{array}{c}\text { Mean Difference } \\
\text { Fixed, } 95 \% \mathrm{Cl}\end{array}$} & \multirow[t]{2}{*}{ Weight } & \multirow{2}{*}{$\begin{array}{c}\text { Mean Difference } \\
\text { Fixed, } 95 \% \mathrm{Cl}\end{array}$} \\
\hline & $\mathbf{N}$ & Mean(SD) & $\mathbf{N}$ & Mean(SD) & & & \\
\hline Subtotal $* \star \star$ & 57 & & 42 & & & $100 \%$ & $-3.74[-12.42,4.94]$ \\
\hline \multicolumn{8}{|c|}{ Heterogeneity: Tau $^{2}=0 ; \mathrm{Chi}^{2}=0, \mathrm{df}=0(\mathrm{P}<0.0001) ; \mathrm{I}^{2}=100 \%$} \\
\hline \multicolumn{8}{|c|}{ Test for overall effect: $Z=0.84(P=0.4)$} \\
\hline \multicolumn{8}{|l|}{ 1.7.2 At 6 months } \\
\hline Jansen - Netherlands & 30 & $0.1(1.4)$ & 28 & $-0.2(1.4)$ & + & $100 \%$ & $0.26[-0.45,0.97]$ \\
\hline Subtotal $\star \star \star$ & 30 & & 28 & & 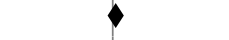 & $100 \%$ & $0.26[-0.45,0.97]$ \\
\hline \multicolumn{8}{|c|}{ Heterogeneity: Not applicable } \\
\hline \multicolumn{8}{|c|}{ Test for overall effect: $\mathrm{Z}=0.72(\mathrm{P}=0.47)$} \\
\hline \multicolumn{8}{|l|}{ 1.7.3 At 12 months } \\
\hline Jansen - Netherlands & 30 & $0.1(1.4)$ & 28 & $-0.2(1.4)$ & 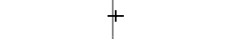 & $1.63 \%$ & $0.26[-0.45,0.97]$ \\
\hline Lam - Hong Kong & 53 & $-5.5(24.8)$ & 39 & $-2.5(18.9)$ & & $0.01 \%$ & $-2.99[-11.93,5.95]$ \\
\hline Vickrey - California & 205 & $-0.1(0.4)$ & 156 & $-0.1(0.4)$ & & $98.36 \%$ & $0.03[-0.06,0.12]$ \\
\hline Subtotal $\star \star \star$ & 288 & & 223 & & & $100 \%$ & $0.03[-0.06,0.12]$ \\
\hline \multicolumn{8}{|c|}{ Heterogeneity: $\mathrm{Tau}^{2}=0 ; \mathrm{Chi}^{2}=0.83, \mathrm{df}=2(\mathrm{P}=0.66) ; \mathrm{I}^{2}=0 \%$} \\
\hline \multicolumn{8}{|c|}{ Test for overall effect: $\mathrm{Z}=0.72(\mathrm{P}=0.47)$} \\
\hline \multicolumn{8}{|l|}{ 1.7.4 At 18 months } \\
\hline Vickrey - California & 129 & $-0.1(0.4)$ & 96 & $-0.1(0.4)$ & & $100 \%$ & $0.06[-0.05,0.17]$ \\
\hline Subtotal $* \star \star$ & 129 & & 96 & & & $100 \%$ & $0.06[-0.05,0.17]$ \\
\hline \multicolumn{8}{|c|}{ Heterogeneity: Not applicable } \\
\hline \multicolumn{8}{|c|}{ Test for overall effect: $\mathrm{Z}=1.04(\mathrm{P}=0.3)$} \\
\hline \multicolumn{8}{|c|}{ Test for subgroup differences: $\mathrm{Chi}^{2}=1.21, \mathrm{df}=1(\mathrm{P}=0.75), \mathrm{I}^{2}=0 \%$} \\
\hline
\end{tabular}

Analysis 1.8. Comparison 1 Case management versus usual
care (primary outcomes), Outcome 8 Quality of life (carers).

\begin{tabular}{|c|c|c|c|c|c|c|c|}
\hline \multirow[t]{2}{*}{ Study or subgroup } & \multicolumn{2}{|c|}{ Case management } & \multicolumn{2}{|c|}{ Control } & \multirow{2}{*}{$\begin{array}{c}\text { Std. Mean Difference } \\
\text { Fixed, } 95 \% \mathrm{Cl}\end{array}$} & \multirow[t]{2}{*}{ Weight } & \multirow{2}{*}{$\begin{array}{c}\text { Std. Mean Difference } \\
\text { Fixed, } 95 \% \mathrm{Cl}\end{array}$} \\
\hline & $\mathbf{N}$ & Mean(SD) & $\mathbf{N}$ & Mean(SD) & & & \\
\hline \multicolumn{8}{|l|}{ 1.8.1 at 4 months } \\
\hline Lam - Hong Kong & 57 & $-1.8(11.5)$ & 42 & $1.2(11.8)$ & & $100 \%$ & $-0.25[-0.66,0.15]$ \\
\hline 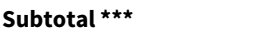 & 57 & & 42 & & & $100 \%$ & $-0.25[-0.66,0.15]$ \\
\hline \multicolumn{8}{|c|}{ Heterogeneity: Not applicable } \\
\hline \multicolumn{8}{|c|}{ Test for overall effect: $Z=1.25(P=0.21)$} \\
\hline \multicolumn{8}{|l|}{ 1.8.2 At 6 months } \\
\hline Chien- Hong Kong 2008 & 44 & $10.2(22.6)$ & 44 & $2.7(22.8)$ & & $100 \%$ & $0.33[-0.09,0.75]$ \\
\hline Subtotal $\star \star \star$ & 44 & & 44 & & & $100 \%$ & $0.33[-0.09,0.75]$ \\
\hline \multicolumn{8}{|c|}{ Heterogeneity: Not applicable } \\
\hline \multicolumn{8}{|c|}{ Test for overall effect: $Z=1.52(P=0.13)$} \\
\hline Chien - Hong Kong 2001 & 46 & $15.6(20.4)$ & 46 & $-1.9(23.8)$ & $\rightarrow$ & $12.95 \%$ & $0.78[0.36,1.21]$ \\
\hline Chien- Hong Kong 2008 & 44 & $16.5(21.9)$ & 44 & $-1.9(23.4)$ & + & $12.33 \%$ & $0.8[0.37,1.24]$ \\
\hline Jansen - Netherlands & 43 & $-2.9(13.4)$ & 37 & $-0.5(15)$ & $\rightarrow$ & $12.04 \%$ & $-0.17[-0.61,0.27]$ \\
\hline Lam - Hong Kong & 53 & $1.9(16.4)$ & 39 & $0.2(11.6)$ & + & $13.63 \%$ & $0.12[-0.29,0.53]$ \\
\hline Vickrey - California & 187 & $0(0.2)$ & 142 & $-0(0.3)$ & 世 & $49.05 \%$ & $0.04[-0.18,0.25]$ \\
\hline
\end{tabular}




\begin{tabular}{|c|c|c|c|c|c|c|c|}
\hline \multirow[t]{2}{*}{ Study or subgroup } & \multicolumn{2}{|c|}{ Case management } & \multicolumn{2}{|c|}{ Control } & \multirow{2}{*}{$\begin{array}{c}\text { Std. Mean Difference } \\
\text { Fixed, } 95 \% \mathrm{Cl}\end{array}$} & \multirow[t]{2}{*}{ Weight } & \multirow{2}{*}{$\begin{array}{c}\text { Std. Mean Difference } \\
\text { Fixed, } 95 \% \mathrm{Cl}\end{array}$} \\
\hline & $\mathbf{N}$ & Mean(SD) & $\mathbf{N}$ & Mean(SD) & & & \\
\hline Subtotal $\star \star \star$ & 373 & & 308 & & $\downarrow$ & $100 \%$ & $0.21[0.06,0.37]$ \\
\hline \multicolumn{8}{|c|}{ Heterogeneity: Tau $^{2}=0 ; \mathrm{Chi}^{2}=19.57, \mathrm{df}=4(\mathrm{P}=0) ; \mathrm{I}^{2}=79.56 \%$} \\
\hline \multicolumn{8}{|c|}{ Test for overall effect: $Z=2.75(P=0.01)$} \\
\hline \multicolumn{8}{|l|}{ 1.8.4 At 18 months } \\
\hline Chien - Hong Kong 2001 & 46 & $17.9(19.2)$ & 46 & $-2.6(20.6)$ & $\rightarrow$ & $22.75 \%$ & $1.02[0.58,1.46]$ \\
\hline Vickrey - California & 161 & $-0(0.4)$ & 120 & $-0(0.4)$ & 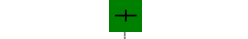 & $77.25 \%$ & $0.02[-0.21,0.26]$ \\
\hline Subtotal $\star \star \star$ & 207 & & 166 & & $\bullet$ & $100 \%$ & $0.25[0.04,0.46]$ \\
\hline \multicolumn{8}{|c|}{ Heterogeneity: $\mathrm{Tau}^{2}=0 ; \mathrm{Chi}^{2}=15.54, \mathrm{df}=1(\mathrm{P}<0.0001) ; \mathrm{I}^{2}=93.56 \%$} \\
\hline \multicolumn{8}{|c|}{ Test for overall effect: $Z=2.36(P=0.02)$} \\
\hline \multicolumn{8}{|c|}{ Test for subgroup differences: $\mathrm{Chi}^{2}=5.57, \mathrm{df}=1(\mathrm{P}=0.13), \mathrm{I}^{2}=46.13 \%$} \\
\hline
\end{tabular}

Analysis 1.9. Comparison 1 Case management versus usual care (primary outcomes), Outcome 9 Caregiver burden.

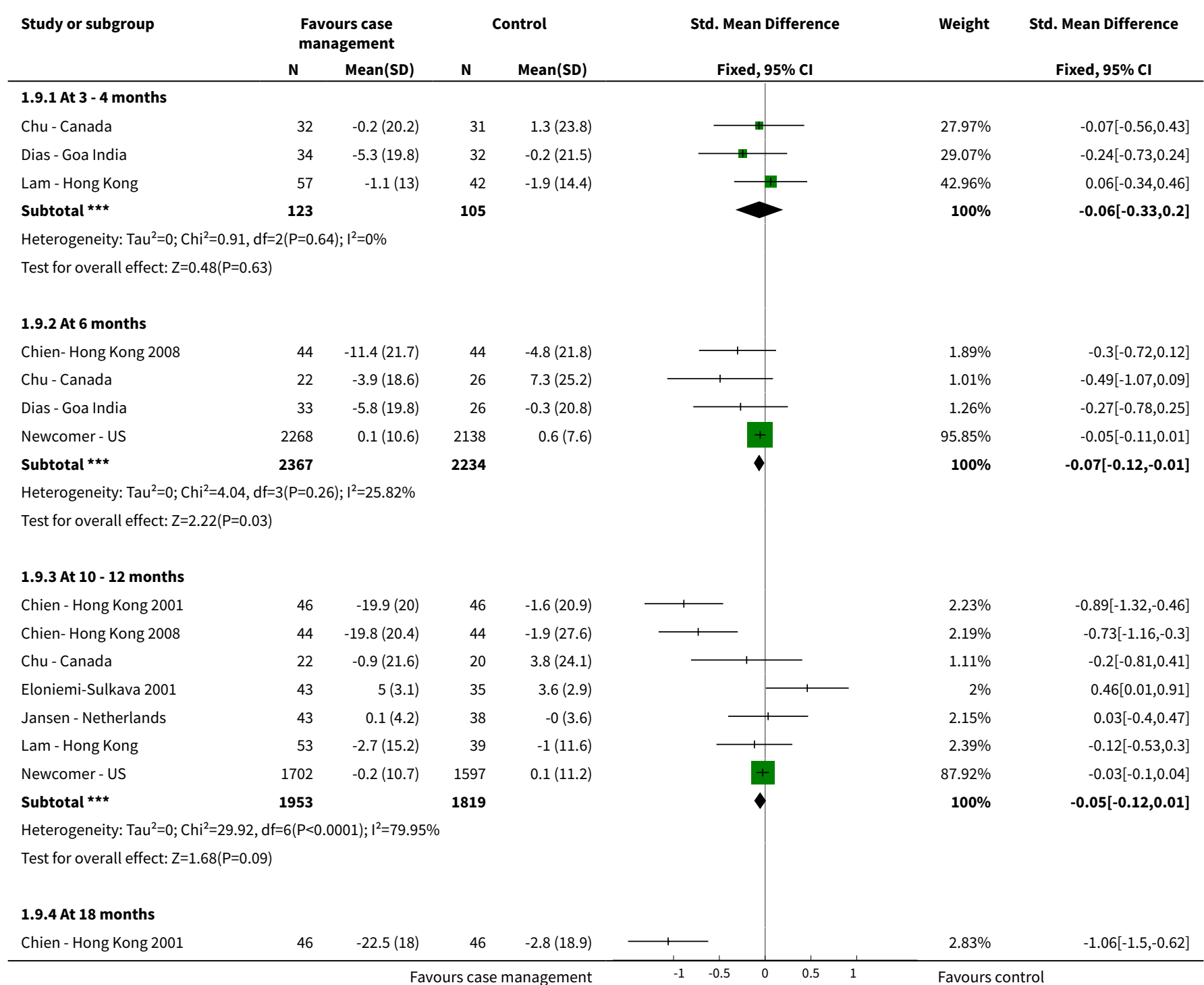




\begin{tabular}{|c|c|c|c|c|c|c|c|}
\hline \multirow{3}{*}{$\begin{array}{l}\text { Study or subgroup } \\
\text { Chu - Canada }\end{array}$} & \multicolumn{2}{|c|}{$\begin{array}{l}\text { Favours case } \\
\text { management }\end{array}$} & \multicolumn{2}{|c|}{ Control } & \multirow{2}{*}{$\begin{array}{c}\text { Std. Mean Difference } \\
\text { Fixed, } 95 \% \mathrm{Cl} \\
\end{array}$} & \multirow{3}{*}{$\begin{array}{r}\text { Weight } \\
1.66 \%\end{array}$} & \multirow{3}{*}{$\begin{array}{l}\text { Std. Mean Difference } \\
\qquad \begin{array}{c}\text { Fixed, 95\% Cl } \\
-0.14[-0.71,0.43]\end{array}\end{array}$} \\
\hline & \multirow{2}{*}{$\frac{\mathbf{N}}{27}$} & \multirow{2}{*}{$\frac{\operatorname{Mean}(\mathrm{SD})}{0.9(16.8)}$} & \multirow{2}{*}{$\frac{\mathbf{N}}{21}$} & \multirow{2}{*}{$\frac{\text { Mean(SD) }}{3.3(17.1)}$} & & & \\
\hline & & & & & +1 & & \\
\hline Newcomer - US & 1437 & $-0.6(10.8)$ & 1283 & $0(11.2)$ & & $95.51 \%$ & $-0.05[-0.13,0.02]$ \\
\hline Subtotal $\star \star \star$ & 1510 & & 1350 & & $\nabla$ & $100 \%$ & $-0.08[-0.16,-0.01]$ \\
\hline \multicolumn{8}{|c|}{ Heterogeneity: $\mathrm{Tau}^{2}=0 ; \mathrm{Chi}^{2}=19.69, \mathrm{df}=2(\mathrm{P}<0.0001) ; \mathrm{I}^{2}=89.84 \%$} \\
\hline \multicolumn{8}{|c|}{ Test for overall effect: $Z=2.24(P=0.02)$} \\
\hline \multicolumn{8}{|l|}{ 1.9.5 At 24 months } \\
\hline Eloniemi-Sulkava 2001 & 24 & $4.8(3.3)$ & 25 & $4.2(3.5)$ & - & $1.67 \%$ & $0.17[-0.39,0.73]$ \\
\hline Newcomer - US & 1528 & $-0.5(10.8)$ & 1354 & $-0.1(11.2)$ & + & $98.33 \%$ & $-0.04[-0.11,0.04]$ \\
\hline Subtotal $* * \star$ & 1552 & & 1379 & & & $100 \%$ & $-0.03[-0.11,0.04]$ \\
\hline \multicolumn{8}{|c|}{ Heterogeneity: $\mathrm{Tau}^{2}=0 ; \mathrm{Chi}^{2}=0.53, \mathrm{df}=1(\mathrm{P}=0.47) ; \mathrm{I}^{2}=0 \%$} \\
\hline \multicolumn{8}{|c|}{ Test for overall effect: $\mathrm{Z}=0.89(\mathrm{P}=0.38)$} \\
\hline \multicolumn{8}{|l|}{ 1.9.6 At 36 months } \\
\hline Newcomer - US & 986 & $-0.6(11.1)$ & 920 & $-0.1(11.3)$ & & $100 \%$ & $-0.04[-0.13,0.05]$ \\
\hline Subtotal $* \star \star$ & 986 & & 920 & & & $100 \%$ & $-0.04[-0.13,0.05]$ \\
\hline \multicolumn{8}{|c|}{ Heterogeneity: Not applicable } \\
\hline \multicolumn{8}{|c|}{ Test for overall effect: $Z=0.98(P=0.33)$} \\
\hline \multicolumn{8}{|c|}{ Test for subgroup differences: $\mathrm{Chi}^{2}=1.11, \mathrm{df}=1(\mathrm{P}=0.95), \mathrm{I}^{2}=0 \%$} \\
\hline
\end{tabular}

Comparison 2. Case management versus usual care (secondary outcomes)

\begin{tabular}{|c|c|c|c|c|}
\hline Outcome or subgroup title & $\begin{array}{l}\text { No. of } \\
\text { studies }\end{array}$ & $\begin{array}{l}\text { No. of } \\
\text { partici- } \\
\text { pants }\end{array}$ & Statistical method & Effect size \\
\hline 1 Cognition measures (participants) & 6 & & $\begin{array}{l}\text { Std. Mean Difference (IV, Fixed, } \\
95 \% \mathrm{CI} \text { ) }\end{array}$ & Subtotals only \\
\hline 1.1 At $3-4$ months & 2 & 154 & $\begin{array}{l}\text { Std. Mean Difference (IV, Fixed, } \\
95 \% \mathrm{CI} \text { ) }\end{array}$ & $-0.21[-0.53,0.11]$ \\
\hline 1.2 At 6 months & 3 & 267 & $\begin{array}{l}\text { Std. Mean Difference (IV, Fixed, } \\
95 \% \mathrm{CI} \text { ) }\end{array}$ & $0.03[-0.21,0.27]$ \\
\hline 1.3 At $10-12$ months & 6 & 518 & $\begin{array}{l}\text { Std. Mean Difference (IV, Fixed, } \\
95 \% \mathrm{CI} \text { ) }\end{array}$ & $0.00[-0.17,0.18]$ \\
\hline 1.4 At 18 months & 3 & 256 & $\begin{array}{l}\text { Std. Mean Difference (IV, Fixed, } \\
95 \% \mathrm{CI} \text { ) }\end{array}$ & $-0.02[-0.27,0.22]$ \\
\hline 1.5 At 24 months & 1 & 49 & $\begin{array}{l}\text { Std. Mean Difference (IV, Fixed, } \\
95 \% \mathrm{CI} \text { ) }\end{array}$ & $0.07[-0.49,0.63]$ \\
\hline 2 Behavioural measures (participants) & 6 & & $\begin{array}{l}\text { Std. Mean Difference (IV, Fixed, } \\
95 \% \mathrm{CI} \text { ) }\end{array}$ & Subtotals only \\
\hline 2.13 - 4 months & 2 & 165 & $\begin{array}{l}\text { Std. Mean Difference (IV, Fixed, } \\
95 \% \mathrm{CI})\end{array}$ & $-0.13[-0.44,0.18]$ \\
\hline
\end{tabular}




\begin{tabular}{|c|c|c|c|c|}
\hline Outcome or subgroup title & $\begin{array}{l}\text { No. of } \\
\text { studies }\end{array}$ & $\begin{array}{l}\text { No. of } \\
\text { partici- } \\
\text { pants }\end{array}$ & Statistical method & Effect size \\
\hline 2.26 months & 4 & 368 & $\begin{array}{l}\text { Std. Mean Difference (IV, Fixed, } \\
95 \% \mathrm{CI})\end{array}$ & $-0.20[-0.41,0.01]$ \\
\hline $2.310-12$ months & 5 & 479 & $\begin{array}{l}\text { Std. Mean Difference (IV, Fixed, } \\
95 \% \mathrm{CI})\end{array}$ & $-0.38[-0.56,-0.19]$ \\
\hline 2.418 months & 2 & 206 & $\begin{array}{l}\text { Std. Mean Difference (IV, Fixed, } \\
95 \% \mathrm{CI})\end{array}$ & $-0.35[-0.63,-0.07]$ \\
\hline $\begin{array}{l}3 \text { Depression/mood measures (partici- } \\
\text { pants) }\end{array}$ & 3 & & $\begin{array}{l}\text { Std. Mean Difference (IV, Fixed, } \\
95 \% \mathrm{CI})\end{array}$ & Subtotals only \\
\hline 3.1 At 3 - 4 months & 2 & 164 & $\begin{array}{l}\text { Std. Mean Difference (IV, Fixed, } \\
95 \% \mathrm{CI} \text { ) }\end{array}$ & $0.12[-0.19,0.43]$ \\
\hline 3.2 At 6 months & 2 & 185 & $\begin{array}{l}\text { Std. Mean Difference (IV, Fixed, } \\
95 \% \mathrm{CI} \text { ) }\end{array}$ & $0.08[-0.21,0.37]$ \\
\hline 3.3 At $10-12$ months & 3 & 259 & $\begin{array}{l}\text { Std. Mean Difference (IV, Fixed, } \\
95 \% \mathrm{CI})\end{array}$ & $-0.07[-0.32,0.17]$ \\
\hline 3.4 At 18 months & 2 & 159 & $\begin{array}{l}\text { Std. Mean Difference (IV, Fixed, } \\
95 \% \mathrm{CI} \text { ) }\end{array}$ & $-0.02[-0.33,0.29]$ \\
\hline 4 Function measures (participants) & 3 & & $\begin{array}{l}\text { Std. Mean Difference (IV, Fixed, } \\
95 \% \mathrm{CI})\end{array}$ & Subtotals only \\
\hline 4.1 At 3 months & 1 & 66 & $\begin{array}{l}\text { Std. Mean Difference (IV, Fixed, } \\
95 \% \mathrm{CI})\end{array}$ & $-0.20[-0.68,0.29]$ \\
\hline 4.2 At 6 months & 3 & 318 & $\begin{array}{l}\text { Std. Mean Difference (IV, Fixed, } \\
95 \% \mathrm{CI})\end{array}$ & $-0.03[-0.25,0.19]$ \\
\hline 4.3 at 12 months & 2 & 251 & $\begin{array}{l}\text { Std. Mean Difference (IV, Fixed, } \\
95 \% \mathrm{CI} \text { ) }\end{array}$ & $0.04[-0.21,0.29]$ \\
\hline 4.4 At 18 months & 1 & 114 & $\begin{array}{l}\text { Std. Mean Difference (IV, Fixed, } \\
95 \% \mathrm{CI})\end{array}$ & $-0.09[-0.46,0.28]$ \\
\hline $\begin{array}{l}5 \text { Carer distress (behavioural) mea- } \\
\text { sures (NPI-distress/reaction RMBPC) }\end{array}$ & 2 & & Mean Difference (IV, Fixed, 95\% CI) & Subtotals only \\
\hline 5.1 At 3 months & 1 & 66 & Mean Difference (IV, Fixed, 95\% CI) & $-2.5[-6.87,1.87]$ \\
\hline 5.2 At 6 months & 2 & 193 & Mean Difference (IV, Fixed, 95\% CI) & $-0.20[-3.23,2.82]$ \\
\hline 5.3 At $10-12$ months & 1 & 126 & Mean Difference (IV, Fixed, 95\% CI) & $-1.9[-4.00,2.20]$ \\
\hline 5.4 At 18 months & 1 & 114 & Mean Difference (IV, Fixed, 95\% CI) & $-0.5[-3.24,2.24]$ \\
\hline $6 \mathrm{Mood} /$ depression measures (carers) & 5 & & $\begin{array}{l}\text { Std. Mean Difference (IV, Fixed, } \\
95 \% \mathrm{CI})\end{array}$ & Subtotals only \\
\hline
\end{tabular}




\begin{tabular}{|c|c|c|c|c|}
\hline Outcome or subgroup title & $\begin{array}{l}\text { No. of } \\
\text { studies }\end{array}$ & $\begin{array}{l}\text { No. of } \\
\text { partici- } \\
\text { pants }\end{array}$ & Statistical method & Effect size \\
\hline 6.1 At 6 months & 4 & 4675 & $\begin{array}{l}\text { Std. Mean Difference (IV, Fixed, } \\
95 \% \mathrm{CI})\end{array}$ & $-0.04[-0.10,0.02]$ \\
\hline 6.2 At $10-12$ months & 5 & 3705 & $\begin{array}{l}\text { Std. Mean Difference (IV, Fixed, } \\
95 \% \mathrm{CI})\end{array}$ & $-0.04[-0.11,0.02]$ \\
\hline 6.3 At 18 months & 3 & 2888 & $\begin{array}{l}\text { Std. Mean Difference (IV, Fixed, } \\
95 \% \mathrm{CI})\end{array}$ & $-0.08[-0.16,-0.01]$ \\
\hline 6.4 At 24 months & 1 & 2887 & $\begin{array}{l}\text { Std. Mean Difference (IV, Fixed, } \\
95 \% \mathrm{CI})\end{array}$ & $-0.06[-0.14,0.01]$ \\
\hline 6.5 At 36 months & 1 & 1910 & $\begin{array}{l}\text { Std. Mean Difference (IV, Fixed, } \\
95 \% \mathrm{CI})\end{array}$ & $-0.07[-0.16,0.02]$ \\
\hline $\begin{array}{l}7 \text { Carer well-being - GHQ (changes } \\
\text { from baseline) }\end{array}$ & 3 & & $\begin{array}{l}\text { Mean Difference (IV, Random, 95\% } \\
\mathrm{CI})\end{array}$ & Subtotals only \\
\hline 7.1 At 3 - 4 months & 3 & 203 & $\begin{array}{l}\text { Mean Difference (IV, Random, 95\% } \\
\mathrm{CI})\end{array}$ & $-2.53[-5.20,0.13]$ \\
\hline 7.2 At 6 months & 1 & 65 & $\begin{array}{l}\text { Mean Difference (IV, Random, 95\% } \\
\mathrm{CI})\end{array}$ & $-2.2[-4.14,-0.26]$ \\
\hline 7.3 At 12 months & 1 & 92 & $\begin{array}{l}\text { Mean Difference (IV, Random, 95\% } \\
\mathrm{CI} \text { ) }\end{array}$ & $-1.90[-4.11,0.31]$ \\
\hline 8 Social support measures & 3 & & $\begin{array}{l}\text { Std. Mean Difference (IV, Fixed, } \\
95 \% \mathrm{CI})\end{array}$ & Subtotals only \\
\hline 8.1 At 6 months & 1 & 88 & $\begin{array}{l}\text { Std. Mean Difference (IV, Fixed, } \\
95 \% \mathrm{CI})\end{array}$ & $0.18[-0.24,0.60]$ \\
\hline 8.2 At 12 months & 3 & 541 & $\begin{array}{l}\text { Std. Mean Difference (IV, Fixed, } \\
95 \% \mathrm{CI})\end{array}$ & $0.17[-0.00,0.34]$ \\
\hline $\begin{array}{l}8.3 \text { At } 18 \text { months changes from base- } \\
\text { line }\end{array}$ & 2 & 382 & $\begin{array}{l}\text { Std. Mean Difference (IV, Fixed, } \\
95 \% \mathrm{CI} \text { ) }\end{array}$ & $0.13[-0.07,0.33]$ \\
\hline $\begin{array}{l}9 \text { Satisfaction with health plan (carers) } \\
\text { changes from baseline }\end{array}$ & 1 & 314 & Mean Difference (IV, Fixed, 95\% CI) & $0.03[-0.13,0.20]$ \\
\hline $\begin{array}{l}9.1 \text { Satisfaction with types of service at } \\
12 \text { months }\end{array}$ & 1 & 157 & Mean Difference (IV, Fixed, 95\% CI) & $0.02[-0.26,0.30]$ \\
\hline $\begin{array}{l}9.2 \text { Satisfaction with quality of services } \\
\text { at } 12 \text { months }\end{array}$ & 1 & 157 & Mean Difference (IV, Fixed, 95\% CI) & $0.04[-0.17,0.25]$ \\
\hline 10 Satisfaction with care (carers) & 1 & 306 & Odds Ratio (M-H, Fixed, 95\% Cl) & $2.24[1.37,3.67]$ \\
\hline $\begin{array}{l}\text { 10.1 Primary care rated as very good or } \\
\text { excellent ( } 12 \text { months) }\end{array}$ & 1 & 153 & Odds Ratio (M-H, Fixed, 95\% Cl) & $3.85[1.82,8.11]$ \\
\hline
\end{tabular}




\begin{tabular}{|c|c|c|c|c|}
\hline Outcome or subgroup title & $\begin{array}{l}\text { No. of } \\
\text { studies }\end{array}$ & $\begin{array}{l}\text { No. of } \\
\text { partici- } \\
\text { pants }\end{array}$ & Statistical method & Effect size \\
\hline $\begin{array}{l}\text { 10.2 Primary care rated as very good or } \\
\text { excellent ( } 18 \text { months) }\end{array}$ & 1 & 153 & Odds Ratio (M-H, Fixed, 95\% Cl) & $1.43[0.73,2.80]$ \\
\hline $\begin{array}{l}11 \text { Leaving the study early (patients) } \\
\text { unwilling or unable to provide infor- } \\
\text { mation (including died/ institution- } \\
\text { alised) }\end{array}$ & 12 & & Odds Ratio (M-H, Fixed, 95\% Cl) & Subtotals only \\
\hline 11.1 At 3 - 4 months & 3 & 223 & Odds Ratio (M-H, Fixed, 95\% Cl) & $0.66[0.28,1.56]$ \\
\hline 11.2 At 6 months & 5 & 5728 & Odds Ratio (M-H, Fixed, 95\% Cl) & $0.99[0.86,1.14]$ \\
\hline 11.3 At 12 months & 7 & 6232 & Odds Ratio (M-H, Fixed, 95\% Cl) & $0.98[0.88,1.09]$ \\
\hline 11.4 At 18 months & 6 & 6034 & Odds Ratio (M-H, Fixed, 95\% Cl) & $0.88[0.79,0.98]$ \\
\hline 11.5 At 24 months & 3 & 5505 & Odds Ratio (M-H, Fixed, 95\% Cl) & $0.87[0.78,0.97]$ \\
\hline 11.6 At 36 months & 1 & 5304 & Odds Ratio (M-H, Fixed, 95\% Cl) & $0.98[0.88,1.10]$ \\
\hline
\end{tabular}

\section{Analysis 2.1. Comparison 2 Case management versus usual care} (secondary outcomes), Outcome 1 Cognition measures (participants).

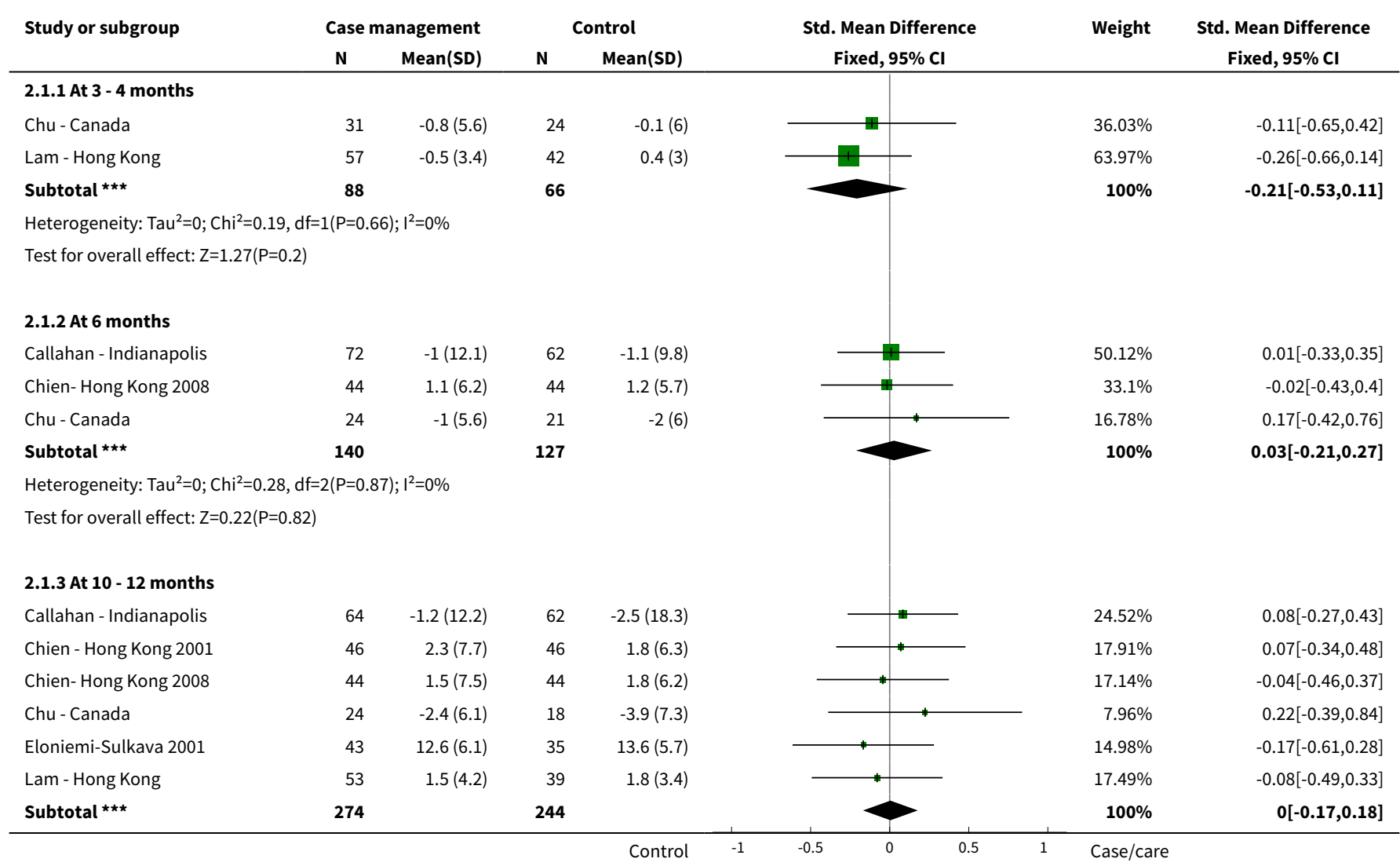




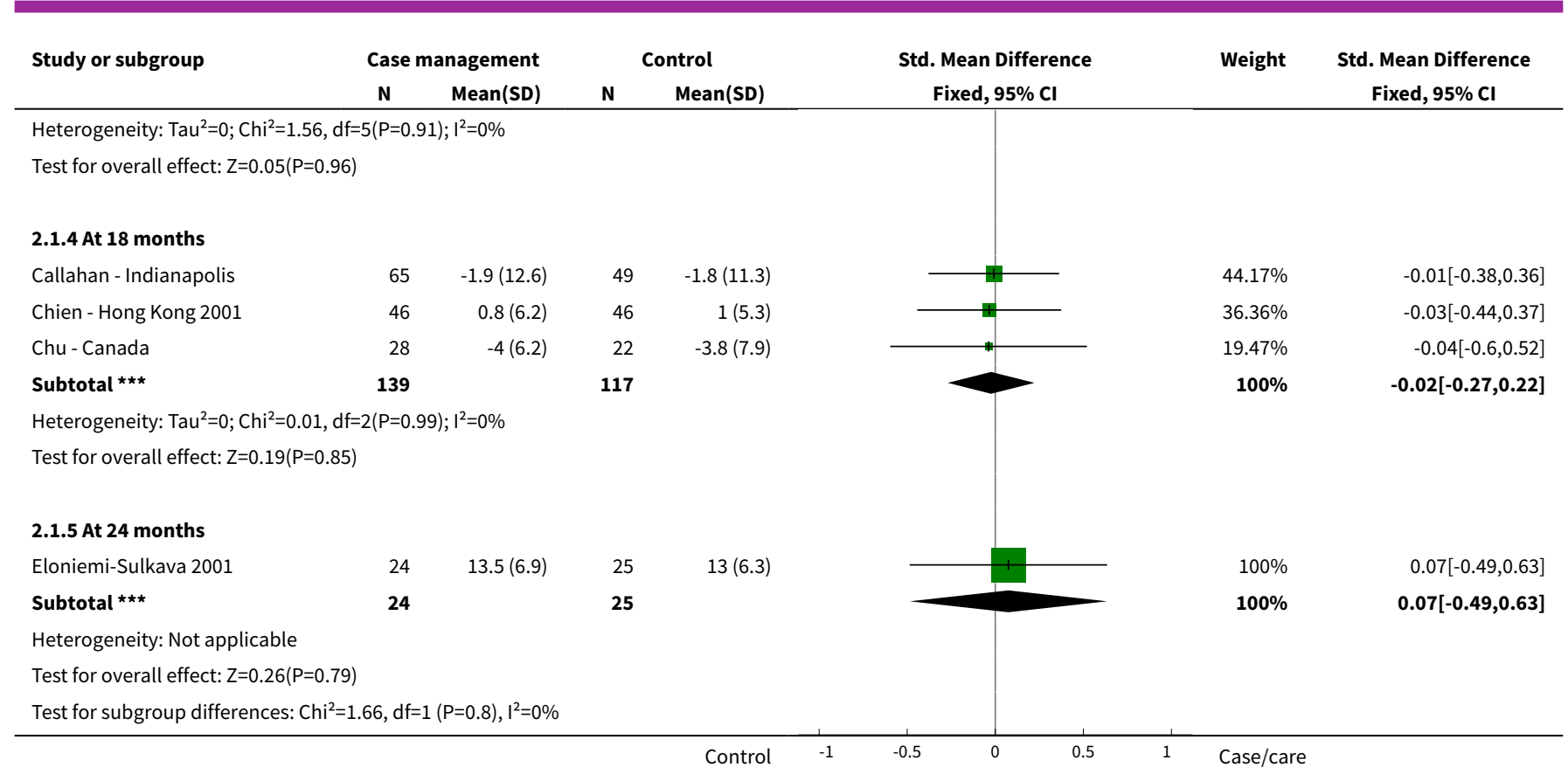

Analysis 2.2. Comparison 2 Case management versus usual care (secondary outcomes), Outcome 2 Behavioural measures (participants).

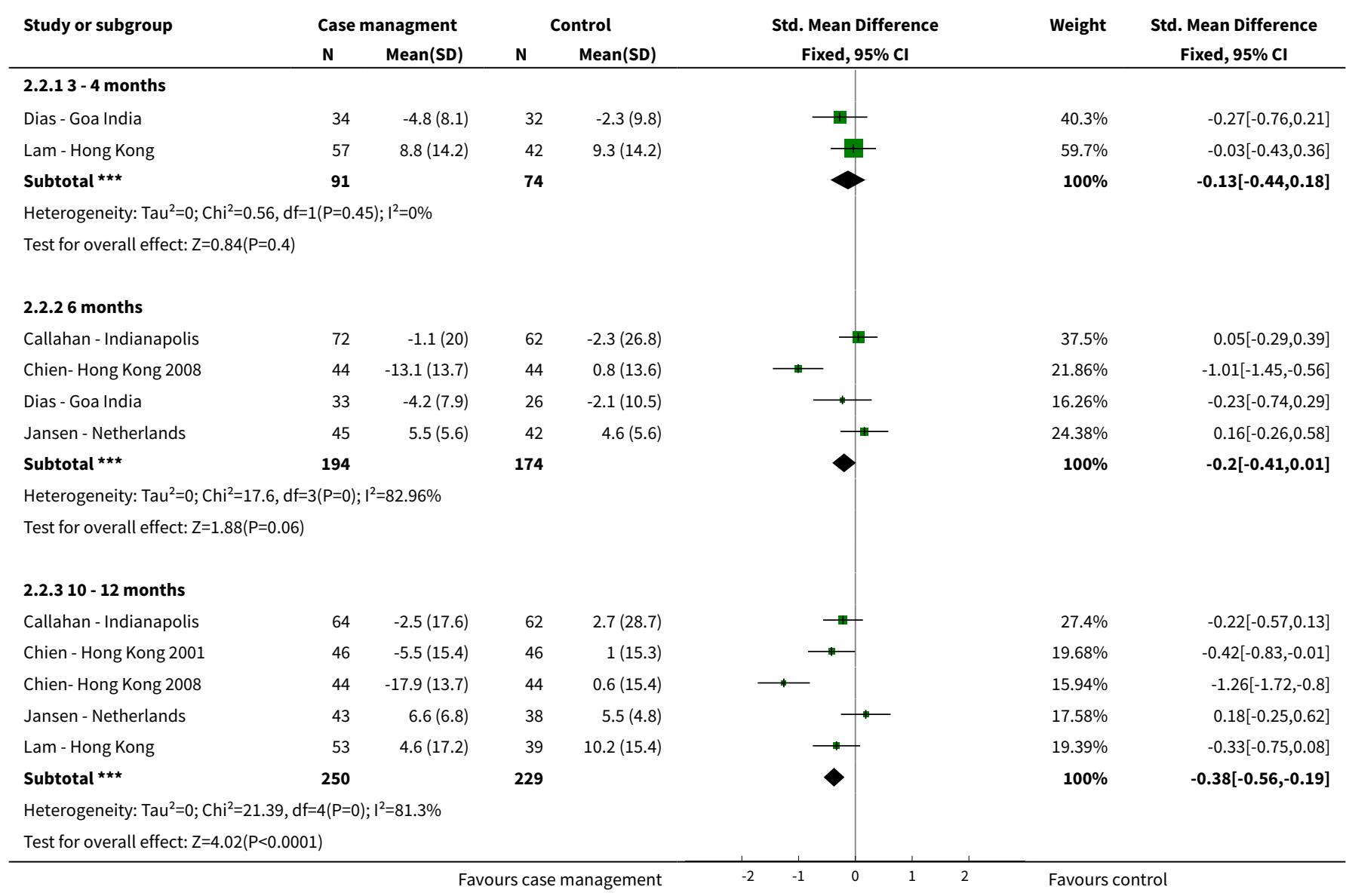




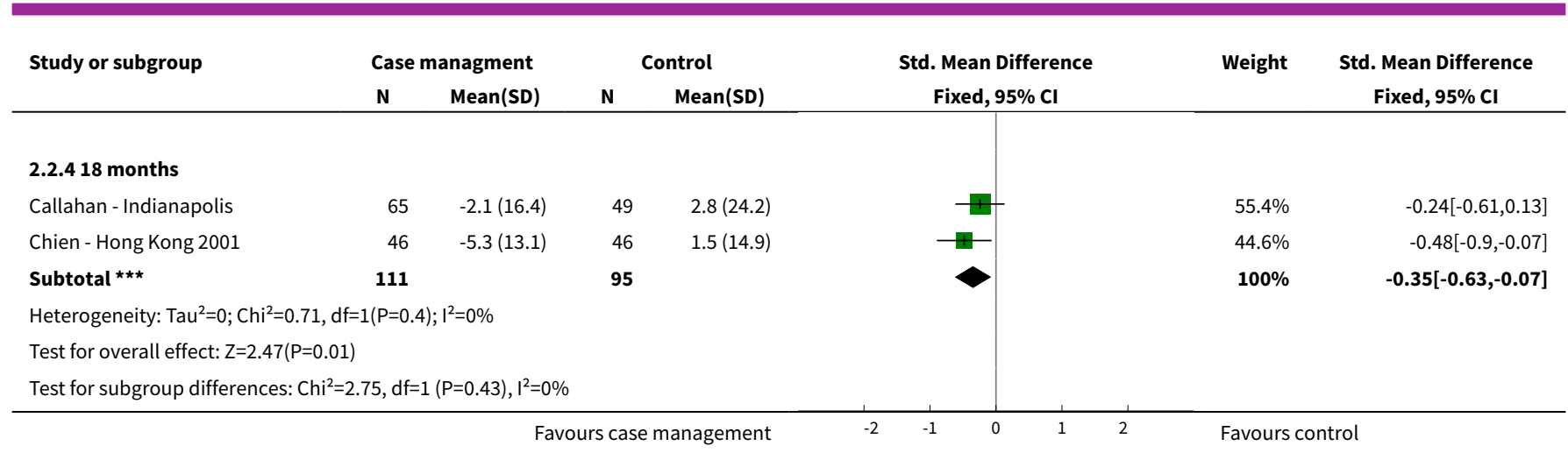

\section{Analysis 2.3. Comparison 2 Case management versus usual care (secondary outcomes), Outcome 3 Depression/mood measures (participants).}

\begin{tabular}{|c|c|c|c|c|c|c|c|}
\hline \multirow[t]{2}{*}{ Study or subgroup } & \multicolumn{2}{|c|}{ case/care } & \multicolumn{2}{|c|}{ Control } & \multirow{2}{*}{$\begin{array}{c}\text { Std. Mean Difference } \\
\text { Fixed, } 95 \% \mathrm{Cl}\end{array}$} & \multirow[t]{2}{*}{ Weight } & \multirow{2}{*}{$\begin{array}{c}\text { Std. Mean Difference } \\
\text { Fixed, } 95 \% \mathrm{Cl}\end{array}$} \\
\hline & $\mathbf{N}$ & Mean(SD) & $\mathbf{N}$ & Mean(SD) & & & \\
\hline \multicolumn{8}{|l|}{ 2.3.1 At 3 - 4 months } \\
\hline Chu - Canada & 33 & $-0.4(2.9)$ & 32 & $0.2(3.9)$ & $\longrightarrow$ & $40.39 \%$ & $-0.18[-0.67,0.31]$ \\
\hline Lam - Hong Kong & 57 & $2.5(5)$ & 42 & $1(3.4)$ & & $59.61 \%$ & $0.32[-0.08,0.72]$ \\
\hline 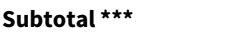 & 90 & & 74 & & & $100 \%$ & $0.12[-0.19,0.43]$ \\
\hline \multicolumn{8}{|c|}{ Heterogeneity: $\mathrm{Tau}^{2}=0 ; \mathrm{Chi}^{2}=2.42, \mathrm{df}=1(\mathrm{P}=0.12) ; \mathrm{I}^{2}=58.7 \%$} \\
\hline \multicolumn{8}{|l|}{ 2.3.2 At 6 months } \\
\hline Callahan - Indianapolis & 72 & $-0.1(2.8)$ & 62 & $-0.2(8)$ & & $72.49 \%$ & $0.02[-0.32,0.36]$ \\
\hline Chu - Canada & 25 & $-0.1(2.9)$ & 26 & $-0.9(3.3)$ & & $27.51 \%$ & $0.25[-0.31,0.8]$ \\
\hline 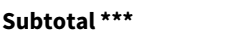 & 97 & & 88 & & & $100 \%$ & $0.08[-0.21,0.37]$ \\
\hline \multicolumn{8}{|c|}{ Heterogeneity: $\operatorname{Tau}^{2}=0 ; \mathrm{Chi}^{2}=0.48, \mathrm{df}=1(\mathrm{P}=0.49) ; \mathrm{I}^{2}=0 \%$} \\
\hline \multicolumn{8}{|l|}{ 2.3.3 At 10 - 12 months } \\
\hline Callahan - Indianapolis & 64 & $-0.9(6.3)$ & 62 & $0.4(8.3)$ & & $49.02 \%$ & $-0.18[-0.53,0.17]$ \\
\hline Chu - Canada & 22 & $0.1(3.5)$ & 19 & $-0.4(3.9)$ & & $15.88 \%$ & $0.16[-0.46,0.77]$ \\
\hline Lam - Hong Kong & 53 & $0.9(6.5)$ & 39 & $1.1(3.6)$ & & $35.11 \%$ & $-0.03[-0.44,0.39]$ \\
\hline 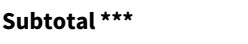 & 139 & & 120 & & & $100 \%$ & $-0.07[-0.32,0.17]$ \\
\hline \multicolumn{8}{|c|}{ Heterogeneity: $\operatorname{Tau}^{2}=0 ; \mathrm{Chi}^{2}=0.92, \mathrm{df}=2(\mathrm{P}=0.63) ; \mathrm{I}^{2}=0 \%$} \\
\hline \multicolumn{8}{|c|}{ Test for overall effect: $Z=0.56(P=0.57)$} \\
\hline \multicolumn{8}{|l|}{ 2.3.4 At 18 months } \\
\hline Callahan - Indianapolis & 65 & $-0.2(6.3)$ & 49 & $0(7.4)$ & & $71.54 \%$ & $-0.03[-0.4,0.34]$ \\
\hline Chu - Canada & 20 & $-0.3(3.2)$ & 25 & $-0.3(4)$ & & $28.46 \%$ & $0[-0.59,0.59]$ \\
\hline Subtotal $\star \star \star$ & 85 & & 74 & & & $100 \%$ & $-0.02[-0.33,0.29]$ \\
\hline \multicolumn{8}{|c|}{ Test for subgroup differences: $\mathrm{Chi}^{2}=1.14, \mathrm{df}=1(\mathrm{P}=0.77), \mathrm{I}^{2}=0 \%$} \\
\hline & & & cas & agement & -1 & Favours & \\
\hline
\end{tabular}


Analysis 2.4. Comparison 2 Case management versus usual care

(secondary outcomes), Outcome 4 Function measures (participants).

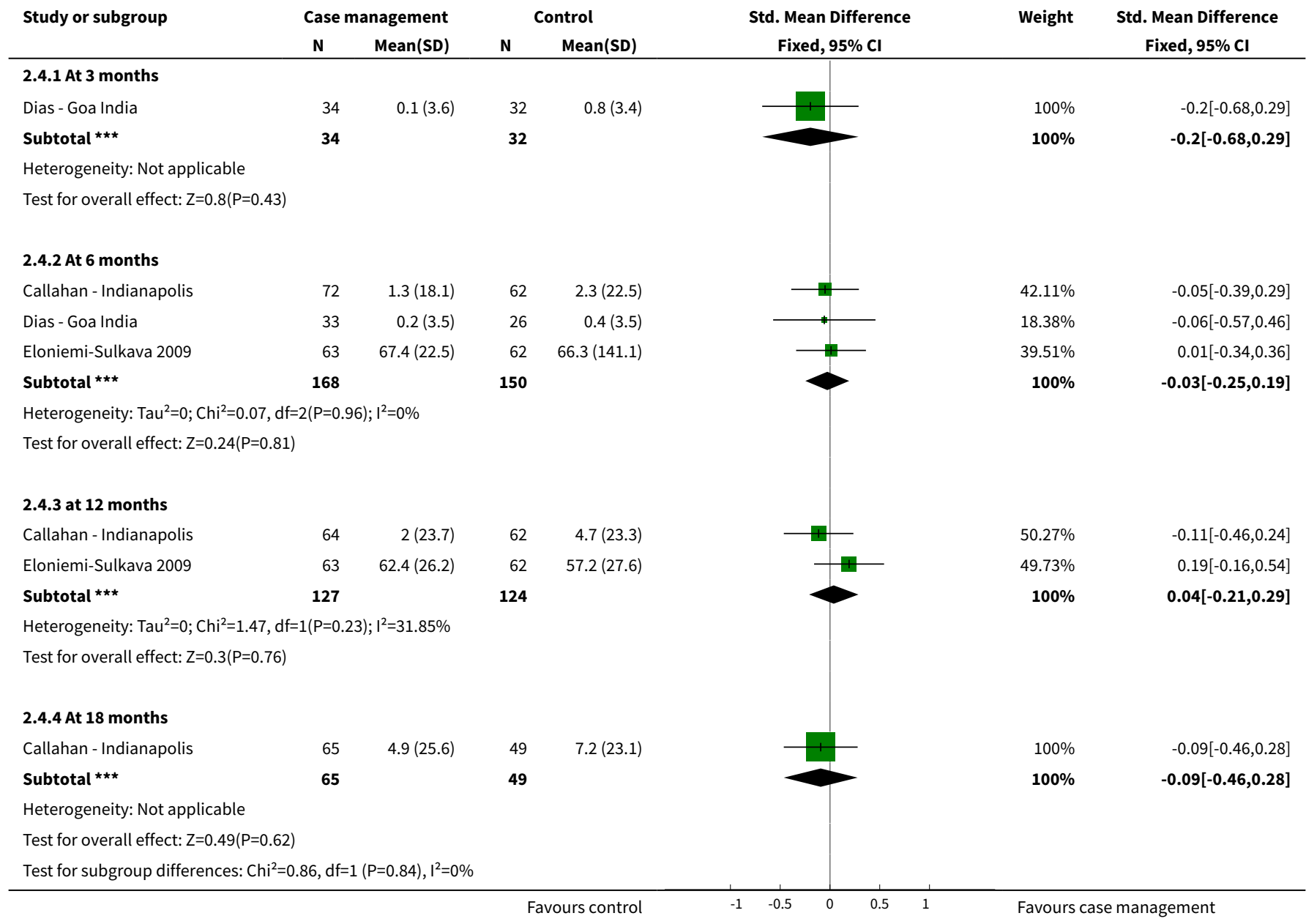

\section{Analysis 2.5. Comparison 2 Case management versus usual care (secondary outcomes), Outcome 5 Carer distress (behavioural) measures (NPI-distress/reaction RMBPC).}

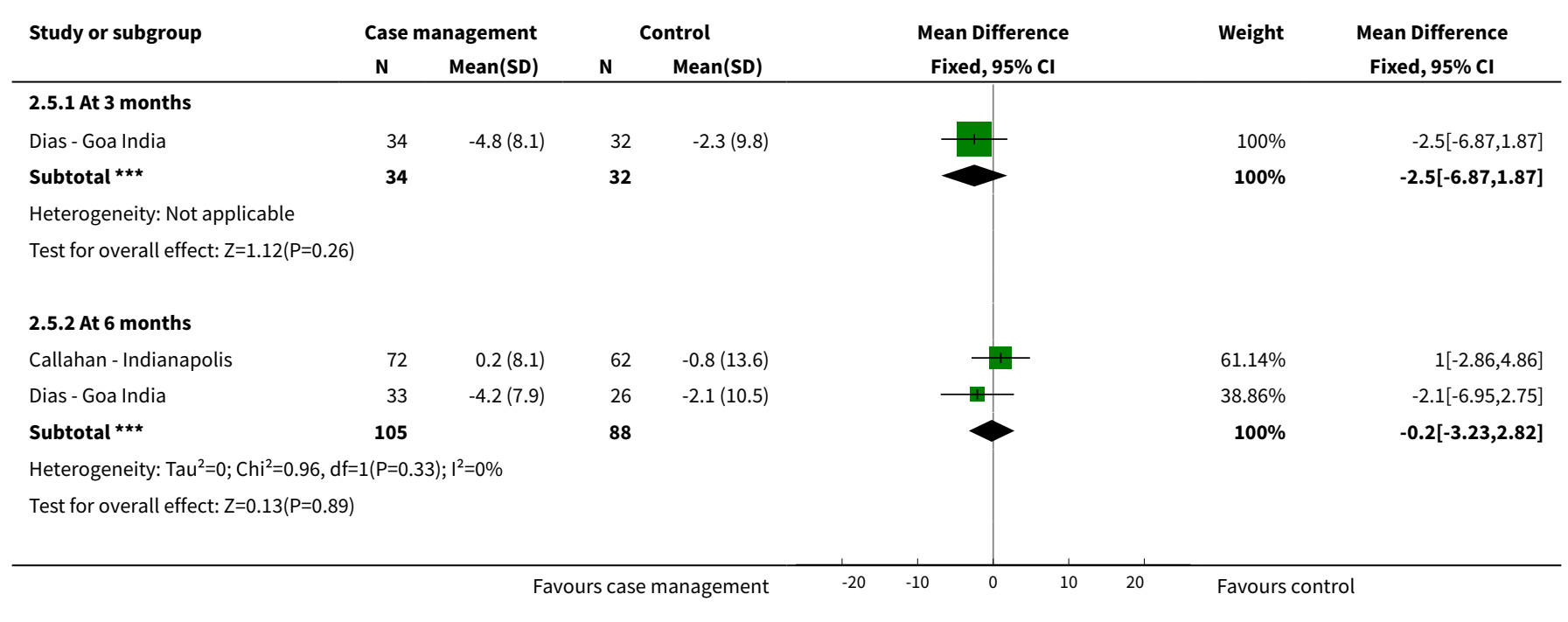




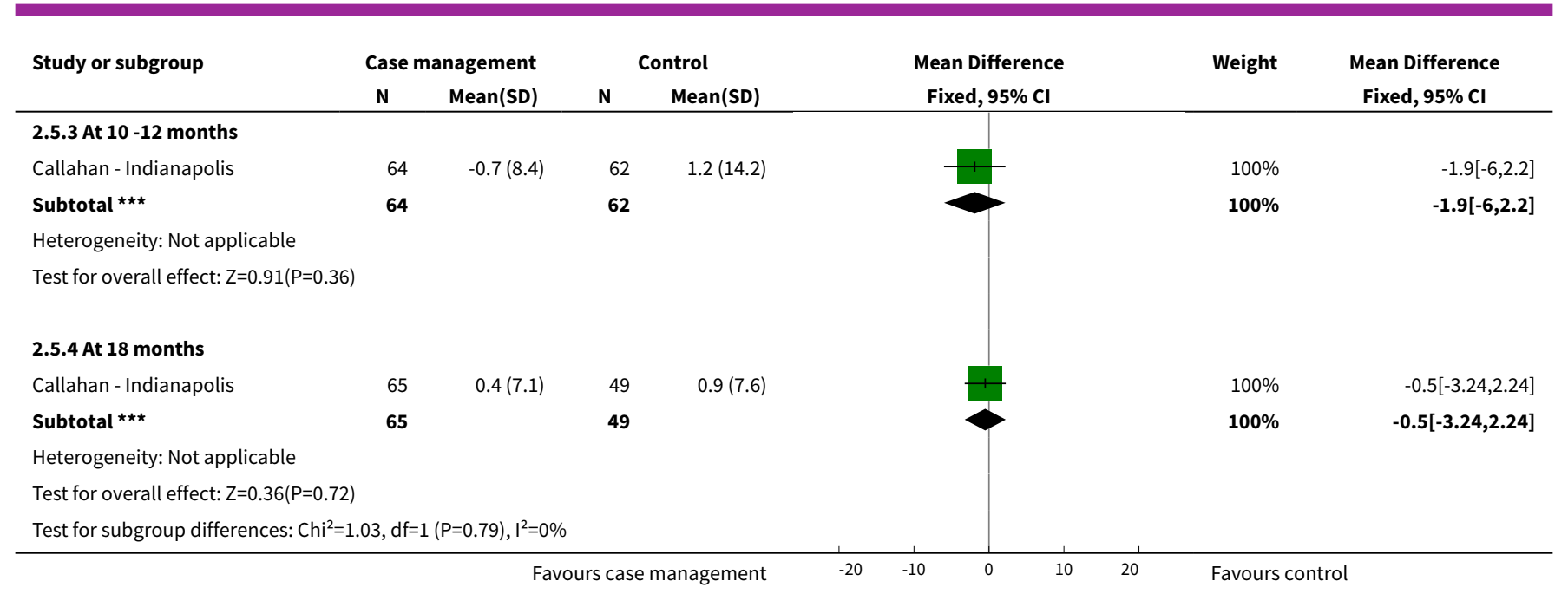

Analysis 2.6. Comparison 2 Case management versus usual care (secondary outcomes), Outcome 6 Mood/depression measures (carers).

\begin{tabular}{lrrrr} 
Study or subgroup & \multicolumn{2}{c}{ Case management } & \multicolumn{2}{c}{ Control } \\
& N & Mean(SD) & N & Mean(SD) \\
\hline 2.6.1 At 6 months & & & & \\
Callahan - Indianapolis & 72 & $-0.2(7.2)$ & 62 & $-0.1(7.6)$ \\
Chu - Canada & 21 & $8(8.6)$ & 26 & $11.1(10.3)$ \\
Jansen - Netherlands & 45 & $11.8(7.5)$ & 41 & $9.7(8.1)$ \\
Newcomer - US & 2269 & $0.1(4.7)$ & 2139 & $0.3(4.8)$ \\
Subtotal $* \star *$ & $\mathbf{2 4 0 7}$ & & $\mathbf{2 2 6 8}$ &
\end{tabular}

Heterogeneity: $\operatorname{Tau}^{2}=0 ; \mathrm{Chi}^{2}=2.95, \mathrm{df}=3(\mathrm{P}=0.4) ; \mathrm{I}^{2}=0 \%$

Test for overall effect: $Z=1.44(P=0.15)$

2.6.2 At 10 - 12 months

\begin{tabular}{|c|c|c|c|c|}
\hline Bass - Ohio & 94 & $0(0.6)$ & 63 & $0.1(0.7)$ \\
\hline Callahan - Indianapolis & 64 & $-0.7(6.4)$ & 62 & $0.2(7.9$ \\
\hline Chu - Canada & 20 & $11.8(11.1)$ & 20 & $10.9(10$ \\
\hline Jansen - Netherlands & 43 & $11.2(6.8)$ & 37 & $11.5(8$ \\
\hline Newcomer - US & 1705 & $0(4.7)$ & 1597 & $0.2(4$ \\
\hline 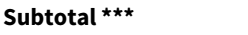 & 1926 & & 1779 & \\
\hline
\end{tabular}

Heterogeneity: $\mathrm{Tau}^{2}=0 ; \mathrm{Chi}^{2}=1.09, \mathrm{df}=4(\mathrm{P}=0.9) ; \mathrm{I}^{2}=0 \%$

Test for overall effect: $\mathrm{Z}=1.3(\mathrm{P}=0.19)$

\subsubsection{At 18 months}

Callahan - Indianapolis

Chu - Canada

Newcomer - US

1358

Std. Mean Difference Fixed, $95 \% \mathrm{Cl}$

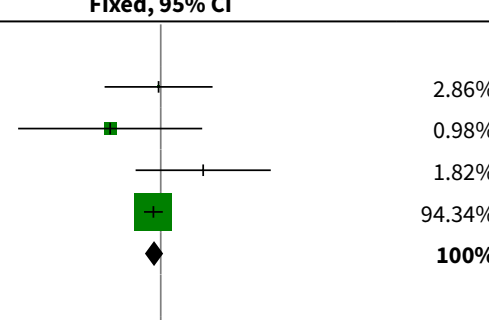

Weight Std. Mean Difference Fixed, $95 \% \mathrm{Cl}$

$\begin{array}{lr}2.86 \% & -0.01[-0.35,0.33] \\ 0.98 \% & -0.32[-0.9,0.26] \\ 1.82 \% & 0.27[-0.16,0.69] \\ 4.34 \% & -0.05[-0.11,0.01] \\ \mathbf{1 0 0 \%} & \mathbf{- 0 . 0 4 [ - 0 . 1 , 0 . 0 2}]\end{array}$

Heterogeneity: $\mathrm{Tau}^{2}=0 ; \mathrm{Chi}^{2}=0.46, \mathrm{df}=2(\mathrm{P}=0.8) ; \mathrm{I}^{2}=0 \%$

Test for overall effect: $Z=2.24(P=0.03)$

2.6.4 At 24 months

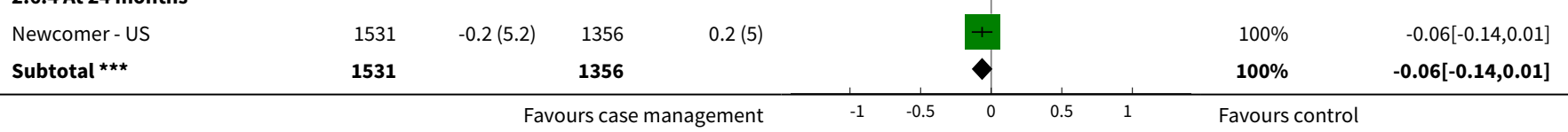




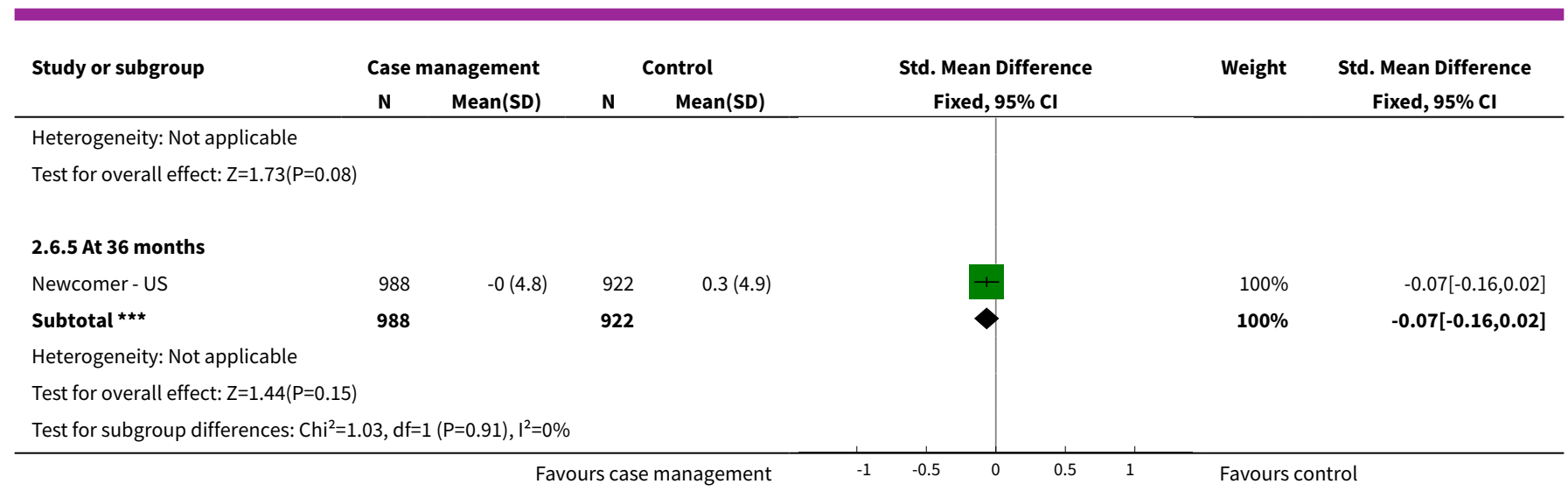

Analysis 2.7. Comparison 2 Case management versus usual care (secondary outcomes), Outcome 7 Carer well-being - GHQ (changes from baseline).

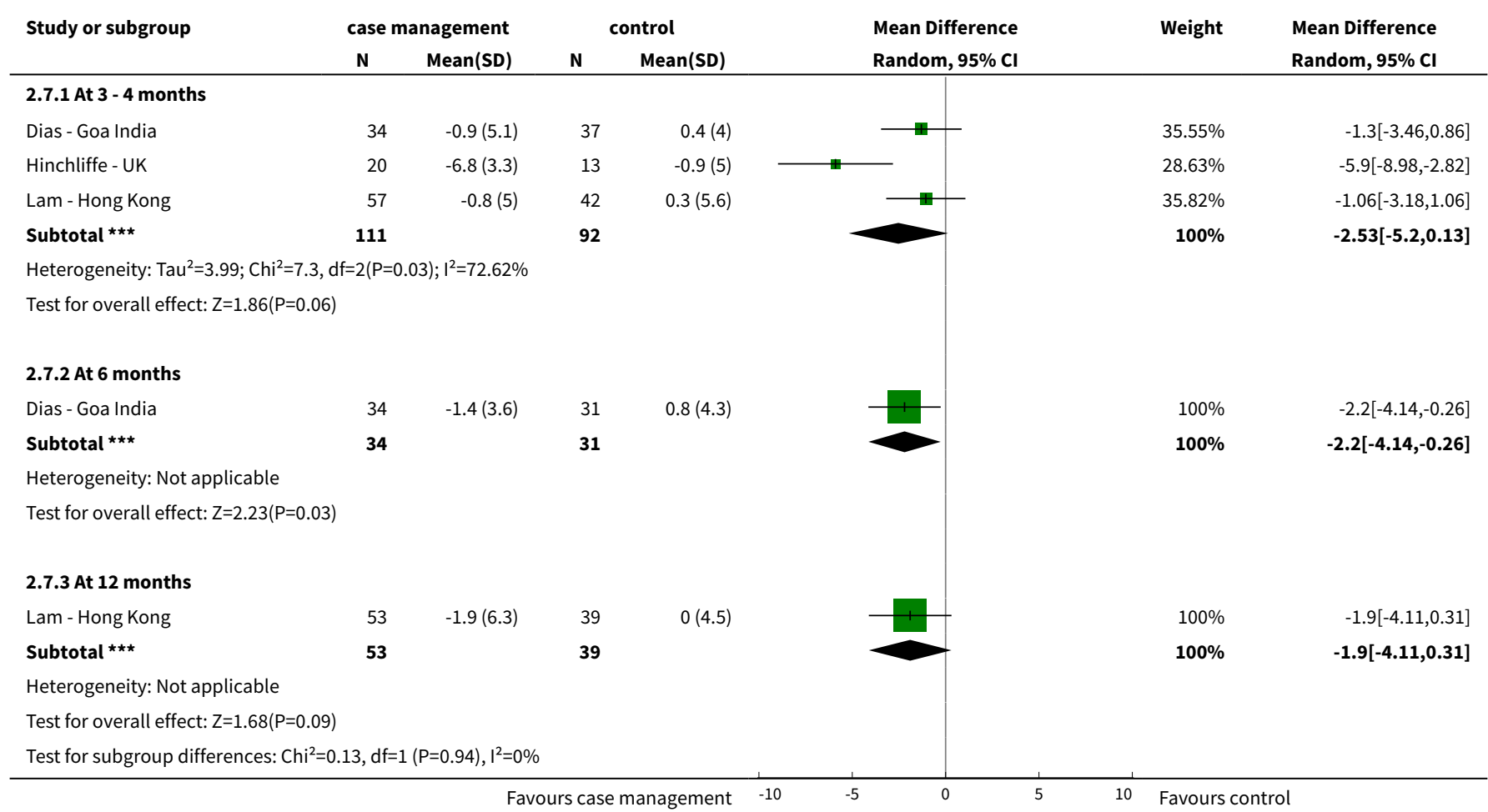

Analysis 2.8. Comparison 2 Case management versus usual care (secondary outcomes), Outcome 8 Social support measures.

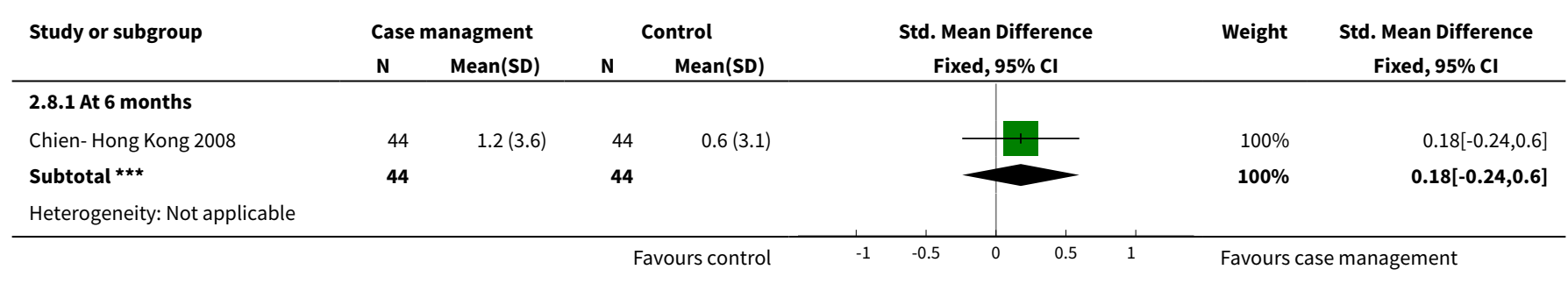




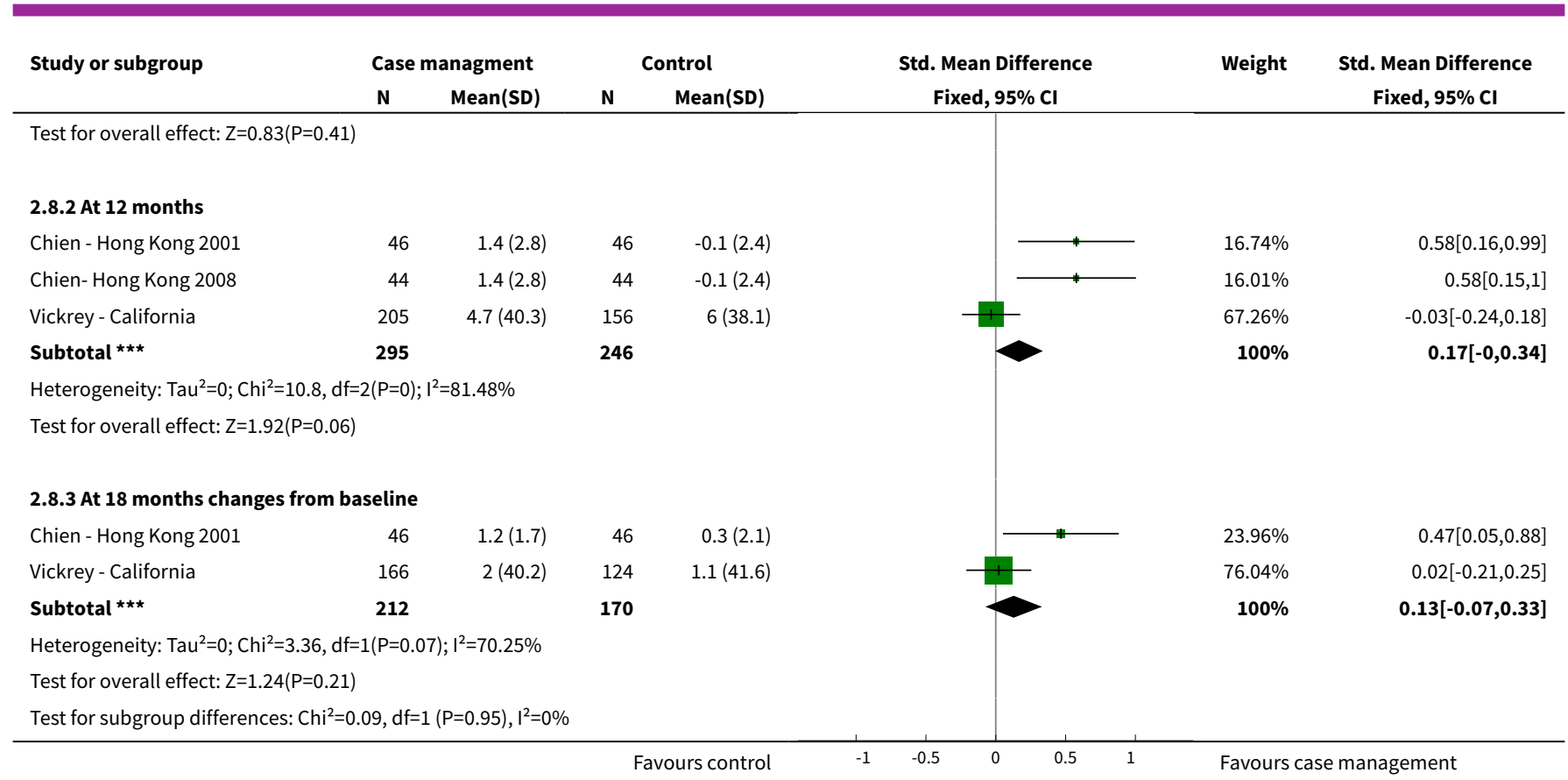

Analysis 2.9. Comparison 2 Case management versus usual care (secondary outcomes), Outcome 9 Satisfaction with health plan (carers) changes from baseline.

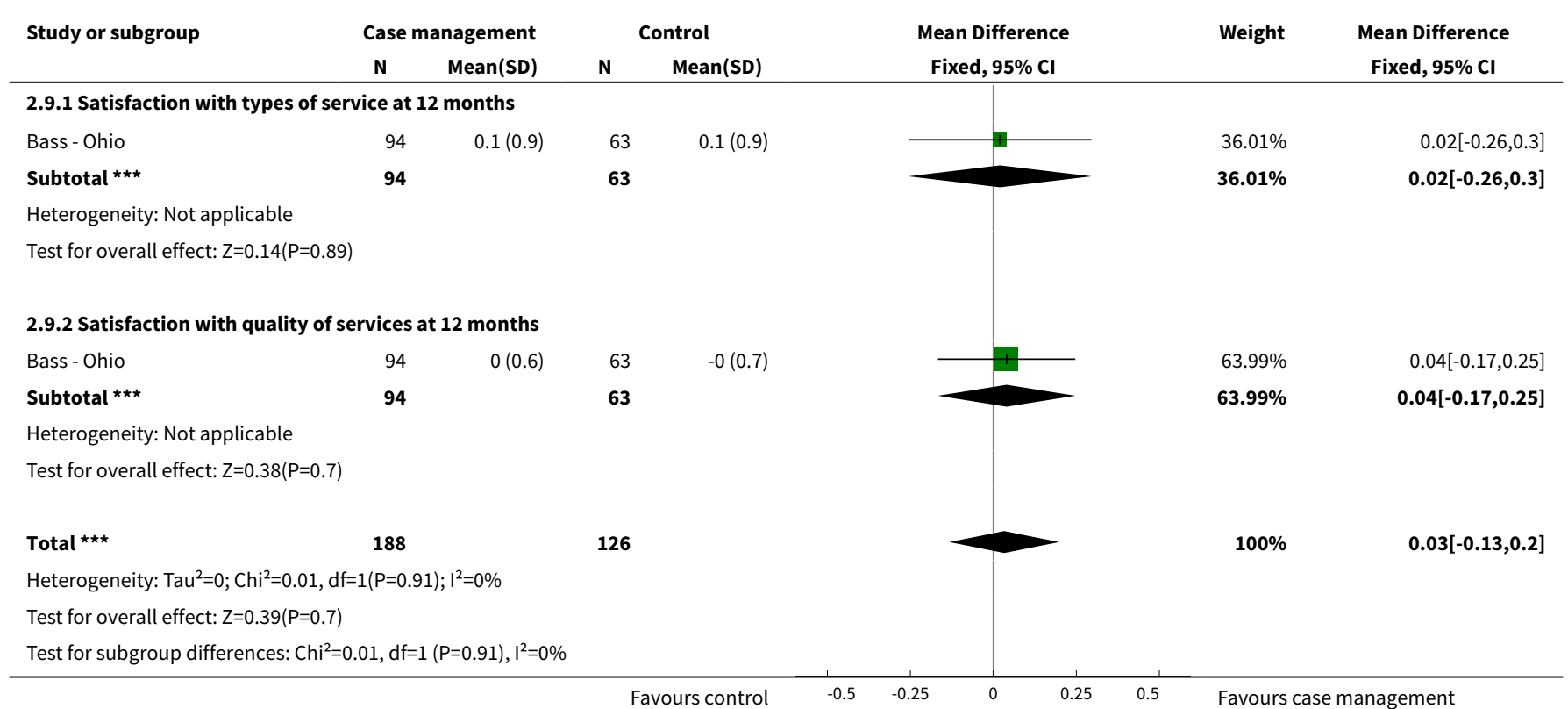


Analysis 2.10. Comparison 2 Case management versus usual care (secondary outcomes), Outcome 10 Satisfaction with care (carers).

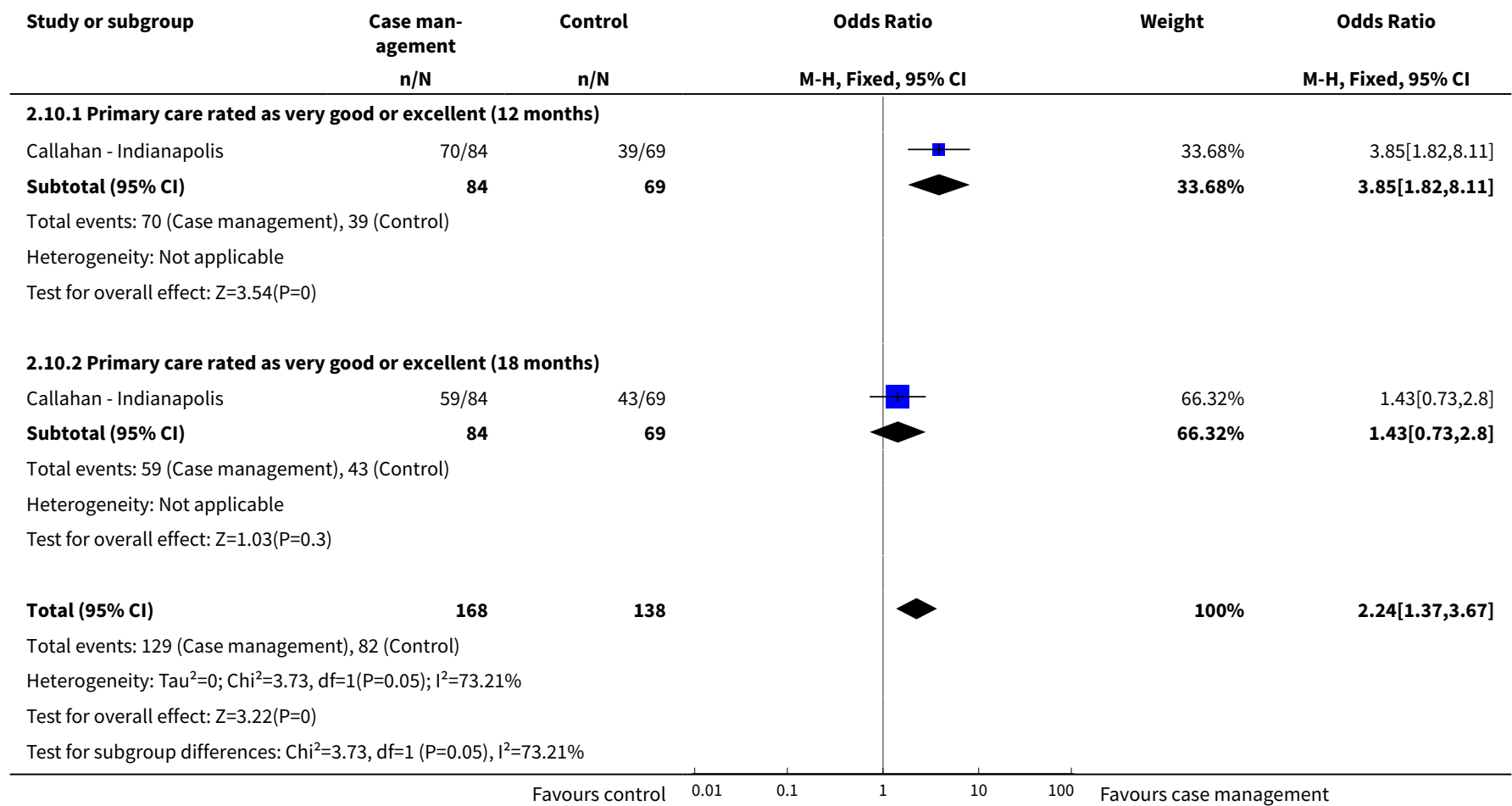

\section{Analysis 2.11. Comparison 2 Case management versus usual care (secondary outcomes), Outcome 11 Leaving the study early (patients) unwilling or unable to provide information (including died/ institutionalised).}

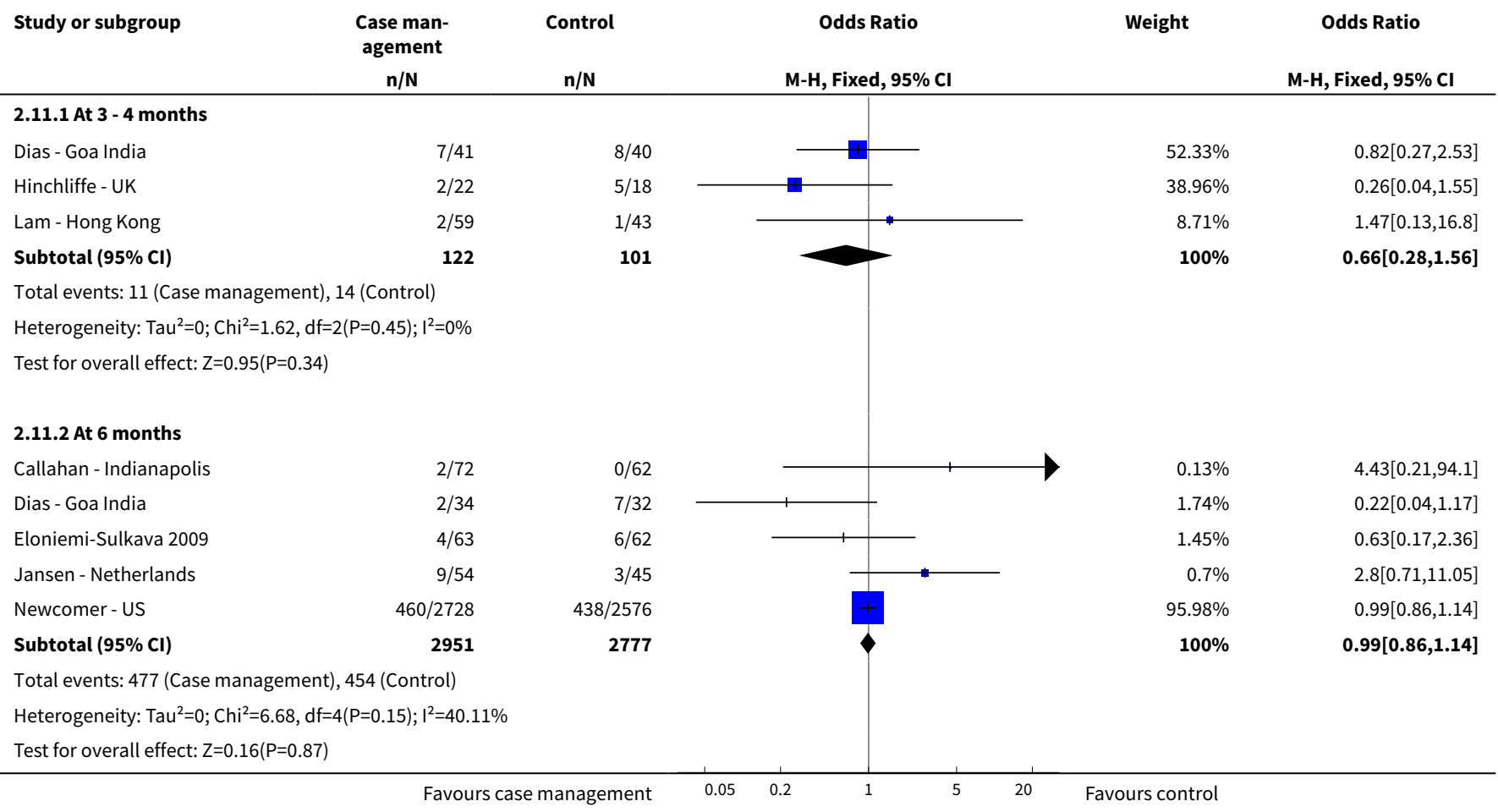




\begin{tabular}{lccc} 
Study or subgroup & $\begin{array}{c}\text { Case man- } \\
\text { agement } \\
\mathrm{n} / \mathrm{N}\end{array}$ & Control & Odds Ratio \\
\hline
\end{tabular}

\subsubsection{At 12 months}

Callahan - Indianapolis

Eloniemi-Sulkava 2001

Eloniemi-Sulkava 2009

Jansen - Netherlands

Lam - Hong Kong

Newcomer - US

Vickrey - California

Subtotal $(95 \% \mathrm{Cl})$

Total events: 1088 (Case management), 1032 (Control) Heterogeneity: $\mathrm{Tau}^{2}=0 ; \mathrm{Chi}^{2}=8.15, \mathrm{df}=6(\mathrm{P}=0.23) ; \mathrm{I}^{2}=26.39 \%$

Test for overall effect: $Z=0.41(P=0.68)$

\subsubsection{At 18 months}

Callahan - Indianapolis

Chien - Hong Kong 2001

Chien- Hong Kong 2008

Chu - Canada

Newcomer - US

Vickrey - California

Subtotal $(95 \% \mathrm{Cl})$

Heterogeneity: $\mathrm{Tau}^{2}=0 ; \mathrm{Chi}^{2}=2.6, \mathrm{df}=5(\mathrm{P}=0.76) ; \mathrm{I}^{2}=0 \%$

Test for overall effect: $\mathrm{Z}=2.4(\mathrm{P}=0.02)$

\subsubsection{At 24 months}

Eloniemi-Sulkava 2001

Eloniemi-Sulkava 2009

Newcomer - US

$12 / 53$

$1200 / 2728$

Subtotal $(95 \% \mathrm{Cl})$

2834

Total events: 1238 (Case management), 1257 (Control) Heterogeneity: $\mathrm{Tau}^{2}=0 ; \mathrm{Chi}^{2}=0.37, \mathrm{df}=2(\mathrm{P}=0.83) ; \mathrm{I}^{2}=0 \%$ Test for overall effect: $Z=2.51(P=0.01)$

\subsubsection{At 36 months}

Newcomer - US

Subtotal $(95 \% \mathrm{CI})$

2728

Total events: 1742 (Case management), 1656 (Control)

Heterogeneity: Not applicable

Test for overall effect: $Z=0.33(P=0.74)$
M-H, Fixed, $95 \% \mathrm{C}$

$\begin{array}{rr}0.15 \% & 0.97[0.06,15.83] \\ 1.52 \% & 0.68[0.26,1.75] \\ 1.09 \% & 0.68[0.22,2.1] \\ 0.58 \% & 0.44[0.08,2.55] \\ 1.93 \% & 0.42[0.16,1.07] \\ 92.66 \% & 0.98[0.88,1.1] \\ 2.07 \% & 1.79[0.93,3.47] \\ \mathbf{1 0 0 \%} & \mathbf{0 . 9 8}[\mathbf{0 . 8 8 , 1 . 0 9}]\end{array}$

$\begin{array}{rr}1.97 \% & 0.7[0.32,1.53] \\ 0.13 \% & 1[0.06,16.48] \\ 0.13 \% & 2.05[0.18,23.44] \\ 1.61 \% & 0.46[0.17,1.2] \\ 92.29 \% & 0.89[0.8,0.99] \\ 3.87 \% & 0.91[0.54,1.53] \\ \mathbf{1 0 0 \%} & \mathbf{0 . 8 8}[\mathbf{0 . 7 9}, \mathbf{0 . 9 8}]\end{array}$

$1.64 \%$

$1.09[0.5,2.4]$

$1.45 \%$

$0.79[0.32,1.95]$

$0.87[0.78,0.97]$

$100 \%$

$0.87[0.78,0.97]$ 
Comparison 3. Case management versus usual care (secondary outcomes: service use/cost )

\begin{tabular}{|c|c|c|c|c|}
\hline Outcome or subgroup title & $\begin{array}{l}\text { No. of } \\
\text { studies }\end{array}$ & $\begin{array}{l}\text { No. of } \\
\text { partici- } \\
\text { pants }\end{array}$ & Statistical method & Effect size \\
\hline $\begin{array}{l}1 \text { Use of community-based services } \\
\text { (number of participants/ carers) }\end{array}$ & 4 & & Odds Ratio (M-H, Fixed, 95\% Cl) & Subtotals only \\
\hline 1.1 Home care at 3 - 4 months & 2 & 174 & Odds Ratio (M-H, Fixed, 95\% Cl) & $2.67[0.79,8.95]$ \\
\hline 1.2 Home care at 12 months & 3 & 5376 & Odds Ratio (M-H, Fixed, 95\% Cl) & $2.28[2.03,2.56]$ \\
\hline 1.3 Home care at 18 months & 1 & 74 & Odds Ratio (M-H, Fixed, 95\% Cl) & $5.63[2.07,15.29]$ \\
\hline 1.4 Day care at 4 months & 1 & 99 & Odds Ratio (M-H, Fixed, 95\% Cl) & $4.51[1.89,10.77]$ \\
\hline 1.5 Day care at 12 months & 2 & 5301 & Odds Ratio (M-H, Fixed, 95\% Cl) & $2.23[1.98,2.52]$ \\
\hline 1.6 Day care at 18 months & 1 & 353 & Odds Ratio (M-H, Fixed, 95\% Cl) & $1.80[0.92,3.51]$ \\
\hline 1.7 Respite care at 4 months & 1 & 99 & Odds Ratio (M-H, Fixed, 95\% Cl) & $2.26[0.09,56.78]$ \\
\hline 1.8 Respite care at 12 months & 2 & 5301 & Odds Ratio (M-H, Fixed, 95\% Cl) & $2.24[1.98,2.53]$ \\
\hline $\begin{array}{l}\text { 1.9 Domestic paid helpers at } 4 \\
\text { months }\end{array}$ & 1 & 99 & Odds Ratio (M-H, Fixed, 95\% Cl) & $5.4[1.97,14.81]$ \\
\hline $\begin{array}{l}1.10 \text { Domestic paid helpers at } 12 \\
\text { months }\end{array}$ & 1 & 92 & Odds Ratio (M-H, Fixed, 95\% Cl) & $3.0[1.12,8.04]$ \\
\hline 1.11 Personal care use at 12 months & 2 & 5284 & Odds Ratio (M-H, Fixed, 95\% Cl) & $1.57[1.40,1.75]$ \\
\hline $\begin{array}{l}1.12 \text { Services from a professional } \\
\text { home health aide at } 18 \text { months }\end{array}$ & 1 & 353 & Odds Ratio (M-H, Fixed, 95\% Cl) & $1.81[1.05,3.13]$ \\
\hline $\begin{array}{l}1.13 \text { Services from a paid professional } \\
\text { caregiver at } 18 \text { months }\end{array}$ & 1 & 353 & Odds Ratio (M-H, Fixed, 95\% Cl) & $1.48[0.85,2.59]$ \\
\hline $\begin{array}{l}1.14 \text { In-home, volunteer, or paid } \\
\text { respite care services at } 18 \text { months }\end{array}$ & 1 & 353 & Odds Ratio (M-H, Fixed, 95\% Cl) & $1.54[0.98,2.41]$ \\
\hline $\begin{array}{l}1.15 \text { Assisted living housing use at } 12 \\
\text { months }\end{array}$ & 1 & 5209 & Odds Ratio (M-H, Fixed, 95\% Cl) & $0.70[0.56,0.87]$ \\
\hline $\begin{array}{l}1.16 \text { Services or information from } \\
\text { local Alzheimers Association at } 18 \\
\text { months }\end{array}$ & 1 & 360 & Odds Ratio (M-H, Fixed, 95\% Cl) & $2.40[1.56,3.69]$ \\
\hline $\begin{array}{l}1.17 \text { Services or information from } \\
\text { care givers resource centre at } 18 \\
\text { months }\end{array}$ & 1 & 360 & Odds Ratio (M-H, Fixed, 95\% Cl) & $2.88[1.77,4.69]$ \\
\hline $\begin{array}{l}1.18 \text { Services or information on meals } \\
\text { on wheels at } 18 \text { months }\end{array}$ & 1 & 360 & Odds Ratio (M-H, Fixed, 95\% Cl) & $0.97[0.53,1.77]$ \\
\hline $\begin{array}{l}\text { 1.19 Participation in a caregiver sup- } \\
\text { port group at } 18 \text { months }\end{array}$ & 1 & 356 & Odds Ratio (M-H, Fixed, 95\% Cl) & $1.64[1.00,2.68]$ \\
\hline
\end{tabular}




\begin{tabular}{|c|c|c|c|c|}
\hline Outcome or subgroup title & $\begin{array}{l}\text { No. of } \\
\text { studies }\end{array}$ & $\begin{array}{l}\text { No. of } \\
\text { partici- } \\
\text { pants }\end{array}$ & Statistical method & Effect size \\
\hline $\begin{array}{l}2 \text { Health service use by participants } \\
\text { (number of participants) }\end{array}$ & 2 & & Odds Ratio (M-H, Fixed, 95\% Cl) & Subtotals only \\
\hline $\begin{array}{l}2.1 \text { Emergency department visits at } \\
18 \text { months }\end{array}$ & 1 & 296 & Odds Ratio (M-H, Fixed, 95\% Cl) & $1.18[0.74,1.87]$ \\
\hline $\begin{array}{l}\text { 2.2 Direct care (occupational ther- } \\
\text { apy, physical therapy, social work, } \\
\text { nursing and respiratory therapy (at } \\
18 \text { months)) }\end{array}$ & 1 & 75 & Odds Ratio (M-H, Fixed, 95\% Cl) & $1.31[0.51,3.35]$ \\
\hline $\begin{array}{l}3 \text { Health service use by participants } \\
\text { (continuous outcomes) }\end{array}$ & 4 & & Mean Difference (IV, Fixed, 95\% CI) & Subtotals only \\
\hline $\begin{array}{l}3.1 \text { Emergency department visits at } \\
12 \text { months }\end{array}$ & 1 & 157 & Mean Difference (IV, Fixed, 95\% Cl) & $-0.17[-0.63,0.29]$ \\
\hline $\begin{array}{l}3.2 \text { Emergency department visits at } \\
18 \text { months }\end{array}$ & 1 & 296 & Mean Difference (IV, Fixed, 95\% Cl) & $0.18[-0.11,0.47]$ \\
\hline $\begin{array}{l}\text { 3.3 Physician visits (per month) at } 6 \\
\text { months }\end{array}$ & 1 & 296 & Mean Difference (IV, Fixed, 95\% Cl) & $0.08[-1.28,1.44]$ \\
\hline 3.4 Physician visits at 12 months & 3 & 353 & Mean Difference (IV, Fixed, 95\% Cl) & $0.21[-0.62,1.04]$ \\
\hline $\begin{array}{l}3.5 \text { Physician and nurse visits at } 18 \\
\text { months }\end{array}$ & 1 & 113 & Mean Difference (IV, Fixed, 95\% Cl) & $5.4[0.51,10.29]$ \\
\hline $\begin{array}{l}\text { 3.6 Outpatients geriatric/psychi- } \\
\text { atric team/diagnostic service over } 12 \\
\text { months (number of consultations) }\end{array}$ & 1 & 70 & Mean Difference (IV, Fixed, 95\% CI) & $0.3[-1.61,2.21]$ \\
\hline $\begin{array}{l}\text { 3.7 Medical specialist over } 12 \text { months } \\
\text { (number of consultations) }\end{array}$ & 1 & 70 & Mean Difference (IV, Fixed, 95\% Cl) & $-0.60[-6.35,5.15]$ \\
\hline $\begin{array}{l}\text { 3.8 Physiotherapist over } 12 \text { months } \\
\text { (number of consultations) }\end{array}$ & 1 & 70 & Mean Difference (IV, Fixed, 95\% Cl) & $0.0[-28.18,28.18]$ \\
\hline $\begin{array}{l}\text { 3.9 Social worker over } 12 \text { months } \\
\text { (number of consultations) }\end{array}$ & 1 & 70 & Mean Difference (IV, Fixed, 95\% CI) & $0.02[-0.52,0.56]$ \\
\hline 4 Cost of service (participants) & 1 & & Mean Difference (IV, Fixed, 95\% Cl) & Subtotals only \\
\hline $\begin{array}{l}\text { 4.1 Total health and social care costs } \\
\text { (1000 Euros; excluding intervention) } \\
\text { at } 12 \text { months }\end{array}$ & 1 & 125 & Mean Difference (IV, Fixed, 95\% Cl) & $-7.99[-16.86,0.89]$ \\
\hline $\begin{array}{l}5 \text { Healthcare and care-giving costs } \\
\text { (USD or EUR)) }\end{array}$ & 2 & & Mean Difference (Fixed, 95\% Cl) & Subtotals only \\
\hline $\begin{array}{l}5.1 \text { Payer perspective, including nurs- } \\
\text { ing home cost at } 18 \text { months (USD) }\end{array}$ & 1 & & Mean Difference (Fixed, 95\% Cl) & $\begin{array}{l}-260.0[-1177.99 \\
657.99]\end{array}$ \\
\hline
\end{tabular}




\begin{tabular}{|c|c|c|c|c|}
\hline Outcome or subgroup title & $\begin{array}{l}\text { No. of } \\
\text { studies }\end{array}$ & $\begin{array}{l}\text { No. of } \\
\text { partici- } \\
\text { pants }\end{array}$ & Statistical method & Effect size \\
\hline $\begin{array}{l}\text { 5.2 Payer perspective,excluding nurs- } \\
\text { ing home at } 18 \text { months (USD) }\end{array}$ & 1 & & Mean Difference (Fixed, 95\% Cl) & $\begin{array}{l}-272.0[-1153.49 \\
609.49]\end{array}$ \\
\hline $\begin{array}{l}5.3 \text { Societal perspective cost at } 18 \\
\text { months (USD) }\end{array}$ & 1 & & Mean Difference (Fixed, 95\% Cl) & $\begin{array}{l}-365.0[-1290.30 \\
560.30]\end{array}$ \\
\hline $\begin{array}{l}\text { 5.4 Total health and social care costs } \\
\text { at } 12 \text { months ( } 1000 \text { Euros; excluding } \\
\text { intervention) }\end{array}$ & 1 & & Mean Difference (Fixed, 95\% Cl) & $-7.99[-16.86,0.88]$ \\
\hline $\begin{array}{l}6 \text { Health services costs (participants) } \\
\text { (Medicare expenditures) (community } \\
\text { services usage) in USD or EUR }\end{array}$ & 2 & & Mean Difference (IV, Fixed, 95\% Cl) & Subtotals only \\
\hline 6.1 At year 1 & 2 & 5276 & Mean Difference (IV, Fixed, 95\% Cl) & $-8.13[-17.00,0.75]$ \\
\hline 6.2 At year 2 & 1 & 3665 & Mean Difference (IV, Fixed, 95\% Cl) & $\begin{array}{l}-654.0[-1462.80 \\
154.80]\end{array}$ \\
\hline 6.3 At year 3 & 1 & 2255 & Mean Difference (IV, Fixed, 95\% Cl) & $\begin{array}{l}-779.0[-1976.72 \\
418.72]\end{array}$ \\
\hline 6.4 Over 3 years & 1 & 5170 & Mean Difference (IV, Fixed, 95\% Cl) & $\begin{array}{l}-705.0[-1170.31 \\
-239.69]\end{array}$ \\
\hline $\begin{array}{l}7 \text { Health service use by carers (di- } \\
\text { chotomous outcomes) }\end{array}$ & 1 & & Odds Ratio (M-H, Fixed, 95\% Cl) & Subtotals only \\
\hline $\begin{array}{l}7.1 \text { Hospitalised during } 3 \text { years (num- } \\
\text { ber of carers) }\end{array}$ & 1 & 412 & Odds Ratio (M-H, Fixed, 95\% Cl) & $0.51[0.33,0.81]$ \\
\hline $\begin{array}{l}7.2 \text { Emergency department visits dur- } \\
\text { ing } 3 \text { years (number of carers) }\end{array}$ & 1 & 412 & Odds Ratio (M-H, Fixed, 95\% Cl) & $0.58[0.38,0.89]$ \\
\hline $\begin{array}{l}8 \text { Health service use by carers (contin- } \\
\text { uous outcomes) }\end{array}$ & 2 & & Mean Difference (IV, Fixed, 95\% Cl) & Subtotals only \\
\hline 8.1 Annual hospital length of stay & 1 & 412 & Mean Difference (IV, Fixed, 95\% Cl) & $0.90[-0.23,2.03]$ \\
\hline $\begin{array}{l}8.2 \text { Number of admissions over } 12 \\
\text { months }\end{array}$ & 1 & 412 & Mean Difference (IV, Fixed, 95\% Cl) & $0.15[-0.20,0.50]$ \\
\hline $\begin{array}{l}8.3 \text { Primary care physician over } 12 \\
\text { months (number of consultations) }\end{array}$ & 1 & 69 & Mean Difference (IV, Fixed, 95\% CI) & $0.0[-5.26,5.26]$ \\
\hline $\begin{array}{l}\text { 8.4 Outpatients geriatric/psychiatric } \\
\text { team over } 12 \text { months (number of con- } \\
\text { sultations) }\end{array}$ & 1 & 69 & Mean Difference (IV, Fixed, 95\% Cl) & $-0.77[-5.33,3.79]$ \\
\hline $\begin{array}{l}8.5 \text { Medical specialist over } 12 \text { months } \\
\text { (number of consultations) }\end{array}$ & 1 & 69 & Mean Difference (IV, Fixed, 95\% CI) & $0.10[-5.93,6.13]$ \\
\hline $\begin{array}{l}\text { 8.6 Physiotherapist over } 12 \text { months } \\
\text { (number of consultations) }\end{array}$ & 1 & 69 & Mean Difference (IV, Fixed, 95\% Cl) & $1.70[-13.06,16.46]$ \\
\hline
\end{tabular}




\begin{tabular}{|c|c|c|c|c|}
\hline Outcome or subgroup title & $\begin{array}{l}\text { No. of } \\
\text { studies }\end{array}$ & $\begin{array}{l}\text { No. of } \\
\text { partici- } \\
\text { pants }\end{array}$ & Statistical method & Effect size \\
\hline 9 Informal caregiver time (hours) & 1 & & Mean Difference (IV, Fixed, 95\% CI) & Subtotals only \\
\hline 9.1 Paid unskilled at 6 months & 1 & 296 & Mean Difference (IV, Fixed, 95\% CI) & $\begin{array}{l}-5.10[-789.73 \\
779.53]\end{array}$ \\
\hline 9.2 Unpaid unskilled at 6 months & 1 & 296 & Mean Difference (IV, Fixed, 95\% CI) & $\begin{array}{l}30.70[-388.03 \\
449.43]\end{array}$ \\
\hline $\begin{array}{l}10 \text { Medicare expenditures; communi- } \\
\text { ty services usage in Dollars }\end{array}$ & 1 & & Mean Difference (Fixed, 95\% Cl) & Subtotals only \\
\hline 10.1 At year 1 & 1 & & Mean Difference (Fixed, 95\% Cl) & $\begin{array}{l}-229.0[-489.48 \\
31.48]\end{array}$ \\
\hline 10.2 At year 2 & 1 & & Mean Difference (Fixed, 95\% Cl) & $17.0[-943.97,977.97]$ \\
\hline 10.3 At year 3 & 1 & & Mean Difference (Fixed, 95\% Cl) & $\begin{array}{l}-325.0[-770.89 \\
120.89]\end{array}$ \\
\hline 10.4 Over 3 years & 1 & & Mean Difference (Fixed, 95\% Cl) & $\begin{array}{l}-167.0[-946.28 \\
612.28]\end{array}$ \\
\hline 11 Cost of services (carers) & 1 & & Mean Difference (IV, Fixed, 95\% CI) & Subtotals only \\
\hline $\begin{array}{l}\text { 11.1 Medicare Part A expenditure in } \\
\text { comparison to control }\end{array}$ & 1 & 412 & Mean Difference (IV, Fixed, 95\% CI) & $\begin{array}{l}-681.0[-1382.40 \\
20.40]\end{array}$ \\
\hline
\end{tabular}

\section{Analysis 3.1. Comparison 3 Case management versus usual care (secondary outcomes: service use/cost ), Outcome 1 Use of community-based services (number of participants/ carers).}

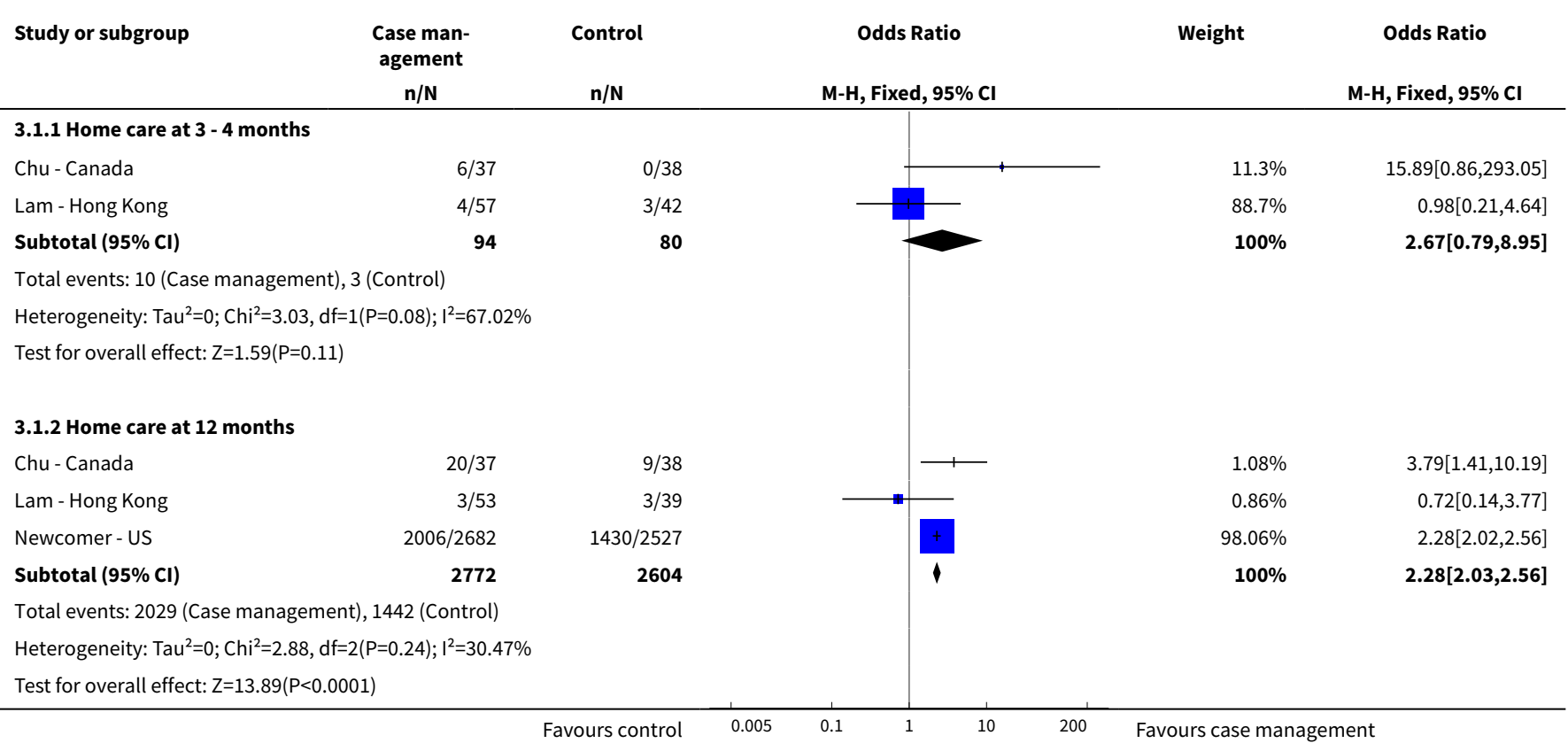




Study or subgroup
agement $\quad$ Control Odds Ratio Odds Ratio

3.1.3 Home care at 18 months

Chu - Canada

Total events: 25 (Case management), 10 (Control) Heterogeneity: Not applicable

Test for overall effect: $Z=3.38(P=0)$

\subsubsection{Day care at 4 months}

Total events: 44 (Case management), 18 (Control)

Heterogeneity: Not applicable

Test for overall effect: $Z=3.4(P=0)$

\subsubsection{Day care at 12 months}

Lam - Hong Kong

Total events: 1032 (Case management), 547 (Control) Heterogeneity: $\mathrm{Tau}^{2}=0 ; \mathrm{Chi}^{2}=1.92, \mathrm{df}=1(\mathrm{P}=0.17) ; \mathrm{I}^{2}=47.83 \%$ Test for overall effect: $Z=12.87(P<0.0001)$

\subsubsection{Day care at 18 months}

$\begin{array}{lr}\text { Vickrey - California } & 31 / 201 \\ \text { Subtotal }(95 \% \mathrm{Cl}) & 201\end{array}$

\subsubsection{Respite care at 4 months}

Total events: 1 (Case management), 0 (Control)

\subsubsection{Respite care at $\mathbf{1 2}$ months}

Lam - Hong Kong

Total events: 1017 (Case management), 541 (Control) Heterogeneity: $\mathrm{Tau}^{2}=0 ; \mathrm{Chi}^{2}=0.35, \mathrm{df}=1(\mathrm{P}=0.56) ; \mathrm{I}^{2}=0 \%$ Test for overall effect: $Z=12.84(P<0.0001)$

3.1.9 Domestic paid helpers at 4 months 


Case man-
agement $\quad$ Control Odds Ratio $\quad$ Weight

3.1.10 Domestic paid helpers at 12 months

Total events: 21 (Case management), 7 (Control)

Heterogeneity: Not applicable

Test for overall effect: $\mathrm{Z}=2.18(\mathrm{P}=0.03)$

\subsubsection{Personal care use at 12 months}

\section{Chu - Canada}

Newcomer - US

Subtotal $(95 \% \mathrm{Cl})$

2719

$859 / 2527$

2565

Total events: 1211 (Case management), 868 (Control) Heterogeneity: $\mathrm{Tau}^{2}=0 ; \mathrm{Chi}^{2}=3.1, \mathrm{df}=1(\mathrm{P}=0.08) ; \mathrm{I}^{2}=67.73 \%$

Test for overall effect: $Z=7.93(P<0.0001)$
3.1.12 Services from a professional home health aide at 18 months Vickrey - California $49 / 201$ $23 / 152$ Subtotal $(95 \% \mathrm{CI})$ 201

Total events: 49 (Case management), 23 (Control) Heterogeneity: $\mathrm{Tau}^{2}=0 ; \mathrm{Chi}^{2}=0, \mathrm{df}=0(\mathrm{P}<0.0001) ; \mathrm{I}^{2}=100 \%$ Test for overall effect: $\mathrm{Z}=2.12(\mathrm{P}=0.03)$

\subsubsection{Services from a paid professional caregiver at 18 months} Vickrey - California

Total events: 42 (Case management), 23 (Control) Heterogeneity: Not applicable

Test for overall effect: $\mathrm{Z}=1.38(\mathrm{P}=0.17)$

3.1.14 In-home, volunteer, or paid respite care services at 18 months Vickrey - California $79 / 201$ $45 / 152$ Subtotal $(95 \% \mathrm{CI})$ 201 152

Total events: 79 (Case management), 45 (Control) Heterogeneity: Not applicable

Test for overall effect: $Z=1.89(P=0.06)$

3.1.15 Assisted living housing use at $\mathbf{1 2}$ months

Newcomer - US $148 / 2682$

$195 / 2527$ Subtotal $(95 \% \mathrm{CI})$ 2682

Total events: 148 (Case management), 195 (Control)

Heterogeneity: Not applicable

Test for overall effect: $Z=3.18(P=0)$

3.1.16 Services or information from local Alzheimers Association at 18 months

$\begin{array}{lrr}\text { Vickrey - California } & 117 / 204 & 56 / 156 \\ \text { Subtotal (95\% Cl) } & \mathbf{2 0 4} & \mathbf{1 5 6}\end{array}$

Total events: 117 (Case management), 56 (Control) Heterogeneity: Not applicable

Test for overall effect: $Z=4(P<0.0001)$
$100 \%$
$100 \%$

$1.81[1.05,3.13]$

$100 \%$

$1.81[1.05,3.13]$

$100 \%$

$1.48[0.85,2.59]$

$100 \%$

$1.48[0.85,2.59]$ 


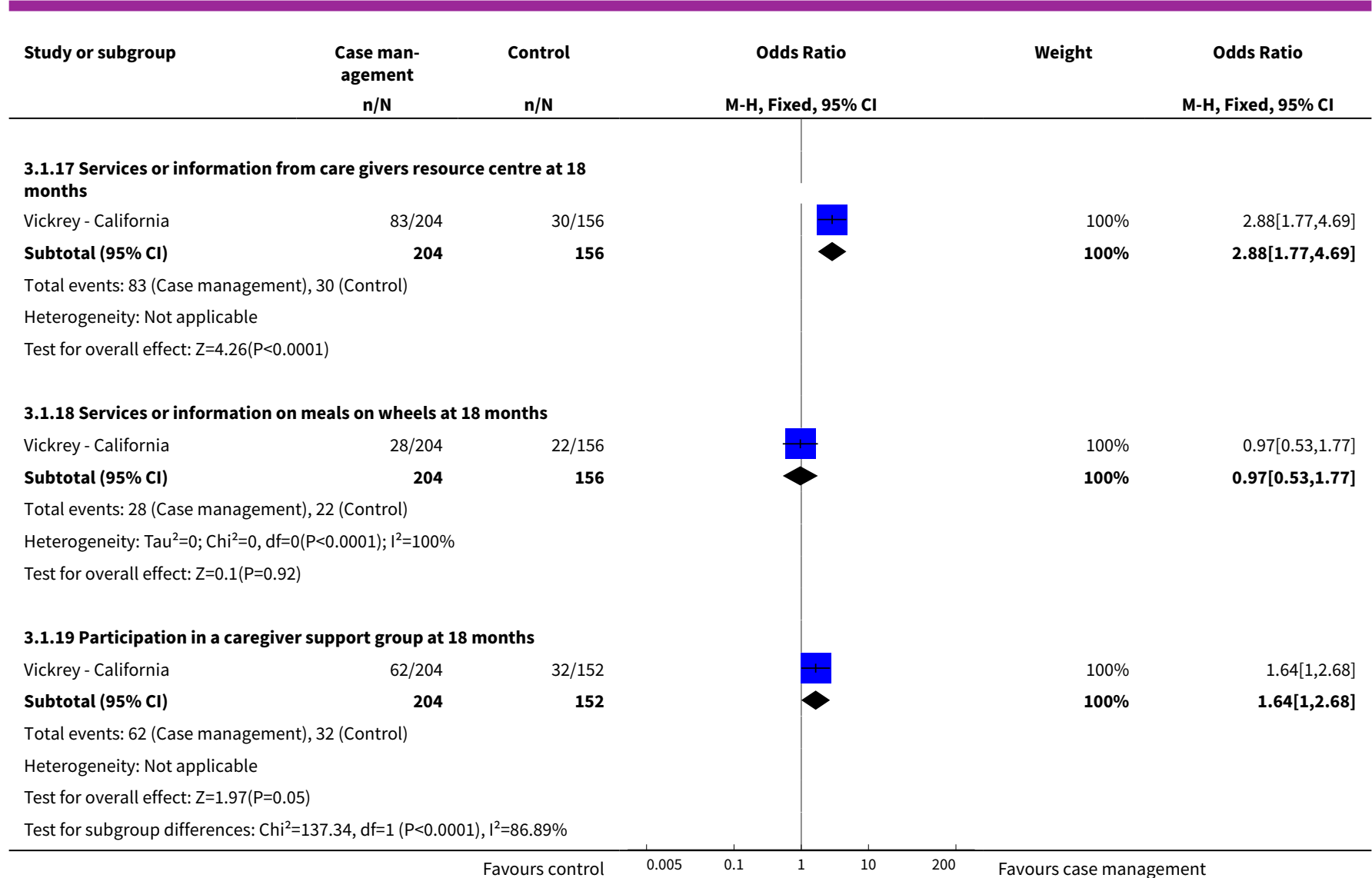

Analysis 3.2. Comparison 3 Case management versus usual care (secondary outcomes: service use/cost ), Outcome 2 Health service use by participants (number of participants).

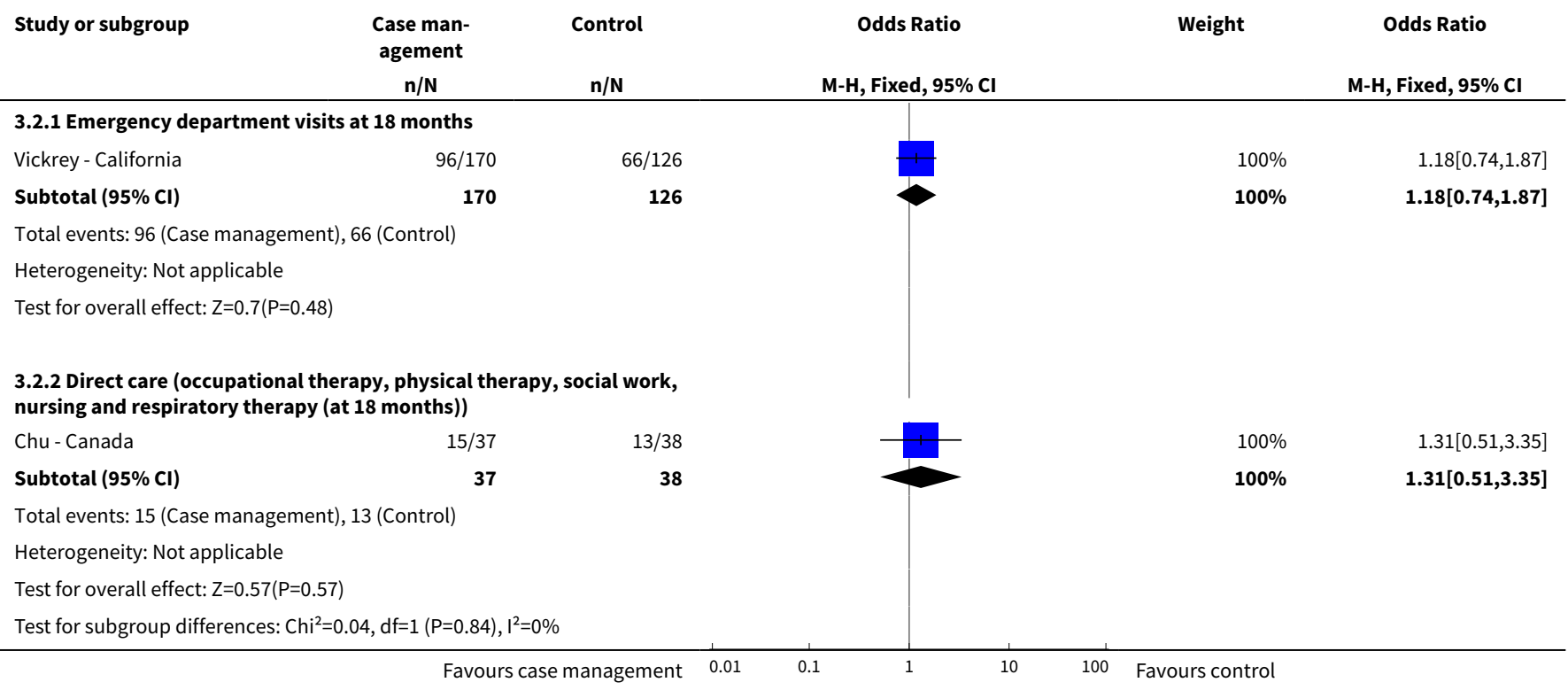


Analysis 3.3. Comparison 3 Case management versus usual care (secondary outcomes: service use/cost ), Outcome 3 Health service use by participants (continuous outcomes).

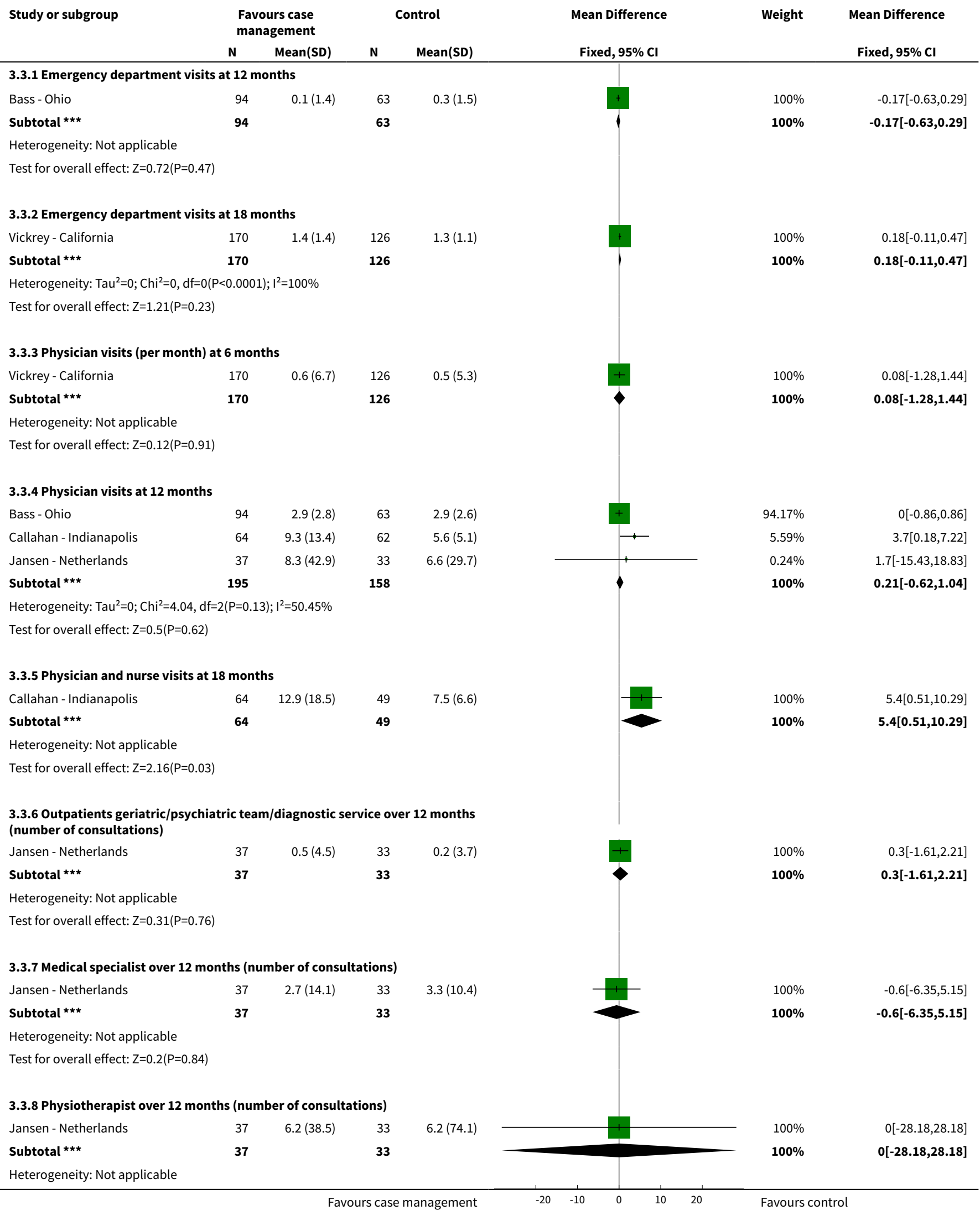




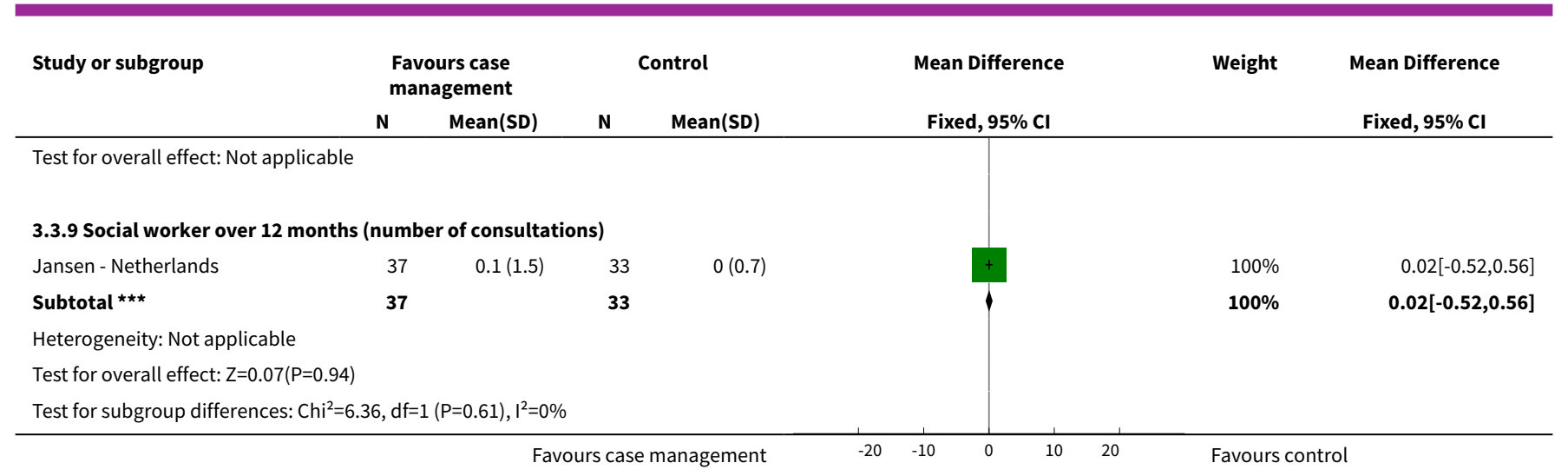

\section{Analysis 3.4. Comparison 3 Case management versus usual care (secondary} outcomes: service use/cost ), Outcome 4 Cost of service (participants).

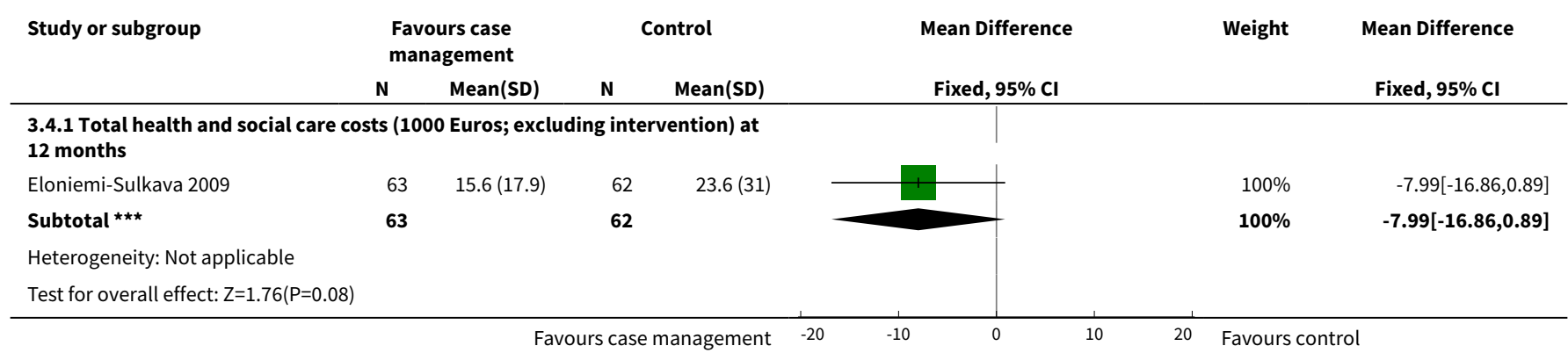

\section{Analysis 3.5. Comparison 3 Case management versus usual care (secondary outcomes: service use/cost ), Outcome 5 Healthcare and care-giving costs (USD or EUR)).}

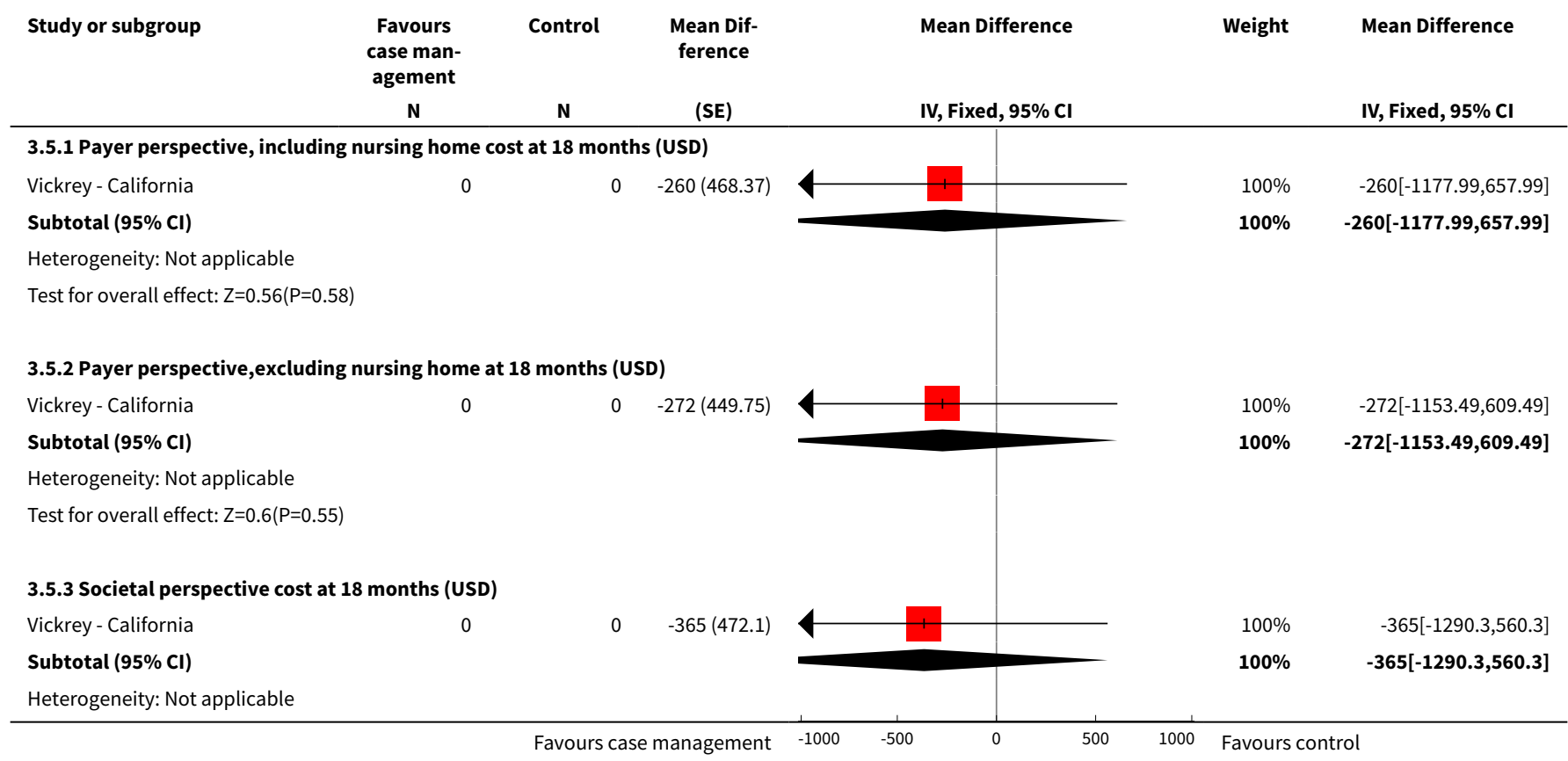




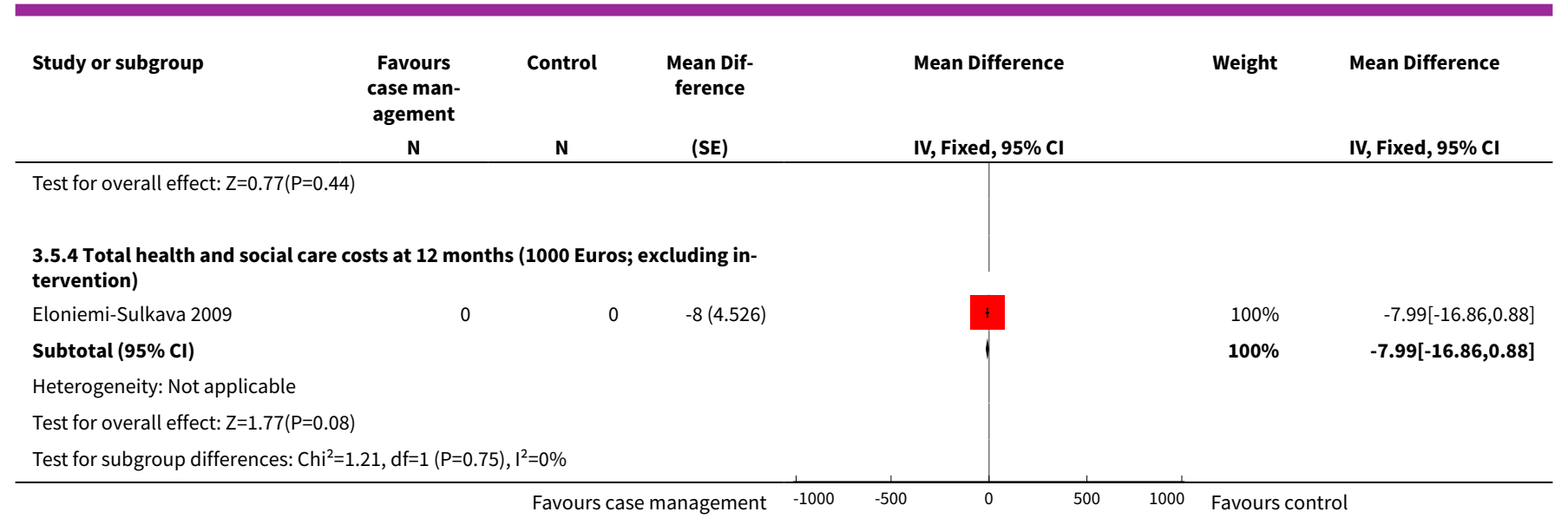

Analysis 3.6. Comparison 3 Case management versus usual care (secondary outcomes: service use/cost), Outcome 6 Health services costs (participants) (Medicare expenditures) (community services usage) in USD or EUR.

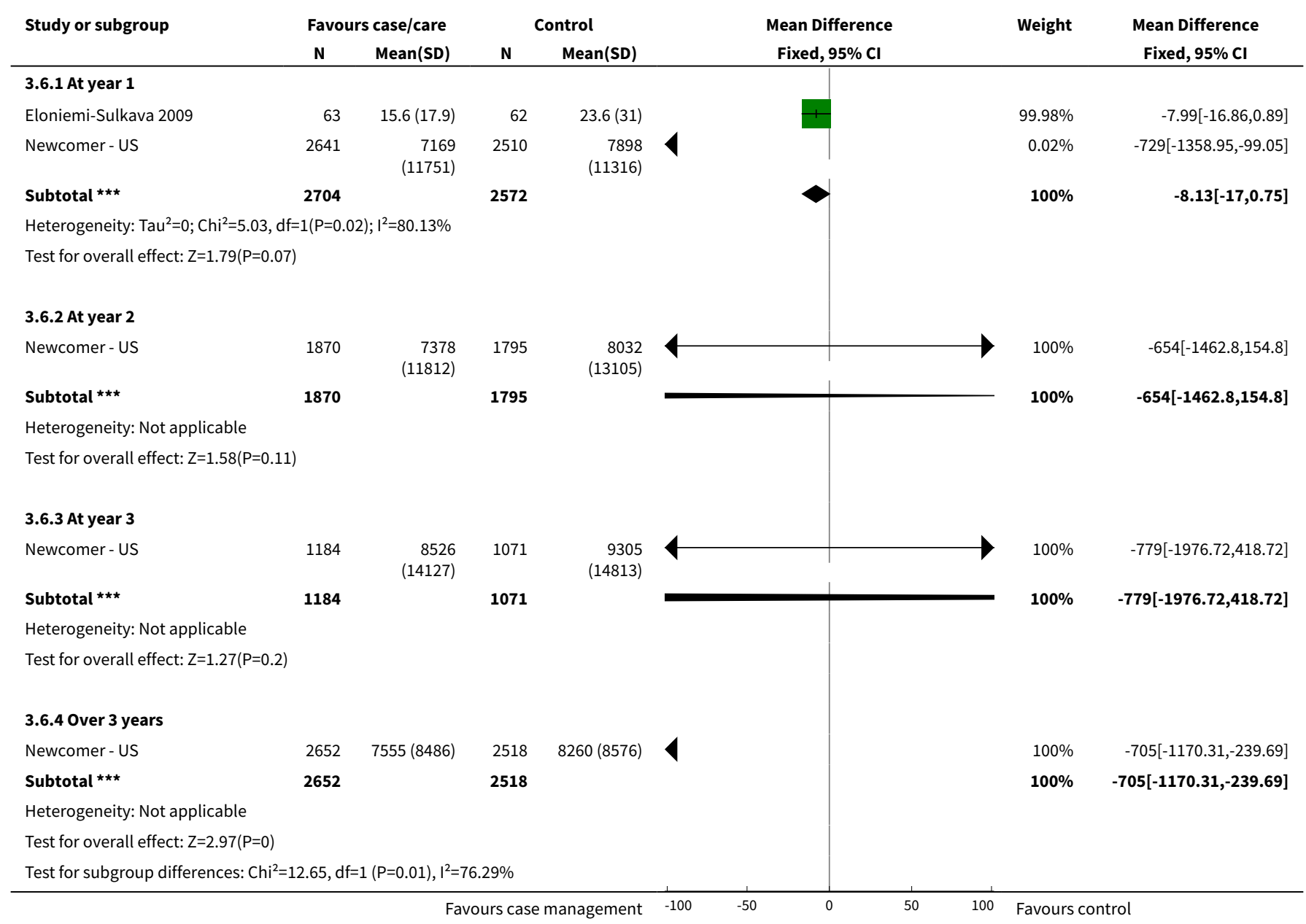


Analysis 3.7. Comparison 3 Case management versus usual care (secondary outcomes: service use/cost ), Outcome 7 Health service use by carers (dichotomous outcomes).

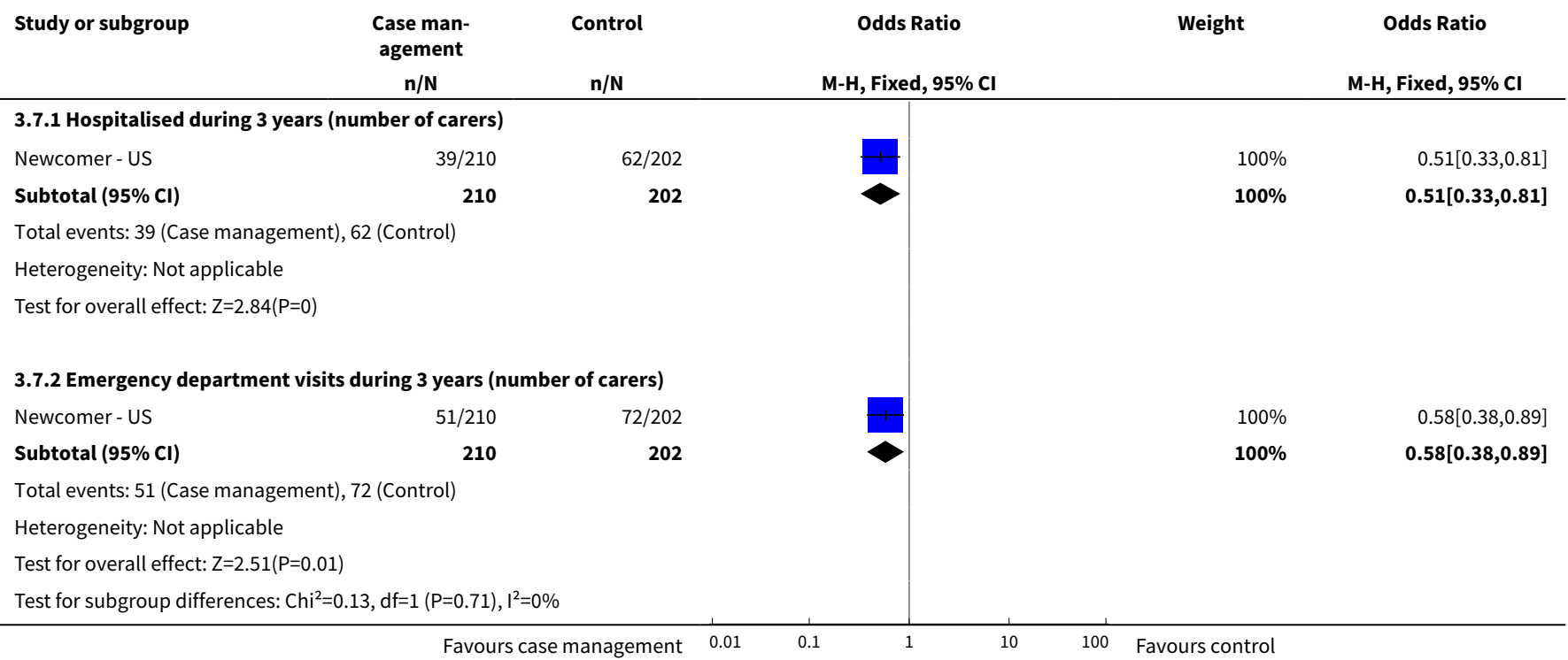

\section{Analysis 3.8. Comparison 3 Case management versus usual care (secondary outcomes: service use/cost ), Outcome 8 Health service use by carers (continuous outcomes).}

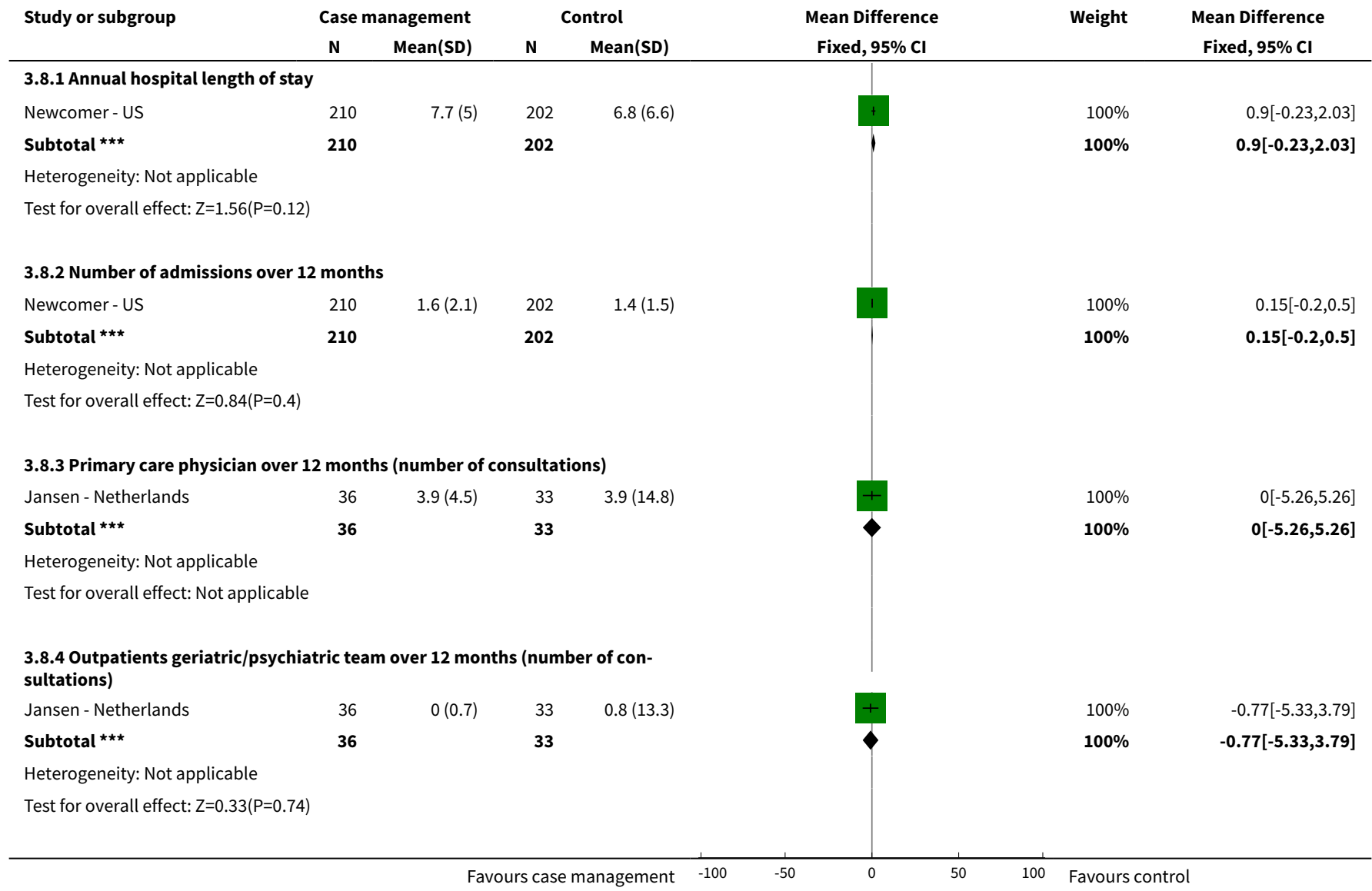




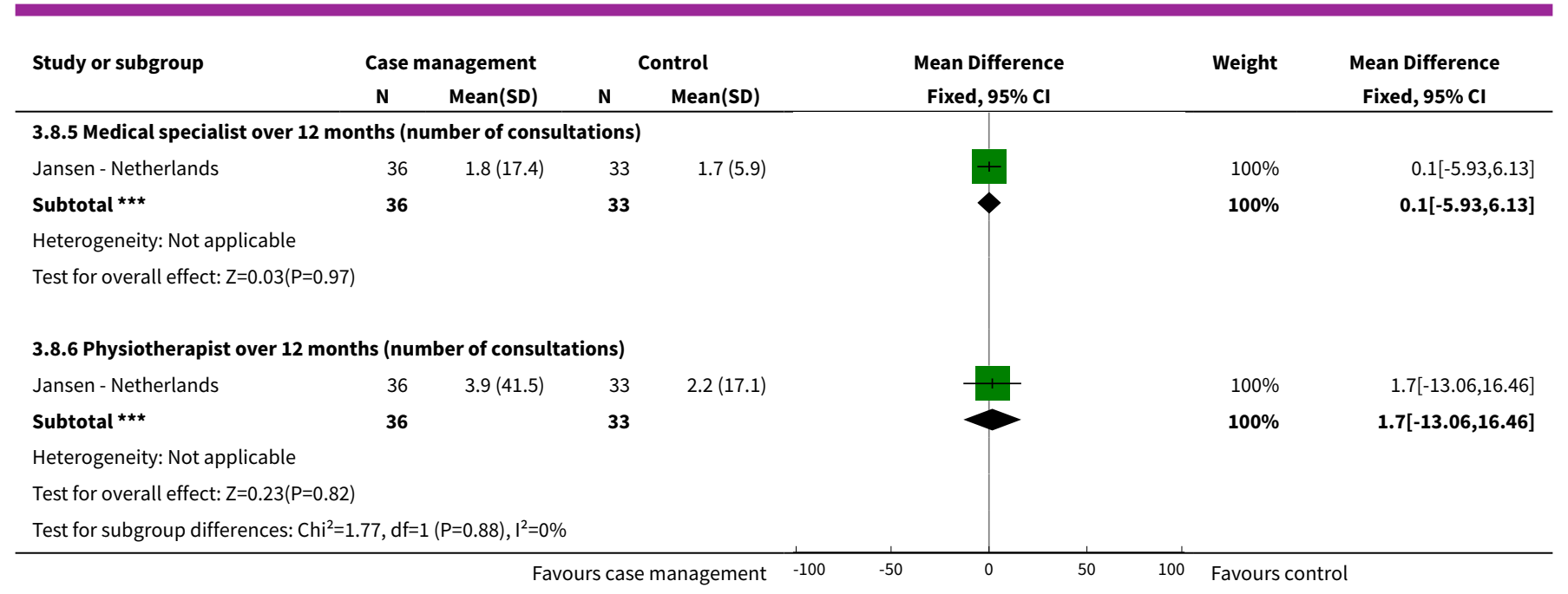

Analysis 3.9. Comparison 3 Case management versus usual care (secondary outcomes: service use/cost ), Outcome 9 Informal caregiver time (hours).

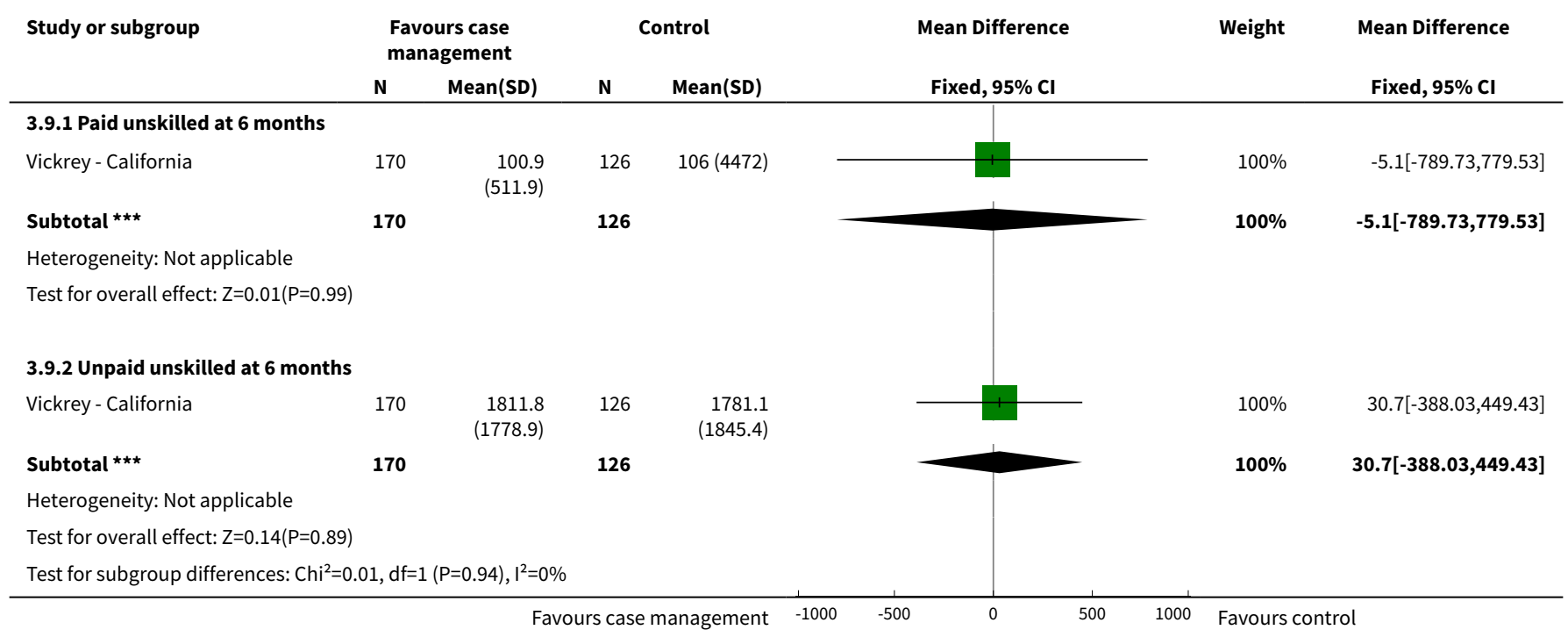

Analysis 3.10. Comparison 3 Case management versus usual care (secondary outcomes: service use/cost ), Outcome 10 Medicare expenditures; community services usage in Dollars.

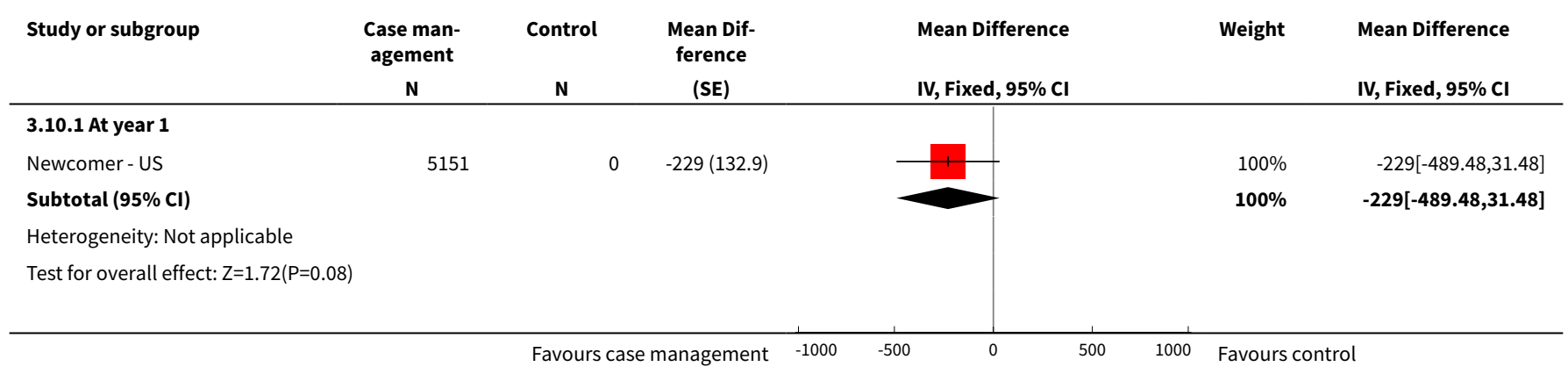




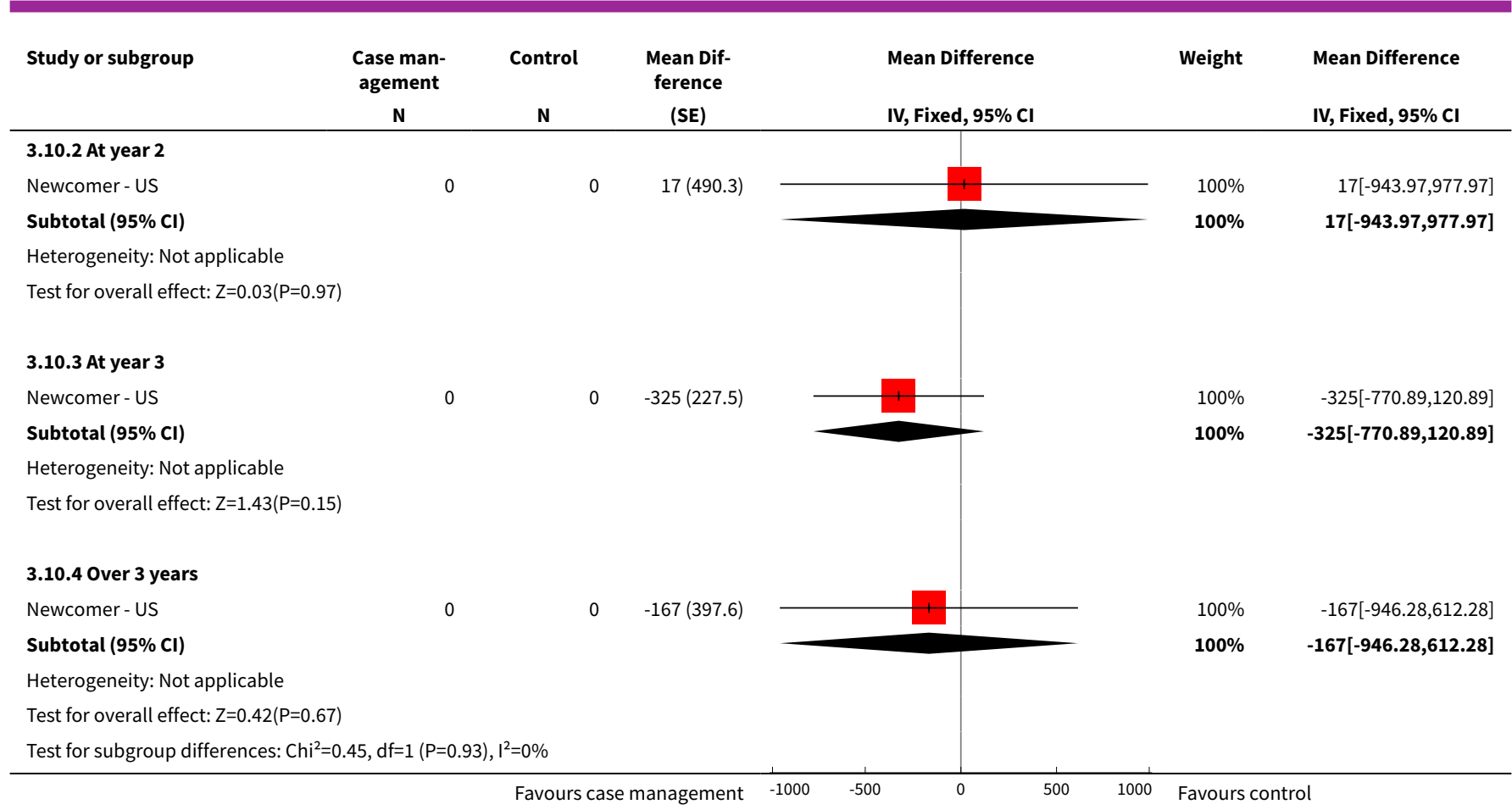

Analysis 3.11. Comparison 3 Case management versus usual care (secondary outcomes: service use/cost ), Outcome 11 Cost of services (carers).

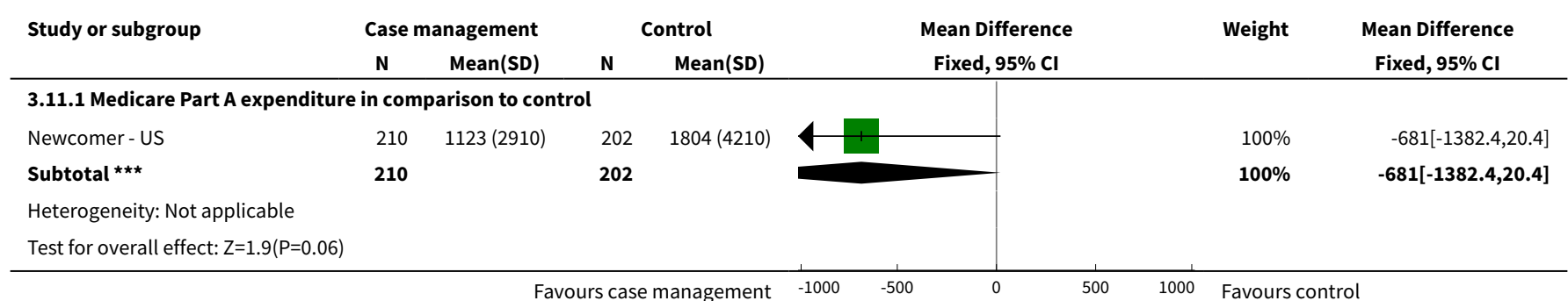

\section{ADDITIONAL TABLES}


Table 1. Goals of case management interventions

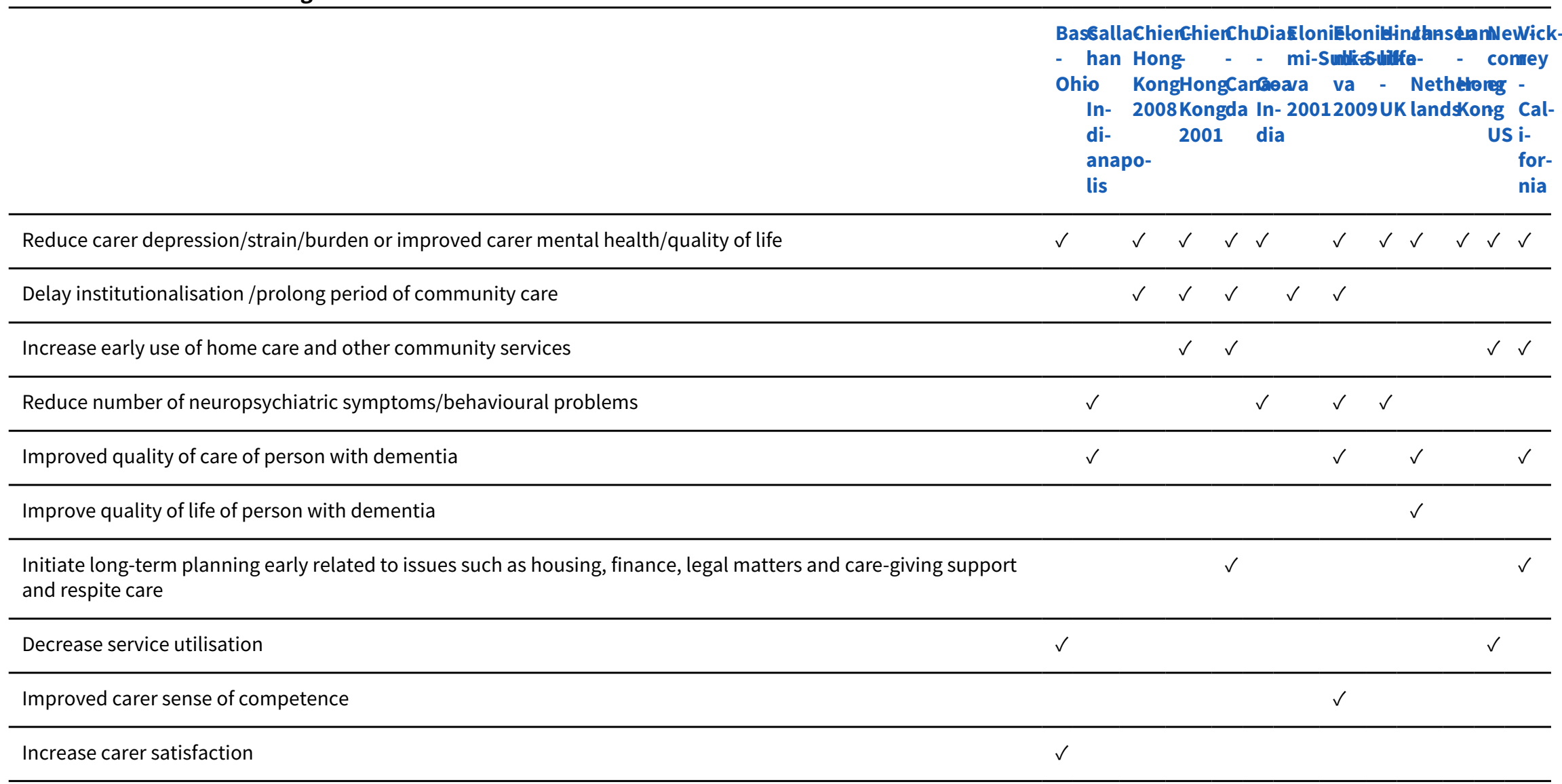




\section{Table 2. Intervention and control description}

\section{Intervention}

Control group

Group A) Studies where the case manager encourages self management of care/empowers carerto arrange own care where possible $a$

Bass - Ohio
Telephone-based coaching programme based on the Chronic Care Model. Care consultants conducted a structured initial assessment and developed strategies for using personal, family, and community resources. They developed a care plan assigning participants, family members, or Association staff/volunteers to work on tasks within a time frame for task completion and reassessment. Tasks often include using other Association services, e.g. education, training programmes, support groups, a respite reimbursement programme, and a nationwide programme to return wanderers safely home. Regular follow-ups (initially biweekly, then 1-month and 3-month intervals) to monitor progress/add to care plan.
Chien- Hong Kong 2008
Programme provided case management, occupational therapy, physical therapy, social work, nursing, respiratory therapy, in-home respite, and out-of-home respite, homemaking, personal care assistance, volunteer service and psychiatric consultation. The objectives of the programme were to assist the participants and family to: 1) initiate long-term planning early related to issues such as housing, finance, legal matters and care-giving support; 2 ) increase early use of home care/other community services; 3 ) improve coping strategies; 4 ) improve care-giving strategies. Goal: to prepare participants and families for the crises during course of the disease.
Participants and carers were able to contact the Association independently and use any of its services other than care consultation. All Association services were free of charge.

6-month educational sessions. Both groups were provided with routine dementia care, such as pharmacotherapy and social and recreational activities for the participants and written educational materials about dementia care for the carers.

Services provided by dementia resources centres: (1) medical consultation, advice to family on condition, treatment plan and ef fects of medications (weekly visiting psychiatrist); (2) advice/referrals for financial aid/social welfare services (social worker); (3) monthly education talks in dementia care (registered psychiatric nurse); and (4) weekly social and recreational activities (staff at centre).

After receiving only education and information regarding dementia, dyads were placed on a waiting list to receive the intervention after 6 months. Free to utilise the existing health services during this time.

Group B) Studies where the case manager ensures appropriate delivery of services (short-term) 


\section{Table 2. Intervention and control description (Continued)}

Hinchliffe - UK The intervention group received an individualised care package for the carer and the person with dementia, which considered medication (for managing verbal and/ or physical aggression, night disturbance, restlessness and sexual disinhibition); psychological techniques (charts recording precipitants of aggressions, involving of participants in pleasant activities, distraction techniques, etc) and social measures (referral to day centre, respite for carers, application for benefits).
Lam - Hong Kong
Waiting list controls received a delayed intervention package at 16 weeks
Case management by a trained occupational therapist for 4 months. The CM offered interventions in the following areas: 1) Assessment and advice: CM evaluated the activities of daily living and neuropsychiatric symptoms of the demented person, and carer distress in care duties. CM also advised carers and demented participants on the following areas: safe performance in basic self-care activities with environmental modification to promote safe home living, behavioural management, and communication techniques.

2) Home-based programme on cognitive stimulation: Participants with family carers received training on home-based cognitive stimulation strategies which included reading newspapers together, reminiscence by old-time photos (Lin 2003; Rentz 1995), and continued engagement in usual household tasks and leisure activities. The cognitive stimulating programme was reinforced by home visits and telephone calls as appropriate for 16 weeks. Afterward, family carers were encouraged to continue with the activities

3) Case management; CM provided support to carers and participants, home visits initially, and later by telephone calls, and follow-up at hospital clinic visits. CM encouraged the participants to be registered with local social centres so that the family could tap into the locally available social services. CM liaised with the staff in the social centres involved, to ensure smooth integration of the participants into the activity schedule.
One home visit for home safety by the same occupational therapist as intervention group at the beginning of the trial (no access to case management). Both groups followed up at 3-monthly intervals in the psychogeriatric or memory clinics.

Group C) Studies where the case manager ensures appropriate delivery of services (longer-term)

Callahan - Indianapolis
Collaborative care management: comprehensive screening and diagnosis programme, care-giver education and support, 1-year care management led by nurse practitioner working with carer and primary care physician. Access to primary care clinic-specific care physician, enrolment in Alzheimer's Association safe return programme, dementia medication if appropriate. At each contact, care manager assessed current problems using a symptom checklist. Based on current problems, the care manager could activate standardised protocols for behavioural problems. Protocols emphasised non-drug management. Approx 12 hours contact (50\% faceto-face) per year. Nurse care managers met with an interdisciplinary support team weekly to review new and/or difficult participants. Participant's progress was monitored with a web-based longitudinal tracking system. Care manager served as an ombudsman for participant's other chronic conditions (navigating the health system). Care manager provided regular updates and care suggestions to primary care physicians. Participants and carers were provided with written educational materials and face-to-face counselling by a geriatric nurse practitioner.
Augmented Usual care: participants and carers were provided with written educational materials and face-to-face counselling by a geriatric nurse practitioner. Meeting between 40 and 90 minutes at primary care clinic. Written materials describing local community resources provided. Control primary care physicians received written notification of the participant's diagnosis from the diagnostic assessment. Referral to community resources.

Participants were given an information package on community re-

sources.
The Early Home Care Program provided case management, occupational therapy,
physical therapy, social work, nursing, respiratory therapy, in-home respite, and out-of-home respite, homemaking, personal care assistance, volunteer service and psychiatric consultation. The objectives of the programme were to assist the participants and family to: 1 ) initiate long-term planning early related to issues such as housing, finance, legal matters and care-giving support; 2) increase the early use of home care and other community services; 3 ) improve the coping strategies related 
Table 2. Intervention and control description (Continued)

to psychosocial issues which often hinder long-term planning and service utilisation; and 4) improve care-giving strategies related to functional and behavioural difficulties of the individuals with AD. The goal was to prepare participants and families for the crises that occur along the course of the disease

Eloniemi-Sulkava 2001
Two-year intervention programme of systematic, comprehensive support by a dementia family care co-ordinator who had access to the physician and co-ordinated the care, services, and support of the families. She provided advocacy for participants and carers, comprehensive support for participants and carers, continuous and systematic counselling, annual training courses for participants and carers, follow-up calls, in-home visits, assistance with arrangements for social and healthcare services and 24-hour-per-day availability by mobile telephone.
Participants received the usual services provided for geriatric patients in community care by the municipal social and healthcare system or the private sector.

Participants received the usual services from the municipal social and healthcare system and/or the private sector, depending on their own initiative. Furthermore, the control families were provided information and referrals to community resources, written educational materials, and opportunities to share experiences and feelings with the study nurse in baseline assessments and at 6 and 12-month study follow-ups.

Usual care: participants could access a variety of healthcare and welfare services on their own initiative, but had no structured assessment and care plan, no access to family meetings, and limited access to the carers' guide.

Participants received usual care; this is not described further.
- high caseload) sites operated with a target case manager-to-client ratio of 1:100 and had a monthly community service reimbursement limit or cap from USD 290 through USD 489 per month per participant. Model A sites (Rochester, NY; Urbana, IL; Memphis, TN; Portland, OR).

Model B (high reimbursement - low caseload) sites had a target case manager-toclient ratio of 1:30 and a slightly higher reimbursement limit of from USD 430 through USD 699 per month per participant. Model B sites (Cincinnati, OH; Parkersburg, WV; Minneapolis, MN; Miami, FL). Case management was provided without charge. Carer support services (subsidised: participants paid $20 \%$ of the price) included education and training, support groups, mental health and counselling services, and transportation to groups. Services reimbursed by the demonstration (intervention) included adult day care, homemaker, housekeeping, general chore, per- 
Table 2. Intervention and control description (Continued)

sonal care, minor home repairs, companion services, non-emergency transportation, adaptive and assistive equipment, consumable care goods, and safety modifications to the home.

Vickrey - California
Intervention components based on the chronic care model, emphasized linkages with community resources and multi-agency coordination. Dementia CMs - key component along with formal procedures for communication within and between organizations and agencies. This included adherence to 23 dementia guideline recommendations, Internet-based CM, collaborative care planning with carers, carer self-management support, ongoing follow-up, and provider education. The care managers performed a structured home assessment, identified problems, initiated care plan actions, and sent summary to primary care physician/ other designated providers. CMs provided ongoing follow-up as needed, with in-home reassessments every 6 months.
Care as usual (meaning they continued to receive care from their usual providers) but were not offered any of the specialised dementia care management.

a See Table 5 Typology of case management interventions in included studies 
Table 3. Case management intervention characteristics

\begin{tabular}{|c|c|c|c|c|c|c|c|c|c|}
\hline Study & $\begin{array}{l}\text { Description/ conceptual } \\
\text { framework/ }\end{array}$ & $\begin{array}{l}\text { Pro- } \\
\text { tocol/ } \\
\text { manual }\end{array}$ & $\begin{array}{l}\text { Professional } \\
\text { group of case } \\
\text { manager or } \\
\text { equivalent }\end{array}$ & Mode of delivery & $\begin{array}{l}\text { De- } \\
\text { scribed } \\
\text { as case } \\
\text { or care } \\
\text { man- } \\
\text { age- } \\
\text { ment by } \\
\text { trialists }\end{array}$ & $\begin{array}{l}\text { Dura- } \\
\text { tion } \\
\text { (months) }\end{array}$ & $\begin{array}{l}\text { Intensi- } \\
\text { ty: case- } \\
\text { load size }\end{array}$ & $\begin{array}{l}\text { Intensi- } \\
\text { ty: fre- } \\
\text { quency } \\
\text { of con- } \\
\text { tact per } \\
\text { month }\end{array}$ & $\begin{array}{l}\text { Breadth } \\
\text { of case } \\
\text { man- } \\
\text { age- } \\
\text { ment } \\
\text { role }\end{array}$ \\
\hline
\end{tabular}

Group A) Studies where the case manager encourages self management of care/empowers carerto arrange own care where possible a

\begin{tabular}{|c|c|c|c|c|c|c|c|c|c|}
\hline Bass - Ohio & $\begin{array}{l}\text { Telephone-based coach- } \\
\text { ing programme based on } \\
\text { Chronic Care Model (CCM) }\end{array}$ & $\checkmark$ & $\begin{array}{l}\text { Care consul- } \\
\text { tants }(C C) \text { - so- } \\
\text { cial workers }\end{array}$ & Telephone & $\checkmark$ & 12 & $\begin{array}{l}\text { Approx } \\
1: 40\end{array}$ & 1 or 2 & A \\
\hline $\begin{array}{l}\text { Chien- Hong } \\
\text { Kong } 2008\end{array}$ & $\begin{array}{l}\text { Dementia CM } \\
\text { programme/education and } \\
\text { support } \\
\text { group for carers }\end{array}$ & $\#$ & Nurse & Face-to-face visits, groups & $\checkmark$ & 6 & - & 2 & $A, B$ \\
\hline $\begin{array}{l}\text { Chien - Hong } \\
\text { Kong } 2001\end{array}$ & $\begin{array}{l}\text { Dementia Family Care Pro- } \\
\text { gramme }\end{array}$ & $\#$ & Nurse & $\begin{array}{l}\text { Face-to-face visits, tele- } \\
\text { phone, groups }\end{array}$ & $\checkmark$ & 6 & - & 2 & $A, B$ \\
\hline Dias - Goa India & $\begin{array}{l}\text { Home-care support pro- } \\
\text { gramme for } \\
\text { carers }\end{array}$ & $\#$ & $\begin{array}{l}\text { Unqualified ad- } \\
\text { visor }\end{array}$ & $\begin{array}{l}\text { Face-to-face visits, tele- } \\
\text { phone, groups }\end{array}$ & $\#$ & 6 & $1: 20$ & $2+$ & $A, B$ \\
\hline
\end{tabular}

Group B) Studies where the case manager ensures appropriate delivery of services (short-term)

\begin{tabular}{|c|c|c|c|c|c|c|c|c|c|}
\hline Hinchliffe - UK & $\begin{array}{l}\text { Multi-disciplinary team in- } \\
\text { dividualised plan aiming to } \\
\text { reduce most distressing be- } \\
\text { haviours }\end{array}$ & $\#$ & Psychiatrist & Face-to-face visits & $\#$ & 4 & $\begin{array}{l}1: \text { ap- } \\
\text { prox } 13 \\
-20\end{array}$ & 3 & $A, B, E$ \\
\hline $\begin{array}{l}\text { Lam - Hong } \\
\text { Kong }\end{array}$ & Case management model & $\#$ & $\begin{array}{l}\text { Occupational } \\
\text { therapist }\end{array}$ & $\begin{array}{l}\text { Face-to-face visits, tele- } \\
\text { phone }\end{array}$ & $\checkmark$ & 4 & $1: 59$ & 1 & $A, B, E$ \\
\hline
\end{tabular}

Group C) Studies where the case manager ensures appropriate delivery of services (longer term)

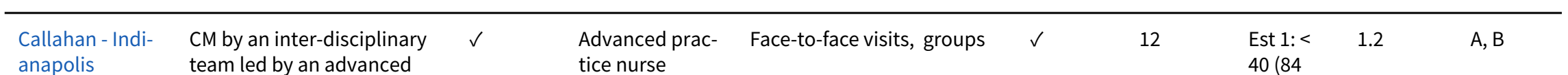


Table 3. Case management intervention characteristics (Continued)

practice nurse working with

the participant's carer

between

$2 \mathrm{CMs}$

$2002-$

2004)

\begin{tabular}{|c|c|c|c|c|c|c|c|c|c|}
\hline Chu - Canada & $\begin{array}{l}\text { CM within a comprehensive } \\
\text { home-care programme }\end{array}$ & $\#$ & Social worker & $\begin{array}{l}\text { Face-to-face visits, tele- } \\
\text { phone, groups }\end{array}$ & $\checkmark$ & 18 & - & 1 & $A, B, C, E$ \\
\hline $\begin{array}{l}\text { Eloniemi-Sulka- } \\
\text { va } 2001\end{array}$ & $\begin{array}{l}\text { Support programme based } \\
\text { on nurse case management }\end{array}$ & $\checkmark$ & Nurse & $\begin{array}{l}\text { Face-to-face visits, tele- } \\
\text { phone, groups }\end{array}$ & $\checkmark$ & Up to 24 & - & $1+$ & $A, C, E$ \\
\hline $\begin{array}{l}\text { Eloniemi-Sulka- } \\
\text { va } 2009\end{array}$ & $\begin{array}{l}\text { Multi-component interven- } \\
\text { tion programme including a } \\
\text { family care co-ordinator }\end{array}$ & $\checkmark$ & Nurse & $\begin{array}{l}\text { Face-to-face visits, tele- } \\
\text { phone, groups }\end{array}$ & $\#$ & Up to 24 & $1: 60$ & $1+$ & $A, B, D, E$ \\
\hline $\begin{array}{l}\text { Jansen - } \\
\text { Netherlands }\end{array}$ & Case management & $\checkmark$ & District nurse & $\begin{array}{l}\text { Face-to-face visits, tele- } \\
\text { phone, groups }\end{array}$ & $\checkmark$ & 12 & - & $\begin{array}{l}\text { Varied } \\
\text { by case } \\
\text { manager }\end{array}$ & $A, E$ \\
\hline Newcomer - US & $\begin{array}{l}\text { CM and Medicare-sub- } \\
\text { sidised community services }\end{array}$ & $?$ & Social worker & $\begin{array}{l}\text { Face-to-face visits, } \\
\text { groups }\end{array}$ & $\checkmark$ & Not clear & $\begin{array}{l}\text { Model A } \\
\text { 1:100; } \\
\text { Model B } \\
\text { 1:30 }\end{array}$ & $?$ & $\begin{array}{l}A, B, C \\
D, E\end{array}$ \\
\hline $\begin{array}{l}\text { Vickrey - Cali- } \\
\text { fornia }\end{array}$ & $\begin{array}{l}\text { Disease management pro- } \\
\text { gramme led by CMs. com- } \\
\text { prehensive CM base on CCM }\end{array}$ & $\checkmark$ & Social worker & $?$ & $\checkmark$ & 18 & $1: 50$ & & $\begin{array}{l}\text { A (pri- } \\
\text { mary } \\
\text { care), B, } \\
C, E\end{array}$ \\
\hline
\end{tabular}

aSee Table 5 'Typology of case management interventions in included studies'

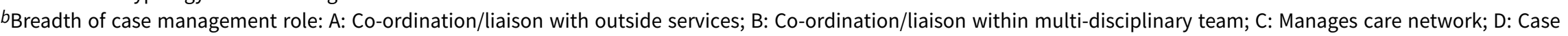
manger holds case management budget; E: Arranges/allocates services

$c$ The 3 case managers spent a mean time of 10.8 hours (range $0.75-28$ hours) a year per participant-carer dyad on the case management intervention. The nurses differed in mean time spent on the intervention per pair; nurse 1 spent 8.8 hours (range $2-26$ ); nurse 2 spent 5.5 hours (range $0.75-15$ ), and nurse 3 spent 15.2 hours (range 9.6 - 28); $F$ $=9.811, \mathrm{P}<0.001$ 
Table 4. Case management tasks and components

\begin{tabular}{|c|c|c|c|c|c|c|c|c|}
\hline & $\begin{array}{l}\text { Bassalla- } \\
-\quad \text { han } \\
\text { Ohio } \\
\quad \text { In- } \\
\text { di- } \\
\quad \text { anapo- } \\
\quad \text { lis }\end{array}$ & $\begin{array}{l}\text { Chierchierchu } \\
\text { Hong - } \\
\text { KongHongCan } \\
2008 \text { Kongda } \\
2001 \\
-\quad\end{array}$ & $\begin{array}{l}\text { Dias } \\
- \\
\text { aGoa } \\
\text { In- } \\
\text { dia }\end{array}$ & $\begin{array}{l}\text { Eloni } \\
\text { mi-Su } \\
\text { va } \\
2001\end{array}$ & $\begin{array}{l}\text { Elonie } \\
\text { Ilsai-Su } \\
\text { va } \\
2009\end{array}$ & $\begin{array}{l}\text { eHinch } \\
\text { Iliffe } \\
\text { UK }\end{array}$ & $\begin{array}{l}\text { blanseam New } \\
\text { - - com } \\
\text { Nethklonger } \\
\text { landsKong- } \\
\text { US }\end{array}$ & $\begin{array}{l}\text { l-Vick- } \\
\text {-rey } \\
- \\
\text { Cal- } \\
\text { i- } \\
\text { for- } \\
\text { nia }\end{array}$ \\
\hline \multicolumn{9}{|l|}{ CASE MANAGEMENT TASKS } \\
\hline Case finding/screening & $\checkmark$ & & $\checkmark$ & & $\checkmark$ & & & \\
\hline Assessment & $\checkmark \checkmark$ & $\checkmark$ & & $\checkmark$ & $\checkmark$ & $\checkmark$ & $\checkmark \quad \checkmark$ & $\checkmark$ \\
\hline Financial assessment & $\checkmark$ & & & & & & $\checkmark$ & \\
\hline Care planning & $\checkmark \checkmark$ & $\begin{array}{lll}\checkmark & \checkmark & \checkmark\end{array}$ & & $\checkmark$ & $\checkmark$ & $\checkmark$ & $\begin{array}{lll}\checkmark & \checkmark & \checkmark\end{array}$ & $\checkmark$ \\
\hline Implementation/management of care plan & $\checkmark \checkmark$ & $\begin{array}{lll}\checkmark & \checkmark & \checkmark\end{array}$ & & $\checkmark$ & $\checkmark$ & $\checkmark$ & $\checkmark \quad \checkmark$ & $\checkmark$ \\
\hline Arranging/allocating services & $\checkmark$ & $\checkmark$ & & $\checkmark$ & $\checkmark$ & $\checkmark$ & $\checkmark \quad \checkmark$ & $\checkmark$ \\
\hline Case budget management/budget holding & & & & & $\checkmark$ & & $\checkmark$ & \\
\hline Monitoring the implementation of the care plan & $\checkmark \checkmark$ & $\begin{array}{lll}\checkmark & \checkmark & \checkmark\end{array}$ & $\checkmark$ & $\checkmark$ & $\checkmark$ & & $\checkmark \quad \checkmark$ & $\checkmark$ \\
\hline Review & $\checkmark \checkmark$ & $\checkmark$ & & $?$ & & & $?$ & $\checkmark$ \\
\hline Case closure & $\checkmark$ & $\checkmark$ & & & & $\checkmark$ & & $\checkmark$ \\
\hline \multicolumn{9}{|l|}{ CASE MANAGEMENT COMPONENTS } \\
\hline Participant information and education & $\checkmark \checkmark$ & $\checkmark$ & & $\checkmark$ & $\checkmark$ & $\checkmark \checkmark$ & $\checkmark \quad \checkmark$ & $\checkmark$ \\
\hline Participant advocacy & $\checkmark$ & $\checkmark$ & & $\checkmark$ & $\checkmark$ & & $\checkmark$ & $\checkmark$ \\
\hline Legal/insurance/benefits/ financial assistance & $\checkmark$ & $\checkmark$ & $\checkmark$ & & $\checkmark$ & & & $\checkmark$ \\
\hline
\end{tabular}




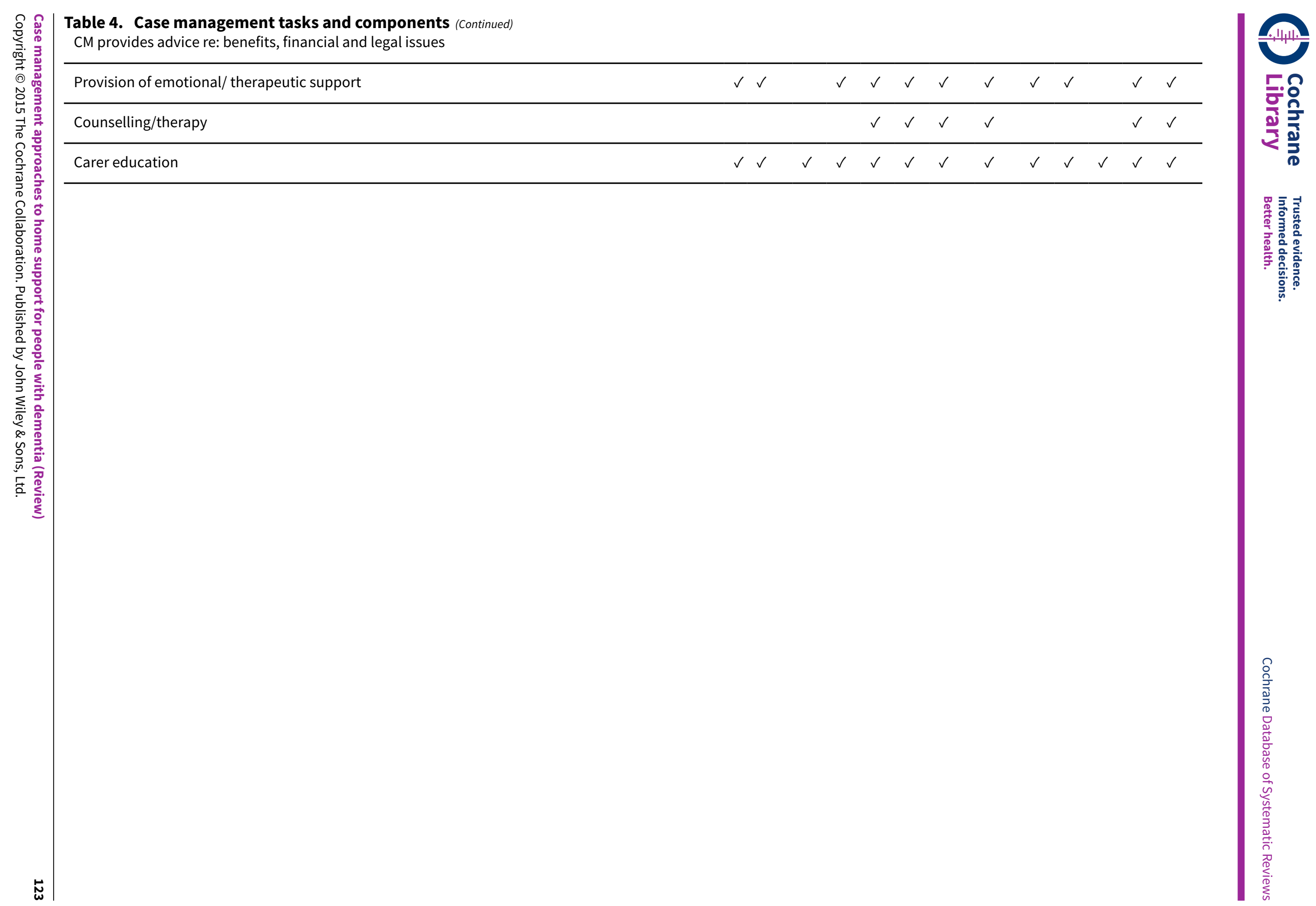


Table 5. Typology of case management interventions in included studies

\begin{tabular}{|c|c|c|c|}
\hline & $\begin{array}{l}\text { Case manager encour- } \\
\text { ages self } \\
\text { management of care/ } \\
\text { empowers } \\
\text { carerto arrange own } \\
\text { care } \\
\text { where possible }\end{array}$ & $\begin{array}{l}\text { Case manager } \\
\text { ensures appro- } \\
\text { priate } \\
\text { delivery of ser- } \\
\text { vices } \\
\text { (short-term) }\end{array}$ & $\begin{array}{l}\text { Case manager } \\
\text { ensures appro- } \\
\text { priate } \\
\text { delivery of ser- } \\
\text { vices } \\
\text { (longer-term) }\end{array}$ \\
\hline Bass - Ohio; & $\checkmark$ & & \\
\hline Callahan - Indianapolis; & & & $\checkmark$ \\
\hline Chien- Hong Kong 2008; & $\checkmark$ & & \\
\hline Chien - Hong Kong 2001; & $\checkmark$ & & \\
\hline Chu - Canada; & & & $\checkmark$ \\
\hline Dias - Goa India; & $\checkmark$ & & \\
\hline Eloniemi-Sulkava 2001; & & & $\checkmark$ \\
\hline Eloniemi-Sulkava 2009; & & & $\checkmark$ \\
\hline Hinchliffe - UK; & & $\checkmark$ & \\
\hline Jansen - Netherlands; & & & $\checkmark$ \\
\hline Lam - Hong Kong; & & $\checkmark$ & \\
\hline Newcomer - US; & & & $\checkmark$ \\
\hline Vickrey - California & & & $\checkmark$ \\
\hline
\end{tabular}

Table 6. Outcome measures from the included studies entered into Review Manager 5

\begin{tabular}{|c|c|c|c|}
\hline Outcome & $\begin{array}{l}\text { Studies re- } \\
\text { porting out- } \\
\text { comes }\end{array}$ & $\begin{array}{l}\text { Name of } \\
\text { Measure / } \\
\text { Source }\end{array}$ & Description of validated measures used to assess outcomes \\
\hline \multirow[t]{2}{*}{$\begin{array}{l}\text { Participant } \\
\text { quality of } \\
\text { life }\end{array}$} & $\begin{array}{l}\text { Jansen - } \\
\text { Netherlands }\end{array}$ & $\begin{array}{l}\text { Dementia } \\
\text { Quality of } \\
\text { Life } \\
\text { (DQOL) } \\
\text { Brod } 1999\end{array}$ & $\begin{array}{l}\text { The DQOL instrument was developed to assess direct subjective individual experi- } \\
\text { ence explicitly and the scale measures } 5 \text { domains: positive affect ( } 6 \text { items), negative } \\
\text { affect ( } 11 \text { items), feelings of belonging ( } 2 \text { items), self esteem ( } 4 \text { items), sense of aes- } \\
\text { thetics ( } 5 \text { items) and a global quality of life rating. The scores are calculated for each } \\
\text { subscale with no overall score. Each item is scored on a 5-point scale, with higher } \\
\text { scores indicating higher quality of life. }\end{array}$ \\
\hline & $\begin{array}{l}\text { Vickrey - Cal- } \\
\text { ifornia }\end{array}$ & $\begin{array}{l}\text { Health Util- } \\
\text { ities Index } \\
\text { Mark 3, } \\
\text { (HUI3) }\end{array}$ & $\begin{array}{l}\text { The HUI3 is a comprehensive health status classification and health state preference } \\
\text { system, which calculates the desirability or preference for each health state. The } \\
\text { HUI3 health status classification system assesses capacity on } 8 \text { dimensions or at- } \\
\text { tributes: vision, hearing, speech, ambulation, dexterity, emotion, cognition (includ- } \\
\text { ing memory and thinking ability), and pain or discomfort. The utility function repre- }\end{array}$ \\
\hline
\end{tabular}


Table 6. Outcome measures from the included studies entered into Review Manager 5 (Continued)

Torrance sents community preferences and scores each unique health state on a scale where 1996; $\quad$ 'dead' has a score of 0 and 'perfect health' has a score of 1 . Because this score captures overall morbidity, it can be interpreted as a measure of health-related quali2000 ty of life; referred to as the 'global utility score'. For each attribute, level 1 indicates 2000 full capacity and levels 5 or 6 indicate the lowest capacity. The single-attribute utility functions provide utility scores for each level with scores ranging between 0 and 1 ; these scores provide a measure of attribute-specific morbidity.

\begin{tabular}{ll}
\hline Lam-Hong & Personal \\
Kong & Well-being \\
& Index for \\
& Adults
\end{tabular}

The Personal Well-Being Index-Intellectual Disability (PWI-ID): This is a parallel form of the original adult PWI (a generic and cross-cultural instrument which was adopted to measure subjective quality of life) designed for use with people who have cognitive impairment PWI-ID (Cummins 2005a; Cummins 2005). A main unique fea-

(PWI-A) ture of the ID version is the incorporation of a standardised pretest for determining

Lau 2005, demonstrates satisfactory psychometric performance in validation studies conduct-

Lau 2006 ed with a wider range of cognitively impaired populations including dementia (Lau 2006). The instrument contains 7 items which ask how satisfied people are with 7 life domains. A 0 - 10 rating scale on satisfaction is used.

\begin{tabular}{|c|c|c|c|}
\hline \multirow[t]{3}{*}{$\begin{array}{l}\text { Participant } \\
\text { cognition }\end{array}$} & $\begin{array}{l}\text { Chu - Cana- } \\
\text { da; } \\
\text { Elonie- } \\
\text { mi-Sulkava } \\
2001\end{array}$ & $\begin{array}{l}\text { Mini Mental } \\
\text { State Exami- } \\
\text { nation } \\
\text { (MMSE) } \\
\text { Folstein } 1975\end{array}$ & $\begin{array}{l}\text { The MMSE is a widely-used screening instrument of cognitive function, which as- } \\
\text { sesses the major cognitive domains affected in Alzheimer's Disease. It consists of a } \\
\text { brief standardised test of cognitive function that measures orientation, memory and } \\
\text { attention. There is a maximum score of } 30 \text {, with scores of } 0 \text { - } 10 \text { commonly described } \\
\text { as severe dementia, } 11 \text { - } 20 \text { as moderate dementia, and } 21 \text { - } 24 \text { as mild dementia. }\end{array}$ \\
\hline & $\begin{array}{l}\text { Chien- Hong } \\
\text { Kong } 2008 \\
\text { Chien - Hong } \\
\text { Kong } 2001 \\
\text { Lam - Hong } \\
\text { Kong }\end{array}$ & $\begin{array}{l}\text { MMSE (Can- } \\
\text { tonese ver- } \\
\text { sion) } \\
\text { Chiu } 1994 \\
\text { Chiu } 1998\end{array}$ & $\begin{array}{l}\text { The MMSE translated into Cantonese. As there is a high level of illiteracy among the } \\
\text { Hong Kong elderly with cognitive impairment, a cut-off point of } \leq 18 \text { is recommend- } \\
\text { ed for elderly people who are illiterate, } \leq 20 \text { for those with } 1-2 \text { years of schooling, } \\
\text { and } \leq 22 \text { for those with more than } 2 \text { years of education. }\end{array}$ \\
\hline & $\begin{array}{l}\text { Callahan - In- } \\
\text { dianapolis }\end{array}$ & $\begin{array}{l}\text { Telephone } \\
\text { Interview for } \\
\text { Cognitive } \\
\text { Status } \\
\text { (TICS) } \\
\text { Brandt } 1988\end{array}$ & $\begin{array}{l}\text { The TICS-M is a brief, 13-item test of cognitive functioning with scores ranging from } \\
0 \text { - 50. Questions include orientation, repetition, naming, and calculations. A 10-item } \\
\text { non-semantically-related word list is recalled both immediately and after a delay of } \\
\text { about } 5 \text { minutes filled with distractor questions. Past research has demonstrated } \\
\text { that the TICS-M is as reliable and valid as face-to-face administration. Cut-off scores } \\
\text { range from } 27-30 \text {. }\end{array}$ \\
\hline \multirow[t]{2}{*}{$\begin{array}{l}\text { Participant } \\
\text { behaviour }\end{array}$} & $\begin{array}{l}\text { Callahan - In- } \\
\text { dianapolis } \\
\text { Chien- Hong } \\
\text { Kong } 2008 \\
\text { Chien - Hong } \\
\text { Kong } 2001 \\
\text { Dias - Goa In- } \\
\text { dia Elonie- } \\
\text { mi-Sulkava } \\
2009\end{array}$ & $\begin{array}{l}\text { Neuropsy- } \\
\text { chiatric In- } \\
\text { ventory } \\
\text { (NPI) } \\
\text { Cummings } \\
1994 \\
\text { Cummings } \\
1998\end{array}$ & $\begin{array}{l}\text { The NPI measures psychopathology in people with dementia and assesses } 12 \text { neu- } \\
\text { ropsychiatric symptoms common in dementia: delusions, hallucinations, agita- } \\
\text { tion/aggression, depression/dysphoria, anxiety, apathy/indifference, irritability, ela- } \\
\text { tion/euphoria, disinhibition, aberrant motor behaviour, sleep disturbance and ap- } \\
\text { petite. Where positive responses are given to the screening questions, the frequen- } \\
\text { cy (score } 1 \text { - 4) and severity (score } 1 \text { - } 3 \text { ) of the behaviour is rated, and these are mul- } \\
\text { tiplied to give a score for each symptom. The NPI calculates scores for the individ- } \\
\text { ual symptom domains and an overall total NPI score, which is scored between } 0 \text { and } \\
\text { 144. Higher scores indicate increasing severity of behaviour symptoms. }\end{array}$ \\
\hline & $\begin{array}{l}\text { Lam - Hong } \\
\text { Kong }\end{array}$ & $\begin{array}{l}\text { Neuropsy- } \\
\text { chiatric In- } \\
\text { ventory/Chi- } \\
\text { nese version }\end{array}$ & $\begin{array}{l}\text { The Chinese version of the NPI. The NPI with Caregiver Distress Scale is as described } \\
\text { above, plus an additional question for each domain which measures the level of dis- } \\
\text { tress caused to carers for each behaviour present (Kaufer 2000). }\end{array}$ \\
\hline
\end{tabular}


Table 6. Outcome measures from the included studies entered into Review Manager 5 (Continued) (NPI)

Leung 2001

\begin{tabular}{|c|c|c|}
\hline $\begin{array}{l}\text { Chu - Cana- } \\
\text { da }\end{array}$ & $\begin{array}{l}\text { Revised } \\
\text { Memory \& } \\
\text { Behaviour } \\
\text { Checklist } \\
\text { (MBPC) } \\
\text { Teri } 1992 \\
\text { Zarit 1983b }\end{array}$ & $\begin{array}{l}\text { The Memory \& Behaviour Checklist (MBPC) is a 64-item carer-report measure of ob- } \\
\text { servable behavioural problems in the loved one with dementia (Teri 1992). It pro- } \\
\text { vides a total score plus scores for } 3 \text { subscales: Memory-Related Problems, Affective } \\
\text { Distress, and Disruptive Behaviours. Scores are computed for the presence/absence } \\
\text { of each problem first, and then for carer "reaction" or the extent to which carers } \\
\text { were "bothered" or "distressed" by each behaviour. The questions derived from } 2 \\
\text { sources: (a) } 30 \text { items from Zarit } 1983 a \text {; Zarit } 1986 \text {, and Zarit 1987) and (b) } 34 \text { items } \\
\text { developed by the authors to include specific behaviours not assessed on the MBPC } \\
\text { and thought to be easily observable and representative of memory-related prob- } \\
\text { lems (e.g. asking repeated questions), depression (e.g., crying), and disruptive be- } \\
\text { haviours (e.g. verbal aggression) in people with dementia. The carer's reaction to } \\
\text { each behaviour, or the extent of distress experienced, were scored as follows: Reac- } \\
\text { tions are assessed by asking how "upsetting" the behaviour was on a scale of } 0 \text { to } 4 \\
\text { ( } 0=\text { Not at all, through to } 4=\text { extremely). Frequency of behaviours is assessed based } \\
\text { on a scale of } 0 \text { to } 4 \text { ( } 0=\text { never occurs, through to } 4=\text { occurs daily or more often). }\end{array}$ \\
\hline
\end{tabular}

$\begin{array}{lll}\begin{array}{l}\text { Participant } \\ \text { depression/ } \\ \text { mood }\end{array} & \begin{array}{l}\text { Callahan-In- } \\ \text { dianapolis }\end{array} & \begin{array}{l}\text { Cornell Scale } \\ \text { for Depres- } \\ \text { sion in De- } \\ \text { mentia }\end{array} \\ & \begin{array}{l}\text { Lam-Hong } \\ \text { Kong }\end{array} & \end{array}$

(CDSS)

Alexopoulos 1988

\begin{tabular}{ll}
\hline Chu-Cana- & Geriatric \\
da & Depression \\
& Scale
\end{tabular}

Yesavage

$1983 a$
An assessment of depression in people with dementia. Depressive signs and symptoms are divided into 5 categories in the Cornell scale: mood-related signs: behavioural disturbance; physical signs; cyclic functions; ideational disturbance. There are 19 items rated on a 3-point scale ranging from absent (0); mild or intermittent (1); severe (2), with a total score of 8 and over indicating significant depressive symptoms.

\begin{abstract}
The GDS is a screening tool for detecting depression in older people, with a predominant focus on the thought processes and emotional symptoms of depressive illness. There are 15 items and each question has a Yes/No answer. Higher scores indicate greater depressive symptoms and a cut off of $6-7$ indicates depressive illness.
\end{abstract}

\begin{tabular}{|c|c|c|c|}
\hline & & $\begin{array}{l}\text { Yesavage } \\
1983 a\end{array}$ & \\
\hline \multirow[t]{2}{*}{$\begin{array}{l}\text { Participant } \\
\text { function/ } \\
\text { dependency }\end{array}$} & $\begin{array}{l}\text { Callahan - In- } \\
\text { dianapolis }\end{array}$ & $\begin{array}{l}\text { Alzheimer's } \\
\text { Disease Co- } \\
\text { operative } \\
\text { Study / Activ- } \\
\text { ities of Daily } \\
\text { Living Inven- } \\
\text { tory } \\
\text { (ADCS-ADL) } \\
\text { Galasko } 1997\end{array}$ & $\begin{array}{l}\text { The ACDS-ADL evaluates individual performance and autonomy in activities of daily } \\
\text { living, either basic or instrumental. The } 23 \text { items measure informant-based observa- } \\
\text { tion of actions or behaviour related to eating, walking, toileting, bathing, grooming, } \\
\text { dressing, telephone use, watching television, conversation, clearing dishes from a } \\
\text { table, finding belongings, preparing food and drinks, garbage disposal, travel, shop- } \\
\text { ping, keeping appointments, being left alone, knowledge of current events, read- } \\
\text { ing, writing, participation in hobbies, using household appliances. Items } 1 \text { - } 5 \text { (eat- } \\
\text { ing, walking, toileting, bathing, grooming) provide a choice of best response and } \\
\text { the remaining items consist of a either a yes, no or don't know response followed by } \\
\text { sub-questions, e.g. did the patient select their first set of clothes for the day? If yes, } \\
\text { which best describes their usual performance: } 3 \text {. without supervision or help; } 2 \text {. with } \\
\text { supervision; } 1 \text {. with physical help. The ADCS-ADL can be used to determine levels of } \\
\text { functional ability across the range of dementia severity, which is scored between } 0 \\
\text { and } 78 \text {. Higher scores indicate better functioning with a score of } 78 \text { indicating full } \\
\text { function. }\end{array}$ \\
\hline & $\begin{array}{l}\text { Dias - Goa In- } \\
\text { dia }\end{array}$ & $\begin{array}{l}\text { Everyday } \\
\text { Abilities } \\
\text { Scale for In- } \\
\text { dia (EASI) }\end{array}$ & $\begin{array}{l}\text { The EASI Scale is a brief } 12 \text {-item informant-based ADL scale that measures function- } \\
\text { al ability. The scale which was developed for the illiterate elderly population in rural } \\
\text { India covers mobility, instrumental and personal care activities. Responses are cod- } \\
\text { ed 'could' ( } 0 \text { ) or 'could not' (1). A higher score indicates greater disability. }\end{array}$ \\
\hline
\end{tabular}


Table 6. Outcome measures from the included studies entered into Review Manager 5 (Continued)

Fillenbaum

1999

\begin{tabular}{lll}
\hline $\begin{array}{l}\text { Elonie- } \\
\text { mi-Sulkava }\end{array}$ & $\begin{array}{l}\text { Activities of } \\
\text { Daily Living } \\
\text { (Barthel) }\end{array}$ & $\begin{array}{l}\text { There are } 10 \text { items which cover eating, mobility, personal hygiene and continence, } \\
\text { which are graded } 0,5 \text { or } 10 . \text { The scale provides an indication of the dependency of } \\
\text { the person and their need for assistance with individual tasks. ADL needs are ranked } \\
\text { from } 0 \text { (very dependent) to } 100 \text { (independent). Higher scores indicate better func- } \\
\text { tional ability. }\end{array}$ \\
$\begin{array}{l}\text { Mahoney } \\
1965\end{array}$ & \\
\hline
\end{tabular}

\begin{tabular}{|c|c|c|c|}
\hline \multirow[t]{4}{*}{$\begin{array}{l}\text { Carer } \\
\text { burden }\end{array}$} & $\begin{array}{l}\text { Chu - Cana- } \\
\text { da } \\
\text { Dias - Goa In- } \\
\text { dia }\end{array}$ & $\begin{array}{l}\text { Zarit burden } \\
\text { Interview } \\
\text { scale } \\
\text { (ZBI) }\end{array}$ & $\begin{array}{l}\text { The ZBI measures subjective burden among carers of adults with dementia. The 22- } \\
\text { item self-report inventory that assesses the level of burden associated with func- } \\
\text { tional/behavioural impairments and the home-care situation. Each item is scored } \\
\text { on a 5-point scale. Response options range from } 0 \text { (Never) to } 4 \text { (Nearly Always). Total } \\
\text { scores range from } 0 \text { (low burden) to } 88 \text { (high burden). }\end{array}$ \\
\hline & $\begin{array}{l}\text { Elonie- } \\
\text { mi-Sulkava } \\
2009\end{array}$ & $\begin{array}{l}\text { Zarit } 1980 \\
\text { Zarit 1983a }\end{array}$ & \\
\hline & $\begin{array}{l}\text { Lam - Hong } \\
\text { Kong }\end{array}$ & Zarit 1986 & \\
\hline & $\begin{array}{l}\text { Newcomer - } \\
\text { US }\end{array}$ & & \\
\hline
\end{tabular}

Chien- Hong Family Care- The FCBI is a 24-item scale measuring the impact of the burden on carers of cogniKong 2008 giving Bur- tively-impaired older people. The multidimensional instrument assesses 5 domains den Invento- of burden (time-dependence, developmental, physical, social, and emotional). The Chien-Hong ry Chinese version of the FCBI was translated and validated by Chou 2002. Items are Kong $2001 \quad$ rated on a 5-point Likert scale from 0 (totally disagree) to 4 (totally agree). The total (FCBI) burden score ranges from 0 to 96 , with a higher score indicating greater burden.

Chou 2002

Jansen - $\quad$ Self-Per- $\quad$ The SPPIC is a 9-item self-report Rasch scale that measures self-perceived pressure Netherlands ceived Pres- from informal care. Items are scored on a 5-point scale: 1 'no!', 2 'no', 3 'more or less', sure by Infor- 4 'yes', 5 'yes!'. To score the SPICC, item-scores are dichotomised and summed submal care sequently. Scores 1 and 2 are recoded into 0 (i.e. not perceiving pressure) and scores (SPPIC) 3, 4 and 5 are recoded into 1 (i.e. perceiving pressure). Scores range from 0 to 9 with Pot 1995

\begin{tabular}{|c|c|c|c|}
\hline \multirow[t]{2}{*}{$\begin{array}{l}\text { Carer } \\
\text { distress }\end{array}$} & $\begin{array}{l}\text { Callahan - In- } \\
\text { dianapolis } \\
\text { Chu - Cana- } \\
\text { da } \\
\text { Dias - Goa In- } \\
\text { dia }\end{array}$ & $\begin{array}{l}\text { Neuropsy- } \\
\text { chiatric In- } \\
\text { ventory } \\
\text { Caregiv- } \\
\text { er Distress } \\
\text { Scale } \\
\text { Cummings } \\
1994 \\
\text { Kaufer } 1998 \\
\text { Kaufer } 2000\end{array}$ & $\begin{array}{l}\text { The Caregiver Distress component of the NPI as described above. This comprises } \\
\text { an additional question on each domain which measures the level of distress caused } \\
\text { to carers by each behaviour. Carers are asked 'How emotionally distressing do you } \\
\text { find this behaviour?'. Items are scored } 0 \text { 'not at all' through to } 5 \text { 'very severely or ex- } \\
\text { tremely'. Higher scores indicate greater carer distress. }\end{array}$ \\
\hline & $\begin{array}{l}\text { Chu - Cana- } \\
\text { da }\end{array}$ & $\begin{array}{l}\text { Revised } \\
\text { Memory \& } \\
\text { Behaviour } \\
\text { Checklist }\end{array}$ & $\begin{array}{l}\text { The Memory \& Behaviour Checklist (MBPC) is a 64-item carer-report measure of ob- } \\
\text { servable behavioural problems in the loved one with dementia (Teri 1992). It pro- } \\
\text { vides a total score plus scores for } 3 \text { subscales: Memory-Related Problems, Affective } \\
\text { Distress, and Disruptive Behaviours. Scores are computed for the presence/absence }\end{array}$ \\
\hline
\end{tabular}


Table 6. Outcome measures from the included studies entered into Review Manager 5 (Continued)

(MBPC) of each problem first, and then for carer "reaction" or the extent to which carers

Teri 1992 sources: (a) 30 items from Zarit 1983a; Zarit 1986, and Zarit 1987) and (b) 34 items

Zarit 1983b developed by the authors to include specific behaviours not assessed on the MBPC and thought to be easily observable and representative of memory-related problems (e.g. asking repeated questions), depression (e.g., crying), and disruptive behaviours (e.g. verbal aggression) in people with dementia. The carer's reaction to each behaviour, or the extent of distress experienced, were scored as follows: Reactions are assessed by asking how "upsetting" the behaviour was on a scale of 0 to 4 ( $0=$ Not at all, through to $4=$ extremely). Frequency of behaviours is assessed based on a scale of 0 to 4 ( $0=$ never occurs, through to $4=$ occurs daily or more often).

\begin{tabular}{|c|c|c|c|}
\hline \multirow[t]{2}{*}{$\begin{array}{l}\text { Carer } \\
\text { mood }\end{array}$} & $\begin{array}{l}\text { Callahan - In- } \\
\text { dianapolis }\end{array}$ & $\begin{array}{l}\text { Patient } \\
\text { Health Ques- } \\
\text { tionnaire-9 } \\
\text { (PHQ-9) } \\
\text { Kroenke } \\
2001\end{array}$ & $\begin{array}{l}\text { The PHQ-9 is the 9-item depression scale of the Patient Health Questionnaire. There } \\
\text { are } 2 \text { components of the PHQ-9: assessing symptoms and functional impairment } \\
\text { for diagnosing depression, and deriving a severity score to help select and moni- } \\
\text { tor treatment. The PHQ-9 is based directly on the diagnostic criteria for major de- } \\
\text { pressive disorder and scores each of the } 9 \text { DSM-IV criteria as } 0 \text { (not at all) to } 3 \text { (nearly } \\
\text { every day). The score is the sum of the } 9 \text { items. A score of } 15 \text { or greater is considered } \\
\text { major depression, } 20 \text { or more indicates severe major depression. }\end{array}$ \\
\hline & $\begin{array}{l}\text { Chu - Cana- } \\
\text { da } \\
\text { Jansen - } \\
\text { Netherlands }\end{array}$ & $\begin{array}{l}\text { Centre for } \\
\text { Epidemio- } \\
\text { logical stud- } \\
\text { ies Depres- } \\
\text { sion scale } \\
\text { (CES-D) }\end{array}$ & $\begin{array}{l}\text { The CES-D is a } 20 \text {-item self-report scale for assessing depressive symptoms. The } \\
\text { questions ask the person to describe how often they had depressive symptoms over } \\
\text { the past week. Items are rated on a 4-point scale from } 0 \text { 'rarely or none of the time' } \\
\text { to } 3 \text { 'most or all of the time'. Scores range from } 0 \text { to } 60 \text {, and a cut-off score of } 16 \text { in- } \\
\text { dicates mild depression, with a score of } 23 \text { and above indicating significant depres- } \\
\text { sion. It takes } 5 \text { minutes to complete. }\end{array}$ \\
\hline
\end{tabular}

Radloff 1977

Radloff 1986

\begin{tabular}{ll}
\hline Bass- Ohio & $\begin{array}{l}\text { Centre for } \\
\text { Epidemio- }\end{array}$ \\
$\begin{array}{l}\text { logical stud- } \\
\text { ies Depres- } \\
\text { sion }\end{array}$ & $\begin{array}{l}\text { The study used a subset of items from the CES-D scale to measure carer mood. Two } \\
\text { items from the short CES-D, reflecting the interpersonal domain (i.e. 'people dis- } \\
\text { like me' and 'people were unfriendly to me'), were omitted, due to concerns about } \\
\text { the cultural variation in the meaning among Hispanic respondents. Two other items } \\
\text { from the full CES-D are used as substitutes (i.e. "bothered by things that don't usual- } \\
\text { ly bother me" and "trouble keeping your mind on what you were doing'). }\end{array}$
\end{tabular}
ified)

Kohout 1993.

Radloff 1977

\begin{tabular}{lll}
\hline $\begin{array}{l}\text { Newcomer - } \\
\text { US }\end{array}$ & $\begin{array}{l}\text { Geriatric } \\
\text { Depression } \\
\text { Scale }\end{array}$ & $\begin{array}{l}\text { A screening tool for detecting depression in older people, with a predominant focus } \\
\text { on the thought processes and emotional symptoms of depressive illness. There are } \\
15 \text { items and each question has a Yes/No answer. Higher scores indicate greater de- } \\
\text { pressive symptoms and a cut off of } 6 \text { - } 7 \text { indicates depressive illness. }\end{array}$
\end{tabular}

$\begin{array}{lll}\text { Carer } & \begin{array}{l}\text { Chien- Hong } \\ \text { Kong 2008 }\end{array} & \begin{array}{l}\text { World Health } \\ \text { Organization } \\ \text { Quality of }\end{array} \\ \begin{array}{l}\text { Quality of } \\ \text { Life }\end{array} & \begin{array}{l}\text { Chien - Hong } \\ \text { Kong 2001 }\end{array} & \text { Life } \\ & \end{array}$

(WHOQoL-BREF)
The WHOQOL-BREF was modified from the WHOQoL-100 by the World Health Organization (1995) and translated into Chinese by Leung 1997. The 28-item Chinese version is a rigorously-tested culturally valid quality of life instrument. Items are structured in 4 domains: physical health, psychological, social relationship, and environment (i.e. 7 items for each subscale). They are rated on a 5-point Likert scale, with a total score range 28 - 144. High scores indicate better quality of life. 
Table 6. Outcome measures from the included studies entered into Review Manager 5 (Continued)

Leung 1997

\begin{tabular}{|c|c|c|}
\hline $\begin{array}{l}\text { Jansen - } \\
\text { Netherlands }\end{array}$ & $\begin{array}{l}\text { Short Form } \\
\text { 36-item } \\
\text { health sur- } \\
\text { vey } \\
\text { (SF-36) }\end{array}$ & $\begin{array}{l}\text { The SF- } 36 \text { short form health survey is composed of } 36 \text { questions and standardised } \\
\text { response choices, organised into } 8 \text { multi-item scales. Besides, } 2 \text { summary scales, } \\
\text { the Physical Component Summary (PCS) measure and the Mental Component Sum- } \\
\text { mary }(0-100) \text { and physical component }(0-100) \text { of the Medical Outcomes Study } \\
\text { (MOS) } 36 \text {-item (MCS) measure can be calculated. Only the MCS is used for this study. } \\
\text { Higher scores indicate higher levels of functioning or well-being. }\end{array}$ \\
\hline & $\begin{array}{l}\text { McHorney } \\
1993\end{array}$ & \\
\hline \multirow[t]{2}{*}{$\begin{array}{l}\text { Vickrey - Cal- } \\
\text { ifornia }\end{array}$} & $\begin{array}{l}\text { EuroQol 5- } \\
\text { Dimensions } \\
\text { (EQ-5D) } \\
\text { Kind } 1996\end{array}$ & \multirow[t]{2}{*}{$\begin{array}{l}\text { A generic Quality of Life utility scale used as a measure of health outcome (EuroQol } \\
\text { 1990). Applicable to a wide range of health conditions and treatments, the EQ-5D } \\
\text { provides a simple descriptive profile and a single index value for health status. The } \\
\text { EQ-5D is designed for self completion by respondents and is ideally suited for use in } \\
\text { postal surveys, in clinics and face-to-face interviews. It is cognitively simple, taking } \\
\text { only a few minutes to complete. }\end{array}$} \\
\hline & $\begin{array}{l}\text { EuroQol } \\
1990\end{array}$ & \\
\hline \multirow[t]{3}{*}{$\begin{array}{l}\text { Lam - Hong } \\
\text { Kong }\end{array}$} & $\begin{array}{l}\text { Personal } \\
\text { Well-being } \\
\text { index for } \\
\text { adults } \\
\text { (PWI-A) }\end{array}$ & \multirow[t]{3}{*}{$\begin{array}{l}\text { As detailed above for patient quality of life, but used to assess the carer's quality of } \\
\text { life. }\end{array}$} \\
\hline & Lau 2005 & \\
\hline & Lau 2006 & \\
\hline
\end{tabular}

\begin{tabular}{|c|c|c|c|}
\hline $\begin{array}{l}\text { Carer well- } \\
\text { being }\end{array}$ & $\begin{array}{l}\text { Dias - Goa In- } \\
\text { dia } \\
\text { Lam - Hong } \\
\text { Kong }\end{array}$ & $\begin{array}{l}\text { General } \\
\text { Health Ques- } \\
\text { tionnaire } \\
\text { 12-item } \\
\text { (GHQ-12) } \\
\text { Goldberg } \\
1979\end{array}$ & $\begin{array}{l}\text { A measure of psychological well-being designed for use in community settings. } \\
\text { Completed as a self-report measure, the GHQ assesses and identifies increased risk } \\
\text { for psychiatric disorder. Derived from the original } 60 \text {-item version of the GHQ, the } \\
\text { GHQ-12 and GHQ-28 scales are used mainly for research purposes and comprise } \\
\text { questions related to: somatic symptoms, anxiety and insomnia, social dysfunction, } \\
\text { and severe depression. Statements related to possible changes in the participant's } \\
\text { psychological state are scored as } 0 \text { 'not at all', } 1 \text { 'no more than usual', } 2 \text { 'rather more } \\
\text { than usual', } 3 \text { 'much more than usual'. Lower scores indicate better health status. }\end{array}$ \\
\hline & $\begin{array}{l}\text { Hinchliffe - } \\
\text { UK }\end{array}$ & $\begin{array}{l}\text { General } \\
\text { Health Ques- } \\
\text { tionnaire } \\
\text { 28-item } \\
\text { (GHQ-28) } \\
\text { Goldberg } \\
1979\end{array}$ & The 28-item version of the GHQ as detailed above. \\
\hline $\begin{array}{l}\text { Carer } \\
\text { social sup- } \\
\text { port }\end{array}$ & $\begin{array}{l}\text { Chien- Hong } \\
\text { Kong } 2008 \\
\text { Chien - Hong } \\
\text { Kong } 2001\end{array}$ & $\begin{array}{l}6 \text { item So- } \\
\text { cial support } \\
\text { question- } \\
\text { naire } \\
\text { (SSQ6) } \\
\text { Sarason } \\
1987\end{array}$ & $\begin{array}{l}\text { A 6-item Social Support Questionnaire (SSQ6) developed to measure satisfaction } \\
\text { with social support available in their immediate social environment. The items are } \\
\text { rated on a 6-point Likert scale, with higher total scores }(0-30) \text { indicating more satis- } \\
\text { faction with the available social support. The Chinese version (translated by Chang } \\
\text { 1999) indicated satisfactory content validity by expert review and internal consis- } \\
\text { tency ( } 0 \text { - } 90 \text { for overall scale) in Chinese families of people with mental illness. }\end{array}$ \\
\hline
\end{tabular}


Table 6. Outcome measures from the included studies entered into Review Manager 5 (Continued)

\begin{tabular}{|c|c|c|c|}
\hline & $\begin{array}{l}\text { Vickrey - Cal- } \\
\text { ifornia }\end{array}$ & $\begin{array}{l}\text { Medical Out- } \\
\text { comes Study } \\
\text { (MOS) Social } \\
\text { Support Sur- } \\
\text { vey }\end{array}$ & $\begin{array}{l}\text { Social support was measured using a 2-item scale derived from the Medical Out- } \\
\text { comes Study Social Support Survey, which assesses satisfaction with and availabil- } \\
\text { ity of support over the previous } 4 \text { weeks. Social support scores range from } 0 \text { - } 100 \\
\text { and a higher score indicate more support. }\end{array}$ \\
\hline & & $\begin{array}{l}\text { Sherbourne } \\
19911\end{array}$ & \\
\hline & & Stewart 1988 & \\
\hline $\begin{array}{l}\text { Patient sat- } \\
\text { isfaction }\end{array}$ & Bass - Ohio & $\begin{array}{l}\text { Kaiser man- } \\
\text { aged care } \\
\text { services }\end{array}$ & $\begin{array}{l}\text { Satisfaction with quality of Kaiser services comprises } 6 \text { items. Factor and reliability } \\
\text { analyses confirm these items form a single dimension representing service satisfac- } \\
\text { tion. This includes: }\end{array}$ \\
\hline & & & - I get excellent care \\
\hline & & & - Care for me is done in a rushed way (scoring for this question is reversed) \\
\hline & & & - I get good information about how to care for my health problems \\
\hline & & & - Help for me is given in a caring way \\
\hline & & & - Help for me is provided in a knowledgeable way \\
\hline & & & $\begin{array}{l}\text { - I do not get enough support for my health problems (scoring for this question is } \\
\text { reversed) }\end{array}$ \\
\hline \multirow[t]{2}{*}{$\begin{array}{l}\text { Carer satis- } \\
\text { faction }\end{array}$} & Bass - Ohio & $\begin{array}{l}\text { Kaiser man- } \\
\text { aged care } \\
\text { services }\end{array}$ & $\begin{array}{l}\text { Satisfaction with the quality of Kaiser services was measured and comprises } 3 \mathrm{sec}- \\
\text { tions which include: satisfaction with types of services, satisfaction with quality of } \\
\text { services and satisfaction with information. }\end{array}$ \\
\hline & $\begin{array}{l}\text { Callahan - In- } \\
\text { dianapolis }\end{array}$ & $\begin{array}{l}\text { Single Ques- } \\
\text { tion }\end{array}$ & $\begin{array}{l}\text { 'Over the last } 3 \text { months, how would you rate the quality of care [the participant] has } \\
\text { received over all from the primary care clinic?' }\end{array}$ \\
\hline
\end{tabular}

\section{APPENDICES}

Appendix 1. Search strategies

\begin{tabular}{|c|c|c|}
\hline Source & Search strategy & $\begin{array}{l}\text { Hits retrieved (in } \\
\text { the February } 2012 \\
\text { search) }\end{array}$ \\
\hline $\begin{array}{l}\text { 1. ALOIS } \\
\text { (www.medi- } \\
\text { cine.ox.ac.uk/alois) }\end{array}$ & "Case Management" OR "care management" OR "multi-component" & 31 \\
\hline $\begin{array}{l}\text { 2. MEDLINE In- } \\
\text { process and oth- } \\
\text { er non-indexed } \\
\text { citations and } \\
\text { MEDLINE 1950- } \\
\text { present (Ovid SP) }\end{array}$ & $\begin{array}{l}\text { 1. exp Dementia/ } \\
\text { 2. Dementia, Multi-Infarct/ } \\
\text { 3. Dementia, Vascular/ } \\
\text { 4. Alzheimer Disease/ } \\
\text { 5. Lewy Body Disease/ } \\
\text { 6. Delirium/ } \\
\text { 7. Huntington Disease/ }\end{array}$ & 404 \\
\hline
\end{tabular}


8. "Pick Disease of the Brain"/

9. Kluver-Bucy Syndrome/

10. Wernicke Encephalopathy/

11. Creutzfeldt-Jakob Syndrome/

12. Delirium, Dementia, Amnestic, Cognitive Disorders/

13. dement ${ }^{\star} . \mathrm{mp}$.

14. Alzheimer ${ }^{\star} . \mathrm{mp}$.

15. $\left(\right.$ lewy $^{\star}$ adj2 bod $\left.^{\star}\right) \cdot \mathrm{mp}$.

16. deliri.mp.

17. ((cognit* or memory $^{\star}$ or mental $\left.{ }^{\star}\right)$ adj3 (declin* or impair ${ }^{\star}$ or los ${ }^{\star}$ or deteriorat $\left.\left.{ }^{\star}\right)\right) \cdot m p$.

18. (chronic adj2 cerebrovascular).mp.

19. ("organic brain disease" or "organic brain syndrome").mp.

20. "supranuclear palsy".mp.

21. ("normal pressure hydrocephalus" and "shunt*").mp.

22. "benign senescent forgetfulness".mp.

23. (cerebr ${ }^{\star}$ adj2 deteriorat $\left.{ }^{\star}\right)$.mp.

24. (cerebral ${ }^{\star}$ adj2 insufficient $\left.{ }^{\star}\right) \cdot \mathrm{mp}$.

25. (confusion* or confused).mp.

26. (pick* adj2 disease).mp.

27. (creutzfeldt or jcd or cjd).mp.

28. huntington*.mp.

29. binswanger ${ }^{\star} . \mathrm{mp}$.

30. korsako*.mp.

31. (mci or "subjective memory complaint" or "episodic memory").mp.

32. ("incipient dementia" or "pre-clinical ad" or "pre-clinical alzheimer*").mp.

33. 1 or 2 or 3 or 4 or 5 or 6 or 7 or 8 or 9 or 10 or 11 or 12 or 13 or 14 or 15 or 16 or 17 or 18 or 19 or 20 or 21 or 22 or 23 or 24 or 25 or 26 or 27 or 28 or 29 or 30 or 31 or 32

34. Patient Care Management/

35. "Case manag*".ti,ab.

36. Case Management/

37. Managed Care Programs/

38. "Managed care".ti,ab.

39. "Care pathway".ti,ab.

40. Outreach.ti,ab.

41. "Crisis resolution".ti,ab. 
42. Disease Management/

43. "Disease management".ti,ab.

44. Intermediate Care Facilities/

45. Care coordination.ti,ab.

46. Community mental health.ti,ab.

47. Community Mental Health Services/

48. Community Mental Health Centers/

49. Home Nursing/

50. Health Services for the Aged/

51. "Geriatric health service*".ti,ab.

52. Home Care Services/

53. Patient Care Team/

54. Admiral nursing.ti,ab.

55. ( carer $^{\star}$ or caregiver $\left.{ }^{\star}\right) \cdot m p$. adj2 support.ti,ab.

56. Family-based therapy.ti,ab.

57. or/34-56

58. randomized controlled trial.pt.

59. controlled clinical trial.pt.

60. (Randomized or randomised).ti,ab.

61. Randomly.ti,ab.

62. Comparative Study/

63. "Interrupted time series".ti,ab.

64. "ITS design".ti,ab.

65. Intervention*.ti,ab.

66. Evaluat*.ti,ab.

67. Placebo*.ti,ab.

68. Groups.ti,ab.

69. or/58-68

70.69 and 57 and 33

71. $\left(2010^{\star}\right.$ or $2011^{\star}$ or $\left.2012^{\star}\right)$.ed.

72. 70 and 71 
4. exp Alzheimer disease/

5. exp diffuse Lewy body disease/

6. exp Huntington chorea/

7. exp Pick presenile dementia/

8. exp Kluver Bucy syndrome/

9. Wernicke encephalopathy/

10. Creutzfeldt Jakob disease/

11. dement ${ }^{\star} . \mathrm{mp}$.

12. Alzheimer*.mp.

13. $\left(\right.$ lewy $^{\star}$ adj2 bod $\left.^{\star}\right) \cdot m p$.

14. deliri.mp.

15. ((cognit ${ }^{\star}$ or memory ${ }^{\star}$ or mental $\left.{ }^{\star}\right)$ adj3 $\left(\right.$ declin $^{\star}$ or impair ${ }^{\star}$ or los $^{\star}$ or deteriorat $\left.\left.{ }^{\star}\right)\right) . m p$.

16. (chronic adj2 cerebrovascular).mp.

17. ("organic brain disease" or "organic brain syndrome").mp.

18. "supranuclear palsy".mp.

19. ("normal pressure hydrocephalus" and "shunt*").mp.

20. "benign senescent forgetfulness".mp.

21. (cerebr ${ }^{\star}$ adj2 deteriorat $\left.{ }^{\star}\right) \cdot \mathrm{mp}$.

22. (creutzfeldt or jcd or cjd).mp.

23. huntington ${ }^{\star} \cdot \mathrm{mp}$.

24. binswanger ${ }^{\star} . \mathrm{mp}$.

25. korsako*.mp.

26. (mci or "subjective memory complaint" or "episodic memory").mp.

27. ("incipient dementia" or "pre-clinical ad" or "pre-clinical alzheimer*").mp.

28. or/1-27

29. "old people".ti,ab.

30. Elder ${ }^{\star}$.ti,ab.

31. Aging/

32. or/29-31

33. Patient Care/

34. "Case manag*".ti,ab.

35. "Care manag*".ti,ab.

36. Case Management/

37. "Managed care".ti,ab. 
38. "Care pathway".ti,ab.

39. Outreach.ti,ab.

40. Crisis Intervention/

41. "Crisis resolution".ti,ab.

42. "Disease management".ti,ab.

43. Disease Management/

44. "Intermediate care facilit*".ti,ab.

45. "Care coordination".ti,ab.

46. "Community mental health".ti,ab.

47. Community Mental Health Services/

48. Mental Health Services/

49. Community Mental Health Centers/

50. Home Care Services/

51. "Geriatric care".ti,ab.

52. "Home care servic*".ti,ab.

53. "Patient care team".ti,ab.

54. "Admiral nursing".ti,ab.

55. (carer ${ }^{\star}$ or caregiver $\left.^{\star}\right)$.mp. and support.ti,ab. [mp=title, abstract, subject headings, heading word, drug trade name, original title, device manufacturer, drug manufacturer, device trade name, keyword]

56. "Family-based therapy".ti,ab.

57. or/33-56

58. Randomized Controlled Trial/

59. Double-Blind Method/

60. Single-Blind Method/

61. Random*.ti,ab.

62. Cross-Over Studies/

63. (time adj series).ti,ab.

64. "ITS design".ti,ab.

65. Intervention*.ti,ab.

66. Evaluat* ${ }^{\star}$ ti,ab.

67. Compar*.ti,ab.

68. ("pre test" or pretest or "post test" or posttest).ti,ab.

69. "control group".ab.

70. or/58-69 

71.28 and 32 and 57 and 70
72. $\left(2010^{\star}\right.$ or $2011^{\star}$ or $\left.2012^{\star}\right)$.em.
73. 71 and 72

4. PSYCINFO
1806-February
week 52012 (Ovid
SP)

4. Dementia with Lewy Bodies/

5. Delirium/

6. exp Huntingtons Disease/

7. Picks Disease/

8. Kluver Bucy Syndrome/

9. Wernickes Syndrome/

10. Creutzfeldt Jakob Syndrome/

11. Cognitive Impairment/

12. dement*.mp.

13. Alzheimer ${ }^{\star} . \mathrm{mp}$.

14. $\left(\right.$ lewy $^{\star}$ adj2 bod $\left.{ }^{\star}\right) \cdot m p$.

15. deliri.mp.

16. ((cognit ${ }^{\star}$ or memory ${ }^{\star}$ or mental $\left.{ }^{\star}\right)$ adj3 $\left(\right.$ declin $^{\star}$ or impair ${ }^{\star}$ or los $^{\star}$ or deteriorat $\left.\left.{ }^{\star}\right)\right) \cdot m p$.

17. (chronic adj2 cerebrovascular).mp.

18. ("organic brain disease" or "organic brain syndrome").mp.

19. "supranuclear palsy".mp.

20. ("normal pressure hydrocephalus" and "shunt*").mp.

21. "benign senescent forgetfulness".mp.

22. (cerebr ${ }^{\star}$ adj2 deteriorat $\left.{ }^{\star}\right) \cdot \mathrm{mp}$.

23. (cerebral ${ }^{\star}$ adj2 insufficient $\left.{ }^{\star}\right) \cdot m p$.

24. (confusion* or confused).mp.

25. (pick* adj2 disease).mp.

26. (creutzfeldt or jed or cjd).mp.

27. huntington ${ }^{\star} . \mathrm{mp}$.

28. binswanger ${ }^{\star} . \mathrm{mp}$.

29. korsako*.mp.

30. (mci or "subjective memory complaint" or "episodic memory").mp.

31. ("incipient dementia" or "pre-clinical ad" or "pre-clinical alzheimer*").mp. 
32. or/1-31

33. Patient care/

34. "Case manag*".ti,ab.

35. "Care manag*".ti,ab.

36. Case management/

37. "Managed care".ti,ab.

38. "Care pathway".ti,ab.

39. Outreach.ti,ab.

40. Crisis intervention/

41. "Crisis resolution".ti,ab.

42. Disease management/

43. "Intermediate care facilit"

44. "Care coordination".ti,ab.

45. Community mental health services/

46. "Community mental health".ti,ab.

47. Community mental health nursing/

48. "Home care servic*".ti,ab.

49. "Admiral nursing".ti,ab.

50. ((carer ${ }^{\star}$ or caregiver $\left.{ }^{\star}\right)$ adj2 support).ti,ab.

51. "Family-based therapy".ti,ab.

52. or/33-51

53. exp Clinical Trials/

54. "Randomi?ed controlled trial*".ti,ab.

55. Random*.ti,ab.

56. (time adj series).ti,ab.

57. "ITS design".ti,ab.

58. Intervention ${ }^{\star} . t i, a b$.

59. Evaluat*.ti,ab.

60. Posttesting/ or Pretesting/

61. or $/ 53-60$

62.32 and 52 and 61

63. $\left(2010^{\star}\right.$ or $2011^{\star}$ or $\left.2012^{\star}\right) \cdot$ up.

64.62 and 63 
(Continued)

5. CINAHL (EBSCO- S1 (MH "Dementia+") 286 host)

S2 (MH "Delirium") or (MH "Delirium, Dementia, Amnestic, Cognitive Disorders")

S3 (MH "Wernicke's Encephalopathy")

S4 TX dement*

S5 TX alzheimer ${ }^{\star}$

S6 TX lewy* N2 bod*

S7 TX deliri*

S8 TX chronic N2 cerebrovascular

S9 TX "organic brain disease" or "organic brain syndrome"

S10 TX "normal pressure hydrocephalus" and "shunt*"

S11 TX "benign senescent forgetfulness"

S12 TX cerebr* N2 deteriorat*

S13 TX cerebral ${ }^{\star} \mathrm{N} 2$ insufficient*

S14 TX pick* N2 disease

S15 TX creutzfeldt or jcd or cjd

S16 TX huntington*

S17 TX binswanger

S18 TX korsako*

S19 TX mci or "subjective memory complaint" or "episodic memory"

S20 TX "incipient dementia" or "pre-clinical ad" or "pre-clinical alzheimer*"

$\mathrm{S} 21 \mathrm{~S} 1$ or $\mathrm{S} 2$ or $\mathrm{S} 3$ or $\mathrm{S} 4$ or $\mathrm{S} 5$ or $\mathrm{S} 6$ or $\mathrm{S} 7$ or $\mathrm{S} 8$ or $\mathrm{S} 9$ or $\mathrm{S} 10$ or $\mathrm{S} 11$ or $\mathrm{S} 12$ or $\mathrm{S} 13$ or $\mathrm{S} 14$ or $\mathrm{S} 15$ or $\mathrm{S} 16$ or $\mathrm{S} 17$ or $\mathrm{S} 18$ or $\mathrm{S} 19$ or $\mathrm{S} 20$

S22 (MH "Patient Care")

S23 AB "Case manag*"

S24 TX Care manag*

S25 (MH "Case Management")

S26 TX "Managed care"

S27 TX "Care pathway"

S28 TX Outreach

S29 TX Crisis intervention

S30 (MH "Crisis Intervention")

S31 TX "Crisis resolution"

S32 (MH "Disease Management")

S33 TX "Intermediate care facilit*" 


\author{
S34 TX "Care coordination" \\ S35 (MH "Community Mental Health Services") \\ S36 TX "Community mental health" \\ S37 (MH "Community Mental Health Nursing") \\ S38 (MH "Home Health Care") \\ S39 (MH "Home Nursing") \\ S40 (MH "Gerontologic Care") \\ S41 TX "Home care servic*" \\ S42 (MH "Multidisciplinary Care Team") \\ S43 TX "Admiral nursing" \\ S44 TX "carer* support" or "caregiver support"
}

S45 TX "Family-based therapy"

$\mathrm{S} 46 \mathrm{~S} 23$ or $\mathrm{S} 24$ or $\mathrm{S} 25$ or $\mathrm{S} 26$ or $\mathrm{S} 27$ or $\mathrm{S} 28$ or $\mathrm{S} 29$ or S 30 or $\mathrm{S} 31$ or $\mathrm{S} 32$ or $\mathrm{S} 33$ or S 34 or $\mathrm{S} 35$

or S36 or S37 or S38 or S39 or S40 or S41 or S42 or S43 or S44 or S45

S47 (MH "Clinical Trials")

S48 TX Random*

S49 (MH "Double-Blind Studies") or (MH "Single-Blind Studies")

S50 (MH "Comparative Studies")

S51 TX "time series"

S52 TX ITS design

S53 TX Intervention*

S54 TX Evaluat*

S55 (MH "Pretest-Posttest Design") or (MH "Pretest-Posttest Control Group Design") or (MH "Crossover Design")

$\mathrm{S} 56 \mathrm{~S} 48$ or $\mathrm{S} 49$ or $\mathrm{S} 50$ or $\mathrm{S} 51$ or $\mathrm{S} 52$ or $\mathrm{S} 53$ or $\mathrm{S} 54$ or $\mathrm{S} 55$

S57 S21 and S46 and S56

S58 EM 2010

S59 EM 2011

S60 EM 2012

$\mathrm{S} 61 \mathrm{~S} 58$ or S59 or $\mathrm{S} 60$

S62 S57 and S61

6. Web of Science (1945-present): ISI Web of Knowledge
Topic=("Patient Care" OR "Case manag*" OR "Care manag*" OR "Managed care" OR "Care pathway" OR Outreach OR "Crisis intervention" OR "Crisis Intervention" OR "Crisis resolution" OR "Disease Management" OR "Intermediate care facilit" " OR "Care coordination" OR "Home Health Care" OR "Home Nursing" OR "Home care servic*" OR "Multidisciplinary Care Team") AND Topic=(dementia* OR alzheimer ${ }^{\star}$ OR AD) AND Topic=(random* or placebo or "double-blind" or trial OR groups OR "controlled study" OR "time series" OR "Comparative Study" OR "Pretest-Posttest Design") AND Year Published=(2010-2012) 
Timespan=All Years. Databases=SCI-EXPANDED, SSCI, A\&HCI, CPCI-S, CPCI-SSH.

Lemmatization $=0 n$

7. CENTRAL (The Cochrane Library) (Issue 4 of 4 , Oct 2011)
\#1 MeSH descriptor Dementia explode all trees

\#2 MeSH descriptor Delirium, this term only

\#3 MeSH descriptor Wernicke Encephalopathy, this term only

\#4 MeSH descriptor Delirium, Dementia, Amnestic, Cognitive Disorders, this term only

\#5 dement $^{\star}$

\#6 alzheimer*

\#7 "lewy* bod*"

\#8 deliri*

\#9 "chronic cerebrovascular"

\#10 "organic brain disease" or "organic brain syndrome"

\#11 "normal pressure hydrocephalus" and "shunt*"

\#12 "benign senescent forgetfulness"

\#13 "cerebr* deteriorat*"

\#14 "cerebral* insufficient*"

\#15 "pick* disease"

\#16 creutzfeldt or jcd or cjd

\#17 huntington*

\#18 binswanger

\#19 korsako*

\#20 (\#1 OR \#2 OR \#3 OR \#4 OR \#5 OR \#6 OR \#7 OR \#8 OR \#9 OR \#10 OR \#11 OR \#12 OR \#13

OR \#14 OR \#15 OR \#16 OR \#17 OR \#18 OR \#19)

\#21 rivastigmin* OR Exelon* OR "SDZ ENA 713"

\#22 \#21 AND \#20
Advanced search: "Case Management" OR "care management" OR "multi-component" AND (dementia or Alzheimers) AND Status: ALL AND date reg: 01/01/12-07/02/12
34
8. ICTRP Search Portal (http:// alsearch) [in-

cludes: Australian cal Trials Registry; ISRCTN; Chinese Clinical Trial Registry; Clinical Trials Registry - India; Clinical Research Information Service - Republic of Korea; 
(Continued)

German Clinical

Trials Register;

Iranian Registry

of Clinical Trials;

Japan Primary

Registries Net-

work; Pan African

Clinical Trial Reg-

istry; Sri Lanka

Clinical Trials Reg-

istry; The Nether-

lands National Tri-

al Register]

TOTAL before de-duplication

Original search:
10440

Feb 2012: 1211

Feb 2013: 820

Dec 2013: 11

(7 identified through other sources)

\section{Appendix 2. Frequency of contacts with case managers}

Bass - Ohio Follow-up started as biweekly, then reduced to monthly, then three-monthly unless more visits were needed. The duration of telephone-based case management was 12 months. The initial paper published in 2003 (Bass 2003) reported that on average care consultants have 12 direct communication contacts with patients and caregivers per year. A subsequent paper (Judge 2011) reported that on average care co-ordinators and dyads had 24.6 contacts during the 12 -month study period (standard deviation $(\mathrm{SD})=15.4)$ or approximately two contacts per month. The median number of contacts was 23.

Callahan - Indianapolis Caregivers and participants were seen by the care manager in the primary care clinic bimonthly initially, and then contacts were lengthened to monthly for a period of one year. The mean number of contacts with the care manager was 14.4 (SD 8.9) over 12 months (range 0 - 51). Approximately half of these contacts were face-to-face and half were telephone contacts.

Chien- Hong Kong 200812 sessions were held every other week and lasted two hours each. The programme consists of 12 two-hour sessions, held once every two weeks. One session concentrated on orientation to dementia care. Three sessions were designed as workshops on dementia care. Six sessions covered family roles and strength rebuilding. One session addressed community support resources and the last session was for a programme review and evaluation. The intervention lasted for six months and was delivered by a multidisciplinary team of a psychiatrist, a social worker and a case manager (nurse).

Chien - Hong Kong 2001The family and the case manager met biweekly, for a total of 10 two-hour sessions. After one month's needs assessment and preparation, the Dementia Family Care Programme (DFCP) was conducted for individual families, lasting about five months.

Chu - Canada The case manager made monthly contact by phone or home visit. The frequency of contacts increased as needed.

Dias - Goa India The minimum frequency of visits was at least once a fortnight for six months. The maximum frequency of visits was based on needs as assessed by the home care advisor (HCA). Thus, the visits could be more frequent depending on the need of that particular family. In the intervention arm, the mean number of visits by the HCA was $12.3(S D=3.1)$. Average time spent on each visit was 45 minutes $(S D=15)$. The mean number of phone consultations was $1.3(S D=2.1)$. A total of nine support group meetings were arranged for the caregivers during the intervention period.

Eloniemi-Sulkava 2001 The frequency of contacts varied from once a month to five times a day, depending on the situation of the participants and their caregivers. 
Eloniemi-Sulkava 2009; A process evaluation was conducted. Data were presented to show that 337 home visits were made over the 24 months (mean 5.35 ; range 1 - 43); 23 office visits (mean 0.37; range 1 - 4); 90 visits to care sites/providers (mean 1.43; range 1-40); 2192 telephone calls to /from families (mean 34.79; range 1-91); 1928 telephone calls to other health care professionals/care providers (mean 30.60; range 1 - 97). Sample size calculations were based on the feasibility shown in the earlier study by the same authors that one family care co-ordinator in partnership with a geriatrician could support a maximum of about 50 - 60 couples (Eloniemi-Sulkava 2001).

Hinchliffe - UK During the 16-week intervention period, each participant and carer received a mean of 12 visits (6 - 19) lasting an average of 58 minutes ( $31-87)$.

Lam - Hong Kong Although not reported in the results, the authors indicate that relatively low minimum requirements for caregiver visits in this study (one visit per month) by the case manage might have limited the intensity of caregiver input and sensitivity of the intervention to modulate caregiver stress. The participants also had access to a telephone hotline during working hours (Monday to Saturday).

Jansen - Netherlands- the three case managers spent a mean time of 10.8 hours (range 0.75 - 28 hours) a year per participant-carer dyad on the case management intervention. The nurses differed in mean time spent on the intervention per pair; nurse 1 spent 8.8 hours (range 2 - 26); nurse 2 spent 5.5 hours (range 0.75 - 15), and nurse 3 spent 15.2 hours (range $9.6-28$ ); $F=9.811, P<.001$.

Newcomer - US Two case management models were implemented which varied in the ratio of treatments-to-case managers, and in the amount of Medicare coverage available each month for treatment benefits. Model A (low reimbursement - high caseload) sites operated with a target case manager-to-client ratio of 1:100. Model B (high reimbursement - low caseload) sites had a target case manager-to-client ratio of 1:30.

Vickrey - California 77\% of the dyads received an initial visit from a care manager and 55\% had a formal reassessment. Reasons for lower rates of reassessment included participant death from disease progression and the care manager's perception that a formal reassessment was not needed (for example, because of continuous awareness of dyad status as a result of frequent telephone contacts). The median number of assessment and reassessment visits was two. There were an average of 15 (median 12) follow-up telephone calls from a care manager per dyad; these calls occurred every 30 days on average.

\section{Appendix 3. Effects of interventions: service use and costs (detailed version)}

Case management compared to usual care: (service use and cost secondary outcomes)

\subsection{Use of community-based services (participants)}

(Analysis 3.1)

Four RCTs reported on different aspects of community-based services usage (Chu - Canada; Lam - Hong Kong; Newcomer - US; Vickrey - California). All significant difference favoured greater use of services in the case management group, apart from one service - assisted living housing use at 12 months (Newcomer - US). The intervention group were significantly more likely to receive: home care use at 12 and 18 months, day care use at 4 and 12 months, respite care at 12 months, domestic paid helper use at 4 and 12 months, personal care use at 12 months, professional home health aide use at 18 months, services or information from local Alzheimers Association at 18 months, services or information from care-givers resource centre at 18 months and participation in a caregiver support group at 18 months.

\subsubsection{Homecare use at 3 - 4 months}

Within the first three to four months there was no difference between both groups in the use of home care services (OR $2.67,95 \% \mathrm{Cl} 0.79$ to $8.95, \mathrm{n}=174, \mathrm{P}=0.08$ ).

\subsubsection{Homecare use at 12 months}

Data were provided from three studies (Chu - Canada; Lam - Hong Kong; Newcomer - US). The results showed that there were a significantly greater number of participants in the intervention group who used home care services at 12 months $(\mathrm{OR} 2.28,95 \% \mathrm{Cl} 2.03$ to $2.56, \mathrm{n}=5376$, $\mathrm{I}^{2}=30 \%, \mathrm{P}<0.0001$ ). When we excluded Chu - Canada (a low-quality study) and reanalysed the data to test the robustness of our findings the results were unchanged but the $\mathrm{I}^{2}$ increased to $46 \%$.

\subsubsection{Homecare use at 18 months}

The results in one study ( $\mathrm{Chu}$ - Canada) showed that there were a significantly greater number of participants in the intervention group who used home care services at 18 months (OR 5.63, $95 \% \mathrm{Cl} 2.07$ to $15.29, \mathrm{n}=74, \mathrm{P}=0.0007$ ).

\subsubsection{Day care use at four months}

A greater use of day care was evident in the intervention group in one study (Vickrey - California) at the four-month follow-up (OR 4.51, $95 \% \mathrm{Cl} 1.89$ to $10.77, \mathrm{n}=99, \mathrm{P}=0.0007)$.

\subsubsection{Day care use at 12 months}

A greater use of day care was also evident in the intervention group in two studies (Lam - Hong Kong; Newcomer - US) at the 12-month follow-up (OR 2.23, $95 \% \mathrm{Cl} 1.98$ to $2.52, \mathrm{n}=5301, \mathrm{P}<0.00001$ ). 


\subsubsection{Day care use at 18 months}

At 18 months we found no difference in the one study which reported day care use (Vickrey - California) $(\mathrm{OR} 1.80,95 \% \mathrm{Cl} 0.92$ to $3.51, \mathrm{n}$ $=353, \mathrm{P}=0.09$ ).

\subsubsection{Respite care use at four month}

The use of respite care was low in both groups in Lam - Hong Kong, with no significant difference at four months (OR: 2.26 , $95 \% \mathrm{Cl} 0.09$ to $56.78, n=99, P=0.62$ ).

\subsubsection{Respite care use at 12 months}

Results from two studies (Lam - Hong Kong; Newcomer - US) showed a significant increase in the respite care use within the case management groups at 12 months (OR $2.24,95 \% \mathrm{Cl} 1.98$ to $2.53, \mathrm{n}=5301, \mathrm{P}<0.00001$ ).

\subsubsection{Domestic paid helper use at four months}

There was a greater use of domestic helpers in the intervention group (Lam - Hong Kong) at four months (OR 5.40,95\% $\mathrm{Cl} 1.97$ to 14.81 , $\mathrm{n}=99, \mathrm{P}=0.001$ ).

\subsubsection{Domestic paid helper use at 12 months}

This study (Lam - Hong Kong also found greater use of domestic helpers in the intervention group at 12 months $(\mathrm{OR} 3.00,95 \% \mathrm{Cl} 1.12$ to 8.04, $n=92, P=0.03$ ).

\subsubsection{Personal care use at 12 months}

Results from two studies (Chu - Canada; Newcomer - US) showed a greater use of personal care in the intervention group at the 12 month follow-up (OR 1.57, 95\% Cl 1.40 to $\left.1.75, \mathrm{n}=5284, \mathrm{I}^{2}=68 \%, \mathrm{P}<0.00001\right)$.

\subsubsection{Services from a professional home health aide at 18 months}

The intervention group in Vickrey - California used significantly more services from a professional home health aide at $18 \mathrm{months}$ (OR 1.81 , $95 \% \mathrm{Cl} 1.05$ to $3.13, \mathrm{n}=353, \mathrm{P}=0.03)$.

\subsubsection{Services from a paid professional care-giver at 18 months}

There were no differences in services from a professional care-giver at 18 months in Vickrey - California (OR $1.48,95 \% \mathrm{Cl} 0.85$ to $2.59, \mathrm{n}$ $=353, \mathrm{P}=0.17$ ).

\subsubsection{In home, volunteer, or paid respite care services at 18 months}

There were no differences in in-home, volunteer, or paid respite care services at 18 months in Vickrey - California $(\mathrm{OR} 1.54,95 \% \mathrm{Cl} 0.98$ to $2.41, \mathrm{n}=353, \mathrm{P}=0.06$ ).

\subsubsection{Assisted living housing use at 12 months}

We found a greater use of assisted living housing use in the control group in the Newcomer - US study $(\mathrm{OR} 0.70,95 \% \mathrm{Cl} 0.56$ to $0.87, \mathrm{n}=$ $5209, P=0.001)$.

\subsubsection{Services or information from local Alzheimers Association at 18 months}

The participants in the intervention group in Vickrey - California received more services or information from local Alzheimers Association at 18 months (OR $2.40,95 \% \mathrm{Cl} 1.56$ to $3.69, \mathrm{n}=360, \mathrm{P}<0.0001$ ).

\subsubsection{Services or information from care-givers resource centre at $\mathbf{1 8}$ months}

The participants in the intervention group in Vickrey - California received more services or information from the care-givers resource centre at 18 months (OR $2.88,95 \% \mathrm{Cl} 1.77$ to $4.69, \mathrm{n}=360, \mathrm{P}<0.0001$ ).

\subsubsection{Services or information on meals on wheels at 18 months}

There were no differences in services or information on meals on wheels at 18 months in Vickrey - California (OR $0.97,95 \% \mathrm{Cl} 0.53$ to 1.77 , $\mathrm{n}=360, \mathrm{P}=0.92$ ).

\subsubsection{Participation in a care-giver support group at 18 months}

The participants in the intervention group in Vickrey - California participated more in a care-giver support group at 18 months (OR 1.64 , $95 \% \mathrm{Cl} 1.00$ to $2.68, \mathrm{n}=356, \mathrm{P}=0.05$ ).

\subsection{Health service use by participants (number of participants)}

\section{(Analysis 3.2)}




\subsubsection{Emergency department visits at 18 months}

There were no differences in the emergency visits reported by Vickrey - California at 18 months (96/170 versus 66/126) (OR 1.18, 95\% Cl 0.74 to $1.87, \mathrm{n}=296, \mathrm{P}=0.48$ ). See also 3.3.1 and 3.3.2 Emergency department visits at 12 and 18 months.

\subsubsection{Direct care (occupational therapy, physical therapy, social work, nursing and respiratory therapy) at 18 months}

There were no differences in the direct care reported by Chu - Canada at 18 months (OR $1.31,95 \% \mathrm{Cl} 0.51$ to $3.35, \mathrm{n}=75, \mathrm{P}=0.57$ ).

\subsection{Health service use by participants (continuous outcomes)}

(Analysis 3.3)

Four RCTs reported data on health services usage for participants (Bass - Ohio; Callahan - Indianapolis; Jansen - Netherlands; Vickrey California). There were no differences between groups on most outcomes apart from a significantly lower number of physician or nurse visits, in the intervention group (3.3.5).

\subsubsection{Emergency department visits at 12 months}

There were no differences in the emergency visits reported by Bass - Ohio (which was rated at high risk of bias) at 12 months (MD - 0.17 , $95 \% \mathrm{Cl}-0.63$ to $0.29, \mathrm{n}=157, \mathrm{P}=0.47)$.

\subsubsection{Emergency department visits at 18 months}

There were no differences in the emergency visits reported by Vickrey - California at 18 months (MD $0.18,95 \% \mathrm{Cl}-0.11$ to $0.47, \mathrm{n}=296, \mathrm{P}$ $=0.23$ ). See also 3.7 emergency department visits for carers below.

\subsubsection{Physician visits (per month) at six months}

We found no significant difference between groups in the one study (Vickrey - California) that reported the number of visits to a physician (per month) at six months (MD 0.08, 95\% Cl-1.28 to $1.44, \mathrm{n}=296, \mathrm{P}=0.91$ ).

\subsubsection{Physician visits at 12 months}

There was no significant difference between groups in the pooled results for three studies (Bass - Ohio; Callahan - Indianapolis; Jansen Netherlands) that reported the number of visits to a physician at 12 months (SMD 0.14, 95\% CI -0.07 to $0.35, \mathrm{n}=353, \mathrm{P}=0.20$ ). The Callahan - Indianapolis study combined cumulative physician or nurse visits.

\subsubsection{Physician or nurse visits at 18 months}

We found a significant difference between groups in the one study (Callahan - Indianapolis) that reported the number of visits to a physician or nurse visits at 18 months (MD 5.40,95\% $\mathrm{Cl} 0.51$ to $10.29, \mathrm{n}=113, \mathrm{P}=0.03$ ).

\subsubsection{Outpatients geriatric/psychiatric team/diagnostic service at 12 months (number of consultations)}

There was no significant difference between groups in the one study (Jansen - Netherlands) that reported the number of outpatients geriatric/psychiatric team /diagnostic service consultations at 12 months ( $\mathrm{MD} 0.30,95 \% \mathrm{Cl}-1.61$ to $2.21, \mathrm{n}=70, \mathrm{P}=0.76$ ).

\subsubsection{Medical specialist over 12 months (number of consultations)}

There was no significant difference between groups in the one study (Jansen - Netherlands) that reported the number of medical specialist consultations at 12 months (MD $-0.60,95 \% \mathrm{Cl}-6.35$ to $5.15, \mathrm{n}=70, \mathrm{P}=0.84$ ).

\subsubsection{Physiotherapist over 12 months (number of consultations)}

We detected no significant difference between groups in the one study (Jansen - Netherlands) that reported the number of physiotherapist consultations at 12 months (MD $0.00,95 \% \mathrm{Cl}-28.18$ to $28.18, \mathrm{n}=70, \mathrm{P}=1.00$ ).

\subsubsection{Social worker over 12 months (number of consultations)}

There was no significant difference between groups in the one study (Jansen - Netherlands) that reported the number of social worker consultations at 12 months ( $\mathrm{MD} 0.02,95 \% \mathrm{Cl}-0.52$ to $0.56, \mathrm{n}=70, \mathrm{P}=0.94$ ).

\section{4 - 3.7 Cost of services (participants)}

Three studies (Eloniemi-Sulkava 2009; Newcomer - US; Vickrey - California) reported data on healthcare costs.

\subsubsection{Total health and social care costs (1000 euros; excluding intervention) at 12 months}

Eloniemi-Sulkava 2009 compared both total health and social costs between the groups at 12 months. Costs were lower in the intervention group but this difference was borderline significant (OR $-7.99,95 \% \mathrm{Cl}-16.86$ to $0.89, \mathrm{n}=125, \mathrm{P}=0.08$ ).

\subsection{Healthcare costs (USD)}


One study (Vickrey - California) reported data on healthcare costs. Results showed no significant difference between case management and control group.

\subsubsection{Payer perspective, including nursing home cost at 18 months (USD)}

In Vickrey - California, there was no significant between-group difference in the healthcare cost (from the payer perspective) including nursing-home cost at 18 months, (MD $-260.00,95 \% \mathrm{Cl}-1177.99$ to $657.99, \mathrm{P}=0.58$ ).

\subsubsection{Payer perspective, excluding nursing home at 18 months (USD)}

In Vickrey - Californiathere was no significant between-group difference in the healthcare cost (from the payer perspective) excluding nursing-home cost at 18 months (MD $-272.00,95 \% \mathrm{Cl}-1153.49$ to $609.49, \mathrm{P}=0.55$ ).

\subsubsection{Societal perspective cost at 18 months (USD)}

In Vickrey - California there was no significant between-group difference in the healthcare cost (from the societal perspective) at $18 \mathrm{months}$ (MD -365.00, 95\% Cl-1290.30 to 560.30, $\mathrm{P}=0.44$ ).

\subsubsection{Total health and social care costs at 12 months (1000 Euros; excluding intervention)}

3.5.4 Total health and social care costs at 12 months (1000 Euros; excluding intervention)

In Eloniemi-Sulkava 2009 there was no significant between-group difference in total health and social care costs (excluding intervention) at 12 months (MD $-7.99,95 \% \mathrm{Cl}-16.86$ to $0.88, \mathrm{P}=0.08$ ).

\subsection{Health services costs (Medicare expenditures) (community services usage) in dollars or euros}

\section{(Analysis 3.6)}

Newcomer - US reported the effects of case management application on Medicare community services expenditures in year one, year two and year three, and for the total three-year period. Eloniemi-Sulkava 2009 reported total healthcare costs between the groups at 12 months. We have used the SMD (to accommodate the two currencies (dollars and Euros)) for year one.

\subsubsection{At year one}

When we pooled data from two studies (Eloniemi-Sulkava 2009; Newcomer - US) at 12 months, we found a significant reduction in the total cost of services between the groups (SMD $-0.07,95 \% \mathrm{Cl}-0.12$ to $-0.02, \mathrm{n}=5276 . \mathrm{P}=0.01$ ).

\subsubsection{At year two}

The lower expenditure did not reach statistical significant difference for year two in the Newcomer - US study (MD -654.00, 95\% Cl -1462.80 to $154.80, \mathrm{n}=3665, \mathrm{P}=0.11$ ).

\subsubsection{At year three}

The lower expenditure did not reach a statistically significant difference for year three in the Newcomer - US study (MD - $779.0095 \% \mathrm{Cl}$ -1976.72 to $418.72, n=2255, P=0.20)$.

\subsubsection{Total three-year follow-up}

The lower expenditure in the pooled case management groups was significantly lower than in the control group for the total three years in the Newcomer - US study (MD - $705.00,95 \% \mathrm{Cl}-1170.31$ to $-239.69, \mathrm{n}=5170, \mathrm{P}=0.003$ ).

\subsection{Health service use by carers (dichotomous outcomes)}

\section{(Analysis 3.7)}

One study (Newcomer - US) estimated the impact of the case management intervention on health services usage for care-givers. Caregivers' utilisation of services was reported for one of the sites (Illinois) in the Newcomer - US study (Shelton 2001). Data on hospitalisation rate and emergency visits were collected over a three-year period.

\subsubsection{Hospitalised during three years (number of carers)}

The risk of hospitalisation for the carers in the intervention group was significantly lower than in the control group (OR $0.51,95 \% \mathrm{Cl} 0.33$ to $0.81, \mathrm{n}=412, \mathrm{P}=0.005$ ).

\subsubsection{Emergency department visits during three years (number of carers)}

The emergency department visits were also significantly lower in the intervention group (OR $0.58,95 \% \mathrm{Cl} 0.38$ to $0.89, \mathrm{n}=412, \mathrm{P}=0.01)$. 


\subsection{Health service use by carers (continuous outcomes)}

(Analysis 3.8)

Carer health service utilisation and Medicare expenditure data were presented for one of the sites (Illinois) for the Newcomer - US study (Shelton 2001). One other study also reported the use of services by carers (Jansen - Netherlands). There were no significant differences on any of the continuous outcomes reported.

\subsubsection{Annual hospital length of stay}

We found no significant difference between groups in the annual hospital length of stay ( $\mathrm{MD} 0.90,95 \% \mathrm{Cl}-0.23$ to $2.03, \mathrm{P}=0.12)(\mathrm{Shelton}$ 2001) (Newcomer - US).

\subsubsection{Number of admissions over 12 months}

There was no significant difference between groups (Newcomer - US) in the number of admissions over 12 months ( $\mathrm{MD} 0.15,95 \% \mathrm{Cl}-0.20$ to $0.50, \mathrm{n}=412, \mathrm{P}=0.40$ ) (Shelton 2001).

\subsubsection{Primary care physician over 12 months (number of consultations)}

We found no significant difference between groups (Jansen - Netherlands) in the number of consultations with a primary care physician over 12 months (MD $0.00,95 \% \mathrm{Cl}-5.26$ to $5.26, \mathrm{n}=69, \mathrm{P}=1.00$ ).

\subsubsection{Outpatients geriatric/psychiatric team over 12 months (number of consultations)}

We detected no significant difference between groups (Jansen - Netherlands) in the number of consultations with outpatients geriatric/psychiatric team over 12 months (MD $-0.77,95 \% \mathrm{Cl}-5.33$ to $3.79, \mathrm{n}=69, \mathrm{P}=0.74$ ).

\subsubsection{Medical specialist over 12 months (number of consultations)}

There was no significant difference between groups (Jansen - Netherlands in the number of consultations with a medical specialist over 12 months (MD 0.10, 95\% Cl -5.93 to $6.13, \mathrm{n}=69, \mathrm{P}=0.97$ ).

\subsubsection{Physiotherapist over 12 months (number of consultations)}

We found no significant difference between groups (Jansen - Netherlands) in the number of consultations with a physiotherapist over 12 months (MD 1.70, 95\% Cl-13.06 to $16.46, \mathrm{n}=69, \mathrm{P}=0.82$ ).

\subsection{Informal care-giver time (hours)}

(Analysis 3.9)

\subsubsection{Informal costs (paid unskilled time spent care-giving (hours) at 6 months:}

There was no significant difference in the time for paid unskilled care-givers between the groups (Vickrey - California) ( $\mathrm{MD}-5.10,95 \% \mathrm{Cl}$ -789.73 to $779, n=296, P=0.99)$.

\subsubsection{Informal costs(unpaid unskilled time spent care-giving (hours) at $\mathbf{6}$ months:}

There was no significant difference in the time for unpaid unskilled care-givers between the groups (Vickrey - California) (MD 30.70, 95\% $\mathrm{Cl}-388.03$ to $449.43, \mathrm{n}=296, \mathrm{P}=0.89$ ).

\subsection{0 - 3.11 Cost of services (carers)}

3.10 Medicare expenditure (community services usages) in dollars

(Analysis 3.10)

In the Newcomer - US study, Medicare Part A expenditure (inpatient hospital, emergency department visits and skilled nursing home inpatient care) were based on the allowed amounts from Medicare claims for the period the Alzheimer's disease participant was enrolled in the demonstration. For most claims, this included the amount paid by Medicare, plus additional amounts paid by individuals. We report results in US dollars (USD).

\subsubsection{At year one}

The Medicare Part A expenditure at the one-year follow-up for the case management group (combining A and B models) did not differ significantly from standard care (MD $-229.00,95 \% \mathrm{Cl}-489.48$ to $31.48, \mathrm{P}=0.08$ ).

\subsubsection{At year two}

The Medicare Part A expenditure at the two-year follow-up for the case management group (combining A and B models) did not differ significantly from standard care (MD $17.00,95 \% \mathrm{Cl}-943.97$ to $977.97, \mathrm{P}=0.97$ ). 


\subsubsection{At year three}

The Medicare Part A expenditure at the three-year follow-up for the case management group did not differ significantly from standard care (MD -325.00, $95 \% \mathrm{Cl}-770.89$ to $120.89, \mathrm{P}=0.15]$.

\subsubsection{Total three-year follow-up}

There was no difference in expenditure for the case management group (combining A and B models) in comparison to controls for the entire three-year follow-up combining all demonstration sites (MD -167.00, 95\% Cl -946.28 to 612.28, $\mathrm{P}=0.67$ ).

In one of the eight sites, Illinois, in which the delivery of care management was facilitated via nurse care managers rather than social workers, the total cost was not much lower than in other sites. A total reduction (-USD 436, 95\% Cl -2321 to 1049) was achieved compared to controls over three years.

\subsection{Medicare Part A expenditure in comparison to control}

(Analysis 3.11)

Although the average annualised Medicare reimbursement (annual health service cost) during the Newcomer - US study for care-givers in the intervention group (combining $A$ and $B$ models) was lower, the difference was not statistically significant ( $\mathrm{MD}-681.00,95 \% \mathrm{Cl}-1382.40$ to $20.40, n=412, P=0.06$ ). The lower expenditure did not reach statistical significance for any of the separate years or for the total threeyear follow-up period.

\section{WHAT'S NEW}

\begin{tabular}{lll}
\hline Date & Event & Description \\
\hline 28 August 2015 & Amended & $\begin{array}{l}\text { Correction to the plain English summary - one word in the last } \\
\text { sentence was changed from 'reduce' to 'increase'. }\end{array}$ \\
\hline
\end{tabular}

\section{CONTRIBUTIONS OF AUTHORS}

SR: developing title and drafting and editing protocol; selecting studies, extracting data, writing the review.

CM: drafting protocol, commenting on and editing protocol, selecting studies, extracting data, contributing to writing the review. $\mathrm{JH}$ : commenting on and editing protocol/review, selecting studies, extracting data, contributing to writing the review.

RM: extracting data, interpreting results, support and advice, contributing to writing the review.

ST: commenting on and editing protocol/review, helping in studies selection, data extraction.

DC: developing title, commenting on and editing protocol/review, selecting studies.

MO: commenting on and editing protocol/review, helping in studies selection.

\section{DECLARATIONSOF INTEREST}

None known.

\section{SOURCES OF SUPPORT}

\section{Internal sources}

- Siobhan Reilly, UK.

University of Manchester, Manchester and University of Lancaster, Lancaster

- Claudia Miranda, UK.

University College London, London

- Juanita Hoe, UK.

University College London, London 
- David Challis, UK.

University of Manchester, Manchester

- Martin Orrell, UK.

University College London, London

- Reem Malouf, UK.

University of Oxford, Oxford

\section{External sources}

- National Institute for Health Research, UK.

NIHR programme grant: Support at Home - Interventions to Enhance Life in Dementia (SHIELD) Application No RP-PG-0606-1083

- National Institute of Health Research School for Primary Care Research, UK.

Siobhan Reilly's training fellowship award from National Institute of Health Research School for Primary Care Research at the University of Manchester.

\section{DIFFERENCES BETWEEN PROTOCOLANDREVIEW}

\section{Title}

We changed the title from 'Case/care management approaches to home support for people with dementia'.

\section{Method}

We stated in the protocol that we would follow the Cochrane Effective Practice and Organisation of Care (EPOC) Group guidelines for the inclusion of controlled before-and-after (CBA) studies and interrupted time series (ITS) designs. There were sufficient RCTs not to warrant including CBA and ITS designs. Thus we made a number of changes to the protocol:

- We removed reference to non-randomised studies from the 'Types of studies' considered for review section

- We removed a sentence from 'Selection of studies' section

- We removed references to EPOC data checklist based on the number of quality criteria in the assessment of risk of bias in included studies section

- We revised the assessment of risk of bias in light of the above

We stated in the protocol that the primary outcomes were maintenance of community residence/avoidance of institutionalisation (measured by rate of institutional care (hospital/long-term care home post-intervention), numbers of admissions (to hospital, nursing and residential care), length of hospital stay and participant quality of life/ ell-being (self-reported or carer-reported, measured by a recognised and validated scale or tool) measured after at least three months follow-up.

We expanded the primary outcomes to cover carer outcomes, including quality of life and carer burden, to reflect the high proportion of studies which reported this as a primary goal of the intervention and its importance in dementia care policies internationally.

We had used broad categories for some of the secondary outcomes, for example, service use. With hindsight, we should have specified which outcomes we would report, as the different types of outcomes categorised under these headings were extensive and not often reported in more than a few studies. The original list of outcomes were as follows:

\section{Primary outcomes}

The primary outcomes were maintenance of community residence/avoidance of institutionalisation (measured by rate of institutional care (hospital/long term care home post-intervention), numbers of admissions (to hospital, nursing and residential care), length of hospital stay and patient quality of life/well-being (self-reported or carer-reported, measured by a recognised and validated scale or tool) measured at least after 3 months follow-up.

\section{Secondary outcomes}

Secondary outcome measures included:

\section{(i) Clinical Outcomes}

For the patient:

- Cognitive Functioning 
- Neuropsychiatric/behavioural and psychological symptoms of dementia (rated by clinician or carers)

- Mood (self-reported, clinically-rated or carer-reported)

- Activities of daily living/dependence (rated by clinician or carers)

- Social engagement/social networks/social support (rated by clinician or carers)

For the carer:

- Carer well-being/quality of life/mood

\section{(ii) Social Outcome}

- Patient's social engagement/social networks/social support (rated by clinician or carers)

\section{(iii) Satisfaction}

- Patient satisfaction

- Carer satisfaction

- Staff satisfaction (the staff providing the care management)

\section{(iv) Services}

- Patient's use of services

- Carer's use of services

\section{(v) Measures of cost}

- Inpatient care/nursing and residential home care

- All health and social care (including the above plus the costs of all other medical and psychiatric care such as: out-patient care and specialist service; and community-based health and social services

- Costs of informal care

- Total costs (including types of costs above plus the costs of accommodation)

\section{(vi) Mortality/ survival time.}

We also added the following:

To facilitate comparison between trials we converted variables that could be reported in different metrics, such as days in hospital (mean days per year, per week or per month) to a common metric (e.g. mean days per month).

\section{INDEX TERMS}

\section{Medical Subject Headings (MeSH)}

*Case Management [economics]; Alzheimer Disease [nursing]; Caregivers [psychology] [statistics \& numerical data]; Dementia [ ${ }^{\star}$ nursing]; Depression [epidemiology]; Health Care Costs; Home Nursing [economics] [^methods]; Hospitalization [statistics \& numerical data]; Long-Term Care [economics] [methods]; Randomized Controlled Trials as Topic; Time Factors

\section{MeSH check words}

Humans 